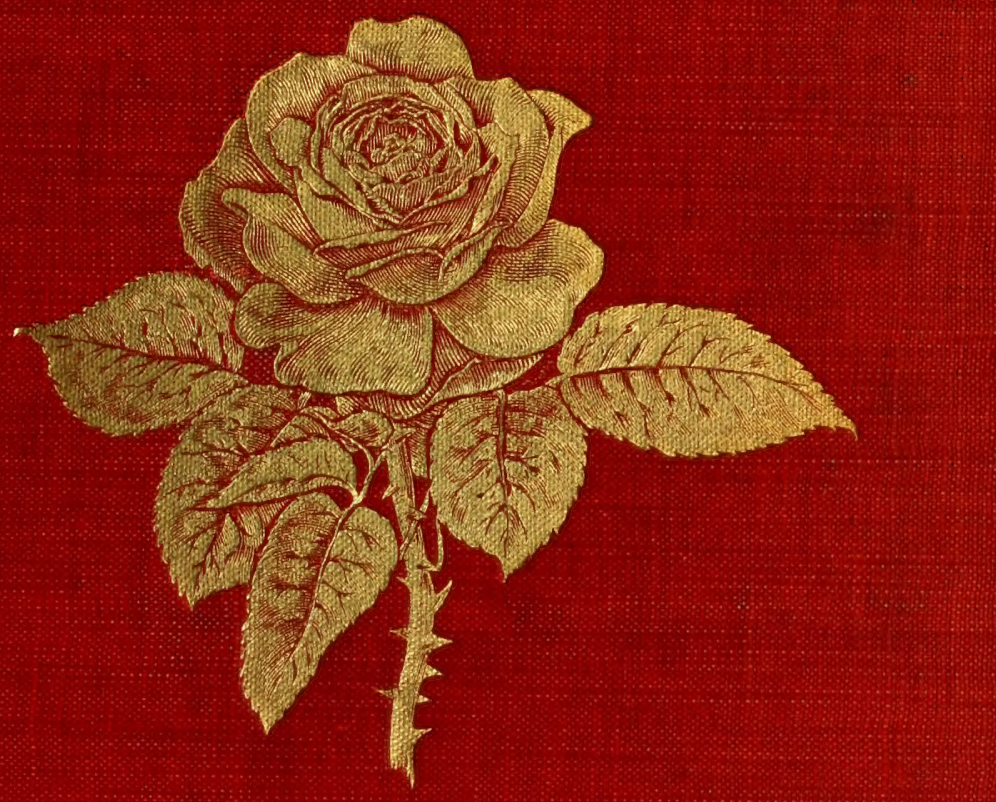




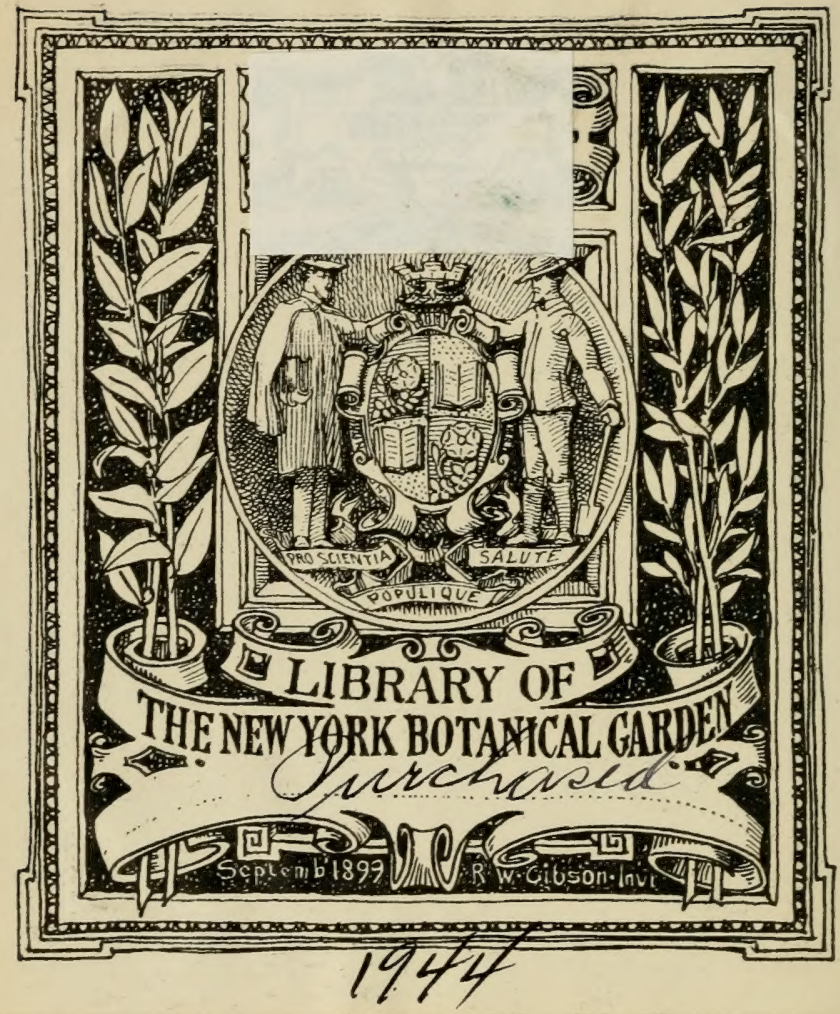


Sijalette Dale J hue 1912 .

LIBRARY

NEW YORK 

THE

BOOK OF THE ROSE 

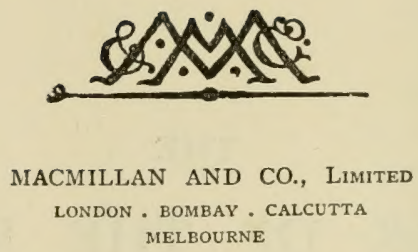

THE MACMILLAN CO. OF CANADA, Ltd. TORONTO 

a. Foster-2nellear 


\title{
THE
}

\section{BOOK OF THE ROSE}

BY

REV. A. FOSTER-MELLIAR, M.A.

RECTOR OF SPROUGHTON, SUFFOLK

FOURTH EDITION

WITH ILLUSTRATIONS

\begin{abstract}
EDITED BY
REV. F. PA G E-R O B E R T S, (PRESIDENT, NATIONAL ROSE SOCIETY), AND
\end{abstract}

HERBERT E. MOLYNEUX VICE-PRESIDENT, NATIONAL ROSE SOCIETV)

MACMILLAN AND CO., LIMITED ST. MARTIN'S STREET, LONDON

I 9 IO 


\section{PREFACE TO THE FOURTH EDITION}

ANothen edition of this valuable book is called for, as it still holds the premicr position amongst Rosarians, especially the Rose Exhibitor as distinct from the Rose lover.

There are portions of the book as to which there may be two opinions, and which we are sure the writer would have altered or modified if he had lived to revise this 4 th edition. The improvement in Roses has been great, especially in those Roses, called Garden or Decorative, largely drawn from the class of Hybrid Teas. This class was in its infancy when the author wrote this book, and he had little liking for it; the old Rosarian's intense love for the Hybrid Perpetual made him look with anything but a welcoming eye upon this new intruder into his favourite's demesne. But one must move with the times and the Hybrid Tea has not only come to stay but has revolutionised our gardens and the Exhibition tent as well. The book was primarily written for the exhibitor; such is still its purpose but one 
cannot shut one's eyes to the fact that the progress in the Rose world-great as it has been in the exhibition flower, per se-lies rather in the other direction, namely, in use of the plant for garden decoration.

It is not for us to criticise the author's obiter dicta or his methods. We are not rewriting the book, but only endeavouring to bring it more up-to-date; therefore have not thought it incumbent on us to alter the matter of many of the chapters, preferring to make any comments or alterations considered necessary by way of foot-notes, except in the Chapter on "Manners and Customs" and in the lists of Roses, where we have been obliged to eliminate many of his old favourites and to replace them by Roses that are now generally recognised as essential from the point of view of the Exhibitor. We feel that in doing this we have his own warrant, as he strongly advises a vigorous weeding out every autumn of all those Roses which having been thoroughly tried have been found wanting.

It is remarkable how few good and reliable Roses of the class he loved, the Hybrid Perpetuals, have been introduced since he wrote and how many Hybrid Teas have been added-but the demand creates the supply and the Rose-loving public has demanded not only "free flowering" Roses but "continuous flowering" Roses as well, in a word, true perpetuals. These true perpetuals are to be 
found largely amongst the Hybrid Teas, and though at one time they lacked the brilliancy of colouring and the fragrance of the old Hybrid Perpetual, they are now rapidly approaching them in both these respects, and in all others have taken the lead; so that in every way, and for every purpose, for exhibition, for garden and for house decoration, they supply all the wants of the lover of the Rose and when one adds that they are nearly if not quite as hardy as the Hybrid Perpetuals there is little more to be said.

Most Rosarians, we think, will agree with us therefore that it is no longer true that it is among the Exhibition Rose varieties that one must look to find adaptability for decorative purposes; on the contrary, it is amongst the non-Exhibition varieties, especially those of recent introduction, that one finds the best example of a decorative Rose from the garden point of view. It has been seen, too, that in the past unfavourable season the Roses that have suffered most have been the Exhibition Roses rather than those used for garden purposes. One feels bound to emphasize this point especially to the beginner who still starts his growing with a list of varieties culled from the Show bench rather than from the nursery or the garden of a Rose-growing friend.

We have to thank Mr. Nason Good for permission to use those photographs against which his name 
appears; also Mr. G. A. Hammond of Burgess Hill, Mr. Prince, Messrs. B. R. Cant \& Sons, and Dr. Campbell Hall for various photographs of Exhibition and other Roses.

\section{F. PAGE-ROBERTS.}

HERBERT E. MOLYNEUX.

March, 1910. 


\section{PREFACE TO THE THIRD EDITION}

I MUST heartily renew my thanks for the increased appreciation shown to this work: and the fact that the Second Edition has been exhausted in little more than a quarter of the time occupied by the sale of the first, seems to testify that Rose-growers have really found it a reliable help in their pursuit.

On account of the shorter interval since the last revision not so much alteration has been required for this new issue, but I have endeavoured to bring the book up to date, so far as it could be done in a reliable manner.

My best thanks are due to Mr. B. E. Cant (B. R. Cant and Sons) for four fresh photographs: and to Rev. R. T. Langtree, of Grange-over-Sands, for one of Mildred Grant.

Much has been done, since the First Edition was sent out, by British professionals in the raising and production of new varieties, and by the National Rose Society and Amateurs in general, in the showing how to deal with them successfully: may we all continue to work in the true spirit of the motto of our craft,

\section{FLOREAT REGINA FLORUM.}

SPRovghton REgtoRy,

November, 1904. 



\section{PREFACE TO THE SECOND EDITION}

Mr warmest thanks are due for the hearty welcome and flattering reception, beyond my highest expectations, which have been so generally given to The Book of the Rose. Not only from the British Isles but from all countries apparently where Roses are grown, I have received kind expressions of approval and commendation, and have gained, I hope, not a few friends.

The present edition has been thoroughly revised throughout; even in matters of routine I have somewhat modified, here and there, the views formerly expressed, for seven years' additional experience should certainly bring a little further wisdom; and in Chapter XII., which seems to have been generally popular, it has been necessary, as might well be expected, practically to re-write the whole. I had hoped, in that chapter, to give more examples than I have done of the different "manners and customs" which some of our best known Roses may have in other lands, but have not been fortunate enough to gain much such information. I must, however, 
cordially thank Dr. Huey, of Philadelphia, U.S.A.; Mr. Halstead, Rose-grower, of Bowral and Hurstville, Sydney, N.S.W. ; H. P. Keatinge, Esq., of Cairo; and F. Riggall, Esq., of Charters Towers, Queensland, for some useful notes on the subject; but the differences, though occasionally well marked, are not very great or much varied.

I have again to thank Messrs. B. R. Cant and Sons, and D. Prior and Son, of Colchester, as well as Mr. Prince, of the Longworth Rose Nurseries, Berkshire, for much kind assistance in endeavouring to secure fresh photographs of typical Roses, as well as C. W. Pilcher, Esq., of Boston, Lincolnshire, for his excellent drawings; and regret that the past season was so bad for Hybrid Perpetuals of typical form that that section is but poorly represented by fresh examples.

I heartily trust that the book may continue to be of assistance and service to the growers and lovers of the Rose.

Sprovghton Rectory, February, 1902. 


\section{PREFACE TO THE FIRST EDITION}

IT seems right to make some sort of apology, as most of my predecessors have done, for putting forth another Rose-book when there are already so many; but perhaps it is not really required, as the columns devoted to the subject every week in horticultural literature show that there is ever something fresh to be said on the different matters connected with the Rose.

My idea was, in the first place, to give, from an amateur, full details of practical culture for amateurs from the beginning to the end; and I ought to be able to do this satisfactorily even if I have not succeeded, as, under unfavourable conditions of soil and situation, I have done with my own hands every portion of the work, from raising and establishing the stocks to carrying off a champion challenge cup at the Crystal Palace. Secondly, to give such descriptions of the best known Roses as should tell of their faults and bad habits as well as of their good qualities and perfections, since I have good reason to believe a record of this sort will be wel- 
comed. And thirdly, if possible, to make a readable as well as useful book: under no circumstances did I aspire to tread worthily in the footsteps of Dean Hole: yet (for to me too the world-even the Rose world- "teems with quiet fun") I did hope to make it fairly light and amusing; but details and practical matter have proved so overwhelming as to get a mastery of the whole.

I have much kind assistance to acknowledge from various sources. From my old friend, Mr. Benjamin R. Cant, Rose-grower, Colchester, and his two sons, I have had very much cordial help in many ways. Mr. Frank Cant, of Braiswick Nursery, Colchester, has freely given me useful information on the subject of Roses under Glass (Chapter X.). Mr. W. D. Prior, of Myland Nurseries, in the same metropolis of Roses, has aided me in the preparation of photographs: and in the same neighbourhood, Mr. and Mrs. Orpen, of West Bergholt, have been good enough to give me opportunities of representing their skill in Rose decoration. I have also received help from Mr. A. Dickson, of the Royal Nurseries, Newtownards, Ireland, in information kindly furnished as to the raising of Roses from seed. Mr. Charles Turner, of Slough, has kindly lent me a photograph of one of his giant Pot Roses.

I am indebted to Dr. Hogg, the proprietor of The Journal of Horticulture, for leave to republish certain matters which I have written in that paper under the nom de plume of " W. R. Raillem," especially Chapter 
XII., which has been thoroughly revised; and to Mr. J. Wright of that office I am very much beholden for kind counsel and advice. For revised reproductions of papers of mine which have appeared in the Journal of the Royal Horticultural Society and in The Rosarian's Year Book, I have to thank the Rev. W. Wilks, Sec. R.H.S., and the Rev. H. H. D'Ombrain, Hon. Sec. of the National Rose Society. My best thanks are due to my neighbour, the Rev. J. H. Hocking, Rector of Copdock, for considerable trouble in the identification of Insects, and to Mr. E. B. Lindsell, of Bearton, Hitchin, for advice and encouragement. MIessrs. A. Hill Gray, J. Bateman, Ismay Fisher, and the Rev. F. R. Burnside have also kindly helped me with photographs, or in other ways.

Mr. William Paul's large work, The Rose Garden, has naturally been consulted and proved of much value, especially in Chapter II., and a further comparison of ideas and methods has been made with the contents of most other Rose-boolss; but my own experience, which is considerable, has been throughout my principal reliance, and where my practice is at variance with the general use, reasons have been given for the procedure recommended.

Sprodghton Rectory,

September, 1894. 



\section{CONTENTS}

PAGE

MEMOTR OF THE AUTHOR. . . . . . . . . . . . . xXiii

\section{CHAPTER I}

INTRODUCTION ................... 1

\section{CHAPTER II}

IITSTORY AND CLASSIFICATION ............ . . 7

CHAPTER III

SITUATION AND SOIL..................... 33

CHAPTER IV

PLANTING : WITH LAYING OUT OF TIL LEIS AND PROTECTIUN 50

CHAPTER $V$

MANURES ..................... . . 74

CHAPTER VI

PRUNING . . . . . . . . . . . . . . . 95

CIIAPTER VII

Sтоск. . . . . . . . . . . . . 114 
CHAPTER VIII

CHAPTER IX

PESTS . . . . . . . . . . . . . . . 160

CHAPTER $\mathrm{X}$

rOSES UNDER GLASS . . . . . . . . . . . . 192

CHAPTER XI

FXIIIUTING ................ 204

CHAPTER XII

MANNERS AND CUSTOMS ................ 237

CHAPTER XIII

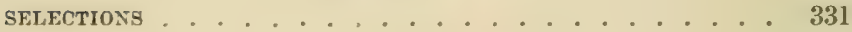

CHAPTER XIV

CALENDAR OF OPLRATIONS ................ 341 


\section{LIST OF ILLUSTRATIONS}

PAGE

REV. A. FOSTER MELLIAR . ........ Frontispiece

THE GREAT ROSE-GROUNDS AT COICHESTER . . . . To fuce 13 AN AMATEUR'S ROSE-GARDEN . . . . . . . , 14

A ROSE HEDGE-AYRSHIRFS . . . . . . . . , 22

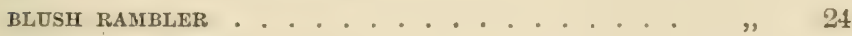

DOROTHY PERKINS . . . . . . . . . . . , , 25

LAURETTE MESSIMT . . . . . . . . . . . , , . . 28

THE GARLAND .................... , . . . . 29

A BED OF IWARF POLYANTHAS . . . . . . . . , 30

MACRA.ІTHA . . . . . . . . . . . , , . . 31

TWO YEARS' GROWTH ON A PERGOLA AT STRATHFIELDSAYE ................... , 52

"SPROUGHTON" HOE .............. . . . page 66

ORDINARY SÉCATECRS. . . . . . . . . . . . , , 98

LONG-HANDLED SÉCATEURS . . . . . . . . . . , , 99

MARÉCHAL NIEL, UNDER GLASS . . . . . . To face 109

ROOTS OF STOCKS .................. . . . 118

GRECLAN SAW ..................... page 123

MINIATURE STOCK AXE . . . . . . . . . , , 124

BUDDING A STANDARD STOCK ............, , 140

CATERPILLAR HIDDEN ON ROSE SHOOT . . . . . To face 162

b 2 
PAGE

MILDEW. THE FIFST SIGN, AS SEEN IN THE CURL OF THE LEAF . . . . . . . . . . . . . . 'T' face 180

A GOOD TWELVE SHOWN BY MR. VIVIAN ROLT . . , , 230 EXHIBITING.- "A GOOD TIVENTY-FOUR" . . . . . . , , 232 ROSE FAULTS. A "DIVIDEO" ROSE ........ . , 240

A. K. Williams . . . . . . . . . . . . , , 242

DUKE OF WELLINCTON . . . . . . . . . . . , 248

FRAU KARL DRUSCHKI . . . . . . . . . . . . . , 252

GUSTAVE PIGANEAC . . . . . . . . . . . . , 254

HORACE VERNET . . . . . . . . . . . . , , 257

MRS. JOHN LAING . . . . . . . . . . . . , 265

PRINCE ARTHUR . . . . . . . . . . . . , , 266

ULRICH BRUNNER. . . . . . . . . . . . . . , , 268

EESSIE BRUWN . . . . . . . . . . . . . . . , " 272

KILLAKNEY . . . . . . . . . . . . . . , " . . 2 280

A BOWL OF LADY ASHTOWN ............., , . . 281

IADY MOYRA BEAUCLERC . . . . . . . . . . . . , , 282

LA FRANCE . . . . . . . . . . . . . . , , 283

IYON ROSE . . . . . . . . . . . . . . . , . . . 284

MILDRED GRANT . . . . . . . . . . . . . . . . . , ". 285

MRS. W. J. GRANT . . . . . . . . . . . , 287

CATILRINE MERMET . . . . . . . . . . . " , 292

CLEOPATRA ..................... , 293

COMTESSE DE NADAILLAC . . . . . . . . . , , 294

ERNEST METZ . . . . . . . . . . . . . , , 296

MADAME JULES GRAVEREAUX . . . . . . . . . . , , 302

MAMAN COCHET .................. , , 303

MiRs. CAMPBELL HALI, . . . . . . . . . . . . . , , 304

MRS. E. MAWLEY . . . . . . . . . . . . . , 305

MURIEL GRAHAME . . . . . . . . . . . . . , 306

SOUVENIR DE PIERRE NOTTINE . . . . . . . . . , 310

WHITE MAMAN COCHET . . . . . . . . . . . , , 312 


\section{LIST OF ILLUSTRATIONS}

$\mathrm{xxi}$

PAGE:

ALBERIC IARBIER. TWO YEARS' GROWTII . . . . To face 313 BENNETT'S SEEDLING . . . . . . . . . . , , 314 FORTUNE'S YELLOW . . . . . . . . . . , , 317 LEUChtSTERN . . . . . . . . . . . . . . , , . . 321

MARÉCHAL NIEL . . . . . . . . . . . , 322

CLIMBING ROSE, RÊVE D'OK ............. , , 327

UNA ........................ . . . . 329

w. A. RICHARDSON . . . . . . . . , , 330

SULPHUREA . . . . . . . . . . . . , , 335

A WEEPING ROSE-AYRSHIRE . . . . . . . , 336 



\section{ANDREW FOSTER-MELLIAR.}

Born 12th October, 1841.

Died 14th November, 1904.

The Rev. Andrew Foster-Melliar was the youngest son of the late Andrew Foster-Melliar, of Galhampton, Doulting and Wells, Somerset. Originally intended for one of the colonial Civil Services, he seems to have drifted, more by accident than design, into the Church. He was educated at Streatham Academy, Uppingham (under the famous Thring) and New College, Oxford. After leaving Oxford, he went to Wells Theological College, and was the first married student that ever studied there.

It was because of an acquaintance made at Wells that he became for the rest of his life identified with Suffolk; he had never been in the county until he began his first curacy there. Mr. (now the Rev.) Holt Wilson was at Wells College at the same time as Mr. Foster-Melliar, and it was through his influence that Mr. Foster-Melliar was offered the curacy of Redgrave, Suffolk. After some years at Redgrave, he was curate at Tostock, near Bury St. Edmund's. In 1885 the late Marquis of Bristol 
offered him the living of Sproughton, near Ipswich; and it was at Sproughton, after nearly twenty years' residence, that he died.

At Redgrave he began to take an interest in rose-growing, an interest that gradually deepened through the years spent at Tostock. At Tostock Rectory he planned and planted a rose garden which, until certainly quite recently, used to be shown on the ordnance survey map as "the rosary," although the roses have disappeared these many years to make room for a tennis-court. But it was at Sproughton that he became so well-known that, just to mention the name of Sproughton, begat a vision of eternal summers among the lovely roses there-the long low beds of them, backed by the brooding beeches in their dark-green summer garb. Perhaps, in his heart, there was no country quite like the old west country; but, in time, he grew to love this Sproughton of his, lying low along the river, that wound softly through its great green meadows-Sproughton and its people, the people whom he came to know so well, whose troubles were his troubles, whose joys were his joys. He knew their lore, knew their speech and habits, or, as he would say, their "manners and customs." And, in return, the people too learnt to love the "old Rector," though they never, perhaps, quite understood the reserved strong character that lived among them nearly twenty years. But, if they never quite understood him, they knew what he stood for. Upright, steadfast, "straight," no case of injustice or oppression passed him by unheeding.

Possibly very few ever understood him really. A great talker, most entertaining when telling 
a story (of which he was very fond) and possessing a deep sense of humour, he was reserved in the extreme about his own feelings, about things that really mattered to himself. On the death of his wife, perhaps the one bitter blow of his life, people might have thought that he did not care. To the outer world, to those who saw him at her funeral, he might have seemed almost indifferent and certainly cold, whereas he was merely too proud, too haughty ever to let anyone see what he felt. It was characteristic of him that, recording his wife's death in his diary, he never wrote down that she was dead, but made the story of a life-long devotion and the stunning tragedy of her death stand out, in five short words, like living fire. And then, in the next few days after her death, follow the most precise, formal statements as to "the funeral," never once mentioning whose funeral.

Very much, especially in later life, a creature of habit, Mr. Foster-Melliar's life was ruled strictly by the clock, and nothing put him out so much as unpunctuality. As the clock struck ten every night, he rang the bell for prayers, and, as it struck eleven, he walked upstairs to bed. At a quarter past eight every morning he stepped out of his dressing-room on to the landing, where he stopped for a minute to whistle to some canaries (always the same tune), and then he walked downstairs and out into the garden to look at the thermometer on the wall. At half-past eight to the minute he rang the bell for morning prayers. He was greatly disturbed and upset when he had to leave home. He would walk about, hours before the time fixed for his departure, looking the picture of misery in his best 
clothes. He hated his best clothes, and clung to his oldest until they were forcibly taken away from him by his wife or one of his daughters. In connection with his clothes an amusing story is told. The daughter who kept house for him had asked him to speak to the gardener one morning about his clothes and to tell him he really must come to work in more respectable garments. In the afternoon there was a tennis party at the Rectory, and, while they were at tea, Mr. Foster-Melliar came and joined the party, dressed in the most disreputable jacket that could be imagined. The sleeves ended somewhere near his elbows, and the bottom part of his coat barely came below the upper end of his trousers. His daughter was horrified. "Where on earth did you get that coat from, father?" she asked. And amidst general laughter he explained how he and the gardener always hung their coats on adjoining pegs in the greenhouse before going to work, and that, by mistake, he had taken and put on the gardener's. "But the amusing part is," he added, " that I have spent the whole day blowing him up for wearing such disgraceful clothes."

To the mind of the writer of this brief memoir, he was a pattern country parson in very deed. $\mathrm{He}$ knew the people, knew their speech, understood their ways of thought. He knew all about agriculture, and could talk informingly with either squire, farmer, or labourer. He had a great fund of sympathy, and could always listen to an old woman's troubles and ailments, and find a gentle amusement in it without hurting her feelings. He had, too, a power, a force of character that he used entirely for good, and by which all with whom he came in contact benefited. 
It was by no means wise to "let the Rector hear of " any underhand deed.

Somehow, he seemed to fit an empty niche in Sproughton church ; and, to those who have seen him standing, lonely, by the altar-tall, upright and with snow-white hair waiting to bless his people, it has never seemed quite the same church again. The sun, shining through the stained-glass windows, still fills with roseate hues the space around the altar, but (and what eternal sadness it is that such things should ever be) the clear-cut face, the outstretched hands, as the voice, low, clear, undoubting, gives out the blessing are gone.

His sermons were never very long, and they were always listened to with rapt attention. He thoroughly understood the art of "making the punishment fit the crime" -in other words, his was an agricultural congregation, and he knew what they would understand. He would draw his conclusions by appeals to nature or agriculture-they knew all about it and could follow his reasoning. Once, indeed, a deputation waited on him to make his sermons longer! He usually spoke for fifteen minutes. In connection with his sermons, there was a rather amusing occurrence one day. He was decidedly awe-inspiring in the pulpit, as well as out of it, and he had a way, when he was notlooking at anything in particular, of having the appearance of staring hard at some very definite object. He had greyish eyes, and they looked stern when fixed hard on anything. On this occasion, he was explaining a portion of the Bible, and just down below and in front of him was a small boy with hair of the most brilliant red imaginable. What he was trying to explain was something 
about David being a youth with a ruddy countenance. "A ruddy countenance," said the Rector, evidently turning over in his mind what would be a suitable explanation, and his eyes, all unseeing, fixed themselves hard and stern on the small boy in front of him. "A ruddy countenance," he repeated; "a ruddy countenance, which probably meant red hair." As he appeared to be glaring hard at the small boy all the time, it can be well imagined how the latter's colour spread considerably beyond his hair. Mr. Foster-Melliar, however, when he was taxed about it afterwards, declared that he never saw the boy, and did not, indeed, know that there was one with red hair in the church.

It was delightful to hear him read the Lessons. He read them so as to make it appear almost as though the scene was actually happening in front of you. The writer has known several people who were drawn to Sproughton church merely to hear him read the Lessons, which are too often merely " intoned."

The precise orderly nature that made him put his watch down in front of him when in the pulpit and take it up again exactly fifteen minutes later, led him to enjoy chess problems. For years he never missed solving the problems set weekly in "The Field," and the initials "W.R.R." were almost unfailing in the column set apart for successful answers. Once, for a month, he was ill and unable to attempt the problems, and this greatly distressed him. The preciseness of a chessboard appealed to him, and it may have been this preciseness which accounted for his attitude with regard to Roses. The controversy "The Rose for the Garden," 
or "the garden for the Rose" he waged with much vigour. There was no doubt about it in his mind: it was perfectly plain, perfectly simple. It was the graceful (one might almost say, classical) outlines of the individual specimen that he wanted. To get the perfect specimen was the object of a garden. For roses in the mass he had no sympathy. In fact, they rather irritated him, his orderly mind telling him all the time that the blooms, however beautiful they might look so massed together, were none of them perfect, were none of them good individually. What he liked, best of all, was to have a single perfect rose in a specimen glass by itself-just to look at it, just to gaze upon its soft, graceful outlines. You could draw him many miles with a promise of that, but he would not step a yard to see "banks of roses, arches of roses, hedges of roses." If you pointed out the beauty of colouring that could be obtained by massing roses in such a way, he would tell you that it was a sign of decadence, and that the real object should be, like that of the Greeks of old, to obtain the "perfect form." And, if you asked if he did not like to see a garden bright and beautiful with flowers, he would say "yes," and would explain how fortunate the country was in having so many good nurserymen willing and capable of supplying you with any amount and any variety of flowers, other than roses. But the rose was to be the thing apart, a very Queen. Whether his views were right or wrong depends on the point of view, and is not the concern of this Memoir; but the result was that his attention was entirely given up to so cultivating roses that they might produce the finest blooms. His advice on 
cultivation holds good whether you wish for the mass or whether you only want the single bloom.

To find humour in everything is a happy gift, and Mr. Foster-Melliar had it in abundance. His humour was sometimes sarcastic, which is dangerous, but more generally he used his gift to poke gentle goodnatured fun at things and people. $\mathrm{He}$ nearly always managed to bring out the funny side of things, and especially did he have unending amusement with his gardener, Paine. Paine was with him for a great number of years, and was a very quaint and rather illiterate individual. At the time that Osman Digma was defeated in the Soudan, Paine had a son born, and he decided that the unfortunate youth should be baptised with the name of Osman Digma. Fortunately, however, Paine wasn't much of a "schollard," and when he was asked for the name in church, he boldly replied "Osborne," and "Osborne" the boy is to this day. But Paine still fondly imagines that the boy is named after the eastern warrior.

Paine had some peculiar disability which prevented him from ever giving an animal or insect its proper sex. He would call the cow "he," the barndoor cock "she," the mare "he," and the tom-cat "she." Mr. Foster-Melliar came into lunch one morning, rejoicing in Paine's latest exploit in this direction. A wasp's nest was being built in a hole under the eaves of the roof, and Paine had been sent up to deal with it. Having dealt with it he reported progress to Mr. Foster-Melliar. It seems he applied smoke to the hole and, as a result, various young wasps dropped down it and were duly despatched. And "at last," remarked Paine with trimmph, "out 
came the old mister." Thereafter, a queen wasp was always known as "the old mister."

Though Mr. Foster-Melliar is chiefly known because of his work "The Book of the Rose" (one admirer has kindly called it "the classic work on Roses"), roses were by no means his first or only love. His first love was natural history, and his greatest love was shooting. A very early letter of his, when about eight years old, says:- "My dear Mama, I thank you for your kind note. But I wish you were come back again, as I have got a goldencrested wren's nest with eight eggs in it to show you when you do." And nearly every letter, whether from Streatham, Uppingham or Oxford, contains some reference to birds, beasts, insects or flowers. His knowledge of natural history has been described as "first-class." However that may be, the writer remembers well how greatly he was impressed-on a strange rare bird being taken to him to identify-by his saying at once and without the least hesitation, "Oh, that's Oedicnemus crepitans" (the Stone Curlew). Shortly before he died, the Town Council of Ipswich had elected him as a member of the Committee of the Ipswich Museum.

His delicacy as a boy often prevented him from the bird-nesting expeditions that he loved, but he quite outgrew his weakness, and was a great cricketer in his young days. He used to play regularly for the Uppingham Rovers, and was at one time Captain of the Suffolk County eleven. His round-arm bowling (then a new-fangled idea) was apt to be deadly, while his batting was distinguished by hard-hitting. The scene of many of his triumphs was on the pretty little ground at Stowmarket, and 
he often used to tell how the people cheered him through the streets after some great batting or bowling display. In the memory of at least one inhabitant of that town, his powers of hitting were, fifteen years after he had laid down the bat for good and all, still enshrined, as the following anecdote will show. One of Mr. Foster-Melliar's sons was batting on the Stowmarket ground, and an elderly man was fielding at point, a ball was bowled rather to the off and pitched rather short, the batsman hit it with all his strength straight into point's hands, point stopped it, dropped it and started jumping about and shaking his hands. Fearing lest he had broken one of his fingers, for the ball was going very fast, the batsman went up to him and hoped he was not hurt. No, he wasn't hurt, but he was annoyed. It was fifteen years since he had had a ball like that, and he had dropped that one too, and he had never known but one person who could hit a ball like that, and was the batsman's name Foster-Melliar? In these days of socialistic enterprise, it is just as well to remember that the hereditary principle will occasionally assert itself.

In his youth Mr. Foster-Melliar was a keen fly fisherman but, in latter years he did not do much, if any, fishing. But the trout pool, hidden beneath the old elm and among the roses, was one of his pleasures. There, on summer evenings, he would sit for hours feeding the fat trout with bread and earwigs, the latter of which he would blow on to the water by means of hollow tubes. He has described in his book how he used to catch the earwigs in those hollow tubes.

His great passion, however, was shooting. He 
was an excellent shot, and always used an old pinfire gun until five or six years before his death. He had had the pin-fire since he was a boy, and had used it so much that it was positively dangerous. He swore by black powder and number six shot, and the noise the gun made when it went off was astounding. Smoke came out all along the barrels (for there were positively holes that you could almost push a pin in down the barrels) and the reverberation was as thunder. If they were shooting the adjacent coverts one knew for miles around when "the Rector" was in a hot corner-it was something like the guns at Landguard Fort. He was induced one day to order a new gun, and he was extremely pleased with the hammerless ejector gun that he got, and came to prefer smokeless powders to the old black. He had many good stories to tell about his shooting experiences, as, indeed, he had about everything else. He was once shooting with a certain baronet, who was also a distinguished colonial administrator. Included in the shooting party was a bishop. The bishop was not supposed to have had much experience of shooting, and the lieeper had been specially instructed to attend on the bishop and see that he shot-in the right direction. The keeper, having a great respect for rank and not having met a bishop before, was sorely puzzled how to address him should occasion arise. When the day's shoot was over, he confided his trouble to his master. "You see, Sir Edward," he said, "Dukes I linow, and Hearls and sichlike" (Sir Edward being evidently, in his keeper's estimation, a "sichlike!"), "but I was wholly stammed by the bishop." "Well," said Sir Edward, "what did you say to him?" "Well, Sir," replied the 
keeper "an old hare got up in front of 'un, and he wouldn't shoot, and then another got up, and he wouldn't shoot that neither, so at last I shouted 'Shoot 'un, Your Holiness, shoot,' and shoot 'un he did!"

On another occasion, he was shooting at a place where the host was not a good shot, and it was Mr. Foster-Melliar's fortune to be the gun next to his host at one particular stand. Mr. Foster-Melliar, of course, was careful not to shoot at any birds that might have been looked on as belonging to his host's stand, with the result that not much damage was being done. In the midst of it all the head keeper crawled round to Mr. Foster-Melliar and whispered in his ear, "Don't you mind nothing about nobody's birds, sir" - which, as Mr. Foster-Melliar said afterwards, was a remark that contained about as many negatives as a sentence of eight words could be expected to carry comfortably.

Mr. Foster-Melliar did not hunt, and his attitude towards foxes was-mildly disapproving, shall we say? But in case any rosegrowers are also foxhunters, here is a story that he used to tell sometimes. In the west country, where all the farmers are or used to be great sportsmen, there was a certain gamekeeper who did not attempt to conceal his aversion to foxes. A farmer was riding to the meet on a very wet and stormy morning, and met the keeper. "Morning," said the farmer. "Morning," said the keeper cheerfully, adding, "foxes 'll most likely be underground this sort of weather." "Mebbe," answered the farmer, "but-who put 'em theere?"

To enter into his toils and triumphs as a rose- 
grower has not been the object of this Memoir. His toils are fully written down by himself; and, if he has omitted the triumphs, does that matter? If not the most successful of amateur rose-growers, he was high up in the first flight, and won quantities of medals and silver cups. He was one of the National Rose Society's judges, and each summer used to see him travelling all over the country to judge at rose shows. His experiences were sometimes very amusing, especially when exhibiting, and sometimes they were almost tragic. One year he had to have a new gardener, and this was a sore trial. He usually took the gardener with him when he went to show roses, and the first attempt with the new gardener was at Norwich. While setting up some roses there, Mr. Foster-Melliar asked the new gardener to bring him the rose that was to win the medal. As the man was bringing it, the head snapped off. Rose-growers will appreciate the irritation caused by a mishap of this kind, but Mr. FosterMelliar merely told him to go and fetch the next best. As the wretched man was bringing it, that one also snapped off at the head. Mr. Foster-Melliar' looked at him. "There, there," he said gently, "go and play on the grass"! It is doubtful if the man ever got over it, and, at all events, he left shortly afterwards. He was prepared to be stormed at, but to be told to "go and play on the grass" was too much for him.

In the height and vigour of his manhood, as it would have seemed, he was struck down. On the Thursday he had just completed, signed and despatched to the printers the preface to the third edition of this book. On the Saturday he was 
shooting, and it was remarked at the time how well he had been doing. On the Sunday morning he was obviously very unwell, and could barely take the services in the church, but he managed to struggle through with them somehow or other. On the Monday he was worse, and, on the Monday morning following, he died. It was how he wished to diein the full possession of his strength and faculties. The crowds that assembled at his funeral, the distressing scenes that were witnessed (many of his parishioners being moved to tears), all testified to the love and respect they had for the "old Rector." The parishioners subscribed over $\mathfrak{E} 300$ for a memorial, which took the shape of a reading room endowed in perpetuity for the use of the villagers, and a numal tablet inside records the fact that it was so endowed in memory of him.

Sproughton Church still stands, Sproughton's river still wanders like a silver thread through the long green meadows; but gone are the roses of Sproughton now, gone are the long, long rows of them that were the Rector's delight; and gone, too, is the dear, kind-hearted old Rector and his greatlyloved wife. Ah, well, tempora mutantur; they sleep together, just as they wished to do, in one gravebetween the church, which they loved so well and served so faithfully, and the silent river.

K. F.-M.

January 26, 1910. 


\section{THE BOOK OF THE ROSE}

\section{CHAPTER I}

\section{INTRODUCTION}

IT is a common saying that the love of flower's is universal; and it is not surprising, seeing that the tendency of the age is to subdivide occupations and interests and make men specialists in smaller branches of subjects, that certain flowers have been selected for cultivation by persons who have given all their leisure, or even the whole of their time, to the study of them. As the Rose has been entitled the queen of flowers without serious dispute for nearly twenty-five centuries, special subjects of such a queen may naturally be looked for; and they may be found among such as style themselves Rosarians, who endeavour to cultivate the Rose in such a manner as to get the finest and most beautiful blooms.

One would naturally suppose that those who study and pursue this subject might be credited with a special knowledge of it at least, if not with some authority; but, oddly enough, a certain number of 
writers on general horticulture are never weary of recounting the errors and absurdities of Rosegrowers and, above all, Rose exhibitors. It is not so that I know of with other flowers; the foremost prize-takers in chrysanthemums or auriculas, for instance, are at least supposed to know as much about the things necessary for the welfare of those plants as other people; and in common life we do not find general physicians proclaiming the ignorance and absurdity of oculists, aurists, and dentists in their several departments; yet the specialists of the Rose are frequently told by authorities in horticulture that their maxims and modes are erroneous and faulty.

I must confess, though the idea may appear heretical to some, that I do not consider the Rose pre-eminent as a decorative plant; several simpler flowers, much less beautiful in themselves, have, to my mind, greater value for general effect in the garden; and even the cut blooms are, I imagine, more difficult to arrange in water, for artistic decoration, than lighter, simpler, and less noble flowers. A good Rose should stand in a vase by itself as a queen should; then let any other flower or combination of flowers rival her if they can. So, with all the best Roses I should not wish for or expect any general display at a distance, but come close and be content if I can find but one perfect bloom.

In my estimation, the value of the Rose is in the glory of its individual flowers; and, in these pages at least, the idea is not the Rose for the garden, but the garden for the Rose. ${ }^{1}$

${ }^{1}$ See Editors note at end of Chapter with reference to this and the foregoing paragraph. 
I write for enthusiasts, for those who make a regular hobby of their Roses, and think of them as fondly and almost as fully in January as in June. There are not a few such, even among amateurs, in all ranks, and some of them, much handicapped perhaps by soil, situation, or circumstances, still retain their ardour though not meeting with much success.

The man of business, who rises at daybreak to attend to his Roses before his day's work in the town; who is quite prepared if necessary to go out with a good lantern on a November night to seize a favourable condition of soil for planting at once some newly-arrived standards or dwarfs; and who later in the winter will turn out in the snow after dark to give some little extra protection that may be required for his beds: this is the sort of man for me, and for the Rose as well.

I remember a certain occasion when a small shooting party met for partridge-driving on a rather dismal bleak day in January. Two of the "guns," who lived some distance apart and did not meet very often, were continually drawing together and chattering away with the greatest enthusiasm; cutting little bits out of the hedge and comparing notes with so much interest that, though both very fond of the sport, on more than one occasion the partridges flew by unheeded whilst they had strayed from their places. Said the host later on to one of his friends, "What on earth do you think A and B, who are generally so keen, had got of such importance to talk about together? It was all about Roses!"

For some months, in the early part of 1894 , I 
received very nearly every day by post as much as and sometimes more than a penny stamp would frank, of letters from a gentleman whom I had seldom seen, and with whom I had hardly exchanged half-a-dozen sentences by word of mouth. This too during the winter months, and all about Roses!

It is pretty well known that another gentleman, with a passionate love for Tea Roses, left his home in Scotland because he could not grow them there, and went searching for a place in Great Britain which should be suitable for their culture; and, having found such a spot, at very great expense laid out and prepared his grounds to form, as they undoubtedly do, the finest amateur Tea Rose garden in the country.

Such instances as these show that the culture of Roses is an occupation that sometimes arouses a great deal of enthusiasm. It will also be seen, from the Calendar of Operations (Chap. XIV), that it affords work and recreation, the whole year round, so that the interest never slackens. And, to any one who lives in the country, is really fond of flowers, and "wants something to do "-I have known some such-I can strongly recommend the thorough culture of Roses as likely to add much to his enjoyment of life in his garden.

I may perhaps be excused for thinking that Rose-growing as a special pursuit and a hobby is particularly adapted for country parsons. No one can deny that it is as harmless a pursuit as any that can be found, and, without the least neglecting his sacred calling if his cure be a small one, he can find many half-hours of daylight leisure among his Roses, where his parishioners will soon learn to 
come and look him up at once if he should be wanted. It will afford him varied interest, exercise, and work in the open air all the year round. In tilling the soil, the special work which God gave to man, he will find many a valuable lesson, which he will be able to tell, with authority and with much interest, to that majority of his unlearned parishioners who are themselves tillers of the soil. If there is no room in the parsonage garden, it is seldom indeed that some little piece of glebe cannot be taken in to be the pride of his heart and the focus of his midsummer hopes. And as the country parson is not usually over-wealthy, there will be the more encouragement for him to do the Rose work with his own hands, and to summon the aid of his single useful man only at actual show time, for the carting of manure, or for pressure in planting.

He will thus become a real amateur, a true son of Adam, and genuine brother of the back-ache, with many thorns in his fingers and rough and hardened hands; but his Roses will be truly his own, he will have won them, and under the Creator will actually have made them himself. And not only will they seem to him brighter and purer and sweeter than any other Roses, but he will probably find in comparison and competition, that they are better than those of his brother amateurs who do not personally attend to their plants; and it will be a great thought for him that other far richer men may have grand and glorious gardens, but that he in his humble little plot with his own hands raises some of the finest Roses in England.

Note.-It is more than ever true, though perhaps 
not quite in the sense that the Author uses the phrase, that "The Garden is for the Rose, and not the Rose for the Garden," but it is no longer correct to say that the "value of the Rose is in the glory of its individual blooms."

In many cases the value of the Rose lies solely in its decorative effect, such Roses as Dorothy Perkins have little merit in the "individual flower," but as seen from "a distance" who will say the effect is not beautiful, unique, and further, one to be obtained by the use of no other "decorative plant." And it is more particularly this use of the Rose as a decorative Garden plant, since this chapter was penned, that has led to its increased popularity. 


\section{CHAPTER II}

\section{HISTORY AND CLASSIFICATION}

The Rose is well known as the emblem of England, and when we consider how often it has unhappily been in conflict with the Lilies of France, it may seem strange to find a large though decreasing proportion of our Roses endowed with French names.

Still, though so many of our favourites were raised the other side of the Channel, Great Britain is the true home of the Hybrid Perpetual Rose; and that, not only because it is more cultivated here with the minute attention which is paid to a "florists' flower," but also because the English climate is better suited to its perfect development.

Continuous sunshine is not the best weather for the blooming of H.P.s; they like two or three hot days, and then a dull, dry, cooler one. Some will not open in rainy weather, others do not mind it; but almost all this large class, so many of which were raised in sunny France, will display far more beautiful blooms on a dull and cooler day following after heat; and it may be, I think, safely said that the finest H.P. Roses in the world are grown in Great Britain and Ireland.

The Rose is native to all countries in the world 
with the exception of a portion of South America, and the actual tropies.

It is very extensively cultivated in Persia and Bulgaria for the manufacture of attar or otto of Roses and Rose-water, which are distilled from the petals. In Persia a variety of the Musk Rose (Rosa moschata) is used for this purpose, but it has not the real odour of musk, which is said to be found only in Salet, a Perpetual Moss Rose. In Bulgaria, the country which is the largest producer of the otto, a variety of the Damask Rose ( $R$. damascena) known as Kazanlik, is used: and experts allege that the Damask and Provence ( $R$. centifolia) Roses are the best representatives of the true inimitable odour of Rose. The modes of distillation in these Eastern countries are very primitive and imperfect, and moreover in Bulgaria there has been considerable adulteration of the valuable otto with geraniol or oil of pelargonium. The finest otto of Roses now in the market is manufactured by modern skilled appliances in Germany, near Leipzig, where the Bulgarian variety of Damask Rose is used, and in France, near Grasse, where a strain of the Provence Rose is cultivated for the purpose. Rose-water and otto of Roses are also made in India, Turkey, and other places.

Few readers of a Rose-book will care for much research into the history of the Rose. The late Mr. William Paul has with much care gone deeply into that subject in his large volume The Rose Garden, and I will only touch a few points, and refer inquirers on this subject to his fuller work.

Homer's allusions to the Rose in the Iliad and the Odyssey are, I suppose, the earliest mentions 
we have. Every one will be aware of Bible references, though it should be mentioned that the Rose of Jericho is generally understood to be a cruciferous plant, and all seem agreed that whatever the Rose of Sharon was, it was certainly not a Rose; nevertheless Dr. Hooker enumerates seven species of Roses which he observed in Syria. A passage in the Apocrypha (Wisdom ii., 8) is interesting as mentioning the custom of crowning with Rosebuds at feasts and banquets, which we know to have prevailed in classic times.

By far the most important ancient quotation is from Sappho, the Greek poetess, who was born about 600 B.C. A translation of a fragment of one of her poems is given in the late Mr. William Paul's book:-

"Would Jove appoint some flower to reign In matchless beauty on the plain, The Rose (mankind will all agree), The Rose the Queen of Flowers should be."

That the title of "The Queen of Flowers" is no modern assumption for the Rose, but has hardly been seriously questioned for nearly twenty-five centuries, is a little item of knowledge which every Rosarian should store by him as a weapon of defence in time of need.

The immense sums spent by Cleopatra, Nero, and other luxurious persons in the time of the Romans, not only on Roses but on "Rose leaves" (petals) for strewing on the floor and the seats, is well known. And there are actually some points of culture that we may learn from the Romans. Horace speaks of growing Roses in beds, and Pliny of digging deeply 
for their cultivation, both of which items-growing them by themselves apart from other plants, and moving the soil to the depth of two feet-have still to be insisted on in this twentieth century.

During the long strange sleep of civilisation which in the Middle Ages followed the Fall of Rome, the culture of the Rose was probably somewhat neglected; but gradually, no doubt, as the pursuits of peace began to prevail, gardening, and with it the love of the queen of flowers, revived.

The National Rose Society gives 1596 as the date at which it is known that the Centifolia (Provence or Cabbage) Rose, the common Moss, and the Austrian Yellow and Austrian Copper were grown. But Rose progress was very slow till about 1815 , when, in spite of the troublous times, Mons. Vibert, the earliest of the great French raisers, founded his nursery. The way had been prepared for him by the patronage of the Empress Josephine, who made Roses fashionable, and caused search to be made for all existing varieties for her garden at Malmaison. Mons. Laffay soon followed Mons. Vibert, and after them we have a grand array of famous French Rosarians, Jacques, Hardy, the Guillots, Lacharme, Gonod, Pernet, Ducher, Margottin, the Verdiers, Levet, Liabaud, Nabonnand and others, to whom we are still indebted for some of our best Roses.

Mons. Desportes in 1829 issued a catalogue containing the names of 2000 varieties, but the majority of these were no doubt worthless or not distinct, and by 1860 there were still but few Roses which we should now consider good, though we had Général Jacqueminot and Senateur Vaisse among H.P.s, and among Teas, Devoniensis, Madame Bravy, Rubens, 
and Souvenir d'Elise, the last still one of the best of the Exhibition Teas.

But taste, experience, and discrimination on the one hand, and demand on the other, were now beginning to tell, and in the next five years (1860-65) the following wonderful additions from France were made of Roses which are still grown:-Alfred Colomb, Charles Lefebvre, Dr. Andry, Duchesse de Morny, Duke of Wellington, Fisher Holmes, Marie Baumann, Marie Rady, Maurice Bernardin, Prince Camille de Rohan, and Xavier Olibo; and in Teas, La Boule d'Or and that wonder among roses, Maréchal Niel.

About this time English raisers first began to come to the front with Roses still recognised as good, and Mr. W. Paul's Beauty of Waltham may be considered as one of the first of these, the origin of Devoniensis being a little doubtful. Messrs. Paul and Son of Cheshunt, with Mr. Rivers of Sawbridgeworth, Mr. Cranston of Hereford, Mr. Turner of Slough, and Messrs. Keynes, Williams and Co. of Salisbury followed, till Mr. Bennett of Shepperton commenced by hybridising to raise what he called "pedigree Roses," and delighted the Rose world with Her Majesty and Mrs. John Laing.

Messrs. A. Dickson and Son of Newtownards, Ireland, also took to hybridising with great and marked success, their first three seedlings, Earl of Dufferin, Lady Helen Stewart, and Ethel Brownlow, being issued in 1887, and there have been few years since that time when they have not sent out new Roses worthy to be reckoned among our best. This mode of obtaining new varieties from seed by careful interchange of pollen, instead of trusting to 
chance cross-fertilisation, as had hitherto been done, is now being pursued by several raisers in the British Isles. More new varieties from our own country, and less from France, now pass their examinations and enter the ranks every year, but a considerable proportion of our best Roses still bear, and will for many years, French names.

The worst of it is that some of these names must be said in full if there is to be no confusion. For instance, there are two Madame Eugène Verdiers, H.P. and Tea, and Souvenir de Madame Eugène Verdier, H.T., as well as Mademoiselle Eugénie Verdier, and Madame Victor Verdier and Victor Verdier, H.P.s. There are also two Madame Hippolyte Jamains, H.P. and Tea, besides Hippolyte Jamain, H.P. In addition to the well-known La France, there is also a Rose called La France de ' 89 , a name which really shows some poverty of invention on the part of the raiser.

A remonstrance might not be well received; for the late Rev. H. H. D'Ombrain used to tell an amusing story of the French raiser of Duke of Wellington H.P. complaining that English growers would not call his Rose correctly, for it should be Duc de Wellington, and some think he was right!

Still, as I have said, though so many of our best Roses owe their parentage to France, they are nowhere better cultivated than in the British Isles, there being a considerable export trade to America, the Colonies, Spain, and in fact all parts of the world; and nowhere are there such famous growers, both professional and amateur, who have made the Rose their special, and in some cases their sole, study. In 



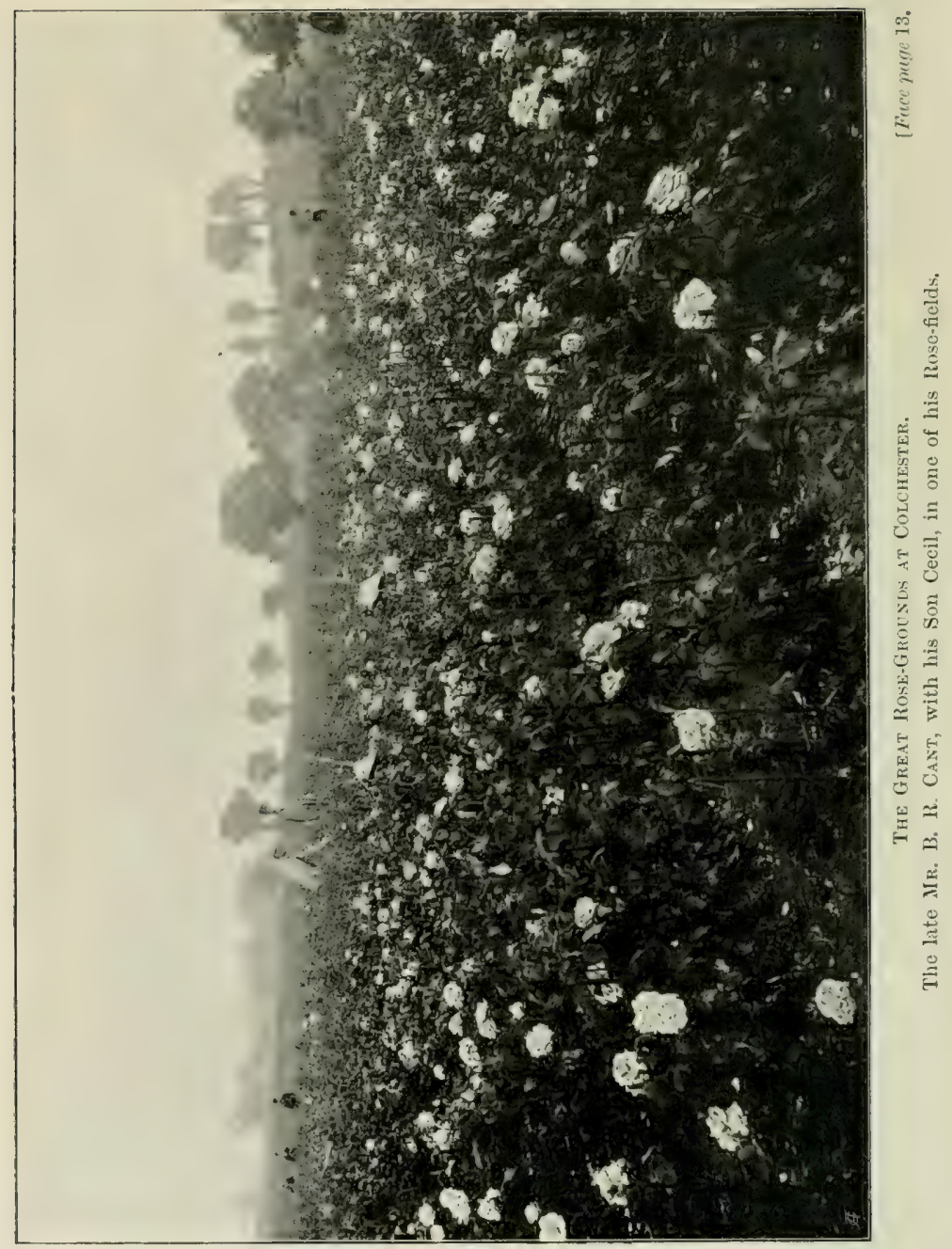


fact, as appears from my correspondence with Rosegrowers in all climates, H.P.s will not do satisfactorily in hotter, or Teas out of doors in colder, countries than Great Britain. In mentioning the names of famous British growers, it is interesting to compare the list, given by Dean Hole in his charming book, of winners at the first National Rose show in 1858 with those who are well known now in 1910. Of nurserymen, "Messrs. Paul of Cheshunt, Cant of Colchester, and Turner of Slough" are still wellknown names; but in the dozen or so of amateurs mentioned, "Fellowes" is the only name with which I am familiar as still growing and exhibiting well. Norfolk has not wanted a good florist or two of the name of Fellowes for many years.

In the very first rank at the present day among professional exhibitors are-at Colchester the separate establishments of Messrs. B. R. Cant and Sons, and Frank Cant and Co., who devote themselves solely to Roses, and Messrs. Prior and Sons ; in Hertfordshire, Messrs. Paul and Son of Cheshunt, and R. Harkness and Co. at Hitchin: and in Ireland Messrs. A. Dickson and Son of Newtownards, who have also a nursery at Ledbury in Herefordshire, and have raised many more fine new Roses than any other British firm, and Messrs. Hugh Dickson of Belfast. No other nurserymen have won either of the N.R.S. champion trophies, but mention must be made of Mr. Prince of Oxford, whose Teas on the seedling briar have often won him the premier prize in that section: and also of the late Mr. William Paul of Waltham, who, by his long experience, his authorship of the largest and most complete book on the subject, the many valuable new varieties he raised, 
and his excellent culture of pot and decorative Roses, long held a high position in the cult of the Queen of Flowers.

There are many others of high standing, a large proportion of whom probably sell as good plants as those I have mentioned. And if they have not come to the actual front yet as exhibitors, it may be that distance or climate, or a disinclination to incur the whole expense and trouble of competing in the first rank, have prevented their names being chronicled hitherto as the winners of the championship.

Among amateurs the best known and most successful exhibitors are Mr. E. B. Lindsell of Hitchin, and Rev. J. H. Pemberton of Havering, for H P.s, and Mr. A. H. Gray of Bath, and Mr. O. G. Orpen of Colchester, for Teas, though in each division there are others treading closely on their heels, and occasionally victorious, notably Mr. Conway Jones of Gloucester.

\section{Classification}

Botanically, the number of actual species of Roses is very great, even the wild Dog-Rose of our hedges being divided into many sub-species, as may be seen from the great variety in foliage and habit in the early growths of briar stocks in nurserymen's quarters. Of the cultivated classes, probably most Rose-exhibitors will only care to know about the two great divisions in which they are interested: viz. Hybrid Perpetuals, including Hybrid Teas and Bourbons, and Teas and Noisettes. Comparatively few will be interested in the Austrian, Chinas, Polyantha, Moss, and Provence races: and 


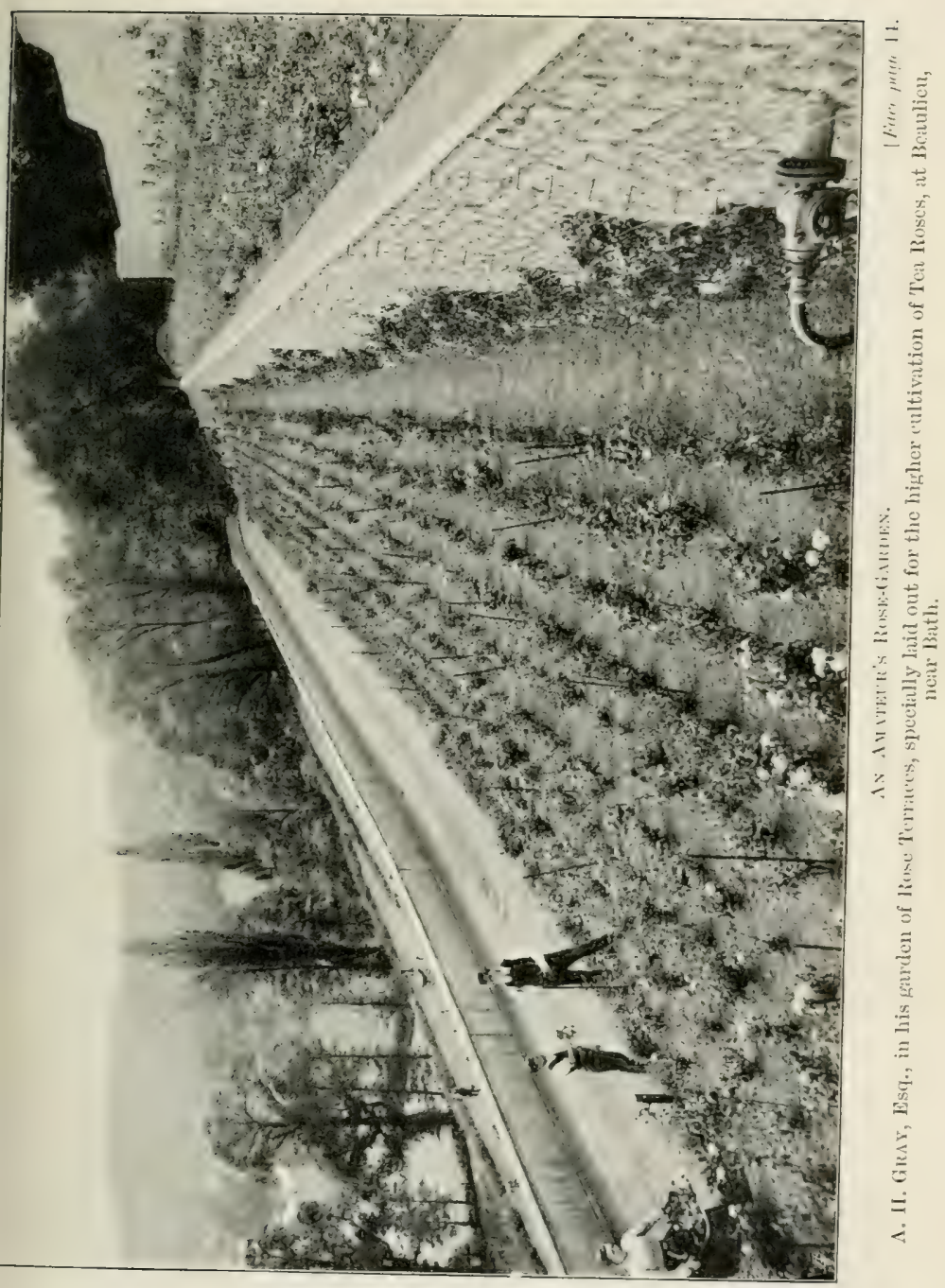



a still smaller number will care to investigate thoroughly the forty-one groups carefully enumerated by Mr. W. Paul in his systematic work.

Now that hybridising and crossing of groups is so largely undertaken, it seems plain that many new divisions and classes are likely to arise, and old lines of demarcation will be confused. Apart from the true climbers, and all summer or botanical varieties, Roses to the novice or spectator at Rose shows are generally divided into H.P.s and Teas, and the more these two great divisions are consolidated and made inclusive instead of being subdivided, the less confusion, to my mind, is likely to arise from crossing and hybridising.

Cultivated Roses are naturally divided into two divisions at the outset: Summer (i.e., those which only bloom once in the year), and Perpetual (i.e. those which have at least something of a second crop). It is obvious that the latter is the more valuable; the H.P.s if taken to include the Hybrid Teas and all Bourbons which are perpetual, and the Teas, with the Noisettes which are mostly crossed with them, form the bulk of the perpetual Roses, and have therefore increased immensely in culture, popularity, and number of varieties, while the sorts which bloom only in the summer have naturally been neglected, though perpetual forms have now been raised among the Ayrshire, Polyantha, Scotch, and Moss classes. The H.P.s and Teas, using the terms in their widest and most inclusive sense, would thus embrace all the Roses which give the finest and most perfect blooms.

The live-stock-keeper's adage, that it costs no more to keep a good animal than a bad one, may, 
CHAP.

with some reservations, be applied to Roses; and the H.P.s, H.T.s and Teas, in the wide sense that I have mentioned, certainly furnish the finest flowers. Still, for old associations some will cultivate the Provence (Cabbage) or York and Lancaster; for beauty of yellow and copper shades, the Austrian; for exhibition of a pot Rose in a mass of bloom, the Hybrid Bourbon or Hybrid China; for beauty in the bud stage only, the Moss; for beauty of foliage and fruit, the Rugosa; for prettiness, the Pompons or Fairies; for certain forms of bouquet decoration, the Polyanthas; for scented foliage, the Sweet-Briars; and for rapid climbing, the Wichuraiana, Boursault, Evergreen, Ayrshire, or Banksians.

\section{Summer Roses}

The Provence Rose (Rosa centifolia).-The type here is the old "Cabbage" Rose, so called merely because it is full, with its petals folded like a cabbage. It is best grown as a bush, and requires fairly close pruning. The original is pink, but there are other varieties of this class, white and striped.

A sub-variety of the Provence is the Miniature Provence. These are simply Roses in miniature, which should not be confounded with the Polyanthas, many of which are quite as small, or with the Lawrencianæ or Fairy Roses, which being Chinas are perpetual.

The Moss Rose is a more important sub-variety of the Provence, the Crested Rose forming a sort of link between them. This group, so well known for 
the moss-like covering of the calyx, has been so popular that great efforts have been made to increase the number of varieties and improve the quality of the flowers. Mr. Cranston, writing in 1855, says that even then several hundred varieties of the Moss Rose had been raised, but though different colours, from white to crimson, have been gained, and one or two perpetual sorts have been issued, very little success in the way of actual improvement has been achieved, the common or old Moss Rose, to which the N.R.S. Catalogue gives the date of 1596 , being still the best in the popular bud state. There are now so many beautiful buttonhole Teas very much superior in beauty of colour and shape, that it seems likely that Moss Roses, which are only valuable in the bud, not of long and pointed form, and apparently incapable of improvement, will suffer somewhat from their rivalry; but many, no doubt, will still be found to cherish them from sentiment or old associations.

The Moss Roses do not do well as standards, and some of them are not very strong growers. They will grow on manetti, but ase generally considered to do best on their own roots, and should be pruned hard, and highly cultivated. Some miniature Moss Roses have been issued, with prettily shaped rosette-like flowers, one of the best of which is Little Gem (W. Paul \& Son, 1880).

The Double Yellow Rose (R. sulphurea) is considered by some to be a form of the Provence. Fifty or sixty years ago, this was the best yellow Rose, if it could be got to bloom; but its "manners and customs" were so very bad, and the blooms so generally malformed or refusing to open at all, that 
it was pretty nearly given up as hopeless, even before Cloth of Gold appeared on the scene.

The Damask Rose (R. damascena) and The French Rose ( $\mathrm{R}$. gallica) are placed under one heading in the N.R.S. Catalogue, and indeed it seems rather doubtful to which of these two sections same of the old Roses belonged. These are the old pink, red, and striped Roses of our gardens, both groups having been grown in this country for at least three hundred years. The three old-fashioned striped Roses, each of which has been called York and Lancaster, are Rosa Mundi (French), which is red striped with white and occasionally self red; Village Maid (French), which is white striped with red; and the true York and Lancaster, which is either (sometimes all on one bush) red, white, red striped with white, or white striped with red, a truly handy bush for a Vicar of Bray in the Wars of the Roses.

The Damask and French Roses are not very strong growers, producing short-jointed wood and large, showy, open flowers. They are not recommended as standards, and are generally grown in the bush form. Fairly close pruning is required, with care as to the shape, that the blooms be regularly placed upon the plant.

The flowers of the French Rose are but slightly scented when freshly gathered, but the perfume develops in the dried petals. The reverse is the case with the Damask Rose, which is principally used in the manufacture of the otto, for the scent in this case is nearly destroyed by drying.

The White Rose (R. alba).-An old-fashioned class of Roses, generally grown as bushes, and still to be found by side-walks and in corners in old gardens 
The majority of them are not pure white, but have a pale pink flush, very pretty in the bud, and open flat. They require rather close pruning. Félicité Parmentier (1828) and Maiden's Blush (1797) are the best known varieties.

The Hybrid China Roses are hybrids between the French or Provence, crossed slightly with the China race, and showing very little of the cross; for the Chinese are true perpetuals, and these remain as summer Roses. They are very strong growers, almost all being vigorous enough for pillars and sufficiently pendulous to form tall standards. They should not be too closely pruned. Blairii No. 2, a fine climber, Chênédolé and Fulgens, of brilliant colour, and Miss Ingram, a well-shaped old Rose of more moderate growth, are now the best known. Madame Plantier, a very profuse bloomer, often placed in this group, seems to have in it some cross of the Noisette race.

The Hybrid Bourbons form a somewhat similar group, being hybrids from the French or Provence with the Bourbon race, but not generally having the autumnal qualities of the Bourbons. Most of them are strong enough in growth for climbing purposes, and should not be pruned too closely when thus used. But in no case is the whole art of pruning more called for than in fine old standards or pot Roses of this group, where the production of a wellshaped head, thickly and regularly covered with large blooms all out at once, is sometimes a triumph of skill and training. Charles Lawson is especially noticeable for its capabilities in this way, when carefully trained as a pot Rose.

Coupe d'Hébé, of a fresh pink with a cupped c 2 
shape, is a name I can never forget, as it was the first rose- a standard-I ever had of my own, about fifty years ago. Paul Ricaut is the best known crimson in this class. Latterly, some hybrid Bourbons have been raised, as perpetual as the original race.

The Austrian Briar (R. lutea).-These are simply wild Roses native in some parts of Europe, nearly single, and lovely in colour. The Copper, as it is called, is the form best known; it is quite single, the petals being a most beautiful shade of coppery red, with orange yellow inclined to buff on the under sides. The others, Single Yellow, Persian Yellow, and Harrisonii, are also noted for their colour, being hardly surpassed in this point by any known Roses. The two last named are double though by no means full, and are no doubt hybrid forms, but Harrisonii is the best grower. They like a dry soil, will not succeed in suburban or smoky atmosphere, and all do best on their own roots, the suckers being encouraged and taken off when rooted if required to form fresh plants. It is best not to prune them at all, beyond cutting out dead wood; the shoots might be thinned, but there is no advantage in this with single Poses, where quantity of bloom is the thing desired; and they should not be shortened, as flower-bearing shoots often issue from the buds near the tips.

Soleil d'Or (Pernet Ducher 1900). - The first new variety in this class for more than sixty years is a cross between Rosa lutea and a H.T., and seems to be a considerable acquisition; for it is of good size and a beautiful colour, but quartered. It has proved the forerunner of many beautiful varieties, and (except perhaps the Wichuraiana hybrids) is the 
greatest break in the hybridisation of Roses of recent years. The raiser calls the new class pernetiana.

The Scotch Rose (R. spinosissima).-The "very thorny" Rose is a briar native in Great Britain, and I have found it growing on the South Downs in Sussex. The varieties are semi-double and are to be found of almost every shade from white to deep crimson. The plant is unmistakable, for no other Rose is so thickly covered with small very sharp thorns. They are not strong in growth, and are best on their own roots, propagated by suckers, like the Austrians. Scotch Roses are generally used to form a dwarf hedge, which has a pretty effect when the little round fragrant flowers are out, but these are very soon over. One perpetual form, however, has been raised-the Stanwell, a fair grower, very sweet, flowering freely from May to November. These Roses are thoroughly hardy, and will flourish in the poorest soil where no other Rose will grow. No pruning, beyond cutting out dead wood, is required.

The Sweet Briar (R. rubiginosa).-This is a native briar, growing freely in some parts of England, and generally where the soil is light and rather poor. The Eglantine, as it is otherwise called, is noted for the sweet scent of the foliage, which pervades the air for a considerable distance after a shower, in spring or early summer. There have been some cultivated varieties more or less double and deeper or paler in colour than the type, and Lord Penzance spent some time and trouble in hybridising them with the laudable view of raising a group of good Roses with sweet-scented foliage.

It is a great mistake to plant these "Penzance" 
or any other Sweet-briars in Rose-beds; for they are very strong growers, thoroughly hardy, and should not be pruned at all, except to cut out dead wood. Their proper place is in a hedge or grown individually in bush form.

The Ayrshive Rose (R. arvensis).-This too, as its name implies, is a native species, found also throughout Europe. They have been well called running Roses, for the growth is extremely long, rapid, and slender. Being very hardy and ready to grow anywhere, they are better adapted for trailing over unsightly places and ugly fences than for actual walls, which are best reserved for more valuable and tender sorts. This and the next group also form good weeping Roses, budded on a tall standard, as the shoots are very pliable, and trail gracefully downwards in a natural manner.

Several of the Ayrshires have probably been slightly hybridised, a mark of the true sorts being that the flowers are not borne in clusters. Dundee Rambler, Ruga, and Splendens or Myrrh-scented are among the best known. The flowers are small, semi-double, and mostly white or pink. The plants are quite hardy, very rampant in growth, and most effective when allowed to ramble at will, unpruned and untrained.

The Evergreen Rose (R. sempervirens).-This group is very much like the last, but is not a native of Great Britain; nor is it, strictly speaking, evergreen, but some foliage is generally retained through most of the winter. The flowers are produced in very large clusters, mostly of white or light pink colours. The plants are thoroughly hardy, as strong in growth as the Ayrshire, and useful for pillars, arches, weeping 


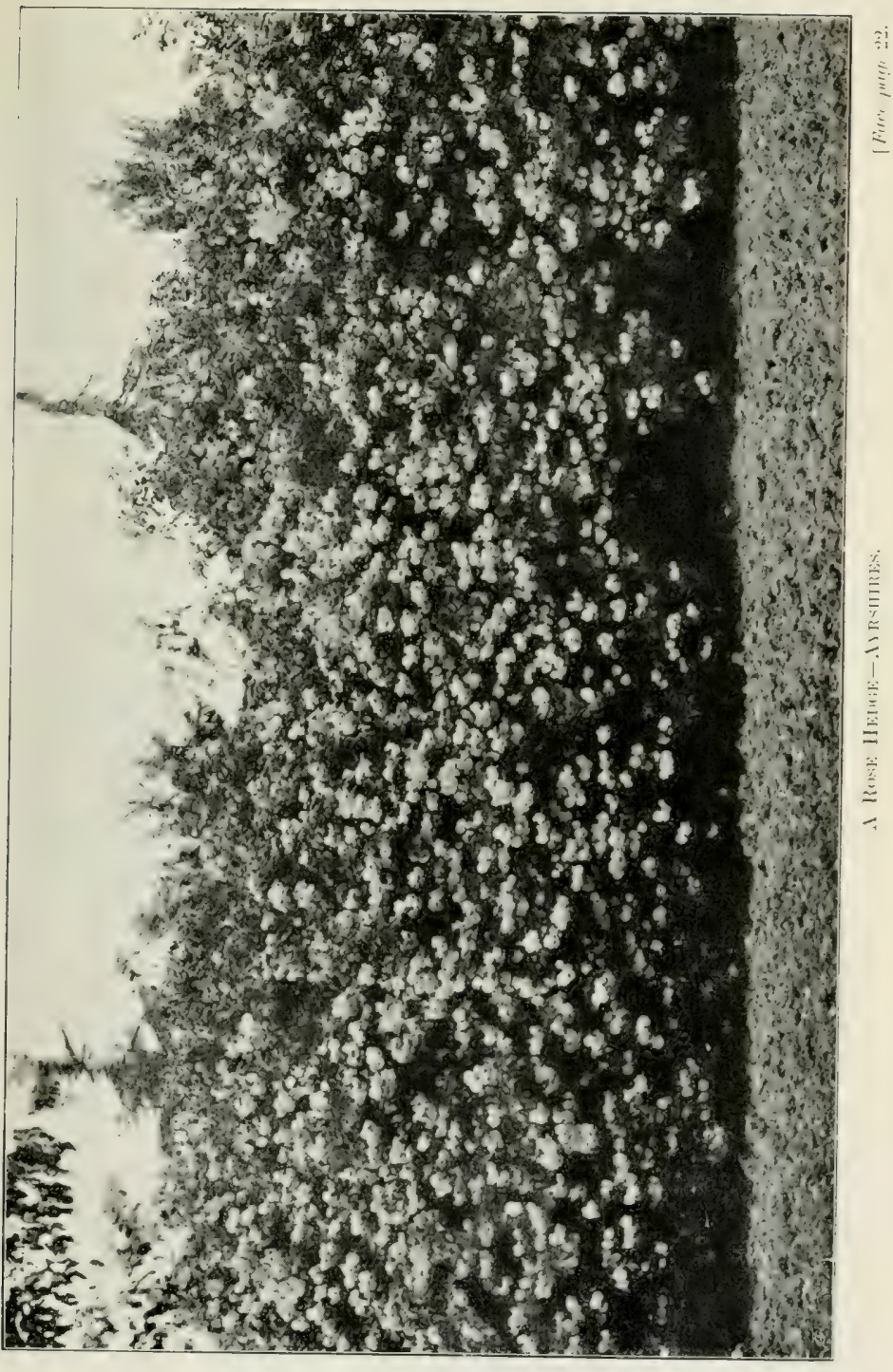



Roses, or covering waste places, the long shoots being left unpruned. Félicité et Perpetué and Rampant are perhaps the best known among them.

The Boursault Rose (Hybrids of R. Alpina). This is another group of strong-climbing summer Roses, with very characteristic smooth wood, not so pendulous in habit as the two last named. The species is a native of the Alps, thoroughly hardy, growing and blooming anywhere with reddish flowers that are often the first Roses of summer. The best-known varieties are Amadis or Crimson, and Gracilis.

The Banksian Rose (R. Banksiæ).-This is a very distinct species, said to have been introduced from China early in the last century, and named after Lady Banks. The plants grow very strongly, but are not hardy, and are liable to be killed outright in severe frost even on a south wall. There are only two varieties worth growing-the Yellow, with very small, but full, scentless flowers, produced in great abundance in clusters, and the White, with rather large flowers, most deliciously and characteristically scented, the odour being compared to that of violets. The plants, which are nearly evergreen in mild winters, should be very little pruned (see page 95); perhaps the best way is to shorten a little in the summer those shoots that have bloomed, cutting out all dead wood.

The Polyantha Rose (R. multiflora).-The older varieties of this class, which bloom only once, are single. These are-Polyantha simplex, a great grower, which has been tested as a stock for Tea Roses, but has not proved satisfactory; and $\mathrm{P}$. grandi- 
flora, similar but with much larger single flowers. A new departure was made in this class by the issue of Crimson Rambler (Turner, 1893). This is a very strong growing Polyantha from Japan, the flowers being produced in conical trusses in abundance, and lasting in bloom for a long period. It is quite hardy, but is not a true rambler, as it often will not grow away from the tops of last year's shoots, but persists in breaking strongly again from the base. It does not do well on a wall, but is best as a pillar or espalier. Several seedlings have been raised from this highly popular variety, two of which have gained the N.R.S. Gold Medal :-J. Veitch \& Sons' Queen Alexandra, 1901, of a terra cotta pink, and B. R. Cant \& Sons' Blush Rambler, 1903, of the colour of apple blossom, sweet-scented, remaining a long while in bloom, and to be recommended as a companion to the well-known parent variety.

\section{Wichuraianas AND THEIR Hybrids}

This increasing and important class must not be omitted, as they are hardy, will grow and flourish almost anywhere, and can be put to a multitude of uses. For pillars, pergolas and arches on tall briers to form weeping standards-for covering banks, for screens, and for rambling amongst trees-in none of these positions are they out of place.

Many of them are sweet scented and not liable to mildew-and further, are almost evergreen, retaining their foliage through the winter unless the frosts are exceptionally severe.

With a suitable selection of varieties they will be 


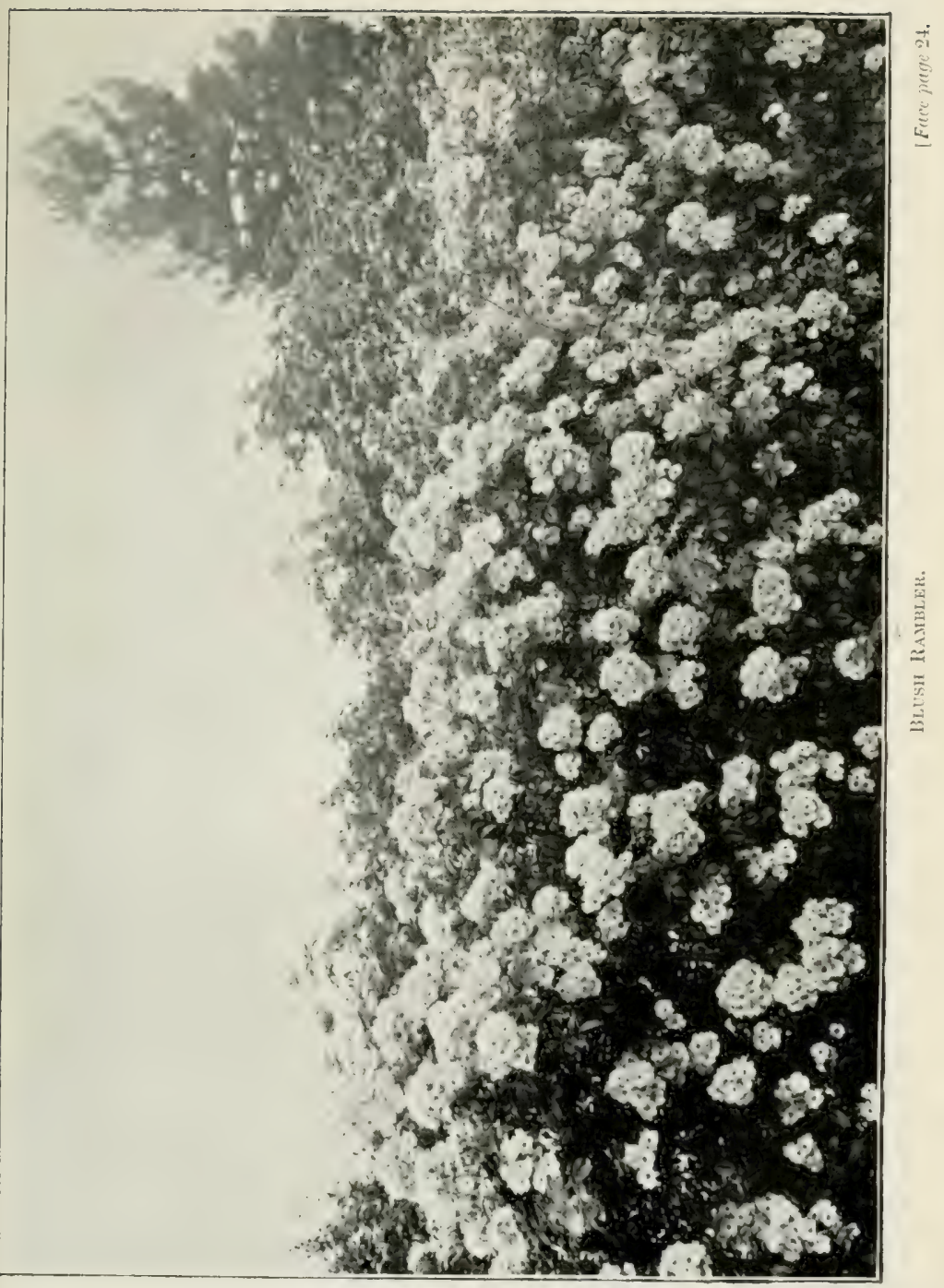






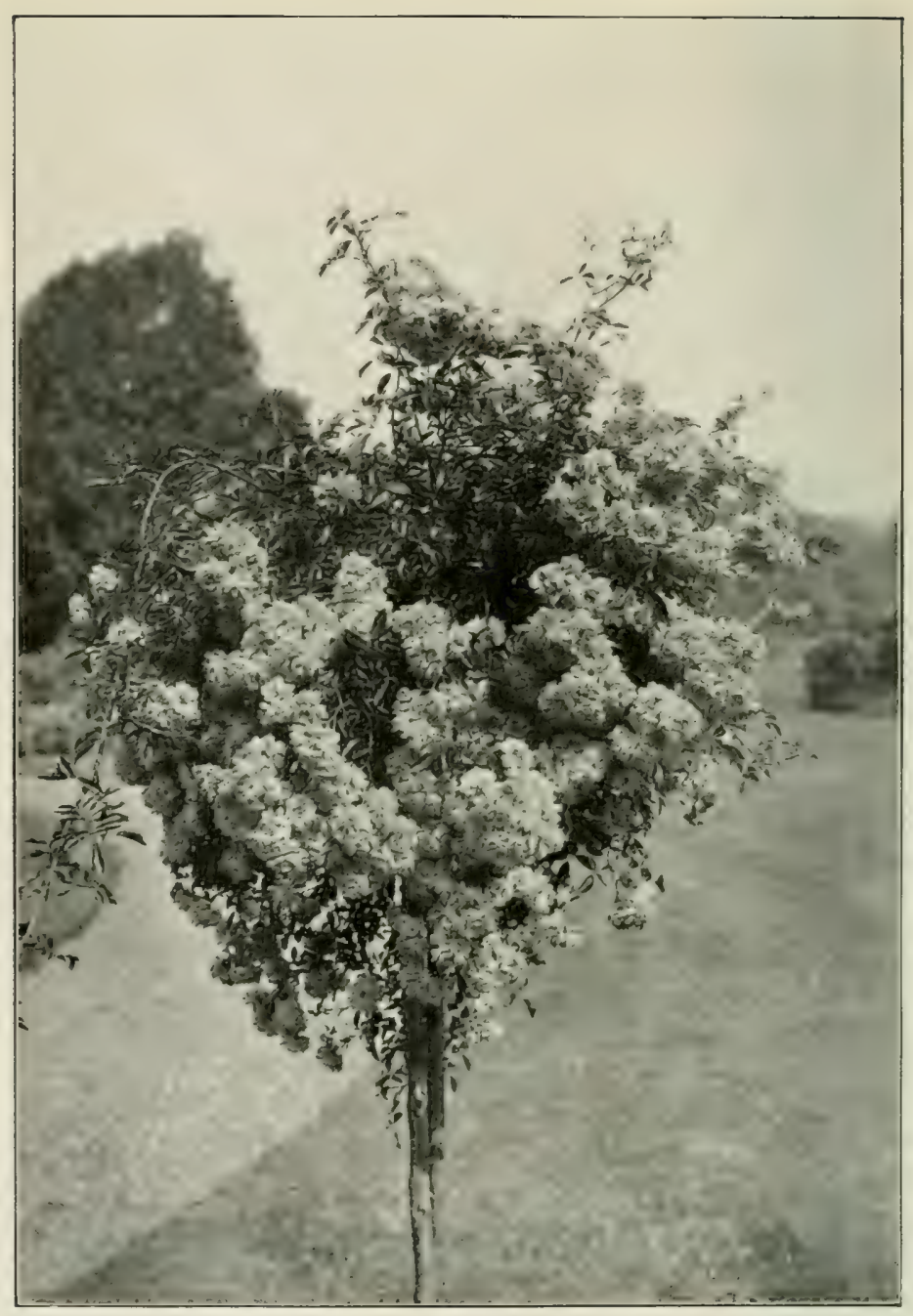

DOROTIT PEISTNS

Fare paren 25.

Plentomvele but F. Metentil Good. 
found in flower from early summer until late autumn, and the following list is so arranged, starting with the earlier flowering varieties.

Gerbe Rose, Alberic Barbier, Gardenia, Jersey Beauty, Ruby Queen, Joseph Lamy, François Juranville, François Guillot, Leontine Gervaise, Lady Godiva, White Dorothy, Minnehaha, and Dorothy Perkins and the type (Wichuraiana) whose fragrant white flowers in a mild season may be picked right up to Christmas.

The following varieties are not true Wichuraianas, but are often classed as such in catalogues, and are useful for the same purposes: Evangeline, Hiawatha, Delight and Tausendschon.

\section{Autumnal Flowering or Perpetual Roses}

The Hybrid Perpetual Rose.-This wonderful group seems to have originated from several sources; indeed, it may no doubt be said with truth that certain strains of almost all other cultivated Roses have now been incorporated, by accident or design, into some of the members of this wide and varied class. It seems to me vain to try and trace the parentage of the most celebrated varieties. The pedigrees of most of them were absolutely unknown even to the raisers, since systematic hybridising and careful choice of seed-parents was not practised by the French Rosarians who issued our most noted strains. Seeds were sown in immense quantities, and the cross fertilisation effected by insects or other agencies was relied on to produce the variations which ensued. 
The Hybrid Perpetual is the Rose of England: for not only are the best crimsons and reds with which a Rose is generally associated to be found in this Class, but also it is undoubtedly better grown in the British Isles than anywhere else. It has been said of our climate that it has no weather, but only samples: this exactly suits the H.P.s, which like a couple of hot dry days, followed by a dull, cool, damp one, and long continued "weather" of any sort will prevent their coming to perfection. From all tropical countries, or indeed from any district where the weather is "settled" during the blooming season, I have the same reports, that Teas and Hybrid Teas are the only Roses worth growing: and the truth of this was seen in the dry tropical summer of 1901, with its abundance of sunshine, when H.P.s were so deficient in form and colour that I found it impossible to get good typical blooms for fresh photographs.

Hybrid Teas intended, originally, to represent the cross between Teas and H.P.s no longer do so, to that extent the classification is unsatisfactory. It is very difficult even now to draw a decided line of division, either on the one side or the other, and it seems more than probable that the task will become almost impossible when the Hybrid Teas are crossed back again into the H.P.s or Teas. As, however, there have been more good new Roses in this Class than in any other during the last twelve years, and they are given separately, in almost all lists, I have placed those considered by the N.R.S. to belong to this Class in a distinct division in Chap. XII. The popularity of this class owing to its hardiness, freedom of flowering, and length of flowering period, 
has so increased of late years that raisers of new Roses hesitate to label their productions anything else. The time is no doubt fast approaching when the old-fashioned lines of demarcation will have disappeared, and the National Rose Society will have to evolve a new classification.

The Bourbon Rose was introduced from the Isle of Bourbon about the year 1825. This group is noted for its sweet scent, and also for its very good autumnal qualities, the true Bourbons generally giving better blooms in the second crop. It has been quite a large class. Mr. William Paul enumerates fortysix varieties in The Rose Garden, but few of them remain except the one celebrated sort Souvenir de la Malmaison. It seems to me highly probable that a much larger proportion of our H.P.s have some of the influence of this grand autumnal strain in their constitutions than is generally imagined; and as the modern Bourbons, Madame Isaac Pereire, Mrs. Paul, J. B. M. Camm, and Purity are evidently hybrids, it was advisable that all perpetual forms of this group also, should be merged in the large class of H.P.s.

The China Rose (R. indica).-This group, truest of Perpetuals, was introduced into this country from China about the year 1789. The Common Pink, otherwise known as the Monthly Rose because it is always in flower, and the Crimson were imported separately about the same time; and all other varieties have resulted from these types. They are not very strong growers, do best on their own roots in a warm soil, and the flowers, with little or no scent, have little to recommend them beyond the one good quality in which they are unsurpassed- 
constant freedom of bloom, early, late, and throughout the season.

Many varieties were issued in past years, but, besides the two types, Mrs. Bosanquet, of a waxy ivory tint, was generally considered the only one worth growing. Laurette Messimy (Guillot, 1887), however, showed an improvement, a pretty buttonhole Rose, pink shaded with yellow, very freeblooming; and several other varieties have since been added, of . which Madame Eugene Résal (Guillot, 1895) is perhaps the best. Very little pruning is required for the true Chinas.

The Lawrenceana, or Fairy Rose, also introduced from China about 1810, is simply a China Rose in miniature. These little toys are often sold in pots in the markets, and should not be confounded with the miniature Provence, which bloom only once : for the Fairy Roses are true Chinas, and if kept in health are ever in bloom. They are best perhaps in pots, but are sometimes successfully grown in rich warm soils as edgings.

The Tea Rose (R. indica odorata).-This most celebrated group, the true aristocracy of the Rose world, was also introduced from China about the year 1810 . The first one was pink, and in 1824 the Yellow Tea Rose was imported.

There can be no doubt that both of these originated from the China Rose, and for many years the group was known as the Tea Scented China. They are like the China group in habit, but differ from it in being more susceptible to frost, and having the peculiar fragrance said to be like that of a newly opened tea-chest. It seems strange and suggestive that Roses with this scent should have originated in 


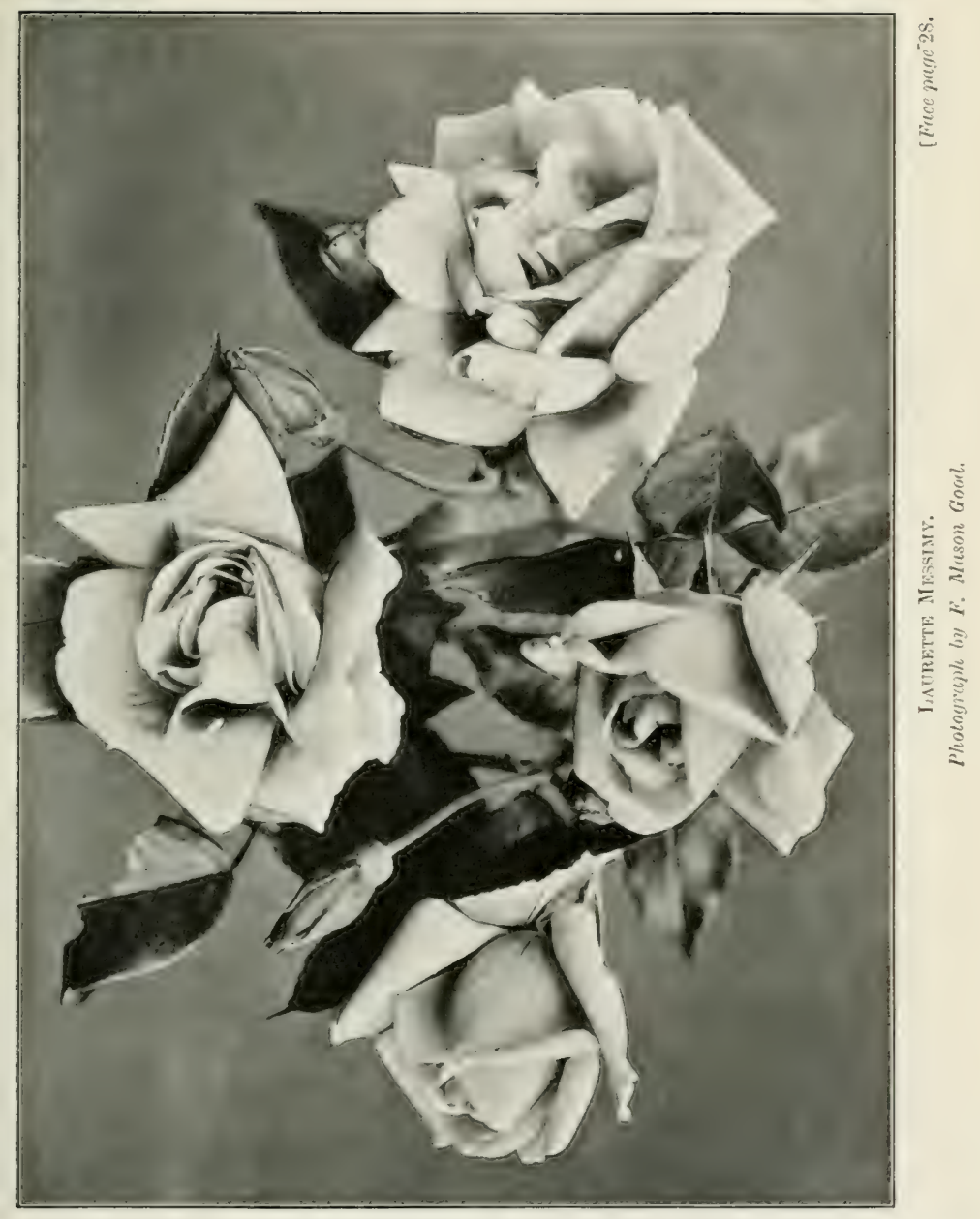






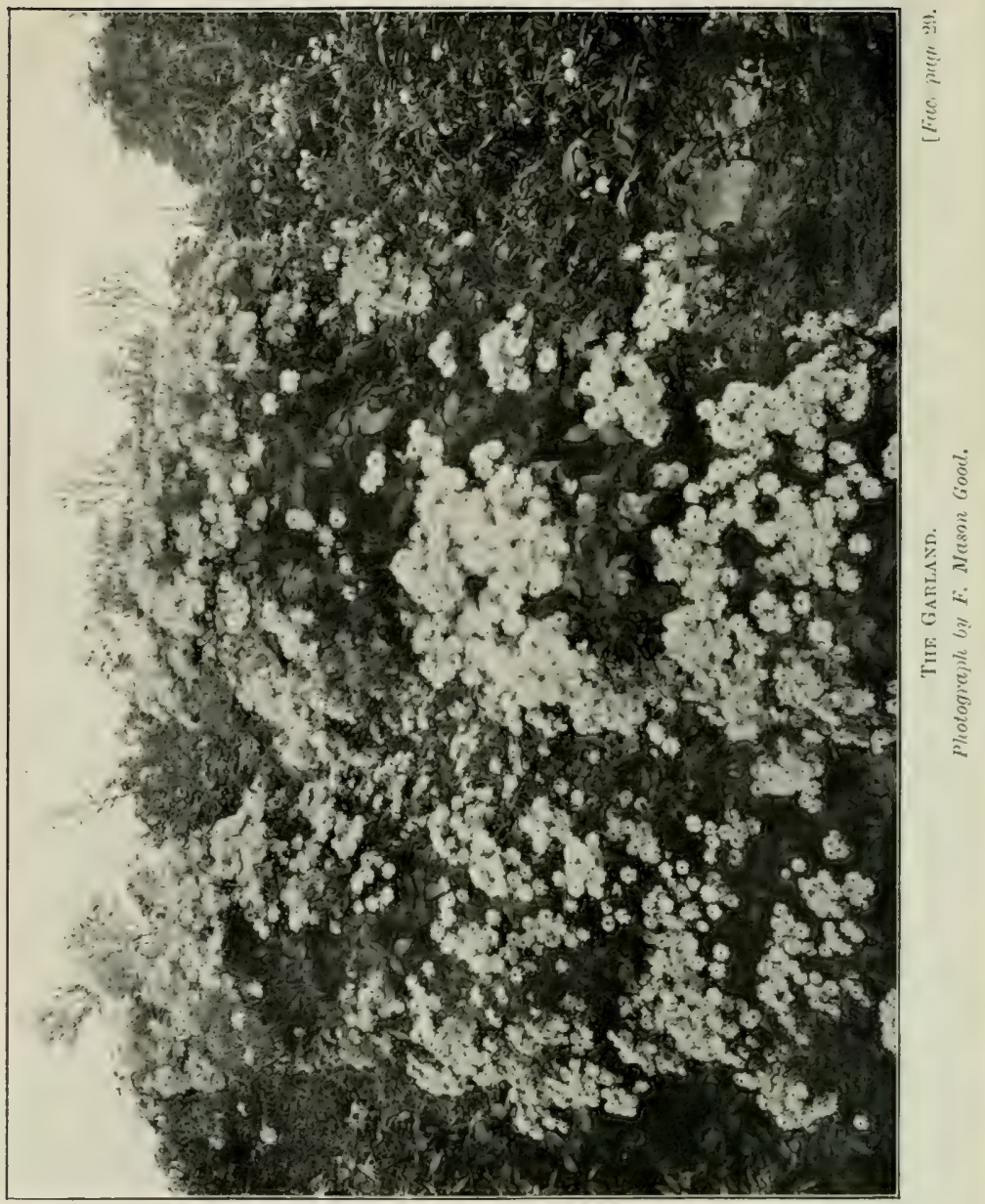


China, but scent experts deny that the odour of Tea is to be found in Tea Roses. The "manners and customs" of this lovely class will be found in Chap. XII.

The Noisette Rose originated in America, and was named after Mons. P. Noisette, who brought it to France, from which it reached this country about 1820. It is supposed to have been an accidental cross between the Musk and the China groups: there is no doubt it had something in common with Tea Roses originally, and the likeness was soon considerably increased by further hybridisation with the Tea Scented China. A few of our H.P.s also show a cross with this group, of which Boule de Neige is a good example. An account of the habits of this class also will be found in Chap. XII.

The Musk Rose (R. moschata).-This species is said to have been introduced to this country something like 300 years ago. It is a strong rambling grower, not hardy, with late-blooming clusters of single flowers, having a peculiar scent. It is a native of Persia and is said to be the sort from which the celebrated attar of Roses is manufactured in that country. The only varieties of this group which are at all well known are Madame d'Arblay and The Garland, strong climbers, which are supposed to be hybrids between the Musk Rose and some form of Rosa multiflora.

The Polyantha Rosa (R. multiflora).-The perpetual forms of this group are of recent introduction, so much so that the name is not even mentioned in the sixth edition of Mr. Cranston's excellent book, published in 1877. The best are dwarf in growth, 
and the flowers are very small, quite tiny, but often exquisite in colour and shape, generally produced in clusters and masses, and to distinguish them from their cousins of the climbing Polyantha group -are called by the National Rose Society pompons. Among the best are Gloire des Polyantha, Anna Marie de Montravel, Eugénie Lamesch, Léonie Lamesch, Perle d'Or, Petit Constant, Cecile Brunner Madame Phillipine Lambert. The majority of the new varieties are no doubt hybrids with the H.T.s and Teas. They are always in bloom, should be very lightly pruned, force well, and are best used as edgings except the taller growing varieties.

The Macartney Rose ( $\mathrm{R}$. bracteata).-This species was introduced from China in 1795 by Lord Macartney. It is of vigorous growth, with bright glazed foliage, not very hardy, and best on a warm wall. The original was single, but Marie Leonida is double, sweet-scented, and generally a mass of bloom through the season in a warm situation.

$R$. lucida, $R$. microphylla, and $R$. berberifolia are not hardy, but with shining foliage, and practically evergreen where well protected. There are double and single forms.

The Japanese Rose (R. rugosa).-These Roses are most distinct, the thickly spined wood and foliage being very fresh and pleasing, the single flowers large and fine, and the bright-red fruit handsome and striking. Originally the two principal varieties were the red and the white, the latter, very pure in colour, being generally the favourite, but there are now many hybrids of different shades, and more or less double. They do well on their own roots in good soil, for clumps, or a small ornamental hedge. 


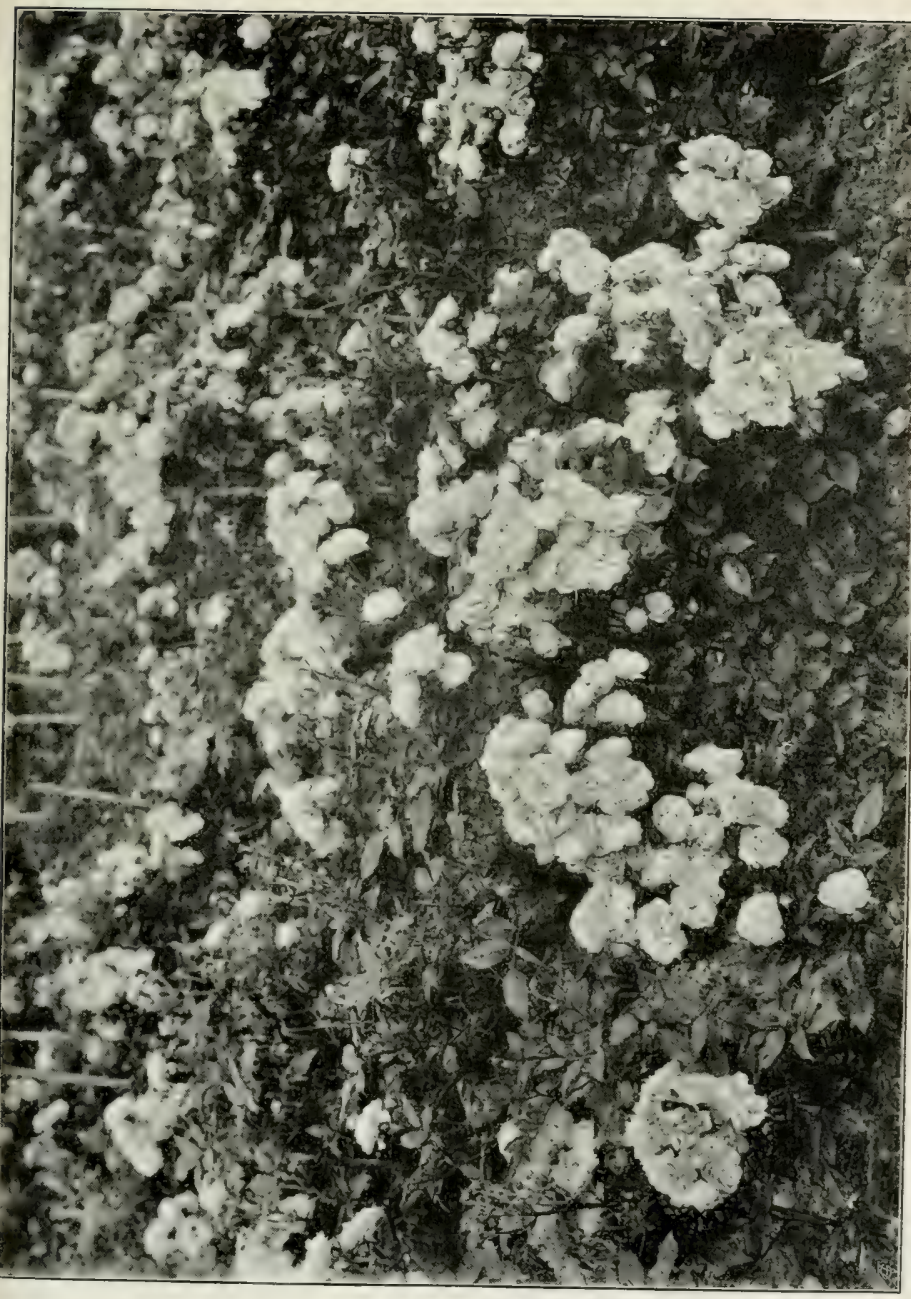






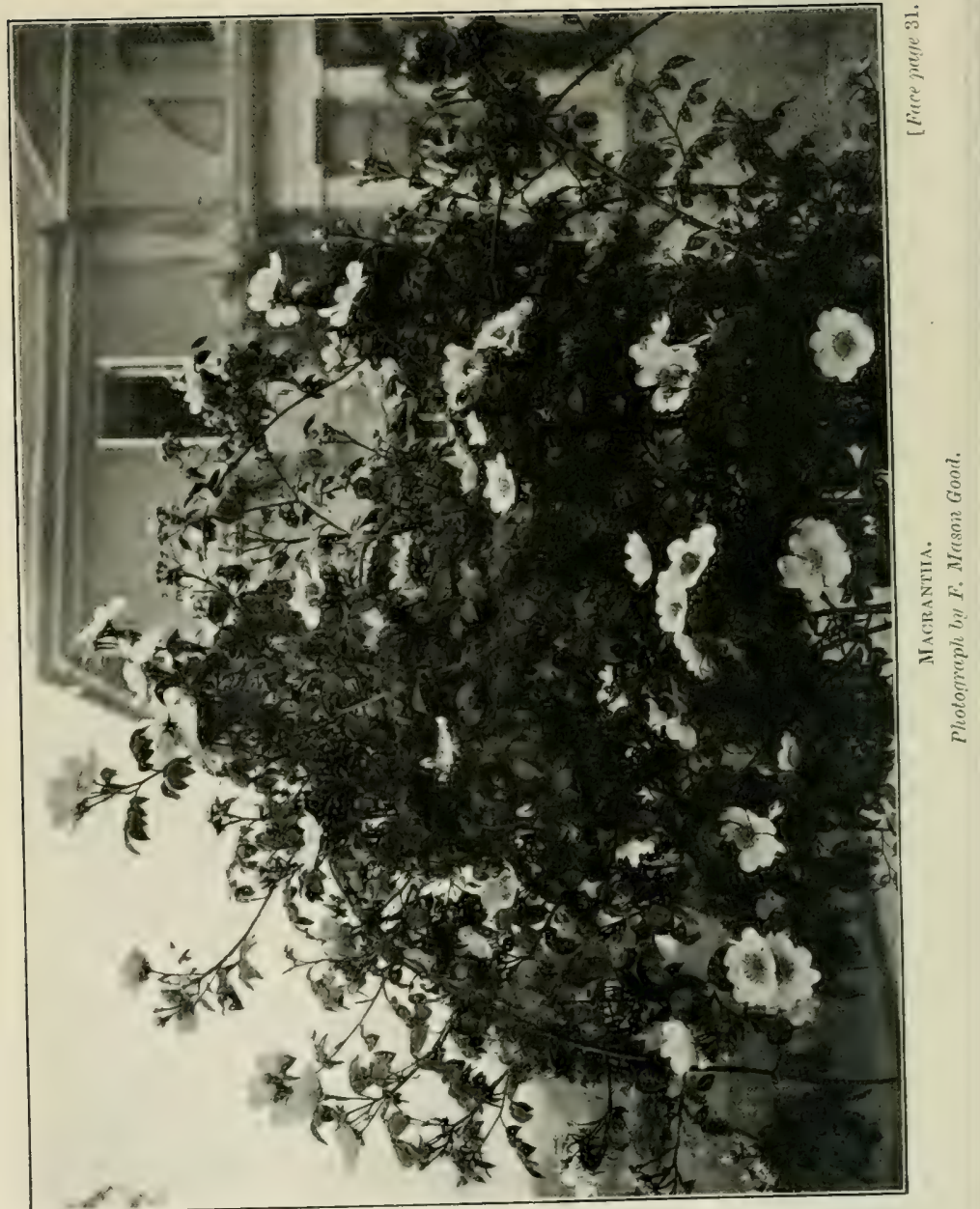


Repens alba (Paul and Son, 1903) is a weeping form of the white Rugosa, of extraordinary growth. It should only be planted where it can have a great deal of room, and if properly cared for will form a striking object when in bloom. Blanc double de Coubert, a semi-double the purest white of any known Rose sweet scented. Conrad F. Meyer, a beautiful shade of pink with large flowers of excellent shape that should be in every garden. Its white sport Nova Zembla is also good.

Other botanical varieties, all single, are $R$. macrantha, a French Rose with long golden stamens; R. pomifera, with apple-shaped fruit; R. rubrifolia, with red stems and foliage; $R$. setigera, the Bramble-leaved Prairie Rose from the United States; and $R$. gigantea, from India, with white flowers five inches across. There are many others, but they are mostly only of botanical interest. The Green Rose is a curious monstrosity of the China race, the colour of the petals being identical with the leaves and almost indistinguishable from the rest of the plant.

A sort of ill-defined division has lately arisen owing to some sorts being called "garden Roses." This term was originally applied, when H.P.s and Teas came into fashion, to the Damask, French, H.B., and H.C. Roses remaining in old-fashioned gardens. Later, it came to be used for all Roses which were not up to exhibition standard, and some raisers of new varieties that were not up to the mark introduced them as "good garden Roses," on the principle of the horse-dealer who, having an animal that would not "draw a hounce or 'ack a yard" decided he "must be a "unter," and sold him as such. The 
N.R.S. has now classes for the exhibition of garden Roses, and issues a list of what may be shown under this head; but for general use, without drawing any hard and fast line around them as a class, the name is useful as representing the hardy, strong-growing, free-flowering sorts, which do not require much care, but are not up to exhibition standard. 


\section{CHAPTER III}

\section{SITUATION AND SOIL}

IN the choice of a situation for the cultivation of Roses we must seek for a spot-

1 , as little liable as may be to severe frosts; and

2 , sheltered, if possible, from violent winds, but not too near large trees or hedges.

1. It is pretty well known that most of the Tea Roses are tender, and likely to be injured or killed by severe frost. In the winter of 1890 the whole of my Maréchal Niels were absolutely killed, though they were grown in a row close to the west side of a high paling, and were well and thickly covered with bracken, with moreover nearly a foot of snow over all. The Hybrid Perpetual Roses, especially if grown as dwarfs, will generally withstand the effects of any winter; but late frosts, in May or even earlier, will seriously affect their young shoots, in severe cases blackening and killing them, and still oftener injuring or destroying the as yet invisible bud. The worst of it is that it is difficult after such a visitation to estimate at first how much damage has been done. A fortnight of genial weather may sometimes be required before we can see whether the shoot is stopped (that is, made "blind"-come 
to an end without a bud), and even if the bud is still to be found apparently sound it has probably received some permanent injury or disfiguration that will render it valueless, but cannot be detected till it is too late. In such cases it would be advisable to remember that the injury is almost always worse than it appears to be at first, and that if the growth is not far advanced the sooner the damaged shoots are removed the better. Of course, too many blind shoots should not be removed, especially if they are the strongest, or if the plant has been lately moved, for such treatment would be likely to seriously weaken the whole season's growth.

Even the native briar standard stocks, just transplanted from the hedges, will sometimes suffer; and many thousands were thus destroyed in nursery grounds in the winter of 1890-91. In one year in the eighties many of my standard H.P.s were thus destroyed, and in almost every case the injury-the frost-bite-was not to the Rose, but to the stock, black dead places, looking like actual bites, appearing in the stems. This was an exceptional case, and it does seem odd, as we rarely see a wild briar injured by frost, that the same plant should be more tender when transferred to a garden; but we must remember that standard stocks for budding have nearly all their fibrous roots cut off, and that they are generally taken from a sheltered place and planted right out in the open, much more exposed to evaporation, and are often perhaps allowed to become dry at the root in moving. It is plain, therefore, that, as frost is such an enemy to the Rose-grower, a situation should be sought where the least damage of this sort may be expected. 
Frost is seldom very severe in England at the seaside, but the salt spray and violent winds would render such a place generally undesirable, though good Roses are grown in some seaside localities. The old-fashioned saying is that "frost falls." This is of course not true in itself, but it is true in effect. Heated air, being lighter, ascends; colder air, being heavier, descends; and it is found that frost is always most severe and dangerous in low-lying places, and that a covering overhead is a better protection than one at the side, because evaporation upwards towards the sky produces cold. My neighbour, a quarter of a mile off on a little hill, has always from three to five degrees less of frost than I have; and even if it were not so I believe that the same amount of frost would be more destructive to vegetation to me in a river valley than it would be to him on the upland. Valleys or low-lying ground, especially if near water, should therefore be avoided, and the uplands in all cases be preferred.

Mere height above the sea-level would not, in most cases, be a matter of much moment; though on the one hand the top of a mountain would not of course be a desirable spot, and on the other a very flat plain with little height above the sea would probably be subject to severe frost; thus the flats of Cambridgeshire, which have such a slight fall to the sea, are well known as registering very low degrees of temperature. Rather high ground, not necessarily the top of a hill, with valleys in the neighbourhood for the cold air to fall to, would probably be a good situation as to comparative immunity from frost. In such a place the heavier or colder air literally drains away to the valleys, which thus 
get more than their share of frost as well as of water.

In dealing with situation, I do not allude to different parts of England, though it is well known that Maréchal Niel cannot be successfully grown out of doors in Yorkshire, while in some parts of Devonshire and Cornwall even sub-tropical plants will live through the winter. I am not supposing that the Rosarian can choose his county for Rose growing: if he could, for combination of climate and soil Herefordshire would probably make a strong bid for the pride of place, at all events for H.P.s. Teas, which depend less upon actual fatness of earth and more upon dryness in atmosphere and soil, may probably in favoured situations be easier 'grown in the Eastern Counties. If a man has only his own grounds wherein to choose a spot for his Roses, let the highest spot be chosen, if it be not the actual bare cone at the top of a hill. A little height will make more difference than one would suppose; and if on a slope, let Teas be planted at the top.

2. SHelter.-Exposure to strong winds is very hurtful to Roses in the flowering season, and at such a time an exhibitor will be more distressed by a gale of wind than by a storm of rain. Anything that rubs or chafes against a petal will injure and spoil it; and to tie every bud up so that nothing can possibly touch it is, among a large number, almost an impossibility. But wind may, and often does, do much more harm than spoiling the blooms: the newly budded shoots of "maidens" are sure to be blown right out of the stocks as soon as they 
get strong and heavy, and the whole plant thus absolutely destroyed, unless they are carefully and constantly tied up to stakes; and moreover these ties must be looked to and renewed even quite up to the autumn, as a strong head is seldom safe from being blown out till it has been pruned in the following spring.

Where there are many standards, and the stakes have not been examined, and renewed where necessary at pruning time, every morning after a gale will probably show several of the supporting stakes snapped off close to the ground, and the Rose plant being injured at the root by swinging in the wind. Not only must a new stake be supplied, but the old stump must be extracted without disturbing the plant; for old decaying wood has, especially in some soils, a tendency to promote the growth of a fungus which is injurious to the roots. The operation, which looks hopeless, can generally be satisfactorily performed with an old pair of garden shears, which will grip the top of the half-rotten stump, and then, by a downward pressure on the handles, lever it out like drawing a tooth. This, however, should not be necessary with bamboo stakes, which are much more reliable and lasting than those of English wood. Every stake should be cut loose and pulled out of the ground every year at pruning time, and then held at the top and struck smartly on the ground. If it does not break, it will last another year, but even a strong sound bamboo, at the end of the second year, is nearly sure to break right across at the critical point, which is the exact line of the surface of the soil 
in which it has been standing. The stake thus shortened may often be replaced, and last at least another year.

Again, although height is as a rule more important than shelter as a protection against frost, the drying power of the east wind in what is called a wind frost is hurtful, especially to newly planted Roses. It seems to dry the sap out of them, and if long continued may do a good deal of harm.

As strong wind is so injurious, shelter should be sought for; and that, not only on the north and east, but also on the south-west, from which the strongest winds generally come. Belts of closegrowing trees or thick and high hedges will be the sort of shelter generally available, but it is most important that they be not close enough, either to shade the Roses, or for their roots to enter the beds. Buildings or walls are the best shelters, as the protection they give is real with some refracted warmth : they drop no seeds or leaves, and especially they have no robbing roots.

A place which has plenty of walls, even if most of them be low ones, offers great advantages in situation for Rose-growing. All the Teas and Noisettes can be grown to greater perfection against a wall than they can in the open, with the two disadvantages that the blooms will be too early for exhibition, and that the autumn crop will probably not be so good. The higher walls will be useful for the Noisettes and climbing Teas, or even for the climbing H.P.'s or Hybrid Chinas; and the lower ones for the true Teas of more moderate growth, which in the Eastern or Home Counties will in ordinary seasons have first-class blooms by the first 
week in June. Many do not know what a beautiful Tea Rubens is, unless they have grown it on a wall; and some of the hot-season Teas, such as La Boule d'Or, Maman Cochet, or Medea, will often succeed on a wall, and even not be too early to show, in seasons when they fail in the open.

No wall should be neglected. I have grown the best of Teas on the low wall surrounding a deeply gravelled stable yard, and have won a medal with Souvenir d'Elise from this hopeless-looking place. I have in such cases planted the stock against the wall and budded it there, with no preparation of the soil. The stock rooted itself firmly and strongly, and when the Rose began to grow I found that a big basin or depression in the soil round the root and plentiful supplies of liquid manure were sufficient for the production of capital growth and splendid blooms.

Walls facing due South are not, however, to be commended for the climbing Roses, except perhaps in the more northerly parts of the country : the full strength of the sun in cloudless summer days is too much for them; the flowers come out in a rush and are soon over, and the plant is too "much forced and exhausted to furnish much autumn bloom.

Apart from walls or buildings, the question of shelter is a difficult one; for it must be carefully remembered that the neighbourhood of trees, shrubs, or hedges whose roots can reach the beds, and also all actual shade, should be sedulously avoided. And, again, the situation must be quite free and open, not close and stuffy; and if no shelter whatever can be had, the finest Roses can still be grown, for the grounds of nurserymen, even those who are most successful at the shows, are absolutely open 
and exposed to the four winds of heaven. After all, then, it is better to be moderately high and exposed than to be too sheltered and too low, particularly if the shelter consist of growing trees or shrubs which stand too close. But, if thus unsheltered, extra and constant care must be given in the growing season to tying and supporting : the majority of the H.P.s should be grown as dwarfs, and stout bamboo stakes should support the standards.

In many cases, however, the would-be grower of Roses has no choice of a situation, but has to make the best of the ground at his disposal; and as I have to grow my own Roses in just such a situation as I have been describing as the worst of all-viz. at the bottom of a valley, near a river, hardly above the level of the water-meadows, only thirty feet above sea-level, on the stony gravel of an ancient sea beach, and moreover surrounded by large treesI can fully sympathise with any one in such a position. The disadvantages of low ground can only be surmounted by choosing the very highest you have-a little rise will tell-and by much care in protecting the Teas through the winter (see Chap. IV). As for the big trees, if they must not be cut down, their shade and their robbing power must be utterly avoided, or success will be impossible. We may generally calculate that the roots will reach to a distance equal to the height of the tree, though some are worse robbers than others, and a specially wide berth should be given to Elms. As to the cutting through the tree-roots before they reach the beds, the labour will generally be found inadequate to the result; a really deep trench, kept open, might answer in some cases, but in many it 
would be a serious nuisance. I have tried cutting the roots and putting tar and other things that I thought would stop them into the trench, before filling it up, but without success.

The general resort of the baffled Rosarian is to take in a piece from a neighbouring field, and this is no doubt the best course to pursue; for, if the soil be good and the field an old pasture without any trees too near, it will be far better to do this at once, even at some extra cost, than to try to grow Roses to perfection in a garden without sufficient elbow-room from large trees and shrubs.

Pure air is essential, and good Roses cannot be grown within the smoke circle of a large town; but on the border land, so to speak, of town and country, in those suburban gardens where clean or foul air may depend upon the direction of the wind, constant loving care may do a great deal to minimise the evil with a few plants. It should be remembered, in such cases, that the leaves are the lungs which are unable to respire when choled with grimy particles, and plenty of syringing, and even sponging of the leaves on the under as well as the upper surfaces, should be resorted to.

\section{SoIL}

The best soil for Roses is a strong rich deep tenacious loam, of a heavy greasy nature without being actual clay, and naturally well drained by resting, not less than two feet down, upon gravel or chalk or some other porous stratum. This will give a general description of what should be the ideal, 
but I do not suppose that anyone can accurately appraise the value of a soil for Rose-growing by simple examination, and even chemical analysis is sometimes fallacious. The test of results is the best and most reliable, and the value of land for wheat or pasture (either of which is a good guide) is well understood by local men in any part of the country. One field will often differ very much in value from another that looks just the same; but this is all well known, as to practical results, by the farmers and labourers on the spot, and much reliance should be placed upon their opinion, in conjunction with examination of the soil, in test holes to the depth of two or three feet at least. The best wheat land, high-rented pasture, a neighbourhood where the English oaks and elms grow large and the hedges are vigorous and strong, with long clean healthy shoots - such signs as these will be better guides to the seeker for a Rose soil than geological maps, which often give no indication as to the nature of the surface.

The principal soils likely to be found are clay, loam, gravel, chalk, and sand.

CLAY.-The general idea is that clay land is most suitable for Roses; but there is a very great difference in the fertility of clays, from the poor blue shale clay of the Weald of Sussex to the rich yellow unctuous butter that feeds fat the Roses of Colchester. The grey, or light-coloured boulder clay is often very deficient in humus, and requires a good deal of manure, or better still dark-coloured soil, to be mixed with it. In this matter there can be no better guide, as I have said, than the local knowledge. which has been gained by generations of experience 
of results, and the obvious test of value is the rent or price demanded and paid.

But clay land has very much deteriorated in value for agricultural purposes of late years, more than any other, and it is not now considered, as it used to be, the best of all soils for Rose-growing; and it must be remembered that even the best of it is very difficult and troublesome to work : it cannot be meddled with at all in wet weather, and unless the surface is dry harm may be done by even treading on it. Planting in such a case is a serious trouble to the conscientious Rosarian, who is told to apply the most powdery soil to the roots of his Roses and to see that it all settles evenly and closely between the layers of fibres, if he has nothing at hand but huge sticky unbreakable clods. The precious cultivation of the hoe, keeping the surface powdery and preventing evaporation by cracks in dry weather, is a serious and difficult task. Even if the land is well drained to start with, which is absolutely necessary, the lower drainage of the pipes 'may become choked by age or neglect of attendance to the outfalls, \&c., and the upper drainage of the cultivated soil is sure to be injured if the ground be trampled on or meddled with in a thaw or at any time when the soil is wet.

If such land should be the portion of the Rosarian, every effort should be made to lighten it, and to keep its particles as separate as possible, and prevent their being squeezed together in a muddle of putty. The agriculturist seeks the aid of frost for the disintegration of clay: if the soil be thrown up roughly and as much as possible exposed to the air, it will found on the first dry time after a thaw in 
fair planting condition, but even then it should be trodden as little as possible. Anything that will mechanically keep the particles apart is good for digging into actual clay: long strawy manure, leaf mould, any vegetable refuse, road-scrapings, grit, light sandy or gravelly soil, or even coal ashes, will all help; but the best of all is the burnt clay itself, mixed well into the land.

The clay should be burnt as follows. A large collection should be made of all manner of vegetable refuse, weeds, and rubbish that will not easily burn, sticks and wood both green and dry, but nothing except just the kindling that will not burn too quickly, Rose prunings and hedge clippings, rotten wood and old stumps, \&c. Two or three large old roots that will smoulder a long time may be placed in the middle, and the heap arranged of such a mixture of fairly inflammable and damper materials that the fire will neither go out nor break into fierce flame. In and upon and around this heap, when well on fire, should be placed the clay in quantity proportionate to the amount of fire. Constant watching will be necessary to add fresh clay when it is needed and to prevent the fire going out or breaking through too fiercely anywhere, the object being to char the clay black and not to burn it red. I recommend, as the best instruction possible for this as for all mechanical operations, seeing it once done by an old and experienced hand. The clay burnt red as a brick will be useful as a disintegrator at all events; but the black charred clay will also have a considerable manurial value, and it is generally agreed that there is nothing like it for 
improving at the same time the consistence and fertility of real solid clay.

Roses in a clay soil make long strong roots, but not many of them. It will be advisable therefore in such places to put in plants from a lighter soil, whether Roses or stocks, which would have a larger number of roots of a more fibrous nature though not so large; and it would be very desirable to have a little lighter soil-lighter in weight, but darker in colour-leaf mould or the top soil of an old garden - to put in immediate contact with the roots. Still, if the clay land be really good and well drained, it will often repay all labour spent on it, especially in a hot and early summer; for the Dog-Rose does like heavy soil, and with a well-cultivated surface above to prevent cracking on the one hand or too great consolidation on the other, and with plenty of moisture in the cool tenacious though well-drained substance below, most of the H.P. Roses may be expected to come to full perfection on this stock.

LOAM.-If there was a choice, I should select rather the best loam with a tendency to clay, what a farmer would call "strong" land. There is very great difference in the value and fertility of what in auctioneer's phrase would be "good mixed soil"; and I can only repeat that the best guide on this matter is local knowledge and the rent that has been paid in past years. The soil ought to be equally good for quite two feet in depth, with effective natural or artificial drainage as a sine qua non. By natural drainage, I mean a sub-soil of gravel, stones, sand or chalk; and for artificial nothing less than actual pipes should be used, laid by a competent 
man, with a fair fall, and outfalls not neglected, but watched, cleared, and properly attended to. The deep, red, adhesive loam of some parts of Herefordshire has always seemed to me to be the perfection of Rose soil, and in the best loam the best Roses of all sorts may and should be grown.

On one occasion, when dining at a friend's house, I had some plum-pudding handed me, of the modern type, very dark, rich, strong, and greasy. I declined it, but regarded it curiously and with interest, my thoughts wandering elsewhere. My hostess, noticing my earnest gaze, asked me if I saw anything the matter with it. Without thinking, and naturally with somewhat unfortunate results, I blurted out the truth: "Oh, no: I was thinking what rare stuff it would be to grow Roses in" !

GraveL.- Soil known as gravelly is often too quickly condemned. It is considered healthy to live on, agreeable to work, and useful for many things, but too hot, poor, and dry for the cultivation of the best Roses; still, as I have had to grow most of my own in such a medium, condemned after careful examination by one of the best judges as hopeless, I can aver that there is no reason to despair of a gravel soil.

There will be some soil at least, light, dry, and powdery perhaps, but fairly fertile, on the top above the gravel, and this, probably the full depth of the spade in the garden but not so deep in the field, should be taken out and laid on one side. Though not the soil the Rose delights in, it is excellent for root formation, for the striking of cuttings, for placing next to the roots of Roses, and for mixing with heavy loam or clay in the making up of the beds. 
The actual gravel must then be taken clean away to the depth of two feet at least from the surface (some enthusiasts say three feet, but I do not think it necessary or even desirable), and sufficient good strong loam procured to take its place. This is expensive, but is absolutely necessary for the growth of good H.P.s, and will last a long time. The greater part of this heavy loam should be placed at the bottom where the gravel was, but a little of the light soil may be mixed with the upper portion. How to do this will be further described in the next chapter; but it is important to notice that when the beds are thus made up of good Rose material in what is naturally a gravel soil, the advantage is gained of having such perfect natural drainage at the sides as well as at the bottoms of the beds as could not well be attained in what is by nature a good Rose soil.

Furthermore, Tea Roses may be grown to perfection on gravel soil. A large quantity of good manure should in this case take the place of the poorest of the gravel both above and below the Rose roots, and a little of the heavy loam may be added, though I do not believe it to be necessary. For Teas there is no occasion to be afraid of the multitude of small stones which are natural to a gravel soil; for I believe Mr. George Paul was right when he stated in the Rosarian's Year Book that "Tea Roses like grit." The bloom of Madame Cusin which gained the medal at the Crystal Palace in 1893 as the best Tea exhibited by an amateur, and was characterised by the Secretary of the National Rose Society as "certainly never equalled in any exhibition on this side of the 
Channel," was grown by me in what is practically an old gravel-pit where stones have been raised for the high road. The pit was refilled with the siftings and levelled, and in this soil, unaltered save by cultivation and manure, the above-mentioned and other good Tea Roses have been grown.

CHALK.-This is as hopeless as anything to grow Roses in, and on the upper chalk of down lands where it is close to the surface, and good loam probably far distant, it would be hardly worth while to attempt it. But in a great deal of the chalk formation of geologists it lies at a considerable though varying depth, and the soil above it, of a sufficient thickness for all Rose purposes, may be gravel, sand, clay, or loam. In many of these places the chalk itself is of a clayey nature, and is then called marl, the fertilising value of which is dependent upon the proportion of clay. Poor dwellings and sheds in Suffolk used to be made of what is called " clay lump." This was marl, mixed with reeds or straw, well watered, trodden by a wretched horse till it was thoroughly compacted, and then formed into very large bricks and left to dry but not burnt. When an old building was pulled down the "clay lumps" were considered excellent, if broken very small, for mixing with light land, and I have no doubt they were. They were thoroughly dry, and one of the great difficulties of mixing clay with other soil is overcome if it can be got so dry that it can be beaten into powder. Marl, as a mixture of clay and lime, was a good deal carted on to the light lands for agricultural purposes in times gone by, as the many old marl-pits in Suffolk testify. 
Some very fertile soils may be found on the lower chalk or marl formation, particularly on the edge of the greensand. Hitchin would be a case in point, where Mr. E. B. Lindsell has for some years grown the best amateur H.P.s, and where Messrs. Harkness and Sons have endeavoured, if possible, to better even their Yorkshire fame.

SAND.-This may be considered in itself to be the worst soil of all, but where it occurs in the greensand from sandy rocks, strong loam is probably to be had within carting distance, and almost all the really sandy part being taken right away to the depth of two feet, good Teas at least might probably be grown in well-made beds in such a place. But in sands like that to be found at the seaside, or as the "blowing" sands on the Norfolk and Suffolk border near Thetford, where thick belts of firs have to be planted to prevent one man's crop, and field too, being actually blown away to his neighbour, I fear the Rosarian must stifle his impulses, change his object of worship, and devote himself, according to the extent of his holding, to hyacinths or partridges. 


\section{CHAPTER IV}

PLANTING: WITH LAYING OUT OF THE BEDS AND PROTECTION

Situation and soil being settled, we have next to lay out and prepare the beds, to plant the Roses, and to protect the delicate and tender kinds from being injured by frost.

Let it be first understood that for proper cultivation the Rose must have a place to itself. Although I sympathise with that large number of cultivators who plant Roses in mixed borders among strong herbaceous plants and even shrubs, it must be said that it is next to impossible to bring the Rose to perfection in such surroundings. When wondering much at the number of extra tall standards to be seen in nurserymen's grounds, and as to who could be found to buy them, I have been told that there is a large demand for them in some gardens for certain situations, "where a tall standard Rose would just come in "- -between two huge clumps of delphinium, perhaps, or "so that it would just show nicely from behind over that bushy shrub." It must be laid down that to make the queen of flowers take a back seat is an impracticable task; 
she cannot stand it, but will inevitably pine away; she tolerates no rival near her throne, and will not show her full beauty if she has one.

It should be understood that in this I am speaking of the best Roses, H.P.s and Teas, as hereafter described, and that there is now an increasing number of Garden or Decorative Roses, as they are called, which may be used in these positions. Few of these are as strong-growing, fine, and perpetual as one could wish, or as they probably will be when Raisers have fully recognised what is required of the ideal Garden Rose; but Lord Penzance's Sweet-briars, for example, are fully capable of holding their own in the company of any herbaceous plants or even shrubs.

For me, beds must be made for the Rose and the Rose alone. No! no mignonette or other annuals to "hide the bare ground," since standards need not be more than two feet high in stem, and dwarfs should be close enough together to do all the ground-hiding required. Lut there be Rose beds sacred to the Rose, and let them all be grown together in the very best situation to be found; for standards dotted about singly here and there by the side of the drive or in holes on the lawn are much more difficult to manage and care for properly than if they were all together in prepared ground. It is well known that you can feed 100 people much better and cheaper in proportion than you can one person by himself. And so, if the Rose is in a big bed with many others, the food can be applied with greater economy and effect, and the roots can find in any direction the same congenial proper soil and nourishment. 
Let "the small man," if he be a true Rose-lover and has a mind to grow them really well, harden his heart against all rival flowers, and go in, practically, for Roses alone. In every department of life a man must be a specialist now if he wants to succeed, and the Rose will amply repay special care. There are several examples among amateur Rose-growers of single-handed men who either unceasingly superintend or do all the work with their own hands; and most of these have not the smallest fear of meeting the best head gardeners in England in any class at the largest shows. This is by no means the fault of the great gardeners, even of such as have fifty men under them, but is simply because the Rose requires undivided care through nearly the whole of the year, and they have such a multitude of other things to attend to that they cannot compete even with a single-handed man who gives all his time to his Roses.

What, then, shall our Rosarium be like in pattern and shape and general effect? Here I fear I shall prove too practical and utilitarian for the taste of many persons. Mr. William Paul in his large work gives several carefully drawn diagrams of geometrical arrangements and of noted Rose-gardens new and old, some of them laid out quite from the landscape gardener's point of view. And Dean Hole says: "There should be beds of Roses, banks of Roses, bowers of Roses, hedges of Roses, edgings of Roses, pillars of Roses, arches of Roses, fountains of Roses, baskets of Roses, vistas and alleys of the Rose." But though these things are good and desirable, they will probably be beyond the means of most of my readers, as they certainly are beyond mine. 


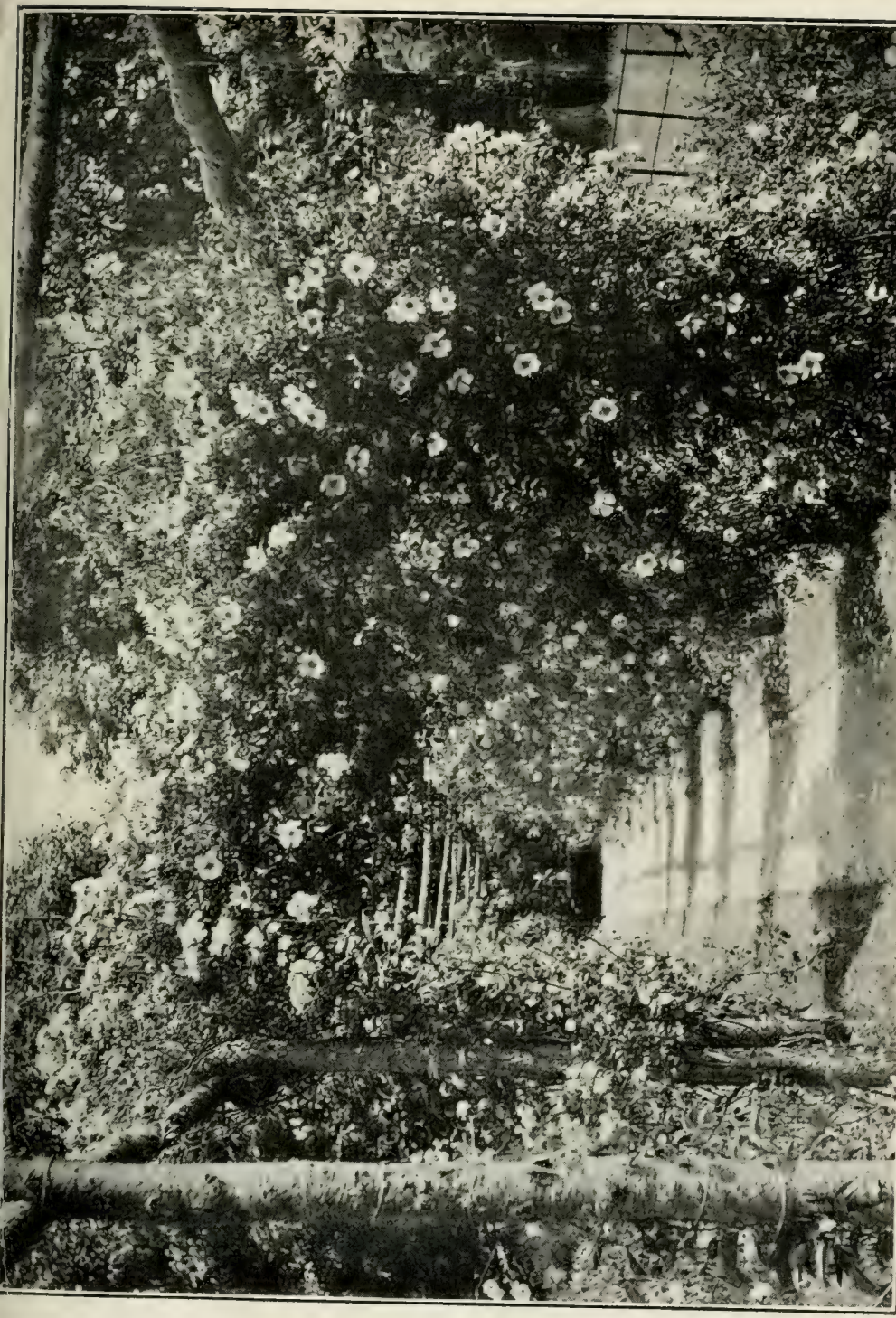



For perfection of culture, which is the principal object of these pages, the best situation must be chosen, even in defiance of artistic surroundings. And for my own personal taste I may say that, given the most perfectly arranged Rosarium that ever was seen, I would leave it for a few plants in a bed in the kitchen garden with cabbages on one side and onions on the other, if there alone could be found the perfect blooms.

As to the shape of the beds, it seems evident that they should not be so wide as to necessitate treading upon the soil to reach and cut the blooms. This points to long and comparatively narrow beds, and when you have them there seems no escape from actual rows, following the shape of the beds, whether straight or curved. Anything else would waste the precious room, for if the whole bed be made of the best soil and fed and manured equally, the room that will hold another plant is precious. Straight rows may be condemmed as formal, and so they are, but they are thoroughly practical and economical, and undoubtedly the best for an exhibitor, who wants to be able to go over all his plants easily and expeditiously.

My own Rose beds are simple parallelograms fiveand-a-half feet wide, and such beds may be as long as you like. I may wish mine were longer than they are but not wider. Longitudinally they are separated by grass paths of the same width, and there should be cross paths here and there, but not too many. Grass paths are much superior to gravel in appearance and in cost of keeping in order; and of course if the Rose beds are made out of a meadow or pasture, the grass is simply left. These paths 
should not be narrower than five feet, not only for the convenience of visitors, but also for the conveyance of water or liquid manure in hand-carts.

In these beds are three rows of Roses, the rows sixteen inches from each other and seventeen inches from the grass, and the strongest and tallest growers naturally in the centre row. There should be no hesitation about planting the Roses pretty close to each other, for the bed will be all prepared and fed alike, and they will not rob each other much. Beginners are apt to make a mistake in this respect, probably having young trees and shrubs in their minds; but they should remember that in the case of ordinary H.P.s and Teas grown in the open for the production of the finest blooms, most of the Rose plants will not increase very much in size, for the annual pruning will prevent this. I have seen many Rose beds where I should have nearly double as many plants, and rows of standards whose distance apart might be counted by yards; there might be some excuse for wanting "to hide the soil " in such cases.

It will be found most convenient for reference and labelling, and especially if exhibiting is contemplated, to place all the plants of one variety together in a row; and though the first idea is to dot them all about the beds, the effect will be better if they are massed together.

Then the distance of the plants from each other in the rows should depend entirely upon the varieties; sorts that are spreading as well as tall and strong, such as Mrs. Paul, should be eighteen to twenty inches apart, while such as are upright as well as small growers, as Lady Mary Fitzwillian, may be 
within nine or ten inches of each other. Between these extremes there will be many gradations, and care should be taken at the same time neither to inconvenience the plants by crowding nor to waste the room. Some tall sorts, like François Michelon or Her Majesty, are upright and not wide and bushy, and do not therefore require much room; while others, like Comtesse de Nadaillac, though dwarf are spreading in growth, and cover more ground in proportion. Some guide to these "manners and customs" of the varieties will be found in Chap. XII. It will be best, however, that the strong growers should be set wider apart if quantity rather than quality be aimed at, as in this case the plants will be allowed to increase in size at the annual pruning. There are also some varieties, both of H.P.s and Teas, which, even for exhibition purposes, should not be pruned much : and obviously more space should be allowed for them. The Gloire de Dijon race, the Maréchal Niel and the Noisettes, which are pruned on a different system and require much more space, should not be planted in the same beds with the H.P.s and Teas.

But I am getting on too fast. We have to make up our beds after marking them out in the grass, and to do this properly everything will depend upon the nature of the soil and subsoil, instructions for dealing with which have been given in the last chapter. Whatever the soil may be, it should be moved at least two feet in depth; and unless the soil under that should prove thoroughly porous, affording good natural drainage, the beds must be properly pipe-drained by a competent and trustworthy man. That is the first thing; without good 
drainage, natural or artificial, no success can be achieved. In any soil there should be perfect drainage, as cultivation depends upon it in many ways. All really worthless soil, chalk, gravel, or sand should be taken away, but long before this should have been the hunt among neighbouring farmers and landowners for good Rose material to take its place. When found and purchased, this good loam-the top spit of an old pasture if possible - heavy and strong, but not actual clay if good loam can be found, should be carted to the spot while the ground is yet hard in September, for the Roses are to be planted early in November, and the soil will do well to rest and consolidate a while before planting.

Let the beds be dug out, as advised, to the depth of two clear spades at least; and let it be understood that the material is to be made up in two portions or layers, whereof the lower is to be the larger. If among grass, reserve the turf to be chopped up and mixed into the upper portion. Next lay on one side all soil in the top spadefuls that seems fairly fertile, however light and dry; it will be useful for a thin layer in immediate contact with the roots, for mixing very slightly with the lower portion but more fully with the upper part, and for forming the topmost two inches of the bed. Then dig out the remainder of the depth agreed on, and see that the drainage is right. If the soil be good replace it, and if it be worthless cart it away, and fill in with the imported soil, which if it be actual clay should also have a good deal of the lighter material worked in as thoroughly as possible. This lower portion should be about two-thirds of 
the whole in depth; and if manure is to be added, let it be mixed freely with the upper part of this lower portion. If the bed is meant for Tea Roses, heavy soil is not necessary, though good loam is desirable, and a large proportion of the lower part should consist of the best manure, remembering the more manure is added the more the beds will sink eventually as it decays.

The upper third of the bed should next be formed. If the imported material be loam, a good deal of this may be used; but if it be clay it should be added very sparingly, and as well worked in as possible with a good deal of the lighter soil and the chopped turf, the upper two inches in all cases being of soil that the hoe will pass through freely and easily. The bed is now made up, with the strongest soil and much of the manure forming the larger lower part over the drainage, and the upper one-third of rather more friable material, getting gradually more porous towards the top, for the admission of air and warmth and the encouragement of fibrous roots. The beds should not be trodden more than can be avoided, if there be time for them to settle; it will be better if they are pressed gently from time to time, or allowed to sink naturally of themselves.

By the first or second week in November the purchased plants ought to arrive, and these should have been selected beforehand, if possible in the nurseryman's quarters, or at least ordered very early, as the good plants are sure to go first. They should not be sent before November, for though you may move your own plants with care in October, they do not stand a long journey well 
before they have lost their leaves. The bundle should be always unpacked at once, unless there be strong frost; and if the frost continue, it will still be well to unpack them, remove the frozen surface from a piece of unoccupied light land, and "lay them in." This should be done with some care, seeing that the roots are not bruised or laid too closely together, that all are deeply covered with soil, and that the tops are also protected from the frost by green boughs, matting, or some such material. They should also be laid in if the weather is wet and planting cannot be proceeded with at once; it is far better to do this than to plant when the soil is sticky. Nevertheless, every effort should be made to get the planting done in November, and not to defer it till the spring; for I have often seen that fresh roots are commenced during the winter months by Roses planted in November.

Great care should be used in disentangling and untying the heads of the Roses when unpacking, as there is still considerable danger, with the "maiden" or one-year-old plants, of the head being clean pulled out of the stock. Good plants will have good roots, that is, many and fibrous, rather than few, strong, and long. In "dwarf" Roses (by which term is understood all sorts even of the most vigorous growth which are budded on the stem of the stock near the root, and not on the branches to form standards), good plants will have very little length of stem between the roots and the point where the stock was budded, whether they be on briar or manetti : a perfect dwarf plant should have no "leg" at all. The wood should 
be ripe, firm, and hard, a fat red fleshy shoot being of no use, as it will certainly have to come off when the plant is pruned. There should be a good union between stock and scion, no failure visible in the joining, and no round knob formed by the Rose at the point of union; but it should be evident that the stock has swelled and grown in proportion to the growth of the Rose.

The roots should be pruned as soon as the Roses are unpacked, in the first place removing with a sharp knife any bruised or injured portions, and seeing that the ends of all the roots are clean cut; secondly, shortening all of extra length, especially those which are fibreless, or stiff ones which go straight down; and thirdly, looking for suckers, which should be cut clean out-an easy way of distinguishing a sucker from a root being that the former gets thicker and the latter smaller the further it gets from the stem. The underground stem or main root should also be strictly examined for buds even in the most embryo stage. These should be carefully cut out, or they will certainly sooner or later form suckers.

The art of packing Roses is well understood by the best nurserymen, and some damp material is generally placed in the package around the roots. It may occasionally happen, however, owing to the parcel being delayed on the railway, that the roots have got dry or even the bark of the Roses become shrivelled. In such a case, if matters have not gone too far, the following method of recovery may be recommended. Lay the Roses flat in the ground and bury them completely, roots and tops, six inches deep; give the spot where they are buried 
a good soaking with water, and at the end of three days the plants will generally be restored to their original condition.

The very first opportunity when the soil is comparatively dry should be chosen for the planting, and one of the most important points to remember is that the roots should never be allowed to become dry; they should be kept under matting or damp leaves or soil till actually wanted, and exposed to the air as little as possible. Some recommend the dipping the roots in a pail of thick puddle composed of clay, cocoanut fibre dust, and water, as a protection from drying air: but I do not think this is necessary or advisable where there are small fibrous roots, as these get matted together and cannot be separated without some danger of injury. In spring planting, if the sun be bright, it is safest to carry the Roses in a pail of water from the place where they have been laid in during the winter to the bed where they are to be planted.

Another equally important point is that the Roses should not be planted too deeply. I consider four inches sufficient for "dwarfs"; standards may be planted an inch or so deeper, and a little further apart from each other. Comparatively shallow planting, especially if the Roses are going to be cultivated, and not neglected, is a great secret of success. A good piece of advice is to mark the line of soil upon the plant, and be careful not to cover it deeper than it was before; and a bad one is to plant deeper in light soil to avoid the drought. The principle of shallow planting and dependence on horizontal surface roots is well understood by gardeners in the case of fruit trees; they will take much pains 
to cut the tap-roots, and will even "lift" the roots of their vines, peach, and other trees if they prove unfruitful, lay them in again nearer the surface, and encourage them by all means in their power to remain there. They know that the produce of tap-roots is gross wood without blossom, and that fibrous surface roots must be looked to for flowers and fruitfulness; yet some recommend the seedling briar as a stock because it roots deeper, although we surely want flowers, not gross wood alone, from the Rose as well as the fruit-tree.

In planting, therefore, at the depth recommended, carefully spread out the roots horizontally, equally in all directions if possible, though this cannot always be done, purchased dwarfs often having roots pointing only in one direction, which arises in some degree from carelessness and haste in originally planting the stocks. If a separate hole be made for each plant, let it be wide enough; do not curve the roots or let them cross each other. If they naturally want to cross, or there be two or more going in the same direction, put some fairly light soil between them that they may lie in layers but always horizontally. See that the soil which is put against the roots themselves, or to cover each layer of roots, is at all events fairly fine and crumbly, if not actually dry and powdery, and especially that no manure is put in actual contact with them; lift the plant by the top up and down a little with a shaking movement to settle the soil more thoroughly amongst the fibres. And remember that the whole operation of planting is done much more thoroughly and expeditiously by two men than one. If single-handed a short pointed stick for scratching fine soil between 
the fibres will often be found more handy than trowel or spade. Just fairly cover all the roots with a couple of inches of soil, tread it very lightly and carefully, and pass on to the next plant, for the rest of the soil can be added at the conclusion of the day's work.

In planting dwarfs the point of union should be, if the stock be manetti, two inches below the surface and one inch if the plants are budded on briar cuttings. The Rose may then eventually throw out roots of its own, which will not only help to feed it, but being nearer the surface will also hold the plant more securely against being rocked and loosened by the wind. Now therefore may be seen the immense disadvantage of a dwarf plant which is not budded sufficiently low on the stem: either the roots must be placed too deep or the point of union must be left uncovered. Order therefore with short "legs," and "see that you get them." It should be mentioned that Mr. Prince of Oxford, who is the principal advocate and the largest user of the seedling briar, does not advocate the covering of the point of union with this stock. I have seen some of his dwarf "cutbacks" on the seedling briar which certainly were flourishing exceedingly with the point of union two inches above the surface; but with the briar cutting I have found Roses do not thrive so well if thus planted, and with the manetti it is absolutely imperative that the point of union be well covered, or the plants will assuredly die.

Standards must be securely stalied at the time of planting, and it is better when the hole is made to put in the stake before any of the roots are covered, or otherwise some of the best of them may be inad- 
vertently bruised and injured. All the plants for the day having been put in, some more soil should be added to each plant; and then tread but lightly, make the surface level, and look to the row again in a few days with a rake, filling depressions and doing away with any cracks that may appear. This will be better than treading too heavily at the time of planting. If the weather should continue very dry, watering may be desirable; and if the plants have good green leaves on when put in, the heads should be watered at once on unpacking, and the plants well watered and syringed immediately after planting.

It is easy to imagine a beginner having some uneasy reflections after following the above instructions. "I have planted my roses only four inches deep, and trained the roots borizontally, as certainly seems right from the analogy of fruit trees and from what I know of the advantage to roots of the fertilising influences of sun, air, and the surface bacteria. But nearly all my manure, and I gave a great quantity of valuable stuff to my Teas, has been buried some distance below the plants, and what is the use of all that manure there, if the roots are not to be allowed to go down to it?"

Here comes in another important principle, to illustrate which I will take as my text the soil in which hyacinths and other bulbs are grown in immense quantities in Holland for sale. This soil is extremely valuable, as the profit on the cultivation in good hands may reach quite $£ 50$ an acre. And what is it? Pure sand and nothing else for a depth of four feet or more, which no English farmer would take rent free. Yet the hyacinth must have plenty 
of water. We all know that in a hyacinth glass a fine plant and a noble flower may be produced from the bulb with nothing but water given. We also know from this glass culture that the roots of hyacinths do go down some depth, considerably more than the height of the glass. And it should further be stated that the sand in the soil spoken of rests upon a water-bearing stratum of clayey peat, in fact the general water-level of the whole country. But it seems almost impossible that hyacinth roots should reach down vertically for four feet or more, and quite impossible that they should start and form such a length of root without the aid of water. If, however, the water was always slightly rising up through the sand, and moreover the roots had a power of attraction almost equivalent to suction, the impossibility would vanish. And so it is. Water, or rather moisture, does rise through the soil by capillary attraction, as it will up through a sponge or piece of flannel. Just so, moisture is always more or less rising up through the earth, though of course a quantity in time of rain or immediately after sinks down through it. It rises most of all when the sun shines hot and the surface is dry, and then the Rose, which likes heat and a friable air-permeated surface above and a "cool bottom" below, rejoices in the rich moisture which the roots appropriate as it rises up through the manure from below.

In thus recommending the placing of all manure at planting time beneath the horizontally lying roots, and incorporating none in the soil at their own level, I must make the proviso that the soil at that level is, as it generally would be, sufficiently rich in "humus." This is decayed organic matter, animal 
or vegetable, probably mostly the lattcr, and as a rule we may judge of the amount of humus in a soil by its colour: the darker it is the more humus would generally be present. Thus, peat, leaf-mould, or manure that has become mould, would be almost entirely humus, and lacking in the mineral requirements of plants: while light-coloured sand, gravel, chalk, or light-grey boulder clay would be almost wholly mineral, and wanting in organic matter. In such a soil, Roses might be grown well for a time, but sooner or later the defect would be seriously felt, and no liquid or artificial manure would atone for it.

Now, the upper portion of most garden or pasture soils has generally sufficient humus, afforded in the one case by manure at different times, and in the other by the gradual decay in course of years of the roots and leaves of the plants of the pasture. But, if light-coloured soil of any sort, or even loam taken from anywhere more than a foot below the surface, be imported, it will be too "raw," and well-rotted manure in large quantities should be thoroughly mixed with it. But it must be well rotted, for I am strongly of opinion that a great many newly planted Roses fail to thrive because too fresh manure is placed close to the roots. This error, and that of planting too deeply, are the commonest faults in planting Roses.

For these reasons I recommend strong rich dark fresh soil in preference to the addition of solid manure, and that if any be used it be placed underneath, where it may be used before it has lost its strength.

It must be borne in mind that shallow planting is of no use without cultivation, which is done by the 
Dutch Hoe constantly at work on the surface. This causes more rapid evaporation from the actual inch or tivo disturbed and it soon becomes dry, but at the same time by closing the pores and filling up cracks it checks the evaporation from below, so that the moisture drawn up from beneath in the manure reaches the roots, and yet cannot escape into the air in vapour. I consider this one of the most important points in the "cultivation" of the Rose.

When I say Dutch Hoe, I mean a Hoe which, passing beneath the surface, does the above-men-

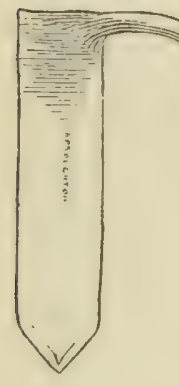

"Sproughton" Hoe.

tioned work of cultivation without undue moving of that surface itself either forward or backward. I do not at all like to advertise here an invention of my own, but as I believe the "Sproughton" Hoe to be much superior to any other, it does not seem right that I should hesitate to recommend it.

It has all the advantagres of the Dutch Hoe without its disadvantages, and with these other virtues in addition :-

The earth, in passing over the blade, does so unimpeded; it does not have to pass through a hole as in the Dutch Hoe, since there is only one commec- 
tion between the handle and the blade. In a stiff soil it can be used sideways, if necessary, plough fashion; and it has a free point, which has many advantages.

Further, and especially, it is a Duplex : it is just as efficacious in drawing as in pushing, and ordinarily should be used for pushing and drawing alternately, thus covering double ground, as it wastes no time in the air. A very short trial will also show that it will work the ground the other side of a plant, between it and the next one, without the user changing his position, as no other Hoe will. I do not like to puff it any further, though the sale of it has never brought me profit or seems likely to do so: but all who have tried it speak of it as the best Hoe, and it would plainly be of no use to mention it without adding where it is to be gotG. C. Bennett and Son, Tavern Street, Ipswich.

As to mulching for winter protection of the roots, I do not believe it to be necessary, but the soil should be loose on the surface even in winter, for a friable and well-cultivated surface is a mulch as has just been seen. Very long shoots of dwarf Roses may be shortened, not too much, but only to prevent the wind getting much hold of them. This does not apply to the Noisettes, Maréchal Niel, or the Dijon race of Teas, whose long shoots must be protected and tied to some support.

If the collection is quite small, labels of as permanent a nature as possible may be used; but in large collections, especially where, for exhibition, many of a sort are grown together in rows, a book with the rows numbered and the names written in order will be found most convenient. 


\section{Protection}

But the tender and delicate Teas are to be protected from frost, and how is this best to be done?

Long manure is unsightly and unclean, and difficult to get away properly, while clean straw looks untidy and messy and is not a good protection, For a long time bracken (the common brake-fern) has been recommended by nurserymen, and good and useful it is where it can be had. If it can be procured at a reasonable price per load, a stipulation should be made that it be cut before it has got quite sere, in fact just when it begins to turn. In this case the leafy parts will adhere much longer to the skeleton stalks; but care must be taken that it be not laid before use even in small heaps, or it will be sure to heat to a certain extent and steadily rot. It should be put lightly yet thickly around and amongst the dwarf Teas and into their heads: there is no fear of its blowing away, but after a heavy snow it may get beaten down a little too much, and a further supply, which should be kept in sheaves, standing in stooks, may be added. For standards it is a capital protection, tied tightly together at the top, and allowed to hang down all round, as a sort of rough thatch; but in making it secure against wind, it should not be fastened to the stem underneath the head, as anything that will hold the damp that does get through the protection will do more harm than good: wheat straw makes a still better job in skilful hands, but if fir or laurel boughs be the protecting material chosen, the plant may be too 
top-heavy to stand a violent wind without some additional support.

For a few dwarf Teas a rude platform of crotched sticks with poles laid on them to support fir or evergreen boughs answers generally very well: in this case it would be good for the plants to remove the protection when there is no severe frost ; and it may be taken as a general rule that frost to the extent of ten to twelve or even more degrees will do no harm in the winter, if it be not unduly prolonged or accompanied by a dry east wind.

Another material for the protection of dwarf Teas that seemed very reasonable and good at first is earth itself. To use this, the rows of plants are earthed up by a hoe, or even in large quantities by a plough, in the same manner that potatoes are treated in the spring, to the height of four to six inches; in any mode, no protection need be applied to the tops of the plants, as a great deal will necessarily be cut away in the spring pruning. But if the roots run horizontally and shallow, as they should do, there is considerable danger of injuring them in scraping up sufficient earth, and a fresh supply for the purpose from elsewhere is heavy and inconvenient to move away again. If, therefore, this mode of protection be used, and it is a popular and effective one, the rows should be at least double the distance apart that I have recommended.

I find the cheapest, most convenient and handy material for the protection of dwarf Teas from frost to be dead leaves, which will just have fallen and should have been gathered together in time for use. If applied thickly enough, they appear to afford ample protection against any frost, and when heaped 
together on the beds they may possibly generate a very small supply of heat in themselves; but only dead leaves should be used, for anything that would ferment and actually beat would probably be injurious.

They should be put a foot to eighteen inches in depth all over, around, inside, and between the plants, and I do not find that they blow away in appreciable quantity, except perhaps on the very outside, where they may be renewed. They will be beaten down and consolidated a little by snow and rain, when a fresh supply if necessary can be added.

I believe these to be the best protection; they are Nature's own covering; the bed-clothes she herself provides for the winter sleep of her tender plants, and even apples accidentally left on the ground under the fallen leaves, have been often found fresh and in good condition in the early spring. Whatever the covering be, it should not be removed till the middle or end of March, unless the quantity be so small that the corering can be very quickly replaced.

Tea Roses on walls can be easily protected by evergreen boughs hung on nails; if fir branches be used, the needles or leaves will begin to drop off in early spring: this has a good effect in exposing the plant gradually, and so hardening it off, but the needles should be swept away and not suffered to work into the soil. It must be remembered in this case and in that of standards that it is no use protecting the upper shoots if any part of the actual liose below is left exposed. The very lowest part of the Tea Rose as budded on the briar is the 
important place; if that be lilled the whole plant is destroyed: but if even an inch of sound wood is alive at the very bottom, though all the rest be killed, the Rose will probably grow up again as strong as ever.

In very severe frosts and on low-lying grounds there is, however, great difficulty in keeping standard Teas alive during the winter. Leaves or earth, the most efficient protectors, seem impossible of application; and as the best Tea Rose blooms are produced on standards, heavy losses are often experienced by exhibitors. Digging the standards bodily up, and, after laying them carefully in rows in the earth, covering them with boughs or soil, has been tried and recommended. For the weakly growers, such as Comtesse de Nadaillac, Princess of Wales, or Cleopatra, if on strong stems, this may answer fairly well; but for the stronger sorts with large heads, such as Marie van Houtte and Amma Olivier, it seems a pity to lose the advantage of established plants. I have tried half-measures, with great success so far as the frost was concerned; this consisted of digging the rows of plants up, or at least loosening them, on one side only, then bending and pegging them down flat on the ground and covering them first with straw and then with earth. Though completely uninjured by severe frost, they did not do so well afterwards as I hoped they would, but it was an exceptional season, and I should try it again but that I have found a higher spot for my standard Teas, where, with due protection of their heads, they have survived severe frost without having to be moved.

Maréchal Niel is very liable to injury from frost, 
especially in the long strong shoots of the year, which if unhurt will produce the best blooms. As a standard in the open, where it can be efficiently protected (the plant from frost in the winter and the blooms from rain in summer), it does not indeed afford such a wealth of early flowers as under glass or against a wall, but it becomes a true perpetual bloomer, and from such plants alone can Roses be cut for exhibition. For the best method of protecting such standards in the open, see Chap. XII., p. 323 .

When briars have been budded with Teas, the tiny bud, on which so much depends, is of course in danger in hard frost. An old piece of advice from Mr. Rivers was to paint it with two or three coats of collodion, which forms a white shin: I tried this for two years but cannot credit it with protection of much value. I strongly recommend for the protection of these Tea buds the little straw covers or cases in which wine-merchants send out their bottles; there can be little difficulty in obtaining these in quantity, as I believe they have no value, except for lighting fires. It should be seen that the ties are secure, especially that the one at the top is tight and sound, and then they form capital nightcaps, which are, I believe, as good protection as could be wished. In the case of dwarfs they are not wanted, as the earth or dead leaves can be used to cover them: but they are just the thing for standards, when the budded lateral is cut back only just short enough to allow the cap to pass over, when it is held quite sufficiently against the wind. The bud is thus actually thatched, and provided with what is practically a waterproof as well as a warm covering, 
though not impervious to air. In one or two very severe winters I have had the inserted buds of tender Teas destroyed by frost even under these caps: and I now wrap a little very thick ("Giant") Berlin wool round the buds before putting the cap in position. 'The cap must be tied very tightly at the top, as the wool would hold water and be dangerous: but I have never lost a Tea bud from frost since using the wool. The caps can be very readily taken off or replaced if necessary at any time to see that all is well.

Any Rosarian who has had valuable Tea Rose plants killed in past winters, will find it a great comfort when he hears the cold north-easter blow, or finds his sponge frozen in the morning, to know that his Rose-pets are well supplied with bed-clothes and night-caps to keep out the frost. 


\section{CHAPTER V}

\section{MANURES}

"Manures" may seem an unsavoury subject to those lovers of the Rose who only know of the flowers as seen in the garden or after they are cut; but to the Rose-nurses, under whose constant care each shoot grows onwards to the perfect bloom, it is as important a matter as the food of a babe is to its mother. The Rose enthusiast, for whom I write, has no objection to exploring the recesses of a muck heap-he rejoices in the discovery of a dead well of really good stuff-and wonders much how others can find any objection to the wholesome and invigorating fragrance from a big watercart full of the drainings of a cow-shed.

The Rose is said to be a gross feeder, but this does not seem a satisfactory statement, for though it will take and absorb, and "answer to treatment" as doctors say, in the reception of large quantities of strong manure, yet is it fastidious in the manner of its application. The roots of the same plant which when strong and well established will rejoice in fairly strong liquid manure, will, when that plant is moved in November, become sickly and perhaps die 
if they are placed in the planting in contact with fresh, raw, and insufficiently decayed manure. The roots of the Rose like to run and feed in thoroughly fertilised soil of the proper texture and quality in preference to actual manure; and this is why fresh soil, the top "spit" of an old pasture with the turf, liquid manner of different sorts, or artificial if the exact amount of proportions can be found, have more satisfactory results as a rule than any quantity of solid manure incorporated in the soil.

It may be said that the soils of many a garden are, from long manuring, thoroughly fertilised earth: and indeed the manetti stock, which seems to like this sort of ground, budded with H.P.s in a favourable situation (that is, well away from trees or shrubs or any strong vegetation), will often give very satisfactory results the first season in an old garden. But this dark old soil, very rich in humus and decayed vegetable matter, though it may be much benefited by a dressing of lime, is generally wanting in some of the mineral constituents which the Rose requires, for though heavily manured it has probably been also heavily cropped, and the Rose likes fresh virgin soil if possible. A naturally strong, rich, rather heavy loam is what the H.P. rose likes, as fresh and unrobbed as possible; but wonders may be done for the Teas by manure, solid and liquid, even on a poor light soil.

1. Natural Solid Manure.-It will be seen from the above that I do not consider solid manure to be the best form in which to give food to Roses, provided they be planted in good fresh dark soil that is sufficiently rich in humus. But many other good authorities may very likely be of a different opinion, 
and I should quite allow that solid manure, in the right condition and properly applied, is of great benefit to Tea Roses.

Taking first the ordinary manure made with straw from stable, cowshed, or pigstye, it is generally allowed that as the Roses like " a cool bottom," and stable manure is "hot," and cow manure "cool," as a rule the former is the worse and the latter the better for the purpose. In clay soils stable manure would be allowable and perhaps even advisable; but, otherwise, that from cowsheds or, better still, from a yard where highly fed bullocks are kept, would be the best of all natural solid manure, the pigstye contribution ranking next in value, and the general heap from a farmyard where horses are not predominant being good enough for ordinary purposes.

The next question is, Is it to be dug into the soil, among established Roses, or used as a topdressing? I would avoid the digging, if possible, by having rich fresh soil with plenty of humus to start with, and perhaps moving the Roses, or replanting them after renewing the beds when they seem worn out. But if the manure is to be got in amongst established Roses, dug in it must be, on all but light soils, with as narrow a spade and as much care as possible.

But if it is to be thus dug in and incorporated with the soil among the roots, we must consider what its condition should be. It should be thoroughly decomposed and "sweetened" so as to have lost its objectionable qualities to the human senses, for not till then is it suited for contact with the roots of the Rose. It is quite true that 
manure does lose some of its valuable constituents by rotting so far, especially if exposed to the wash of heavy showers; if the solid be preferred to the liquid, it should be protected from rain, and yet kept just damp enough to decompose thoroughly, and turned of course, as every labourer knows how, to prevent too rapid heating.

If a top-dressing be used, no confusion must be made between this and a mulch. It is not uncommon to find, in instructions on planting, one to the effect that when a job is done a coating of long manure, which may be forked in at spring time, should be laid on the top to protect the roots from the frost. In the first place it is the plant itself, not the roots, which most requires protection from frost; next I do not know how any manure, much less long stuff, is to be "forked" into the soil in a useful and harmless manner; and I wonder quite as much what good can be done by long straw, washed clean by the winter's snow and rains, if it is got in. A manure and a mulch are two different things, and should not be confounded; the former is for feeding and fertilising objects, and the latter for protection against frost, heat, or drought. Some little good may be washed out of it into the soil, but when wanted no longer it should be removed.

Well, then, shall we apply our solid manure, for food during the spring and early summer, as a topdressing? If we do, it is plain that the roots can only feed on what is washed from it through the soil by rain or watering, and that the same advantage could be got by liquid manure alone. To this it might be answered that a long drizzling yet thorough 
rain would wash "the good" out of the top-dressing more gradually and with better effect than could be produced by applying liquid manure in quantity, and if the top-dressing was exhausted by much rain, a new supply could take its place. This is true, but a top-dressing has its drawbacks:-not only in its unsightliness, for the enthusiast will think nothing of that-he wants the most perfect Roses and will endure anything for that object -but that, if laid on thick enough to be of any service in feeding, it hinders the beneficent influences of sun and air, brings weeds of its own and makes their extirpation troublesome, and, above all, prevents the most important cultivation of the surface during May and June by the Dutch or rather the "Sproughton" Hoe.

Nevertheless, on light soils, by which in this case I mean light in colour and light in weight, decomposed solid manure has a very good effect when applied as a top-dressing, and does act as a mulch as well. On hungry and porous soils, such farmyard inanure, sufficiently far gone for the straw to have lost all colour, or "short" enough to be moved with a shovel or spade, even though it be laid on several inches thick, completely disappears in the course of a year, and hardly any sign of it except a darker colour to the soil remains.

On poor gravelly ground, where no fresh soil has been imported, a liberal top-dressing of this sort, especially if plenty of good manure has also been placed beneath the roots, will enable Standard Teas to be grown to perfection; for it will not hinder but facilitate the use of liquid manure, natural or artificial, as well. On such ground, poor, porous, and wanting 
in humus, no hoeing on the surface can prevent the plants from suffering in a hot dry summer, and something in the nature of a top-dressing or a mulch is necessary. But that will not make it a Rose soil, where H.P.s can be grown satisfactorily.

A very good authority recommends that, in planting, the manure be applied in the fashion of a sandwich ; that is, I take it, manure below, then soil, then the roots, then more soil, some manure over that, and the soil again at the surface. The danger here, I think, would be of either making the top layer of manure so thin as to be nearly useless, or getting the roots too deep.

Top-dressings of brewers' grains, or other compounds, are recommended by Dean Hole and other writers, but I think that on a proper Rose soil some of the above disadvantages would be found connected with any one of them.

Of solid manure not made up of straw, night-soil is perhaps the most important. And as a strong believer in the earth system I am tempted here to enlarge upon the well-worn theme of the folly of civilised mankind in wasting immense quantities of manure, which they spend large sums in replacing, by discharging in into the rivers where it does untold harm, instead of returning it to the earth, as God commanded Moses, to the great advantage of their health, their pockets and their gardens and fields.

Science continues to show more and more, on the one hand by the light it throws on the dissemination by water of typhoid fever and cholera, and on the other by the discovery of the purifying mission of the bacteria in the surface soil, that earth is the best receptacle for night-soil and water the worst. 
But after all the earth system is not practicable in large towns, and is troublesome to enforce in villages.

There is naturally great difficulty in dealing satisfactorily with night-soil as a manure for Roses, and often it is probably not worth the trouble when it can be dug in quickly for vegetable crops, and other good manure is procurable. Mr. William Paul, in his large work, The Rose Garden, describes a mode of using it which involves mixing with earth, burying for six months, and afterwards mixing and turning over once or twice more. This seems to require a good deal of labour, but then it must be noticed that he considers it the best of all manures for Roses on light soils, and that it has a very marked effect on the growth I can testify from an instance in my own garden. During the winter a quantity of night-soil was deeply buried near to a sweet-briar, into which I had put a bud of Maréchal Niel; and one of the shoots from that bud, being laid along a wall, reached in the course of the summer a length of 27 feet. But, on the whole, it will be found in most cases that the trouble of dealing with it outweighs its value, where other manures are to be had.

Manure from the fowl-house or dove-cote is good, but transitory; it should be kept from rain, and not put on in the winter.

The old custom of burying the carcases of dead animals in vine borders is now discredited, and I should not recommend it for Roses. Bones, though most useful for the phosphates they contain, do not supply all the necessary constituents, and had better be left to the manufacturers of artificial manures.

2.-Liquid Manure.-I have hinted at the advan- 
tages which I conceive to belong to manure in a liquid state. (1.) In the first place, it is plain that the roots of a Rose cannot take up anything except fluids: consequently, only those parts of solid manure which are soluble can be of any use as food, and therefore liquid manure can supply everything that solids can. (2.) Secondly, the problem is by this means solved of how to get fresh food to tho roots without disturbing them. (3.) And lastly, the food can be given just when it is wanted, and withheld when it is not wanted.

1. As to the first of these points, let the beginner not only remember himself, but also diligently inpress upon his assistant, that Roses drink but camnot eat. The ordinary labourer will not believe in the strength or virtue of a clear fluid-from perhaps a hazy comparison with his own beer, he distrusts anything that is not thick; and he will be careful to apply the dregs of the liquid manure cart or cask. "because that's where all the good is." It should be pointed out to him that what cannot be dissolved in water camnot be assimilated by the Rose, and he should be told not to put on the dregs, which may sometimes do harm. Of course time, chemical changes, and the power of the earth bacteria may and do eventually dissolve materials which remain solid in ordinary water; but liquid manure is as a rule for present immediate use, and therein lies one of its great advantages.

2. By liquid manure we can reach all the roots at once without disturbing them at the actual time of their most vigorous growth; and we can supply the Rose with what it wants, soil thoroughly stored with food ready cooked as it were for immediate 
absorption, rather than solid manure in the soil which may or may not have all the materials ready in a soluble state.

3. To obtain fine fruit, from an apple, pear, or peach-tree, for instance, every gardener knows that manure is wanted when the fruit is set and beginning to swell: that earlier it may induce too much wood: and that a tree which has no fruit is best without manure, as the extra nourishment is more likely to produce wood than fruit buds. Roses do not form quite an analogous case : for in most cases manure given early will not hinder the flowering, and a certain length and strength of stem are necessary for a good bud, but occasionally it might cause the wood to be longer than necessary and the bloom to be delayed. At all events it is when once the tiny bud is formed that the Rose most needs support; all the powvers of roots and leaves are at that time devoted to the Rose itself, and then is the special opportunity for feeding with a lavish hand. Do not be afraid of making your Roses "coarse" ; we can always find room for superfluous energy by less rigorous pruning in spring, or later by judicious caution or delay in disbudding.

The ordinary liquid manure which I should recommend would be the drainings after rain from cowyard or pigstye or both, but not from the stable, which is often, from being less diluted, too strong. Free access to a tank containing the drainings and storm-washings of a cow or bullock yard is well worth paying for by any Rosarian. Unless obviously very weak, it should always be diluted; too weak can do no harm, but too strong may. Without appearing to hurt the strong roots, it may injure the 
young tender fibres, and the plant will eventually suffer. The contents of a tank from a covered yard would be much too strong; but, as to one which receives the storm-washings of an open yard, it is a fortunate circumstance that after rain is the best opportunity for applying liquid manure, viz., just the time when such a tank would be full and probably not much too strong.

This should be remembered as a possible error for an assistant to make; he may be apt to think that when the ground is dry is the time for liquid manure, but it is not so: the drier the ground and the season the weaker the manure and the purer the water that should be given. If in a dry time liquid manure is available, and it is desired to put it on, it would be advisable to give a thorough soaking with pure water first. But, as I have said, it fortunately happens that liquid manure is generally to be had just when it is advisable to apply it-after a good rain.

An ordinary labourer, besides the mistalie of thinking "the good" is in the dregs, of which he may be convinced by a comparison with tea-leaves after tea has been made from them, is also apt in watering Roses or fruit trees to put it all much too close to the plants. He should be reminded that as his hand is at the end of his arm and he cannot take hold of anything pushed against his shoulder, so the mouths of the roots are at their extremities, and it is there they should be fed. The Rose bed should be equally soaked all over:

Another mistake that may be made is this:- "I have only got a certain amount of liquid manure, and that healthy vigorous plant does not want it, I 
am sure; but this poor weakly thing would certainly be the better for a dose."

This would be an error in principle as well as in fact. The principle is a Gospel one, and may be found in St. Luke xix. 24-26. It comes into Rosegrowing in more than one way ; notably, in pruning, that less in proportion should be cut away from strong growers than from weakly ones; in selection (for ordinary purposes, not for exhibition), that a man should cultivate most specimens of the varieties which do well with him, and not endeavour to make up the balance by growing more of those which only sometimes come good; and here, in feeding, in two ways, for not only does it pay better, as graziers and all keepers of live stock know, to encourage the healthy than to coddle and nurse the weak, but also the weak cannot use the rich food which makes the strong still stronger. Giving strong meat to babies wastes the food and also seriously injures the feeble, who must take but cannot assimilate it.

We should never be afraid of making our plants too strong; for we can always divert the stream of sap and lessen its supply to each bud by leaving a greater number of shoots or buds on the plant at the two periods of disbudding. I have even heard of cutting the roots of La Boule d'Or in the early summer when the thick strong fleshy buds by their extra vigour seem unlikely to open properly, but should never advise it. At all events the weakening of a shoot or plant may be easily and speedily accomplished; it is the getting up of full steam that taxes all our time and energy.

In speaking of weakly plants, I do not mean the naturally "dwarf" and "moderate" growers, which 
if healthy and doing well according to their habit will take their full share and enjoy it, though natnrally not requiring so much as the stronger growers. Comtesse de Nadaillac will require her food and answer to it in size of glorious flowers, but an extra dose will not raise her to the stature of Ulrich Brunner. I mean either an evidently unhealthy plant, or one which though fairly healthy does not from some unknown cause thrive and do as well as the others. Such a one had always better be removed than kept and nursed : try giving it away; it does not sound very generous, but removal to a different soil and situation will be either kill or cure, and experience will show many wonderful instances of the latter eventuality.

Care should also be taken that newly moved plants may have their liquid manure very much weaker till they have made some strong growth with large healthy new leaves. The wrong principle, then, is the supposing that because a plant is the strongest in the bed it therefore wants the least of the liquid manure; on the contrary, it wants, because it can use, the most.

The time for using liquid manure is May and June, especially after rain if possible; if some be given in April, be careful of the young foliage, and do not give any to "maiden" dwarfs till they have made some growth, being extra careful in this case that no drops fall on the plant itself. But will this be sufficient for a whole year's food? That would depend a good deal on the soil, and whether artificial or natural solid manures were used as well. It is not advisable to apply any in the autumn after July, as the second growth of wood 
is always much stronger than the first and will not require further encouragement which might make the plants grow too late and fail to ripen properly. If we put on liquid manure in the winter, no doubt a good deal of its virtue is washed away before the roots can feed on it; but some of it will remain, and $I$ think it is always worth doing. At that time it may be supplied much stronger and more concentrated than in the summer without fear of harm.

As to the manner of application, it may be put on by water-pot, pail, or hose, or whatever is quickest, provided it soaks in. Unfortunately the surface of the soil is often such that the wash and dash close the pores of the earth, and the liquid for the moment camnot penetrate but rums off. Where much watering with liquid manure is contemplated, or under any circumstances where the natural soil is light and porous and the drainage good, it is best to have the surface of the beds below the general level of the ground; the whole can then be flooded, as it were. If, however, the beds are somewhat raised, and the liquid runs off, there is nothing for it but patience; a little at a time, and come back again and again to the same place.

In early spring we may sometimes find an occasion, in a light frost, when just the crust of the surface is sufficiently frozen to prevent the wash of the particles, and the pores remain open; at such times, on my beds, the liquid will sink in at once as through a sieve as long as you like to pour it on. Given the time, and plenty of good stuff, a large amount and depth of soil may be fertilised on such opportunities.

'Two good rules for watering with liquid manure 
or plain water are:-Firstly, mind it is done thoroughly; be sure you give a good soaking while you are about it; remember "an inch of rain" means nearly five gallons to the square yard, and always do a little space at a time satisfactorily and fully rather than a mere wetting over a large extent.

And secondly, be sure that the surface is always stirred by the hoe as soon as possible after every soaking, whether it be the natural one of rain or the artificial one of water or liquid manure. This is most important; when the sun shines on the thoroughly soaked ground in summer it is sure to cause it to crack, often before the top is quite dry; as soon as you can work it, get just the surface dry again and as fine and powdery as possible with the hoe, for this keeps the moisture in, whereas the cracks allow it to escape.

Soap water from a laundry has some value as a liquid manure, though too much may render the land sour. And though not sufficient for Roses by itself, it is a capital thing to use mixed with other liquid which may be considered too strong. It is well in this case to be specially guarded against the dregs, a greasy scum which chokes the soil pores, and also to remember that nothing smells nastier than soapsuds which have stood for three or four days, especially in a hot sun. Amatemr Inspector's of Nuisances are not always aware of this.

The overflow water from a cesspool is very gnod as liquid manure, and hardly ever too strong for anything; my overflow tank is regularly emptier on my garden at night every full moon by pump and hand cart, for nothing from my house goes into the river, but all into the garden. There is some 
obvious inconvenience about this in the summer, and we have at that time to choose our nights with care; I do not then put it on the Rose beds, as it has sometimes to be done hastily, and more care and better light would be required. It should be understood that the contents of the overflow or second cesspool are nearly as good as the night-soil itself, for much of the value is in the liquid. It is desirable, if possible, to have a separate tank with pumps for the contents of housemaids' slop-pails; this will be the most valuable liquid manure that comes from the house, and will generally not be so offensive but that, with choice of opportunity, it may be applied in the day-time.

Soot water is good, but would be expensive and troublesome to use in quantity; it is more useful for pot plants. The soot should be tied up in a bag and sunk in a cask or tank, and the result is a clear liquid of a wine colour, much appreciated by gardeners for mild fertilisation.

Artificial MIANuREs. - It is not necessary to go into the discovery by the great scientists of the possibility of manufacturing by chemistry plant nanures, which are called artificial not because they are not the real things, but simply because they are made and compounded by art and science. It will suffice to state that those wonderful fellows, the analytical chemists, who are always wanting to find out what things are made of, showed tinat as growing plants consist of certain soluble minerals in different proportions, so (they insisted) those minerals with the addition of nitrogen would, in the proper proportions, make real, though artificially made, manure. They first of all discovered 
the component parts of a plant by burning it and analysing the ashes, and they then said (and proved it), These are the things of which the plant is made, and therefore with these things it can be fed. They found next that the different parts of a plant, roots, stem, leaves, and flowers, often had the principal constituents in very different proportions, but this could be allowed for in considering which part of the plant is most valuable. The obvious next step was to analyse the soil too, and it was found that some of the mineral constituents of plants are practically present in sufficient quantities in nearly all soils, but that some land is deficient in one material and some in another. A pleasing picture was then presented to the cultivator, that, with the analyses before him of his own soil and of the plant he intended to grow, it was comparatively easy to see just how much he required of each mineral constituent to feed his plants fully and perfectly.

But in practice, I am bound to say, the matter is by no means so simple. Analyses both of soil and of plants have proved very fallacious, at all events to those who, like myself, are not chemical experts: and specially compounded Rose manures have often proved disappointing, particularly in dry seasons.

Still, I give here an account of what is probably the best known Artificial Rose Nanure, which may at all events be worth a trial.

In the Rosarian's Year-Book for 1889, edited by the late Rev. H. D'Ombrain, Sec. to the National Rose Society, there was a very interesting and valuable paper on artificial manure for Roses, by Mr. E. Tonks, B.C.L. The analysis of the ashes of the 
Rose are there given in a table from Wolff's Aschen Analysen, Berlin, 1871, 1880, as follows:-

\begin{tabular}{|c|c|c|c|c|c|c|c|c|c|}
\hline - & 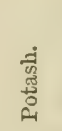 & 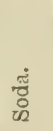 & 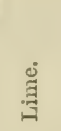 & 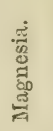 & ઠีં & 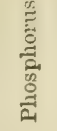 & $\frac{\stackrel{\overrightarrow{3}}{a}}{\frac{a}{3}}$ & 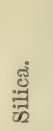 & 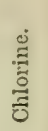 \\
\hline Roots ................. & $13 \cdot 45$ & $4 \cdot 20$ & 40.88 & $7 \cdot 15$ & $2 \cdot 86$ & $29 \cdot 14$ & $1 \cdot 95$ & $0 \cdot 21$ & 0.21 \\
\hline Wood .................. & $14: 25$ & $2 \cdot 57$ & $51 \cdot 50$ & $7 \cdot 62$ & $4 \cdot 23$ & $10^{\circ} 62$ & $2 \cdot 22$ & $4 \cdot 35$ & $2 \cdot 78$ \\
\hline Leaves ................ & $33 \cdot 13$ & $1 \cdot 47$ & $31 \cdot 29$ & $9 \cdot 23$ & $2 \cdot 49$ & $11 \cdot 68$ & $4 \cdot 31$ & $5 \cdot 71$ & 0.89 \\
\hline Flowers......... & $47 \cdot 41$ & $2 * 44$ & $13 \cdot 25$ & $5 \cdot 94$ & 0.97 & $28 \cdot 46$ & $3 \cdot 17$ & 1.52 & 0.57 \\
\hline
\end{tabular}

On reasoning from this to get a proper chemical manure for Roses, the first thing to remember is that there is one most important item not found in ash analysis, and that is nitrogen, for which in a chemical formula the uninitiated must look for the words "nitrate" or "ammonia." Nitrogen is the stimulant which gives life to the whole, like a spark of fire which gives such mighty power to the loaded cannon, or (to use more humble imagery) a penny in the slot which sets the whole elaborated machinery in motion. Mere nitrates, such as nitrate of soda, show immediate and wonderful results on unexhausted land, when all the plant wants is a start; but it is like drawing a cheque upon a bank, a capital way of supplying the needful as long as the bank is replenished accordingly, but otherwise not a mode of raising money likely to be successful for long; so the nitrate makes the mineral stores (such as potash and phosphates) available if they be there, but camnot replace them. 
To continue using nitrates alone would be like the Irishman who, having a note from his bank that he had overdrawn his account and that they required a remittance, sent them a cheque upon themselves for the amount to make things square.

Plenty of nitrogenous matters may be found in the best of the solid and liquid natural manures recommended, but these have to be changed into nitrates by the action of the earth bacteria before they can be assimilated by the Rose, so that the stimulus is most immediats when applied in the form of nitrates. Another important point about the nitrates is that they are the very first of manurial matters to be washed out of the ground into the drains by heavy rainfall; the soil does not retain them so well as the other constituents of manure, and of course they go soonest in a porous or light soil. This points to the use of some nitrate, or good natural liquid manure which would very soon afford nitrates, in the growing season after long and heavy rains, when the soil is known to be well stored in other respects. Nevertheless, it should be stated that there is some little nitrogen in the rain itself, though not in ordinary water.

Potash and Phosphates of Lime are much the most important items, and the others, such as soda, silica, dc., which are mostly present in very small quantities, are generally disregarded, as they would be present in sufficient quantities in almost all soils. Silica means flinty particles. It may seem strange to think of these as soluble, yet there is much silica in corn, straw, canes, and tall grass stems, affording the smooth surface, and the brittle sharp nature; and as Tea Roses are found to succeed in these soils 
which are gritty, it would be interesting to know if their ashes would show a larger proportion of silica, or whether it is only the extra drainage and consequent heat of the soil that proves favourable to them.

Iron is present in but small quantities, highest in the stem and lowest in the flowers. Sulphate of iron is said to give a better colour to the foliage, and in some sorts, such as Anna Olivier, to the bloom as well, but I do not place much reliance on it. In fact I have sometimes omitted the iron from the formula below, for the small quantities cause a good deal of trouble to the makers, but it should be remembered that every one of the constituents is necessary, or the others are by so much rendered valueless; so perhaps it had better be included, though most soils and natural manures have it in sufficient quantity.

The following is the mixture recommended by $\mathrm{Mr}$. Tonks for the Rose, as deduced from the ash analysis :

Superphosphate of lime, 12 parts.

Nitrate of potash,

Sulphate of magnesia,

Sulphate of iron,

Sulphate of lime,
10 parts.

2 parts.

1 part.

8 parts.

33 parts.

The manure is to be applied in early spring: immediately after pruning would generally be soon enough perhaps, but February would be better. It is to be evenly scattered on the previously hoed surface, at the rate of $\frac{1}{4} \mathrm{lb}$. to the square yard, so that the Rose grower can soon calculate how much 
he wants. In some cases it might be difficult to procure it in small quantities, unless some manufacturer could be found to make it on speculation for such sale. If not, small Rosarians, who have difficulties with natural liquid manure, should combine to order it. A thoroughly trustworthy firm should be applied to, as the adage "see that you get it" applies very strongly to chemical manures. With many Amateurs price is an object: I therefore feel bound to state that for several years I obtained the above manure, made according to the formula and with guaranteed analysis, direct from a large firm of manufacturers at $9 s .6 d$. per cwt. And I mention without comment that I have seen it advertised at $25 \mathrm{~s}$. per cwt.

A 48 flower-pot full of manure may be taken as $1 \mathrm{lb}$, which would suffice for a square marked out by a six foot rod; but, with observation and care, the "rule of thumb" will soon come in and measurement become unnecessary. It should be kept in a dry place and used fresh if possible; if caked together let it be thoroughly crushed with the back of a dry shovel. I should advise another hoeing in preference to watering it in, as no artificial watering can equal the soaking power of gentle rain. A second and lighter dressing, carefully avoiding the foliage, may sometimes be given at the end of May, if heavy rains have occurred, or nitrate of potash, the most expensive item, may be used for that purpose.

As a sort of summary, I suggest:-

That strong fresh soil, which has not been more than a foot below the surface of the ground, and is rich enough not to require manure at first, is the best of all: 
That poor soil, deficient in humus from any cause, must have well-rotted natural manure mixed with it, and even then will not be so satisfactory:

That old, very dark, over-manured garden soil, which has too much humus, should be treated with lime or basic slag:

That liquid manure may be applied with advantage in the winter, and much weaker in spring and dry weather:

That nitrates, such as Nitrate of Soda, Sulphate of Ammonia, or Nitrate of Potash, may be sparingly applied in the spring, as stimulants:

And that all other artificial manures, though I do not wish to decry them, may possibly be attended with disappointment. 


\section{CHAPTER VI}

\section{PRUNING}

THE severe pruning to which many of the best and finest Roses are amnually subjected may well cause some dismay to a novice, who might perhaps not only ask why we should destroy such a large part of the plants we so cherished the year before, but also go on to the wider question "TVhy is pruning necessary for any purpose? TVhy should not our Rose-trees grow as fine and large as they will?"

The answer is to be found in the manner of the natural growth of the Rose. By watching an unpruned Rose-tree, either wild or cultivated, it will be found that the first strong shoot flowers well the second season but gets weaker at the extremity in a year or two, and another strong shoot starts considerably lower down or even from the very base of the plant, and this soon absorbs the majority of the sap and will eventually starve the original shoot, and be itself thus starved in succession by another. A rose in a natural state has thus every year some branches which are becoming weakened by the fresh young shoots groving out below them. This is one of the 
principal reasons why pruning is necessary. A rose is not a tree to grow onwards and upwards, but a plant which in the natural course every year or two forms fresh channels for the majority of the sap, and thus causes the branches and twigs above the new shoots to diminish in vitality. In seems better, therefore, to speak of Rose-plants than of Rosetrees, especially since standards are now less used, and so many new varieties are dwarf in their growth.

The objects of pruning are:-To maintain the life and strength equally throughout the plants, to mould and preserve their shape, and to give more vigour, colour, and substance to the flowers. Owing to the natural habit of growth before mentioned, a considerable amount of wood must be taken away annually to prevent the shoots robbing each other, and when nature is interfered with art must go a little further to make and to keep a plant of well-balanced shape. And also, even for ordinary garden purposes, a considerable amount of strength and sap must be reserved for each bloom, or, in the case of the dark H.P.s for instance, they will not show their true colours at all.

The principal art of pruning-that of forming and maintaining a shapely plant of well-placed shootshas almost died out in modern out-of-door Rose culture. This is owing to the neglect now shown to the Hybrid Chinas and Hybrid Bourbons, really strong-growing varieties but only blooming once: to the decreased popularity of standards where a well-balanced head is more noticeable and necessary than in a dwarf or bush plant: and to the fact that most enthusiastic Rosarians care more for perfect 
blooms than for well-shaped plants. When I first learnt to prune, a long time ago, H.P.s were quite new and very few in number, and there were still many large standards of summer Roses, each of which was a study in itself for the pruner's art.

First, as to the instruments required. A pruner of the old school would condemn the use of scissors or secateurs, be horrified to see a shoot cut off square, and would consider the neat smooth sloping cut of a sharp knife to be the only legitimate appearance. He would also perhaps scorn the use of gloves and think he could do his work better without them; but this must be a matter of taste, for it is useless to deny that Roses have thorms, which are especially hard and sharp at pruning time. A Rosarian does not much heed summer thorns on the young woodgreen, and comparatively pliable and soft; but on all ripe wood, where they have become dry, hard, and brittle, they are another matter. It is well to remember that in using a knife, especially to budded lioses of one year's growth, the plant must be firmly held with the other hand, or a serious brealiage is very apt to occur.

Two good knives, a whetstone, a strong pair of sécateurs, and a mat to kneel on by the dwarf plants, will probably prove a sufficient equipment. One of the knives should have a strong blade, the other a narrower and smaller one. The smaller and thimner the blade the easier it will be to use and to keep sharp: a large part of ordinary pruning may be done with a budding-knife. The hone shonld be carried about and not left behind, or the tearing off of a valuable branch will soon be the result of a blunted blade. The sécateurs or scissor's 
will be useful for very small shoots, and for bits of dead wood or.anything in an awkward position, but in all such cases the cuts should afterwards be trimmed and smoothed as much as possible with a knife. A small pruning-saw is most effectual for thick pieces of dead wood, but in many instances cannot be used; in some such cases, the very powerful sécateurs with long wooden handles will

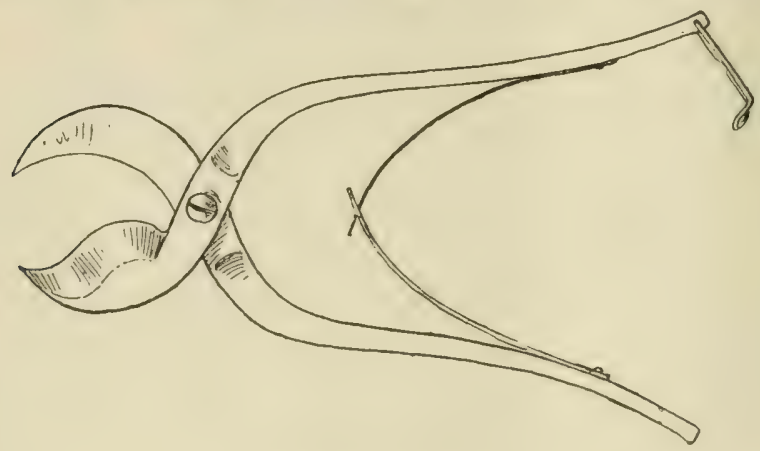

ORdiNARY ŚÉCATEURS.

be found useful. In the use of all such instruments, scissors, or sécateurs of any kind, it should be remembered that the force ought to be applied in one direction only at a time without twisting or screwing : any wringing of the tool is sure to impair it. Professionals will not only prune but will even bud their dwarf plants by simply stooping over them, but I confess it makes my back ache even to see them at it. For kneeling on the wet soil I have found a piece of waterproof about eighteen inches square more satisfactory and less tiring than kneecaps, but it should be borne in mind that the weight of the body will bring moisture through any 
alleged waterproof that has not an actual skin of indiarubber.

Next as to the time of year. Some recommend a certain amount of thinning in early autumn, to

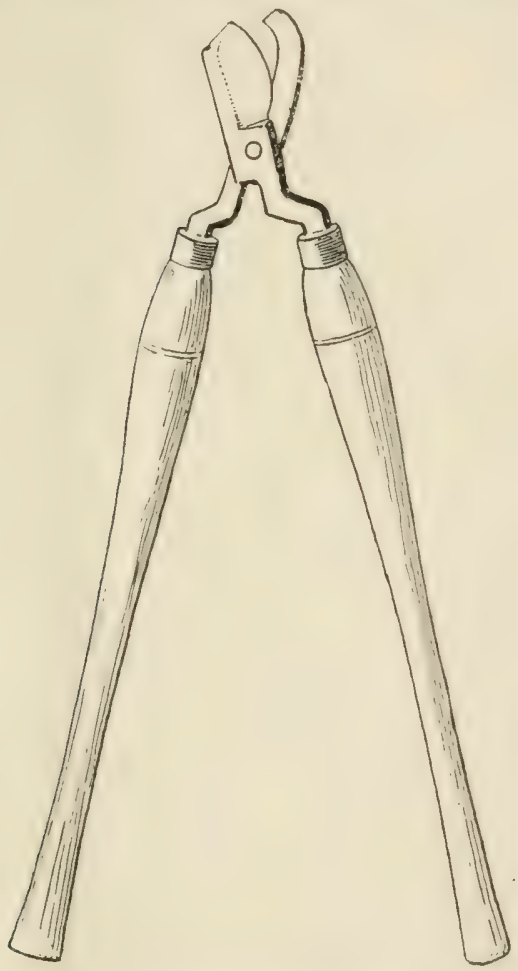

JONG.HANDEEN SÉCATEURS.

ensure the ripening of the remaining shoots. If the plants are to be but lightly pruned in the spring this may be desirable treatment; but there is a danger of causing low dormant buds wanted for next year to push at once, the root power is probably 
slightly checked, and the benefit gained is very slight, if the plants are to be severely pruned.

We may commence with Roses trained on sunny walls about the middle of February, and in this case, whether nailed or tied to wires, the operation will be very similar to the pruning and laying in of a peachtree. Begin by taking out all dead and weakly wood; then consider which shoots are required for laying in, giving preference to the ripest rather than the fattest, and steadfastly resisting the temptation to train them too close together; of the remainder for which there is no room on the wall, the gross shoots should be clean cut out and the mediumsized ones thinned if necessary and moderately spurred back.

A rule for all climbing Roses, but especially for Maréchal Niel, the Noisettes, and the Dijon race, is that long strong shoots of the year should not be cut back much, but either laid in at least three parts of their length or removed altogether. Unless additional height is wanted, such shoots should not be trained upright, as that is likely to lead to more wood and less bloom. The Banksian Roses need special treatment, for the flowers will not proceed from the strong shoots of the year, but from the laterals or side growths. There must accordingly not be any pruning, but merely a thimning out of dead wood and a slight shortening of long strong shoots; the weakly-looking twigs alone will blossom. Tea Roses, not of the climbing races, which are grown on low walls may be pruned more severely if quality rather than quantity of bloom be desired.

March is the month for pruning all Roses in the open except Teas and Noisettes; and I think an 
amateur will not be doing wrong if he picks his days and gets throngh as much as he can whenever it is warm and fine. If some are pruned in the first rveek of the month and some in the last, bitter weather intervening, but little difference will be found in the time of flowcring. It is best to leave Tea Roses in the open undisturbed till April ; and it is safer to leave the early-flowering IIybrid Teas also till that time, especially in situations liable to May frosts, for it is the early strong shoots whose buds are already formed which suffer most in such visitations. On the other hand, in early seasons, like 1893, Roses which have made some growth at the top are apt to "bleed " when pruned severely, especially where old wood is cut into. In some cases the soil around the roots is liept quite damp from this cause for some days and the matter looks serious but does not often prove to be so: the cut heals in abont a week, and the subsequent srowth does not seem to be impaired.

As to the method, we will take first, as being the most complicated, the case of summer Roses, H.P.s, and other fairly strong varieties where the object is to form handsome plants for general decoration with a quantity of good blooms for cutting.

The first care will be to pull up and test all stakes, as recommended on p. 37, and the next to cut out all the dead wood, and all wood however thick and old which, as shown by the small growth made last season, is becoming wealily in comparison with the rest of the plant. Now we can study the whole and see what we have got left. Our object is to form a well-shaped head or plant, and by "well-shaped " I mean that the plant itself should be of the even 
globular form of a Rose. Rose petals are evenly arranged, and do not cross each other in an inward direction; such should be the shape of the plant. Bearing in mind that the top bud left of each shoot will grow first and in the direction in which it points, we should always cut back to a bud that looks outward, and take care that the centre will not be overcrowded. To get rid of a misplaced shoot it should be clean removed at the very bottom; merely cutting it hard back will only make it grow the more. It must be our endeavour each year to do away with as much old wood as possible, and in the case of strong growers to lessen the number of their shoots rather than their length. We should picture to ourselves what the plant will look like in full growth, and remember that a lover of Roses is more likely to leave too many than too few shoots. There is a saying in East Anglia, "No man should hoe his own turnips," meaning that he is not likely to thin them sufficiently; but those who are used to thinning grapes and other garden produce will probably have got over this difficulty.

The next question is, how far, i.e. to how many buds, are the shoots to be cut back; and the answer is to be found in the golden rule of pruning, that more buds are to be left on each shoot in proportion as the plant, both as a variety and an individual is strong, and less in proportion as it is weak. To a novice in Rose-growing it appears strange at first that we should cut away almost all there is left of a weakly-growing and precious variety, which would seem to be almost exterminated by such severity, and yet leave longer shoots on a strong sort which seems better able to stand the rough treatment; but 
the rule is nevertheless in strict accordance with the law of nature-Darwin's survival of the fittest-and the law of God, "Whosoever hath, to him shall be given." I have elsewhere (p. 84) endeavoured to show that the same rule applies in Rose-growing to the application of liquid manure to strong and weakly plants, and to the number of each variety which should be grown by those who are not exhibitors.

A wise editor used to give as his advice to young authors in whom he had confidence, "Don't arguelay down the law" ; and the counsel of a judge to judges of all sorts to give their sentences without their reasons is well known as pointing out the most useful and prudent course to pursue. But the reason for the above rule in pruning seems so clear that I think it should be added. In proportion as a plant is strong in growth, from the natural habit of the variety or in a less degree from the condition of the individual, leave more buds, to perhaps six as a maximum, on each shoot; because the strong grower has the capability of supplying several buds on each shoot with a sufficiency of sap for good blooms, and if a due number be not allowed, the shoots will either run to wood without flower or produce coarse and ill-shaped blooms. And in proportion as a variety or plant is weakly in growth, fewer buds should be left; because the weak grower has only sufficient strength to supply sap to one or two buds on each shoot, and if more are left the power will not be sufficiently concentrated to form good blooms. The general habit of the variety should therefore be well borne in mind in determining how many buds to leave on each shoot; remembering always, with a 
view to the future outline of the plant, to prune to an outlooking bud, and that as a general rule the more a shoot is cut back, the longer will be the growth from the bud left at the top.

After a warm summer most of the young wood on a well-pruned and healthy plant will be found moderately ripe; but we occasionally find an extra well-ripened shoot, almost as firm and brown as the old wood, with large plump buds ready to start at the first chance. This is very valuable and plenty of space should be allowed for its development, less ripe shoots being removed to make way for it. On the other hand, we often find gross late unripened shoots, much thicker but greener, with a larger proportion of pith. These are comparatively useless, and should generally be cleanly removed. If a shoot has been injured by frost, and on cutting down to an apparently sound bud the pith appears brown instead of white, it is evident that the injury has gone farther than we supposed, and it will be better if possible to cut a little lower. If any shoot by its unusual size evidently absorbs a large proportion of the whole of the sap, it should be, according to its ripeness and the condition of the rest of the plant, either removed altogether, or left a good length and have other weaker shoots removed that might hinder its development.

If a plant is carefully pruned from the beginning it seldom presents many difficulties as long as it continues in health; but those which have been neglected for only one year sometimes require to be cut back sufficiently to form an entirely new framework during the following season. A good deal may be done to remedy faults and defects by a careful 
examination of each plant in early May, when a thinning of the pushing buds may be practised where it is necessary. Of those growing too close together or in a wrong direction or filling up the centre, one or two may be rubbed off. But we must not be rash; if undecided, it may be prudent to adjourn the examination for a week or so, when we can still take the shoot off, but cannot put it back. It is best, when an actual shoot of an inch or more has to be removed, not to rub it out, as this leaves a deep ugly scar, but to shave it closely off with a knife.

For bedding purposes the pegging-down system is fairly successful with really strong-growing varieties of not too stiff habit. But it must be understood that it will not be satisfactory, unless the soil and culture be of the best, and the most free varieties in growth and bloom be selected. All must be cut away save two or three (not too many) of the strongest shoots, which are bent down and pegged over the bed. They will break and bloom all over, and in late summer other shoots will probably spring from the base, a selection of which will take the places of the old ones in the following spring.

Extra tall standards trained to form weeping Roses are beautiful objects when in bloom. It is impossible, however, to make any varieties, which are not naturally of flexible or pendulous growth, take this form successfully by bending them down. The Hybrids of Wichuariana and the summer climbing Roses, such as the Ayrshire and Evergreen classes, should therefore be used for this purpose. The heads should be vigorously pruned back the first year, or 
even the second if the growth is not satisfactory, and when the shoots reach the ground they should be thinned if too many and tied to some supports the proper distance apart. The pruning will afterwards consist of spurring back the blossoming laterals, or occasionally taking clean out a weakly branch and allowing another to fall down in its place.

Pruning for exhibition purposes is often quite a different matter from pruning for decoration or display. The object in this case is to get the finest possible blooms, and to attain this end the exhibitor will not care very much about the shape of his plants. If number be required, then the plants must be multiplied, as but few show flowers can be expected from each. Pruning in this case loses most of its art; only the strongest shoots will be retained, and these will be cut back very closely to two or three buds, while with weak growers in some cases not more than one bud of new wood will be retained. This is a rule, however, which even among the H.P.s has several exceptions, which will be found noted in Chap. XII.

The further revision of the pushing buds and young shoots, at the end of April or early in MIay, will for exhibitors be an important matter, requiring much care and foresight. A good knowledge of the habit of growth and of the "manners and customs" of the different varieties will be necessary to know how many shoots should be retained, and an extra strong one however ill placed will be pardoned among the weaker varieties. If injured by frost or grubs it must be decided as early as possible whether the damage is serious enough to warrant the removal of the whole shoot. In some cases the severe 
pruning will cause buds to push at once from the old wood: and among the weaker varieties, whose blooms are best on maiden plants, such buds should be encouraged; but in the case of the stronger growers, the blooms will probably be best from last year's wood. Some sorts have particularly robust and ample foliage; in this case the shoots should be left longer in the pruning, and the top buds, or those that are as far apart as possible, alone retained. Thus Madame Gabriel Luizet is strong enough to support from four to six, or even perhaps more first-class blooms upon each plant; but as the foliage is large and full, the shoots should be left at the pruning four or five inches long, and the top outlooking bud alone retained on each, all others being removed as fast as they appear. Varieties apt to come coarse and too full should also be left a little longer in the pruning, and have more shoots retained; but it is most important that the special idiosyncrasies of the varieties, as shown in Chap. XII, should be carefully studied, or the results may be disastrous. Thus some, as La France and Marie Rady, will show the perfect blooms only on comparatively weak shoots: some, like Madame Eugène Verdier, will canker and die if pruned too hard : and several others, like J. B. Clark and Duke of Edinburgh, will make too much wood and have but poor blooms after all unless the shoots are left a fair length.

For ordinary and decorative purposes, Tea Roses in the open, if well fed and spared by the frost, might be pruned but little; still they should not be allowed to become leggy and scraggy, and a fair amount of pruning on the same lines as recommended for the H.P.s will tend to keep the plants 
in health and vigour. But in many parts of the country, particularly in low-lying districts, we often find, on removing the protecting material in March or April, that a considerable part of the plant has been killed during the winter; and are only thankful if we can find some real life to cut back to. For exhibition purposes the pure Teas should be in nearly all cases pruned back as hard as the H.P.s; there is no fear of these free-flowering and most charming Roses failing to bloom.

It is important to remember that Sweet-briars, Austrian briars, and in fact the single Roses in general, should not be pruned at all, beyond the cutting out of dead or dying wood.

Where Gloire de Dijon or any of its race, Maréchal Niel, or any of the strong-growing Noisettes are cultivated in the open, they should be treated as mentioned above on the pruning of wall Roses. These varieties if in good health make loug strong flowerless shoots late in the summer, which should be retained nearly to their full length as they will give the finest blooms. These shoots should be trained, while still soft, in as near an approach to a horizontal position as is practicable without bending them too much, and will last about two years, when they will probably become weak and should be removed to make way for others.

This habit of making strong flowerless growths late in the summer renders the following special treatment advisable for the training and pruning of Maréchal Niel under glass.

In a house fitted with wires up the roof as for vines let a strong maiden standard be planted, at the front of the house where a vine would be placed, 

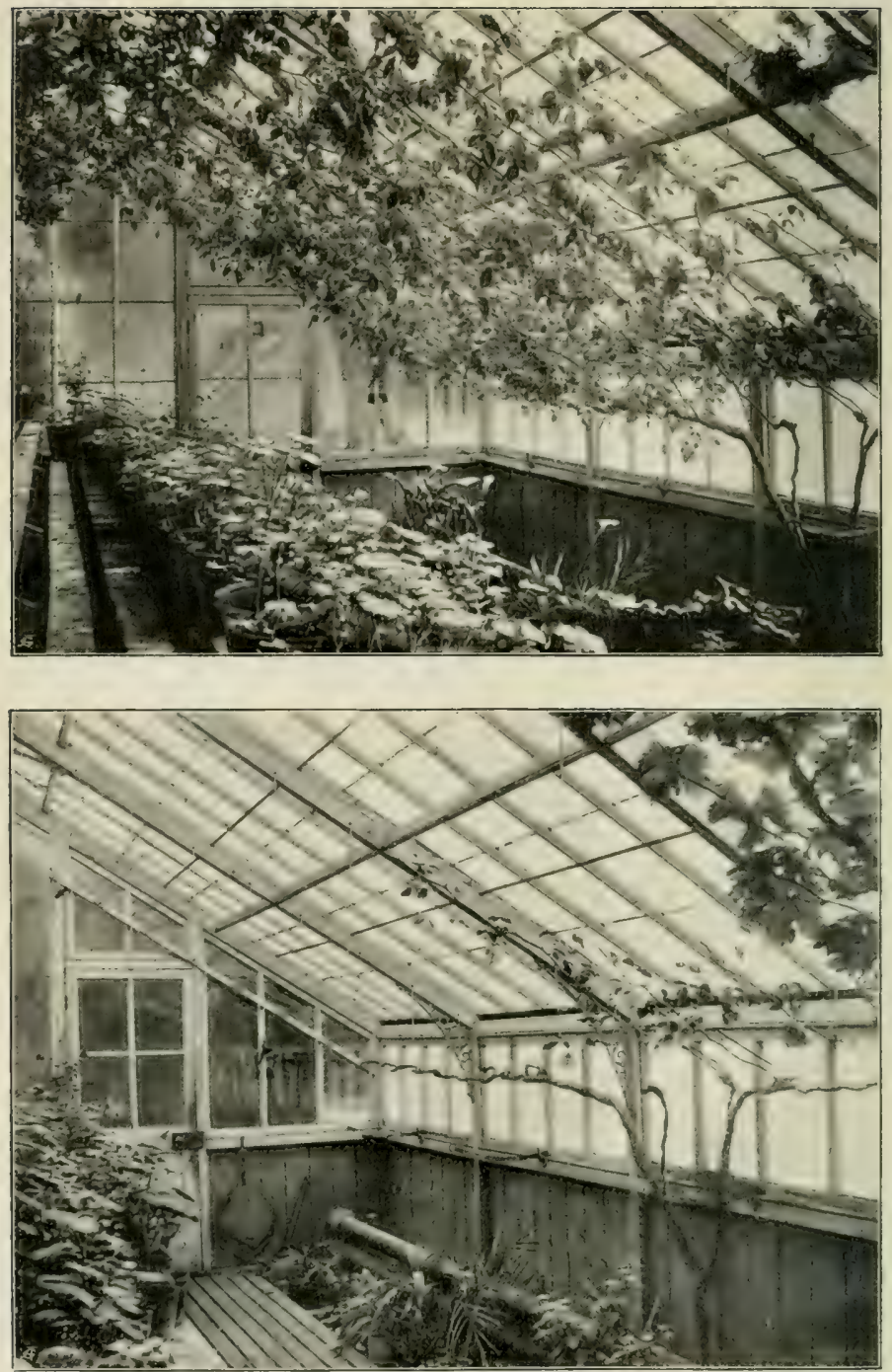

Maréchat NiEL, tNDER GLASS,

[Fire preate $10 \mathrm{~s}$.

The upper plate represents the Plant in full blomm, with about 300 fine Roses on it, April th, la! 14 . The lower one shuws the same plant on April 2ith in the same year, the whole of the upright rods, with the exception of two or three small portions, still bearing unexpanded buds, having been eut back to the permanent horizontal arms. 
with plenty of room for extension on either side. The roots may be inside or out, but in either case ample provision must be made for the supply of abundance of rich food. The Rose should be completely cut back at the time of planting to within an inch or two of the stock. When it begins to grow, two shoots only should be selected, all others being rubbed off, and these should be trained horizontally right and left immediately under the bottoms of the wires. If still growing when they reach the end of the house or as far as it is intended to cover, train each up the end wires, and should they reach the top, twist them about anywhere where room can be found but do not break or stop them. No pruning whatever will be necessary during the following winter, but the plant must always be highly fed. The Tose will probably bloom freely along the rods in the next spring, and as soon as the blooms are over, the upright rods (if any) must be cut quite back to the horizontal part, from which all shoots must be clean removed.

We have now left, probably about April, a plant shaped like a T, a stem with two simple horizontal arms, and this will be the whole of the permanent part of the Rose. The horizontal arms will soon begin to break in several places, and shoots must be trained under the wires about fourteen inches apart, all other buds and new shoots being rubbed off. The chosen shoots may appear weali at first, but they will gain in strength, and the autumn growth, if the plant be well nourished, will be very rapid. Probably all the shoots will not reach the top of the house this year, but they should be allowed to grow as far as they will, and to ramble anywhere where 
there is room when they have reached the top, till growth ceases for the winter. If the pitch of the roof be steep, as soon as the buds seem inclined to break in the spring, the time being of course dependent on the amount of heat supplied, all the ties should be unfastened and the long trailing shoots most carefully let down for a few days to give the lower buds an equal chance of breaking with the upper ones. They should then be retied in their former positions, and the ends reaching further than the top of the house, for which no room can be found, may be cut off.

Almost every bud should now produce a flower-a splendid sight which may last a month. The blooms will be greatly superior to those grown out of doors in general perfection of shape, but the petals will be thinner in many cases, and the flowers less lasting. They should be cut before they are expanded, as they are then at their best, and also all yellow Roses improve in colour by being shaded or removed from bright sunshine. Great care should be taken in the spring growing season to avoid cold draught, as the foliage is very tender and susceptible to mildew. As the blooms are cut, or wither, the upright rods should be gradually shortened till the whole is clean removed back again to the main horizontal arms at the bottom of the house. The check to the plant will be lessened by the gradual removal of the shoots, and fresh growth will soon start to be trained up during the summer and autumn in their place as before.

This is a simple, systematic, and regular method, which I have found to answer extremely well. It may be objected that all autumnal bloom is lost by 
it, but we ought not to want Roses under glass when there are plenty out of doors. I know of no system which will so well provide for the utilisation of the strong autumnal growth; and the blooms from these strong shoots are far superior to any that can be gathered from older wood or weak laterals.

As the cultivation of Maréchal Niel under glass by this method should result in the production of a large number of fine Roses all at once, and there will probably be a desire to send some away to friends by post or rail, this seems a good place to say something as to the packing and carriage of Rose blooms in general. For sending large quantities by rail, the method that professionals have learnt by experience had better be followed: in a shallow box the Roses, gathered quite dry, should be laid flat in rows as closely together as possible, and all the same way; the ends of the shoots are wrapped in a mass of strips of some slightly absorbent paper well wetted -a much cleaner material than moss-and the whole made as tight as possible and covered with clean paper.

Roses often travel badly by post, the reason being that, if packed as above in an oblong box, the parcel is often carried perpendicular in the postman's basket, and the Roses standing on their heads will all work down to one end and bruise the most tender and beautiful parts-the tips of the petals. For choice specimens, or at any time for small quantities, I would recommend that each actual flower be carefully wrapped in soft tissue paper, with a little cotton wool at the bloom end of the package, and much greater security by post can be attained by tying the stems in some simple manner to the 
bottom of the box to prevent shifting. It is no use sending away full-blown Roses; they should in all cases be undeveloped and scarcely past the bud stage; and another noteworthy and important preparation for a successful journey consists in placing the flowers in water for two or three hours before packing.

Many of the H.P. Roses grown out of doors will require a considerable thinning of the flower buds, not only for exhibition, but in order to get presentable blooms. The majority of the crimson H.P.s, such as Madame Victor Verdier, form great clusters of buds at the end of the strong shoots, and the result will be most unsatisfactory if they are all allowed to remain. The centre bud will open first or try to do so, but it will be so hampered by want of room and so robbed of its nutriment by its many companions as to fall very far short of what it might have been. It is generally not cut, as its stem is too short mless the other buds are cut unopened, so it withers and spoils the appearance of the "truss" just when two or three of the other poor things come out even smaller than the first one; and so the whole life of the shoot is a failure -it has not produced one Pose worthy of the name, and yet it and the plant have been exhausted by flower formation more than if the buds had been properly thimned to one or two and a glorious bloom had been obtained and cut.

Those who grow Roses merely to enjoy their beauty without any thought of exhibiting them will find that this thinning of the buds makes an immense difference to the quality and beauty of their blooms, and will give them, in the case of many 
varieties, really fine flowers instead of a mere mass, wherein are some dead, some overblown, some not out, and all poor. I can never pass such a great head of buds in a neighbour's garden without my fingers instinctively longing to be at them and ease the struggling competing crowd.

It should be remembered that the production of fruit, flowers, or even flower buds, has just the opposite effect upon the constitution of a plant to that which is given by the growth of shoots and leaves. In the latter case the plant is growing, and the roots are increasing in proportion to the leaves. But in the former case the plant is engaged in reproduction, which is to some extent weakening and exhausting. So all lovers of flowers should bear in mind that as the removal of leaves, to any considerable extent, weakens a plant, so the cutting off of flower's or buds strengthens it. We should never be afraid to cut hose-blooms; we sometimes hear, "Oh! I thought it was a pity to cut that splendid Rose on that little plant," when as a matter of fact it was still more a pity to have left it.

A large head of clustered Rose-buds is a great strain on the root and the plant, and the sooner this strain is relieved the better by far will be the bud that is left and the earlier and finer will be the autumnal bloom.

In growing for exhibition this operation of disbudding is most important (see Chap. XI) and must be strictly practised on the Teas as well. But for general purposes many of the Teas are greatly improved in beauty if a bud or two be left with the Rose, only those immediately surrounding the central bud being removed. 


\section{CHAPTER VII}

\section{STOCKS}

Roses are not generally grown on their own roots but "worked," that is, budded or grafted, upon other more free-growing sorts. This is done, firstly, to save time: a plant in its full strength, capable of giving the finest flowers, can be obtained much quicker by budding the Rose on the wild stock, as it thereby gets at once the full benefit of the strong roots of the briar, and often yields the best blooms the first year after budding. In the propagation of new Roses, where it is required to raise as large a number of plants as possible for the following season, nurserymen are often able, by commencing in the winter under glass, to raise three generations in one year.

And, secondly, Roses are not grown on their own roots, simply because the very large majority of them do not either grow or flower so well when thus treated, as when worked on suitable stocks. This is a fact, easily capable of demonstration: nevertheless, instructions for propagating Roses on their own roots will be found at p. 155 .

The principal stock used is the common Dog- 
Rose or briar (Rosa canina) of our fields and lanes, and probably three-fourths of the Roses cultivated in this country are now grown upon this stock. It is used in three forms: first, as a standard, which is the actual wild plant dug up from the hedges, with the Rose budded on the lateral branches proceeding from the stem. Secondly, the briar cutting, which is a shoot of the briar struck as a cutting, and budded, after it is well rooted, as low down on the stem as possible. Thirdly, the briar seedling, which is the growth from the seed of the wild Rose, and has the bud inserted on the actual main root or underground stem.

Next in popularity comes the manetti stock. This is a form of wild Rose, introduced from Italy, some sixty years ago, by the late Mr. Rivers of Sawbridgeworth: it is only used in the form of plants struck from cuttings to make dwarf Roses. Other sorts of Roses which root strongly as cuttings have been used as stocks, such as the De la Grifferae, used by some for the Gloire de Dijon race and strong climbing forms of Teas and Noisettes, and the Polyantha, which as a seedling and a cutting has been tried and found wanting; but at present the stocks that "hold the field" are the three different forms of the briar and the manetti cutting - with the latter much diminished in popularity of late years.

A large proportion of amateur Rose-growers will, from various causes, be unable or unwilling to propagate their own plants, and so will have to rely upon those they purchase from nurserymen. Even in this case it is desirable that they should know something about the different forms of stocks, so 
that they may order those most suitable for the several varieties and the purposes for which they are designed. Except that we cannot, fortunately, purchase Teas upon the manetti stock, as the union is universally acknowledged to be a failure the principal varieties of Roses may now be obtained of those nurserymen who make them a speciality upon the four recognised stocks - standards, briar cuttings, briar seedlings and manetti. Which shall we choose?

The advantages and disadvantages of the standard stock may be summed up as follows. It does very well for the old-fashioned summer Roses of the Hybrid China and Bourbon races, where a fine head and a grand mass of bloom just in the season is desired, but is not suitable for the Mosses, Austrians, and the majority of the other linds that bloom but once. It is also a good stock for most of the H.P.s, forming large heads with the stronggrowing sorts, and perhaps producing more refined flowers from those which are inclined to be coarse. For a time the weaker-growing varieties also do well on this form of stock, perhaps even better than as "dwarf" plants, but only the very hardiest and most vigorous are as lasting on the standard as are properly planted specimens on the cutting and seedling briar.

A majority of all sorts of Teas and Noisettes give better and fimer flowers on standard than on dwarf stocks. The natural idea would be to have the stronger forms of Teas, such as Marie van Houtte and Anna Olivier, as standards, and those of weaker growth, such as Comtesse de Nadaillac and Cleopatra, as dwarfs. As regards the outward 
appearance of the plants when first put in, this would perhaps be correct, but experience shows that some of the more vigorous Teas do as well on dwarfs as on standard stocks, and that the weaker ones, though they do not scem suited for the position, yet give the best flower's when grown in that form. In fact, the Teas of "moderate" (i.e., weakly) growth do undoubtedly grow much better on standard stocks of medium height, and besides giving better blooms form finer plants than the same varieties when budded on cutting or seedling briars.

The purchaser should, however, take notice that there are several disadvantages bolonging to the standard stock. One of the greatest of these is that every plant must be staked, and with a large number this becomes a serious item, as a gale of wind is sure to break some of the ties and the stakes themselves if they be wooden ones. Standards are also more expensive, and there is often far less choice of really good plants. A great deal of care in graduating the height of the stems is also necessary to make the Rose-bed "look nice," while a good general appearance is much more easily arranged with a bed of dwarfs.

Standard stocks are only used, I believe, in Europe: the bare stems will not stand very severe winter cold, and appear equally to suffer from extreme summer heat. And this seems to be one of the reasons why some of our finest Exhibition Teas, which do best with us in our hottest summers, are yet not grown to perfection in tropical climates.

I advise then that the standard form be not 
chosen for the H.P.s, for as a general rule quite as good blooms and a better general appearance, with less cost and trouble, can be obtained from dwarfs. La France, Lady Mary Fitzwilliam, and some of the H.T.s must be taken as exceptions. Let the strongest-growing Tea Roses also be grown as dwarfs, if a bed of beautiful Roses be desired rather than extra fine blooms, or if the locality be liable to severe frost; but for exhibition purposes, or in any case where the quality of the flowers is the principal object, they should be grown as standards, if it be found practicable to keep them alive during the winter.

The next question, and it has long been a keenly debated one among Rosarians, is, which of the three dwarf stocks, briar cutting, briar seedling, or manetti cutting, is the best for purchased plants. The voice of the majority in the Rose world, with which I thoroughly agree, places the value of these stocks for permanent plants in the order named above. The advantages of the briar cutting are that it makes the finest permanent plants, that, taken all round, it gives the best blooms, and that its tendency to comparatively shallow roots makes it the most amenable to good cultivation. Its only disadvantages are that it is not quite so early in blooming as plants on the manetti stock, and that its want of deep roots prevents its being able to stand neglect as well as those on the briar seedling. This is, however, a poor advantage to claim for the briar seedling, as the growth from the deep roots will not be so satisfactory or free-flowing. Even if the tap-roots are taken off, the plants are generally somewhat inferior to those on the cutting, and are the latest 

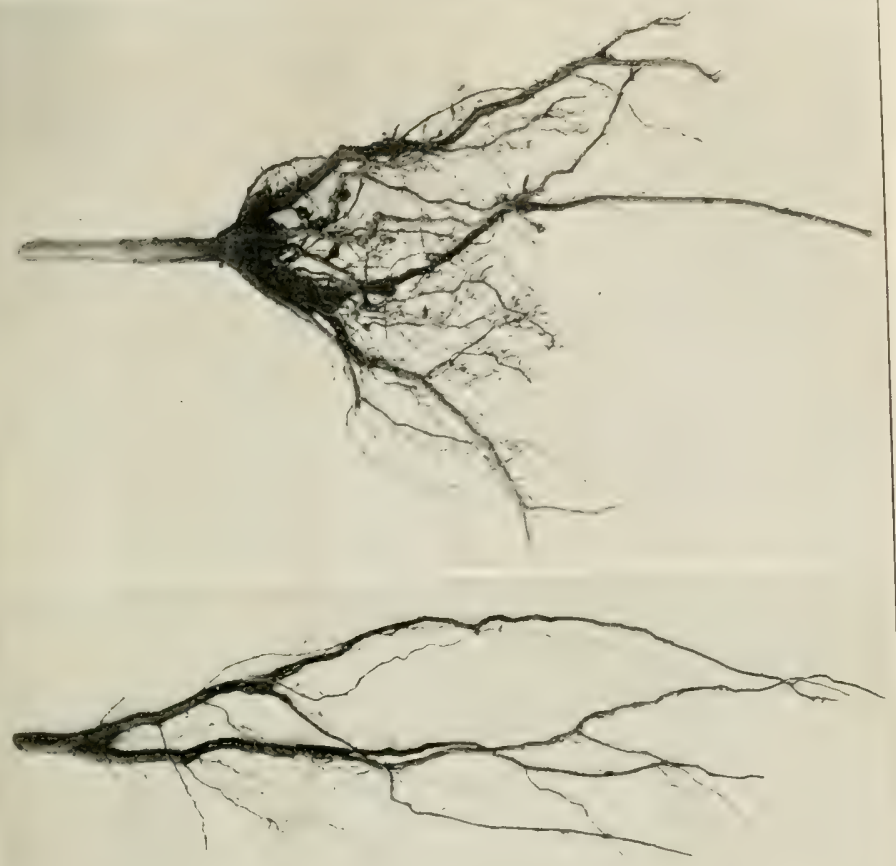

些

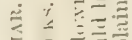

$\bar{\Xi} \equiv$

$\approx \bar{\tau} \bar{\vdots}$

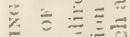

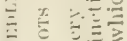

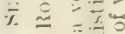

开

焉胥

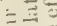

$=\frac{1}{3}$

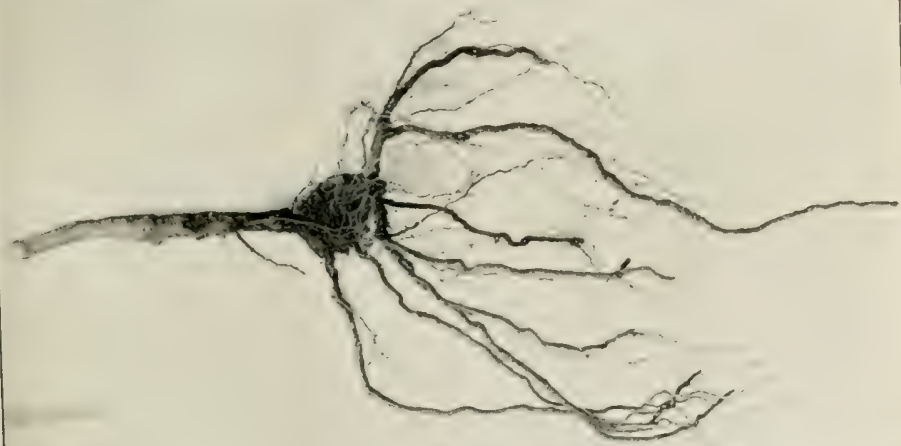



in blooming of all. Mr. Prince's magnificent culture of Tea Roses on this stock caused it to be very generally tried and used for this purpose, but I have not found any advantage from its adoption.

The manetti stock is not suitable for purchased plants. Its disadvantages are that mnless the union of stock and scion is planted at least an inch below the surface of the soil, the Rose will simply die:- - that as a general rule it dwindles and gets weaker every year, though there are exceptions to be found where the rose itself has thrown ont roots to aid the stocks:- and that the suckers, which it is sure to throw up as the plant gets weaker, are so like the growth of the Rose, that it requires a trained eye to detect the difference. The manetti has its uses, in the propagation of new Roses and in the growth of "maiden" plants of some of the H.P.s for exhibition blooms, but it should not be employed for permanent plants. Some years ago it was difficult to get dwarf plants upon any other stock but this, which was said to be generally more suitable to the lighter soils: but, with the increased use of the cultivated briar for dwarf stocks, this idea has died out, and dwarf H.P.s upon either of the three stocks can gencrally now be obtained of the leading professional Rose-growers.

There are still, I believe, a few amateurs who grow Roses in quantity, and show them well, yet never bud or propagate them themselves. I cannot understand this, for I find a large part of the delight of the pursuit in the raising of my own Roses, and I have but a few among all my plants which were not budded with my own hands. There is much 
fascination in the whole operation of budding;-you have before you rows of strong wild plants, rough and untidy as the worst of hedges, and in one short year you transform these into splendid Rose-plants of all varieties, with noble foliage and glorious flowers of many shades, certainly as good and probably better than any that can be got from bought plants. A due mingling of hopes and fears is essential to true enjoyment, and there is plenty of both in Rose-budding from the planting of the stock to the cutting of the maiden bloom. But when all dangers are passed and over, is not that glorious flower more truly and verily your own? You may see your Rose marked for the Silver Medal at the National Rose Show as the best in its section. Yes! it is your Rose, even if it was your gardener who ordered, planted, pruned, fed and cultivated the plant, and cut and sbowed the bloom. But if it was you alone who had found, chosen, and grubbed out the stocli from the hedge, or cut, prepared, planted, and transplanted the briar or manetti cutting-if no hand but yours had budded it, cared for it in all stages, and finally cut and shown the Rose, then, when perchance it is declared on all hands to be the finest specimen of the variety ever shown, it must be an additional pleasure to know that it is your Rose indeed, for that, as far as all human aid is concerned, you made it yourself !

Or again, you go to see a brother enthusiast, and to admire and take stock of his collection. You see one or more, perhaps several, Proses which are new to you and you would much like to possess. If you are not a "Buddhist," you can only take down the names, and order a plant or two of each from 
your nurseryman to be sent you in November. It may be that you do not mind the cost, but plant as carefully as you may, with all possible good fortune, you will be lucky if you get any first-class blooms the next year from these newly-moved plants. But if you have plenty of good healthy stocks at home ready to be budded, how much more speedy and effectual and less costly the whole matter is! Your friend immediately cuts you off a shoot or two of the required sorts with good buds on each, or promises to send you them by post if there are none now ready. If the leaves are at once snipped off, all but the last inch of the footstalk of each, they may be safely carried home, or they will arrive in good condition by post, wrapped in damp moss or paper shreds. Do not be afraid your friend will refuse you, unless his plant is very small, weakly, and precious; not only from the universal good-fellowship of the craft, but also because he naturally expects that you will do the same for him, and that the benefit will thus be mutual. You put in these buds which have cost you nothing but an exchange which you can rery well spare, and the very next summer you have the shoots and flowers in their fullest vigour, with the additional charm of watching a variety which is new to you spring into leaf and bud and bloom from the tiny bud which you brought home in your pocket.

What a pleasure, too, to help a beginner, or one who has lost his plants, by sending a large parcel of buds in early August when they are plentiful and you can spare a good quantity of them. But still, the choosing and cutting, preparation and 
packing of them takes some time, and I should advise the making of a rule that whoever asks for buds by post should send labels with the names and the number of buds required, as this will save some trouble at least. From budding Roses, the amateur will very likely be led on to budding his own Apples on Paradise, and his own Plums and other fruit-trees, and his interest in all these features of the garden will be much increased when his own hands have thus propagated his fruits and his flowers.

I would strongly advise the enthusiastic amateur, if he lives quite in the country and has plenty of room, to get and raise his own stocks. Not only because it will greatly add to the interest of the matter and save expense, but also because the stocks themselves, especially standards, will be stronger and better. A sufficient number can be raised every year by one man to keep up a collection of Roses large enough to enable him to show in the highest amateur classes. As standards undoubtedly produce as a rule the finest Tea Roses, and there are probably few amateurs who personally get their own stocks from the hedges, I will endeavour to describe my mode of procedure.

First, as to outfit:-I never had any special suit, but an old one each year is condemned to the work, and verily it is never likely to be used for anything else afterwards. In a short time it is more fitted for a scarecrow than a parson, but my craze is known, and I keep to the fields. An old hat capable of protecting the ears is necessary, for you must get your head into the very thick of it; and strong boots and gaiters will of course be required. One 
other article of dress is wanted; even if not used for pruning, strong thick gloves are necessary for stockgetting, for there are no thorns in England like the curved scimitars of Rosa canina. Summer thoms may be disregarded, for whilst they are green they are fairly pliable and soft; in winter they are as hard and sharp as steel, and as brittle as glass. Under the microscope, the point of a fine needle looks like a great coarse blunt cone compared to the sharp point of a Rose-thorn. Get the white stiff hedger's gloves at the village shop, made I believe of horse-

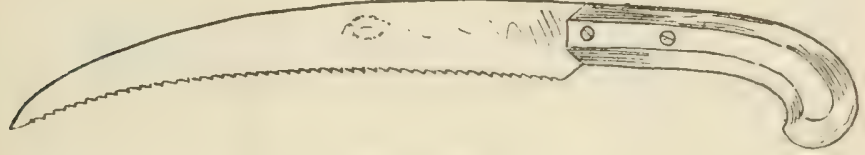

Grectan Saw.

skin : they are very hard and uncomfortable at first, but become more supple by use.

For instruments, first and most useful is the "Grecian" pruning draw saw, which might perhaps be kept in a sheath attached to a waist-belt, though I have always simply carried it: any of the large seedsmen will supply this tool, which must be sharpened occasionally as you have to cut through the earth with it. Next in importance is a small stock axe : $I$ have quite a miniature one which was made on purpose for me and can be used with one hand: the small amount of digging that is required can be done with this, and there is no use for aspade. A pruning-knife and strong sécateurs or pruningshears in the pocket coinplete the equipment. It is here, I suspect, in his instruments, that the amateur 
has such an advantage over the professional stockgetter. It is impossible to do justice to this, the very first step in successful Rose cultivation, with a spade, a bill-hook, and a full-sized stock axe. It is very difficult to strike accurately with the lastnamed tool in a thick place, and many is the fine stock that has been grievously injured by a hasty

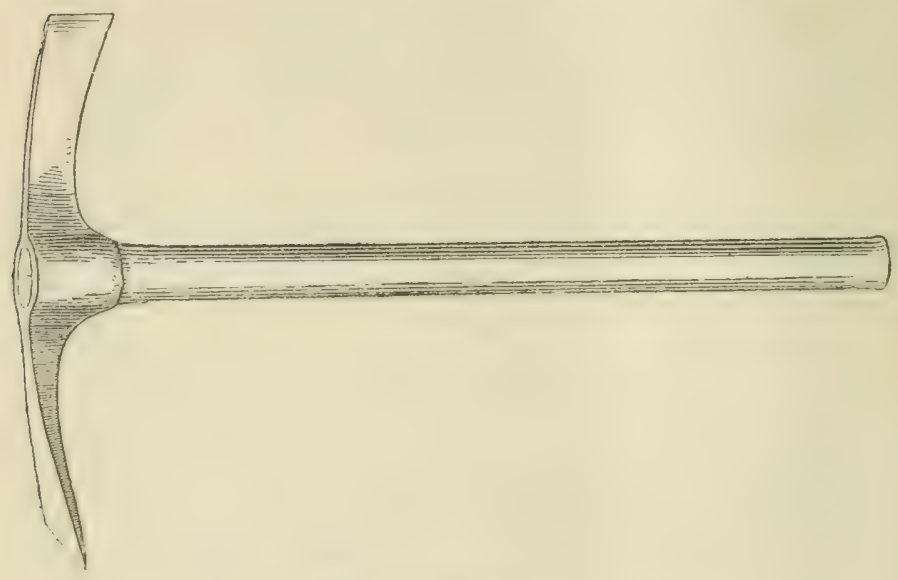

Miniature Stock Axe.

stroke turmed aside by a twig, and I am sorry to say sometimes mended afterwards with putty. I use my tiny stock axe almost exclusively for digging round the roots, and all of any size are then severed neatly and cleanly in the ground with the Grecian saw. The sécateurs will clear the way a bit, and lop off the head, and the pruning-knife will cut off and shorten all bruised roots, and make the edges"smooth where the saw has done its work. The result will be far better stocks than those gathered by professionals, for even Mr. William Paul 
recommends trimming the roots of standard stocks, before planting, with a bill!

The greatest number of stocks, and the finest to look at, will be found on heary land, but, as a rule not without exceptions, those on lighter land will have more numerous and fibrous roots. The stocks will be either rooted suckers from the main stool, or, if young enough, the actual plant itself with the stout principal root of the seedling briar. In either case, as little as possible should be reserved of the underground stem or main root, consistent with the preservation of some fibres; for it is these latter, with many others which form in the spring, that will support the new growth of the plant: the thick main roots and underground stems will only throw up sucliers if they live, and if they die are likely to harbour fungus which is hurtful to the living fibres. If planted early enough, say before Christmas, the stock will grow well enough in most cases without any fibres: it will be sufficient to leave about three inches of clean root, squarely and smoothly cut at the end.

In many localities the hedgebanks are the only available places, where the stocks are difficult to get at, and naturally have roots only on one side, and often fantastically curled about. Briars growing in the open undergrowth of a wood, or in any rough half-uncultivated level space, are much easier to get at, and probably have a more even spread of roots. When going along hedgerows, I lay the stocks out as I get them on the edge of the ditch with the roots covered with wet leaves and grass, and collect them as I come back. I then cut an elm sucker as a withe and make a little faggot, which, regardless 
of the sufferings of my poor coat, I carry home rejoicing. Sometimes it may be more convenient to reserve till reaching home the work of the pruning knife, in shortening bruised roots, smoothing saw cuts, sharing off suckers, and carefully cutting out all semblances of buds below the ground surface.

In selecting standard stems, if there is plenty of choice, take only two-year-old shoots; next threeyear-old, leaving one-year-old shoots for next year, and avoiding old stems, unless you are very hard up. I have seen a great many stocks in nurserymen's quarters that I should never take unless I was very short-old, spotted and cankered. For it is instructive to notice that canker may certainly be found on the wild Rose, in its natural state, even where there seems to have been no outward injury to the stem. It is true that some of the grey hidebound old stocks will make very good growth when cut back and transplanted, but some will not, and you never can tell where they will break. A sharp frost, after they are moved, would be fatal to most one-year-old stems, which are too soft and pithy to stand the ordeal of transplanting.

There are a great many varieties of the Dog-Rose, and a great difference will soon be noticed in the general appearance of the stems. It used to be said that the red-barlied, very thorny, variety is the best, and perhaps this is true, but I have formed fine plants on smooth stems. I should not generally choose the water briar with its deep green bark, and running slender growth almost like the Ayrshire, but I have grown good Teas upon it. The sweet briar does not form a good stock, though, as I have 
found it growing wild only in light soil, I fancied at one time it ought to do well with Teas on gravel.

It is not always the thickest stems that are the best; those not stouter than the forefinger, if healthy and with good roots, will often do as well if not better for the Teas of moderate growth. Still, an extra stout stock is a prize for strong growers that should not be neglected; vitality can always be diminished in many ways; it is the increasing it that takes almost all our care and trouble. I cut all my standard stems to the height of two feet, making them thus what are termed half-standards, for there does not appear to be any advantage in having them higher, except for the formation of weeping roses; even for the middle row of a bed, more expensive stakes must be used - the wind exercises more leverage upon the roots, and suckers are more likely to be formed. It is said, however, that in very close sheltered places tall standards are better, as exposing the Rose to less stagnant air.

It should be understood that laterals or branches, however small, should be left on the stems, and it is better that there never should have been any sidegrowth from the portion of two feet which is left. They should be planted in rows, the stocks a foot and the rows a yard apart, but they may be a little closer if for Teas, and room be precious. I plant in double rows, every other row being only one foot apart. Of course this is too close together for permanent plants to stand, but even if you succeed in making every stock into a Rose-tree, every other one can be removed when the Rose has made its maiden growth. Do not plant too deep: the 
"collar," that is, the place from which the stem springs (generally at an angle) from the root, should not be more than an inch or two below the surface. No stakes will be needed during the year of wild growth and budding, but it is a good plan to put a thick smear of paint over the pith exposed at the top of the stem. For an insect pest in the spring will be on the watch for any such exposed pith, even on large shoots pruned back on the Rose itself, and the grub which proceeds from its egg bores down the pith, leaving a hole which holds the rainwater and leads to decay.

Mr. W. D. Prior, in his useful little book upon Rose-growing, suggests the cultivation of standard stocks by layering. To do this, any old useless stock or briar plant should be cut quite down to the ground and encouraged to form side suckers running through the soil for a little distance. A nick beneath the underground stem of these suckers will cause them to root independently, specially if a little cocoa fibre be added, and rooted standard stocks will be produced. But the time and trouble required for all this will not be appreciated where wild standard stocks are available. I have collected 1800 of these in one winter, but they were not selected ones or all of first-class quality.

I feel, however, that very few amateur Rosarians will appreciate with me the charms of getting standard stocks from the hedges-most could not, from various circumstances, if they would. The stock-man, who would probably say that I have been trying to take the bread out of his mouth, must therefore be relied on, but if possible let the barbarity of his tools, the big stock-axe and the billhook, be pointed out, and the charms of the Grecian 
saw explained to him. If a novice, it will be well also to ascertain that he knows a Dog-Rose when he sees it. When I was ill one winter, I was pleased to hear that a parishioner had brought me a nice lot of stocks at a reasonable price. One of the first acts of my convalescence was to inspect their quality. And alas! not only were the majority practically useless from chops and other injuries, but a third of the whole were not Rose stocks but blackberries!

This reminds me of another amusing incident, which I will relate exactly as it occurred. It refers to the spelling of the word briar, but throws no light upon the debated point whether an 'e' should take the place of the 'a.' 'The occasion was the examination of a night school for the Government grant, and at that time the teachers were allowed to conduct it subject to the rules sent to them. A young East Anglian labourer was going through the reading ordeal, and his teachers, of whom I was one, were anxiously watching his struggles. He had sunk twice-I mean he had made two mistakes in his allotted piece-and three would mean failure. $\mathrm{He}$ came to the word in question, stopped dead, and spelt it slowly. We encouraged him, and patted him on the back, for he had all the appearance of having a word in him but of being afraid to part with it. At last, after much exhortation to play the man and "out with it," he spelt it again very carefully, "b-r-i-a-r," and then the word burst forth quite suddenly like an explosion, "brumble-bush!" "Well! well! yes, oh yes!" said my dear old colleague (long since deceased): "eh? pass thatoh yes! he knows what it means." I said nothing, and I am afraid the Education Department was 
slightly defrauded; but my Rosarian conscience was against it, for I knew that to the Suffolk rustic both briars and blackberries were "brumble bushes."

An amateur will want even more briar cuttings than standard stocks. These are cheap to buy, ready rooted for next year's budding, and it is not always easy to raise a good crop of them at home. There is a good deal of trouble connected with it, and it may perhaps be said that all this extra labour to raise one's own stocks is like the enthusiasm of the man who blacked himself all over to play Othello. Still, too much enthusiasm is better than too little, and as I can raise better briar cuttings than I can buy, the way to do it shall be described.

It is rather a monotonous business, with much less interest in it than the getting of standard stocks. About the middle of October is the time for commencing operations, which should be got over before the planting of Roses and rooted stocks is undertaken. The ripest possible wood of the year's growth should be chosen and cut up into lengths of ten inches. Naterial for this choice will be found in the wild growth of the briar stocks budded that year, and only pieces without any lateral growth should be selected. The cuttings should now be trimmed with a sharp knife, every bud except the two nearest the top being clean cut out with the knife, not rubbed off with the fingers, and all the thorns removed. All this is important, as every other bud or part of a bud left will be sure to produce a sucker, and the thorns will prove a hindrance in many ways if suffered to remain. The bottom of the shoot should be a clean cut, not too 
sloping, and no "heel," or portion of older wood, should be retained. A "heel" is recommended where cuttings of the Roses themselves are taken, as it makes root growth more easy; but, as a sure and fruitful source of suckers, it must not be allowed for briar cuttings, which will generally root fairly if they be formed of ripe wood and are properly planted and cared for.

We have now the cuttings ready for planting, smooth shoots of wood ten inches long, with two buds left at the top. These should be at once set in a piece of fairly light and very clean soil, deep enough to almost cover the lower bud. Double rows may again be used, ten inches and four inches alternately separating the rows, and the cuttings three inches apart from each other. It is advisable to set twice as many as you expect to want; for, though the trimming of the cuttings takes a considerable time, the crop is uncertain, and there is much virtue in the comfortable old adage to " make a job of a thing while you are about it." The soil should be made as firm as possible about the cuttings, but nevertheless if you come after a sharp frost and just touch the top of one with your finger you will find that it has been raised up, sometimes an inch or more, in its hole. They should all be gently pushed down again till they rest firmly.

They grow but slowly in the spring, but increase in rapidity of growth when they have once become rooted, and some will probably make quite strong shoots in the autumn. These might in some instances be budded at once, but it is best to leave them all to the next year for that operation. With the summer will be realised the advantage of the 
advice to choose a piece of clean soil free from weeds. The shoots are close to the earth, and the first ones grow horizontally almost on the ground. Not only therefore is it almost impossible to hoe them, but a full growth of weeds can almost entirely smother the briar shoots. The weeds must therefore be hand-picked, a troublesome and unpleasant job.

In the planting season they must all be dug up, remembering how deep they are planted and that all the roots which are to be utilised are at the bottom, and the plants trimmed. All roots must be cut cleanly off, except those proceeding from the very base of the plants, and those retained shortened to a uniform length. The growth at the tops may also be shortened to two or three buds, and the plants then transferred to their budding quarters. Here they should be planted about two inches deep, care being taken if possible to spread the roots out in every direction, as few fresh ones will come from the base of the cutting, and if there is a side on which there are no roots the plant will never be firm against the wind from that quarter. If the plants are permanently to remain where they are budded, the distance between each will depend upon the varieties of Roses worked on them, as explained on p. 54. But if it is intended to move them after the maiden growth of the Rose, nine inches apart between the plants, more or less, according as they are intended for Teas or strong H.P.s, will do for the distance.

It is plain that by thus raising our own briar cuttings we lose a year compared with the plan of buying them ready rooted. This difficulty should be overcome by buying rooted cuttings the first year, as 
well as setting a supply at home. An amateur commencing business had better buy a double supply of cuttings the first year, half rooted for budding the next year, and half unrooted for the year after.

Manetti cuttings, which may be useful to an exhibitor for the production of early maiden blooms of the H.P.s, may be raised and treated in exactly the same way. They strike much easier than the briar cuttings, and there should be very few which fail to root.

I have never gone the length of trying to raise briar seedlings, as they are cheap to purchase in quantity, and I have not much faith in the stock for highly cultivated Roses. The seeds should be rubbed out of the ripe heps, and sown an inch deep in drills about a foot apart. All will not germinate, and a great amount of difference will be found in the plants by the end of the year. Many will still be quite tiny things, and a person unacquainted with their power of growth would think the finest far too weak for budding the following August. But the second year's growth is astonishing: puny plants, with shoots hardly bigger than knitting-needles, will sometimes in that short time have become veritable bushes with strong fleshy upright shoots, and a main root to bud on as thick as a man's finger. Those that are evidently too small for budding the following summer should be reserved for another year, or transferred to pots for budding or grafting there.

The seedling briar has naturally a tap-root; in fact, as with all seedlings, there is only a tap-root at first. When purchased, the length and straightness of the roots are remarkable: and it seems probable 
that this want of balance between the head and the roots accounts for the remarkable growth of the second season. The tap-loots should be boldly shortened, as it is our object to encourage comparatively shallow roots as much as possible. There will still be a tendency to root deep, and, when Rose plants on the seedling briar are moved, roots with a downward inclination should be suppressed and any horizontal ones encouraged. In planting out briar' seedlings for budding, the "collar," or place where root ends and stem begins, should be open upon the surface of the ground, not beneath it, for the rose is budded in this case upon the main root below the collar. 


\section{CHAPTER VIII}

\section{PROPAGATION}

BUDDING is so much the most important mode of propagating Roses, that it naturally occupies the first place. We will suppose that a goodly supply of stocks-briar standards, cuttings, and seedlings, and manetti cuttings-have been planted during the winter as described in the last chapter, and commenced their growth in the spring. Do they need any special care till the time for budding aryives? If they do, they very seldom gret it; but the Rosarian who intends, and is able, to do everything thoroughly, to promote all that is useful to his Roses, and war against all that is hurtful, may find some useful work here. During the grub and caterpillar season in April and May he will give occasional turns of examination and handpicking to the wild growth on his stocks, besides the systematic and close search which he will make on his Rose plants. It is true the wild growth will battle through the insect attacks, and there is no bloom to be injured; but some check at least will be experienced from these causes by the stocks, and if the insects are allowed to fulfil their course they will breed and increase, 
and we shall have to deal with their progeny on the Roses. We can hardly exterminate these pests, but we ought not to allow them to breed on our premises, on the ground that they are not doing much harm just where they are.

The next point of importance is the treatment of the standard stocks. In almost all the books on the subject that I have read it is advised that, sooner or later before budding, all shoots from the standard stems be removed except the two or three near the top which are reserved to be operated upon. I would say: Do nothing of the sort-do not remove unnecessarily a single leaf, save of suckers from beneath the surface of the soil, and let these be gently but firmly pulled out as will hereafter be described. Remove no lateral branch or part of one during the whole season of growth: and as this seems opposed to general recommendation, I will endeavour to give the reason for the advice.

A plant in its natural state has always a complete balance of strength between the parts above ground and underground-the branches and the roots. If, in summer, or during the period of growth, the roots be injured, cut off, or lessened, the foliage, which is the most prominent outward sign of vigour, will suffer in proportion, but if not killed, will restore the balance of root power as soon as possible. If, on the other hand, shoots or leaves are cut off or injured during the summer, the roots will cease to increase till they have restored the balance of power to the foliage. Thus, in summer, cutting back the root hinders the growth of the plant, and taking away shoots with leaves on them checks the growth of the roots. 
But if roots or shoots are cut off during the sleep of winter, no immediate check is given by either to the other, and the first thing the plant does when it wakes up in the spring is to try to restore the balance. If it finds itself with a large growth above ground and roots that have been lessened, the plant will comparatively stand still just alive till the roots have grown up to the balance again. If, however, it finds itself with strong powerful roots, and only two or three buds left on the plant into which the sap can pass, it makes up the balance as quickly as it can by unusually strong growth and large fleshy leaves.

This is what we aim at in trying to make a maiden Rose plant by budding on the wild stock. We want it to grow as strongly and quickly as possible, for among H.P.s the very finest blooms are thus produced, and some very choice varieties give their best flowers only during this first year of extra strong growth. We therefore bud on wild briars which have as many branches as possible-knowing that each branch represents so much root power below-that if one of these be removed the roots will cease to increase till the balance has been restored-and that if we can next spring divert the root powver of many wild branches to the one or two buds we have inserted, the growth is sure to be extra strong and fine.

This principle is well known in the difference resulting from the summer and winter pruning of fruit-trees. If we pinch back the strong leafy shoots in summer, next year's growth is partially checked because the roots suffer awhile in proportion: the lower wood buds therefore ripen and 
consolidate to form fruit buds. But if we cut back these strong shoots in winter, when there are no leaves and all is at rest, the roots when they wake in the spring try to make up the balance of the foliage by strong luxuriant growth equal to that which has been cut off.

So it is with our standard briars. If we cut off any shoots in summer, we hinder the roots from attaining their full development. But if we cut them off in winter, when the roots have attained to their maximum and are resting, their full strength can be devotea to the buds in the spring.

But some of the advocates for the removal of those branches which are not to be budded have given their reasons for the advice. They say the object is to divert the entire strength of the plant into the selected shoots before they are budded. This is not quite correct: the full strength of the plant will be lost, for the check to the roots will be considerable. Yet it is true that the selected shoots will grow more vigorously, for the plant will try to make up the balance in both ways, in lessened root power and also increased growth in such branches as remain. But, in the first place, we do not want such extra stout branches to bud on; if big enough, the union will be better than on a very large shoot, because a small one will have to swcll and increase with the strong growth rising from it. And, in the second place, what we do want especially is as much extension and strength in the roots as we can get for the support of the maiden growth of the Rose.

It is naturally much easier to bud upon standard stocks where some of the shoots have been removed 
than it is upon such a rampant hedge of thorny growth as will be formed by a row of unrestricted stocks if they have grown well. But the knowledge that all this prickly luxuriance represents the power we are going to put into the growth of our buds next season should be an encouragement for a bold attack, and a comforter against thorny assaults. The branches should be carefully shifted and turned aside to expose the places for operation, and the thorns can be compelled to malie themselves useful, as the branches will catch and hold to one another wherever laid without tying.

The principal time for budding is the latter part of July and the whole month of August. I have successfully budded Roses out of doors in each of the seven months commencing with April and ending with October, and there would not be much difficulty in finding stocks in the proper condition in June and September, but to get buds in the right state would then be more difficult. Manetti stocks may be well budded with hardy H.P.s as late as September; but commencement should be made with the Teas first of all if possible. This is not only because the inserted Tea bud will thereby become better ripened and more able to withstand the winter, but also because these buds, in many of the varieties, are difficult to procure, and it is good policy to begin early, and use them whenever they can be got.

The illustration on the next page may be of service, but for all manual operations example is far better than precept, and I would strongly recommend the seeing it done by an old hand, even if only once, in preference to relying upon descriptions or figures 


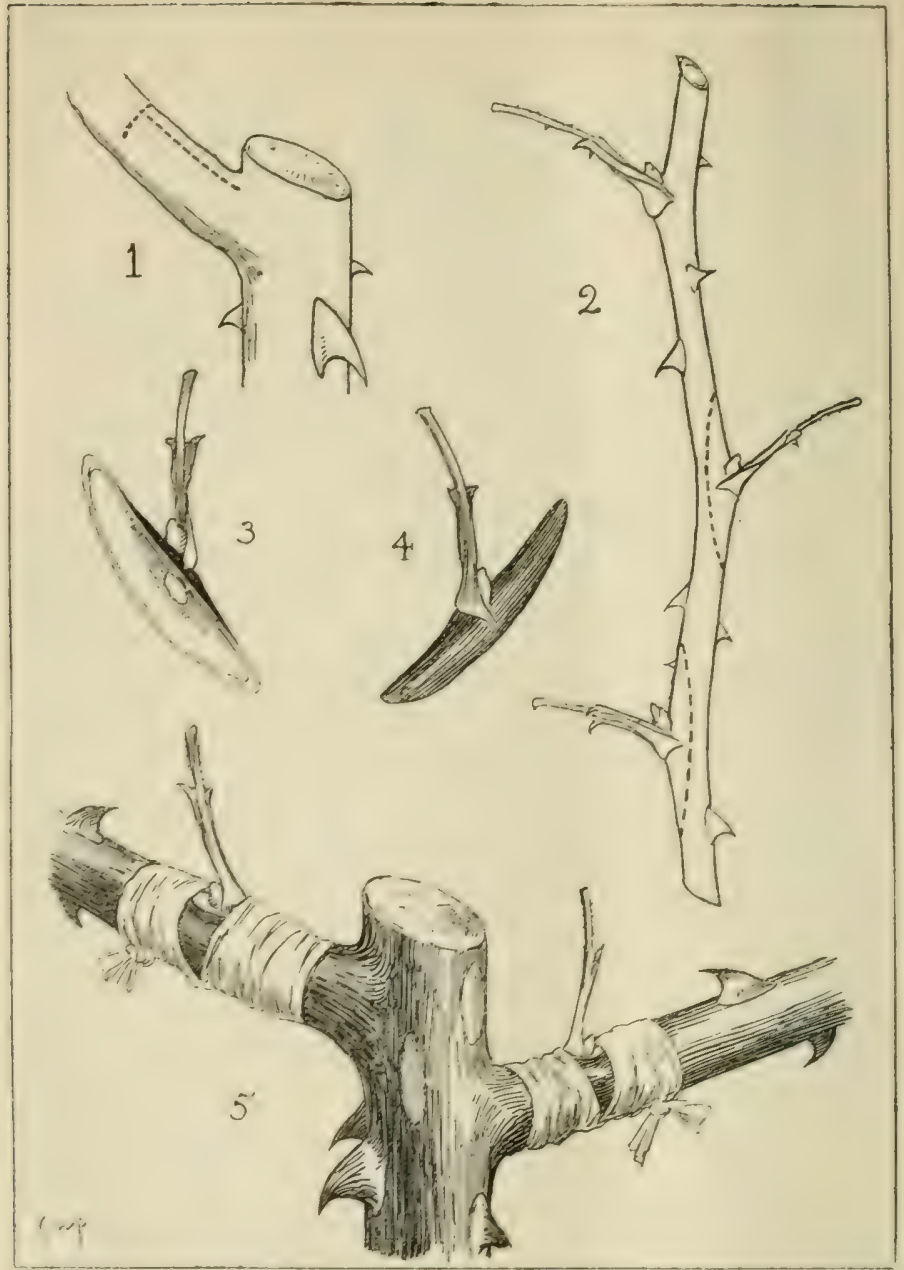

[3roniso.

1. Lines of incision in the lateral shoot of the Stock. 2. Jines showing how the buds are to be cut out of the scion. 3. Inner surface of prepared bisd, showing the eje intact. 4. Outer ditto. 5. Burdding enmpleted. 
alone. It is best for an amateur to learn of an amateur, provided of course the teacher be experienced and trustworthy; for, without throwing any discredit upon the wonderfully clever and rapid performances of professional budders, it is plain that an amateur works upon rather different lines. He has not such a wealth of "stuff" to fall back on, either of buds or stocks, and having more time can afford to be more careful and particular about every stage of the operation.

No tools are required beyond a budding knife. It is hardly necessary to say that this should be as sharp as possible, but a hone is not so often required as in pruning, since no hard substances will require to be cut. The curve at the end of the bone handle for turning up the bark of the stock is made of different shapes, and a young operator will soon find which is most convenient for him. A bundle of ties of Raffia, split where too thick, and shortened to ten inches or a foot each (better too long than too short), should be fastened to the waist so that one tie can be slipped out easily as required.

The buds chosen should be half-ripe, and plump but not grown out. Experience will soon teach the proper condition: but, as a general rule, at the end of July and beginning of August, buds in the proper condition will be found on the shoot from which a bloom is then cut; before that time the shoot must mature more or less after the flower is cut before the buds are ready: after it the buds will be ready on the shoot before it has bloomed, and in September only the latest shoots which are still growing will be of use. Those who grow for exhibition will generally have a difficulty in finding early buds; the 
shoots are so forced by high oulture and thinning that the buds berin to grow out all up the stems before the flowers open, and a more natural state of things later on must be waited for. A fully developed plump bud is desirable, but this is of less importance than the condition of the shoot, wilich should not be more than half-ripe, with the sap still flowing freely so that the wood parts easily from the bark. Professionals will often use a shout for budding, where some amateurs would say that there were no buds, as none are risible. There is always a bud under every leaf-stalk, and it is far better to use those in this undeveloped condition when the wood will come out satisfactorily than older and more attractivelooking buds which cannot be properly prepared.

As a rule, buds should always be tahen from a shoot which has, or has had, a gooul blowm on it. Some sorts. like Franyois Michelon, often bave long strong flowerless shrots, with plenty of goul word buds on them. If these buits be ween there is a strong probability of no flowers being produced the fust year. In Tea Finses, the bude next to the bloom are cenerally flettish and pointed instead of round and plump. These should not be used. as they will often produce. if they take, just a poor little blown upon an inch or two of stalk perhops with no lesves at all, and soon die. It is safest in all coses not to use the next bud to the bloom.

The chosen ahoute should be ont off with soissors, and all the leave: immediately enimped off. leaving about an inch of fontstalk to each. This is uot only for convenience, since it must be done before the buds are used, but also because evapnration takes place through the leaves, and the whole shoot will 
soon wither if they are left on. A quantity of buds may be carried about for some time without taking any harm if the leaves are thus removed at once: but if a great quantity is taken at a time, or the buds have been received by post, it is better to carry them about in water.

Standard stocks are budded upon the laterals, the growth of the year, as close to the upright stem as possible. The general practice is to bud two branches, for the insect pests which attack the growing bud in the spring will be found to be far more prevalent on standards than on dwarfs. Should both of these fail, a use will be found for the other laterals, which have not been removed for the reasons given above, for it will be better to bud on these fresh shoots as the reserved ground than on one where a bud has already failed.

Like the buds, the branches of the stock should be "half-ripe." If worked on too soon, while still soft, or when the wood appears green instead of white when the bark is turned back, the chances of success are much diminished, and the shoot is very likely to break off at the closs cut. If attempted too late, a stock which has not got a strong roothold often ceases to grow for a while in a dry August, and the flow of sap being lessened, the bark does not rise freely and readily. It is absolutely uscless to attempt budding in such a case, where there is any difficulty in raising the bark. An experienced eye can generally tell by the appearance of growth or the want of it in the tips of the shoots, whether the bark will rise and budding may be done.

Do not necessarily choose the strongest laterals, but medium-sized shoots half-ripe but growing 
freely. Rub the thorns off the two inches of the branch to be operated on which are nearest to the main stem. Next make a cross cut half an inch long and about an inch from the stem, and be sure it goes clean down to the wood, then make a clean straight longitudinal cut at right angles to the first one as far as the stem. Insert the bone handle of the budding knife into this cut, and pass it evenly down under the bark on both sides from cross cut to stem, raising it a little, so that the two cuts form a $\mathrm{T}$. It is best so to choose the position that the longitudinal cut does not pass through or near a wild natural bud, as this will leave a little projection which will hinder the smooth passage of the bud. It is not worth while to try to get the new bud just where a wild one was before.

The stock is now ready, and we turn to take a bud from our Rose-shoot. This should be sliced off so that we have the leaf-stalk with the bud under it in the centre of about an inch of bark, the other side being flat and smooth and containing a portion of the wood of the Rose.

Now comes the most critical point. The wood has to be cleanly removed from the inside of the shield of bark without taking with it the immature soft growth or cambium, which forms the inside of the bud. If the bud is in the right condition, the wood generally breaks away from the bud, leaving the appearance of an eye or hole which is filled up. But if the inside of the bud appears hollow, a fresh one should be taken, as a large percentage of failures arises entirely from this cause. Occasionally some may grow, but a good union is unlikely and most will fail utterly. 
The point of the budding knife carefully inserted at one end is usually the means by which the wood is got out, though I knew an old gardener who said he "kept a thoomb-nail o'purpose," a gruesome object which he exhibited with pride. The beginner had better try several ways till he finds what suits him best, remembering that the one object is to get the wood out clean, and yet leave the inside of the bud. Which end of the wood should be raised first will naturally depend upon whether it is to be lifted, pulled, or pushed out.

If the wood comes out all right, leaving the base of the bud level with the inside of the bark, there will probably be no trouble with any buds on that shoot. And vice versa, for it is the condition of the shoot which is at fault. If you find that you have pulled the interior of a bud out, take extra pains with the other buds on that shoot if a better one is not to be found; in obstinate cases, the knife itself may be passed down under the bark, and help the desired object. But care must be taken that the inner surface of the bark of the bud be not bruised or cut and that no grit or foreign substance whatever gets in.

If the wood will not come out clean but adheres in places, the bud is over-ripe and should not be used. If it be very small or not ripe enough, some advise that it be inserted without removing the wood. In such a case the bud will sometimes grow, but this is grafting, not budding, and the union will not be so good or lasting.

The bud thus prepared must without any delay be slipped under the cross cut and down the longitudinal one, so that it just touches and fits to the cross cut. 
This is not essential, but is more likely to ensure success. Many make the shield of bark containing the bud considerably longer than the longitudinal slit which is to enclose it, and cut it across when it is in so that it exactly fits the cross cut. This is the mode generally adopted by professionals, and requires a steady hand, good sight, and a very keen knife. Amateurs probably more often make the bud the right length to start with, cutting the upper end square. The leaf-stalk will form a useful handle for pushing the bud down into position.

The bud should now be tied in, making the bands of raffia touch one another and cover the whole of the slit wood except the bud itself. The tie should be made firm and fairly tight, and should not be removed for four weeks, unless it is seen to be cutting into the bark. The bud will generally have taken or failed by the end of three wceks, but sometimes this is a little too soon to remove the ties entirely. No shading is necessary in the hottest weather, if the stock continues in good growing order.

There should be no shortening of the budded shoots, before, at the time, or after budding. Shortening checks the flow of sap to the bud instead of increasing it. When the ties are removed, standard stocks that have failed may be re-budded on fresh shoots. The date of budding each stock or row should be entered on the label or in a book, that the proper time for removing the ties may be known.

Some recommend budding with only the longitudinal cut and $n o$ transverse one. This may be a 
more satisfactory operation when it is done, but it requires an expert hand to get the bud in under these circumstances, and the cross-cut system answers very well.

Budding on cutting or seedling stocks to make "dwarf" plants is practised in just the same way, except that in this case the bud is not put into the branches, but into the old wood of the main stem, beneath, if possible, the surface of the ground. As before, no growths should be cut away or stopped, but the shoots may be bent back to allow access to the stem. A trowel or the blunt stump of an old knife may be used for removing the earth round the stock to the depth of an inch or more. The stem should then be rubbed with the hand or a piece of old flannel or cloth to make it clean and free from grit, no harm being done by the removal of the epidermis or outer skin of bark.

The operation now proceeds as in standards, only one bud being put into each stock, and great care being taken that no particles of earth or extraneous matter get in between the bud and the stock. With extra strong manettis, or in any case where a small bud has to be put into a strong rough thick-barked stock, thin slices may be taken from the lips of the bark to prevent its completely meeting over the bud, and "drowning" it in growth. Formerly the material used for the tying in of buds was bast or Russian matting, and then soft thick white cotton, called "bommet cotton," was much used by amateurs. But the introduction of Raffia supplied a material of just the right consistence, softness and pliability, which has also the happy knack for the purpose, 
when close to the damp earth, of gradually rotting, so that at the end of a month or more the ties on dwarf plants become loose of themselves.

It is not therefore necessary to unfasten them: but amateurs will generally like to inspect the result of their operations, and where there has been a failure the stock can generally be rebudded on the other side, or lower down. The bud will be the better for being exposed to the air, but, after it has taken, accidental re-covering of earth will seldom do any harm.

Seedling briars are to be budded on the main root immediately below the "collar," which is full of dormant buds. This root is often crooked, with fibres proceeding from it, and the best available spot for budding should be chosen even if it is some little way down. It is the most difficult stock to work, and, in case of failure, room can seldom be found for a second attempt.

Occasionally the buds will "grow out," as it is termed, that is, start into growth and even give good blooms the same season that they are budded. There is no harm in this provided it has not been forced by the shortening of the wild growth. On the contrary, with hardy sorts it makes the establishment of the Rose-plant a matter of certainty. The shoot should be secured to a stake and not shortened, but pruned back very close in the following spring.

No further care will be required for the budded stocks, beyond removing the ties at the expiration of four weeks or a little less, till November. When the sap ceases to rise even in the most fleshy shoots, and the leaves begin to fall, all the wild giowth 
may be cut away-in standards, reserving one or two wild buds only on the worked shoots above the inserted bud, and cleanly removing all others which have been unsuccessful or umbudded, and on dwarfs cutting away the actual stem with all the wild growth upon it to within three or four inches of the bud.

The buds of Teas will, in many places, require protection during the winter, as described in Chapter IV. Some of the earliest buds may begin to grow even in March, and all, whether dormant or growing, will need constant examination during April to protect them from insect enemies, especially weevils and the black grub.

Some recommend the pinching closely back of those buds which start with only one shoot, to cause them to break again in two or more shoots. I used to find it necessary to "harden my heart" very much to perform this operation; and, when a sharp frost supervened one year and lilled nearly the whole of these mutilated buds, I gave it up completely, believing one shoot " in the hand (or at all events securely tied up) to be worth two in the bush." It is regularly done, however, in many large nurseries, even with the tenderest Teas; and I have taken to it again for the earliest buds, as a single shoot is a bad foundation for a good plant. Great care should be taken that the bud is not rubbed out of its socket, as it may easily be by a blow or even an unconscious touch, for then it will be ruined. The first pushing buds are those that should be operated on, and as pinching is rather hazardous for a novice, let those buds which have grown (say) $\frac{1}{4}$ of an inch be cut clean across by a pair of scissors, or 
by a sharp knife with a thumb-nail pressed against the other side of the bud, quite low down and close to the socket: in a week or two the small dormant buds which are always in existence on each side of a healthy one will begin to show, and the operation will be successful.

It is absolutely necessary that the growing shoot be tied to some support as soon as possible, and that care should be taken throughout the first season to see that it is really secure. Great caution should be used in making the first ties with a strong stiff shoot-the union is very insecure, and even a crack from bending too much, or a sudden jar, may ruin all in a moment. Never mind spoiling the shape or look of the plant; we may think of that next year. The union is not perfect, at least for some time, during the first season, and the shoot is generally top-heavy. The finer the growth, and the better the head formed, the more certain it is to be blown out if not securely tied. Nothing is more aggravating than to come out some morning in summer and find the whole thing blown clean out of the stock. The plant is absolutely destroyed, and all the time and labour from the first getting of the stock are simply thrown away.

It is best not to try to be economical in such a case, or when buds have failed, by budding on the same stock again. Fresh stocks are better in every way, and briar cuttings whose buds have failed will not form good dwarf standard stocks for the next year, though I have often tried them.

Bamboos are now the best stakes and supports, at all events of a temporary nature. Budded stocks of manetti, briar cuttings, and seedlings should 
have fairly strong bamboos, of length according to the growth expected of the Rose, driven firmly in beside them, and securely tied to the small portion of stem left of the cuttings, and to the root, if possible, of the seedlings. Without this tie, if the bamboo recives a blow or a push, the Rose shoot fastened to it may be pulled out. The stake should not be behind the stock, that is, on the opposite side to the bud, but beside or in front of it, for if the shoot is stiff and grows out at an angle there may be a difficulty in fastening it securely till it has grown some length.

Extra stout bamboos should be employed for standards, a foot or more, according to the variety budded, higher than the topmost bud. The same stake will thus support the stock and the growing shoot of the Rose. As soon as the bud has fairly started in the standard stocks, the small portion of the wild shoot remaining may be cut away with a clean sloping cut close to the bud. The reason for leaving it is, that it may sometimes be found useful in coaxing a bud to start, by letting a wild bud push for an inch or two, thus drawing a flow of sap, and if that does not answer stopping it back again.

These dormant buds that will not begin to grow are a great trial to the standard stock as well as to the patience of the cultivator. The strong roots, equal in balance to all the growth that was removed in November, lieep sending up full supplies of sap, and the plant will endeavour to get rid of it by making growth in every possible direction, above ground and below, except sometimes through the one tiny channel where it is desired. Such buds will occasionally start after all, in June or July, or: 
even the following year; but there is something amiss with them, and they are not likely to form good plants.

The principal thing to remember of the maiden growth of newly-budded plants is that no search for insects, remedies for mildew, or admiration of the glorious blooms should hinder the one care of tietie-tie, or all may be lost in a moment.

Grafting.-This mode of working the Rose upon another stock is so inferior to budding in many ways that it only survives because, with the aid of heated houses, it can be practised in the winter. A nurseryman, or any one who has the proper appliances, can thus increase his stock of any particular variety many fold in the middle of winter, and multiply the number of buds he will be able to use when the outdoor stocks are ready.

It is in this way that new Roses are so quickly propagated, but of course any other variety which has become scarce can be increascd in the same manner. Healthy young stocks not too large should be established in pots the year before for the purpose. They may be manetti or briar cuttings, but the manetti is best, from its ready rooting power, and its susceptibility and readiness to grow when exposed to heat. If the supply of stocks be short, suitable pieces of briar-root, taken from stocks where budding has failed, have often been found to answer the purpose well.

The operation is generally performed in January, when both stocks and scions are in a dormant condition. All available shoots of the Rose should be cut off and stuck into the ground somewhere where they will not be injured by frost or excited 
by heat, but kept in the winter sleep. The stocks, however, should be just a little forwarder, by having been brought into the house a short time before, not actually started, but ready to grow at once on the application of heat.

The method of grafting usually employed is the easiest and simplest-whip-grafting, which is an ordinary plain splice, such as a fisherman would make to bis broken rod. The stock is cut straight across with scissors an inch or two above the soil in the pot, and is then sliced up on one side only with a sharp knife to form the stock half of the splice.

For the scion only one bud is used. The shont is snipped into little bits, by cutting across as close as possible above each bud. This will leave, below each, an inch or more of wood, which should then be sliced up to form the other part of the splice. Stock and scion should be as nearly as possible of the same diameter, but it will not matter if the stock is somewhat the bigger of the two.

The essentials of grafting are:- that on one side at least the inner bark of stock and scion should exactly meet, that flow of sap in the stock should take place at once, and that air should be excluded till the scion has made some growth.

To meet the first of these necessary points is very important. Of course the two parts to be brought together will not fit exactly once in a hundred times, and the only care therefore should be that the scion should fit on one side of the stock and not be placed in the middle.

To prevent its slipping during the tying is rather a difficult task till one has seen "how it's done." 
Two or three turns of a thin bit of Raffia are first taken round the lower part of the sloping cut on the stock leaving the ends underneath. A third hand comes in very usefully here, and the operator generally utilises his mouth for the purpose. The end of the scion is thus held ready for putting into position under the tie, which is then tightened and finished by the hands.

It is not necessary to make the circles of the tie touch each other, nor are wax and clay used for keeping out the air. The pot is immediately placed in bottom heat in a frame which excludes the air, and it is most interesting to watch the callus or cambium growth forming between the two barks. The bud will probably start in about three weeks, and then air will be gradually given, and a high but even temperature maintained till the plant has grown sufficiently to be hardened by degrees and to stand exposure to an ordinary mild atmosphere.

The young growths will be very liable to "damp off," and the usual precautions against this catastrophe, of admitting air above, even in frosty weather when the heat must be increased, must be strictly attended to. Roses raised in this manner are not so good for planting out as budded ones, but are useful for providing buds for outdoor propagation, and nowadays good pot plants, especially of the climbing varieties, are established in this way.

Where there are no appliances of close frames with bottom heat, the operation must be deferred to a little later in the year, the stocks must be in a more forward condition, and grafting wax must be used to cover the whole of the operated parts closely, as is the case with fruit-trees grafted in the 
open air. French grafting wax which can be used cold is preferable to home-made material, but winter grafting can hardly be considered worth the trouble for amateurs, unless it be carried out on a large scale, and close frames with bottom heat in properly constructed houses can be provided.

Roses on thcir own Roots. - It is constantly being put forward as a new discovery that Roses, especially some varieties, may themselves be struck as cuttings, and will in time form fair plants and give decent blooms. "Why then," it is said, "take all this trouble about stocks and budding? You plant your cuttings in the autumn, in any quantity, as it is all wood that you will cut away at the spring pruning, and you thus get real genuine Rose bushes-Roses on their own roots, which cannot be killed by frost unless root and all perish together, and whose suckers are welcome as they are only increase to the Roses."

The simple answer to this is, that not only does it take longer thus to form plants which will give fair flowers, but that it is a fact that Roses on their own roots do not grow so well or flower so well as those which are budded on stronger rooting stocks. Nevertheless some varieties, especially of the free and hardy garden sorts, will answer in this way, and the best modes of striking the cuttings shall therefore be described.

The usual time for taking them is November. They should be prepared of as ripe wood as can be found of the current year's growth, about ten inches in length. The thorns had better be trimmed off, but none of the buds as all these will help if they grow. If a small portion of "heel " or older wood 
be left at the bottom, the likelihood of striling will be increased. If taken so early that the leaves yet remain, all should be removed save the two top ones, and in this case a good soaking with water should be given after the cuttings are set out.

They should be set deep, only two buds showing above the soil, in double rows as recommended for briar and manetti cuttings. It will be a great help to the emission of roots if the shoots rest firmly at the bottom upon some sharp sand or sifted cocoafibre dust. Attention must be paid to them, as to briar cuttings, after sharp frosts which lift the shoots in their holes. In the winter they may be gently pressed down again, but if thus raised by frost later when possibly roots may have formed, it will be better to tread the soil firmly round them. In the following antumn those that have made good growth may be moved, and planted shallower in their permanent quarters, and it will then be seen how poor are the roots in comparison to those of the stocks on which Roses are budded.

If this method of propagation is carried out during the summer, a close frame or at least a hand-glass is necessary. The cuttings need not be more than four inches long, and should consist of short-jointed wood with a heel to each. They should be syringed and kept close for a while, and much care will be requisite to prevent damping off. Bottom heat is a great help towards getting them on quickly, but all this is generally great waste of time and energy, as only a few of the hardiest, strongest, and commonest sorts will do well on their own roots, and these will root fairly as November cuttings.

Suckers and Layering.-The Scotch and Austrian 
Roses and some other sorts, when grown on their own roots, form suckers at some little way frorn the plant, and these when rooted may be cut off and transplanted to form plants elsewhere. A cut on the underside of the sucker beneath the ground will encourage the formation of roots.

Dwarf plants of any free-growing variety may be "layered." To perform this operation the shoot must be bent down so that it will touch the ground some little way from the tip. A small hole should be prepared here and filled with rooting material, such as leaf-mould, sand, and cocoa-fibre dust: the shoot should be cut halfway through and then longitudinally so as to form a tongue, and then pegged into and planted in this hole, when in due time roots will be produced and a new plant formed.

It is possible also to raise Roses from mere buds or eyes as vines, but letting the leaf remain. There are other methods of inducing the wood and buds of Rose shoots to put forth roots, but for the propagation of established sorts there is nothing to equal budding with winter grafting for the rapid multiplication of rare varieties.

Roses from Seed.-A chapter on propagation would be very incomplete without at least some reference to the raising of Roses from seed, the principal means by which new varieties are gained, and to the hybridising or crossing of special sorts which has been so successful of late years with some raisers. Unfortunately I can give no minute practical details, not having attempted it myself, and successful hybridiser's being naturally unwilling 
to part with the secrets of their craft. But something may be said on the matter, which may give an outline of the proceedings, and perhaps lead some amateurs to make experiments in such a fascinating pursuit.

It is hardly worth while to undertake it except on a somewhat large scale: only a very small proportion of the seedlings raised will be found worth anything at all, a good many coming single, and of those that are pretty good, ferv will be found to be any advance upon existing kinds. A great deal of patience will be required: it is sometimes as much as six years before a representative bloom can be got, and two or three years more at least, perhaps twice the time, may elapse before a good stock of the sort can be worked up.

Hybridising consists in preventing the pistil of a Rose being fertilised by its own stamens, and conveying to it the pollen from the stamens of another Rose. This is sometimes, perhaps often, done in the open by bees and other insects, and some means must be taken, by muslin bags or by working only under glass, to prevent their access to the blooms. When the stamens of the Rose to be crossed have been taken away, and the pistil is ready, the pollen is conveyed to it repeatedly for a day or two from the stamens of the other Rose by a small camel'shair pencil, and this pollen may be stored if necessary in a box in a diy place before the operation, which should be performed with great care on a dry and sunny day.

Both plants should, of course, always be liept in a thoroughly healthy condition, and as the ripening of the hep or seed pod will take about three months 
even in favourable weather, it is plain that the crossing should take place early in the season.

The seeds should be sown at once, when the pod is ripe, a point that may be judged from the bright red colour and general appearance of the Rose-fruit. They should be sown in pots in a compost of equal parts of loam, burnt earth, and sand, well-drained but pressed firm. About half an inch of sand should cover the seeds, which may be put about an inch apart. The pots should now be thoroughly watered and liept in a temperature of from $45^{\circ}$ to $55^{\circ}$; but, however managed, the seeds come up most irregularly, few germinating before the lapse of six weeks, and some taking as many months or even a year or two before they grow.

Even when they have come up, a good many will soon die though the utmost care be given them; and with anything like neglect of the strictest requirements of young plant life, wholesale destruction may be expected. The first opportunity should be seized, after they are pricked out and have commenced to grow, for budding or grafting them on manetti or briar stocks, for it is very difficult, especially for a novice, to estimate the value of the first bloom on the seedling plant itself.

If unwilling to experiment in hybridising, an amateur may still leave a few of his earliest Rose pods on the chance of their ripening, as many did in the hot season of 1893. If these be carefully sown, as described above, a rich prize may possibly be attained (though the number of blanks is astounding), for a large number of our best Roses were raised in past years by French nurserymen in this haphazard fashion. 


\section{CHAPTER IX}

\section{PESTS}

Is treating of Pests which injure Roses, it will be understood that I naturally refer only to those which are to be found in the British Isles: and perhaps even within those limits there may be some (though not many, I think) which have not come under my personal observation.

IxSECTS.-A large number of insects of different sorts are injurious to Roses and Rose plants, and I do not propose to treat of these entomologically but only from the Rosarian's point of view-what they are, what harm they do, and how to destroy them. As to what they are, which in ordinary scientific description would mean giving the generic and specific Latin names of each, my very slight investigations into the matter tend to show that this is no simple task, the specific and even generic names depending a good deal upon the authority studied and followed. However, a remembrance of the many Rose synonyms for the same flowers convinces me that it is not politic for Rosarians to find much fault in this direction; and in most cases what we want to know is how to keep the enemies off, and how to find them 
when present, and there will not, I think, be much trouble about their identification.

The keeping the plants in vigorous health is the first preventive measure, for it seems undoubted that aphides, the scale insect, and red spider show a partiality in their attacks for plants which are in a weak and sickly condition. Against all caterpillar and grub depredations, late pruning, after the plants have burst into leaf, is the only prevention that I know of: when this measure has been found necessary through the earliness of the season, a considerable diminution is found in caterpillar numbers; and it is plain that in such cases the parent insects have laid their eggs on the bursting buds at the top of the shoots, and that all have been happily swept away at the pruning.

I was surprised on first looking into the matter to find that most of the common caterpillars or grubs which haunt and injure the Rose are the larve of moths. We sometimes see a good many flies of different sorts and sizes about our Rose shoots on sunny days in April and NIay, but rarcly moths, though there may be, later on, several moth grubs on every plant. The reason of this would probably be that the parent moths visit the plants only at night or at all events in the dusk, and that they are mostly small, insignificant, fluttering insects of the most harmless appearance, and likely in general to be unnoticed.

Among the flies we may perhaps notice some active creatures, less than half an inch long, looking something like slender-bodied long-legged ants, with iridescent wings; these will be saw-flies, the parents of very hurtful grubs, and each one caught will 
probably save some trouble and loss. On the other hand some of the flies may be ichneumons, which lay their eggs in the bodies of caterpillars and therefore do good. But it is a safe rule to suspect all insect life; foes are numerous and friends are few, and the more free the Roses are from insects of any sort, the better they will be. Bear in mind, however, that, next to the aphis or green fly, certain small moths are the commonest enemies of Rose plants, and if any such innocent-looking flutterers be seen among them they should be hunted and destroyed.

Earliest in appearance among the moth larvæ is what is generally known as the black grub. This is "the worm $i$ ' the bud," the Rose grub par excellence, being the larva of a pretty and delicatelooking moth (Tortrix). It may be found in April or even earlier, the inserted buds on what are to be maiden standards being often infested, even before they have begun to grow. It is more like a fat brown maggot than a caterpillar, but has the power of spinning a thread with which it fastens the leaves together to form its concealment; and it can let itself down to the ground when disturbed, by a line which serves for a ladder on its return. A little experience of the proper appearance of healthy Rose foliage and of the twisted and folded leaves which betray the presence of this pest will suffice for its discovery on a developed shoot, but it is not always so easy to detect it on the precious first pushing bud of a maiden plant. As soon as there is any warmth in April, these dormant buds on Standard Stocks should be examined, at least every other day, with a magnifying glass, spectacles, or 


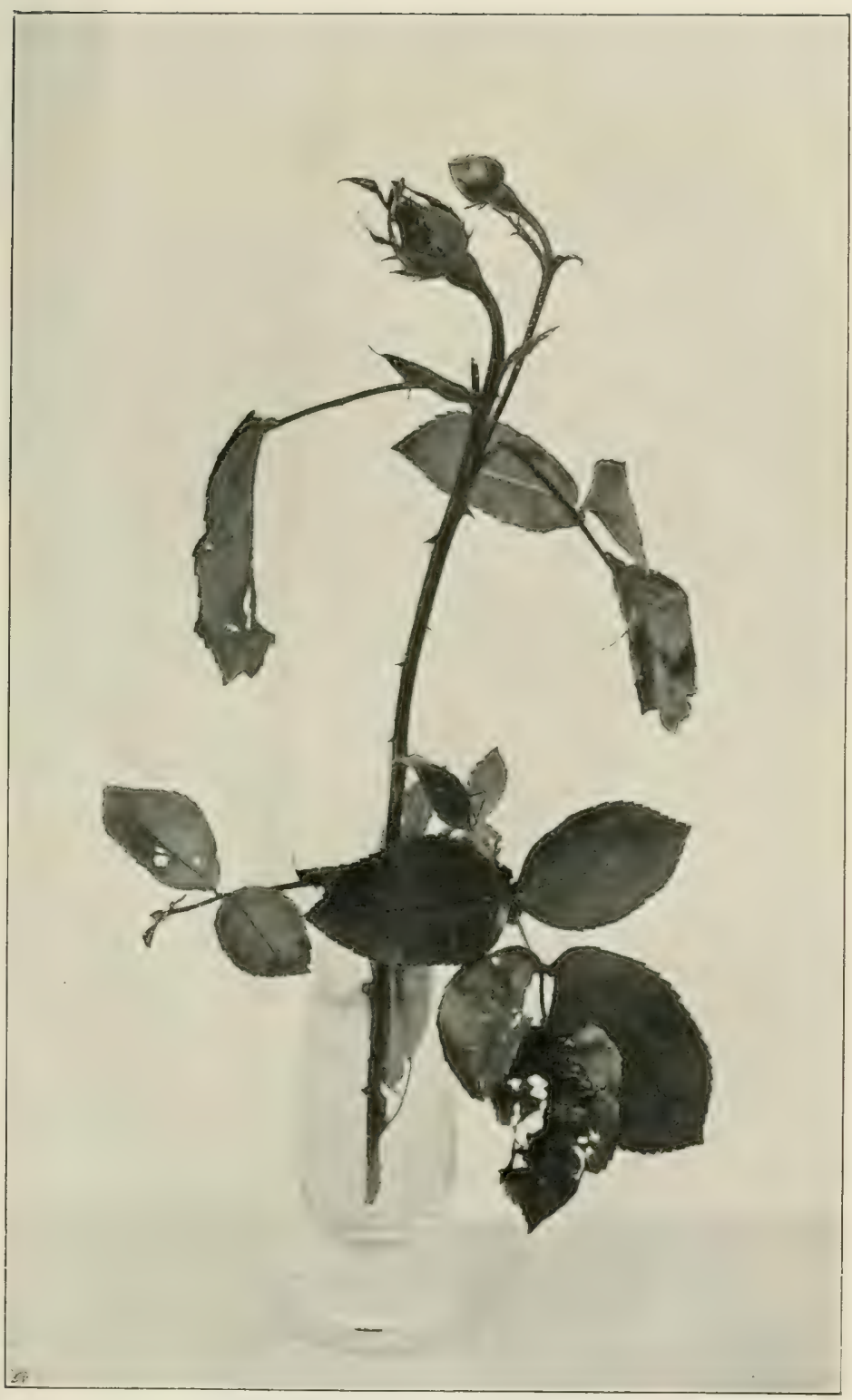

Caterpillar hiddex ox Rose Shoot.

[Face juere ]62.

The lower leaves have heen unrolled in rain, the creature having passed to the upper leaf, on the left, nearer to the Bud. 

pince-nez being best, for both hands will be required. Where a tiny heap of dust is seen upon the bud, the egg has been hatched, and the destroyer is within. I have found the point of an ordinary quill toothpick the most efficacious instrument for dislodging the intruder; it is quite sharp enough, and a pin is too rigid. Do not be afraid to probe right to the bottom of the bud till you have found and got out the tiny invader: for the main bud is already spoilt, and your hopes are shifted to the supernumerary side buds, which are always in existence and dormant, invisible. Having got out the grub, no harm will have been done, for you should have two shoots instead of one, the grub having forced you to the operation of "staving," as on p. 149.

Next in point of time, and continuing much later, is another moth larva, of the same group (Tortricina), and with the same sort of manners and customs. This is a dark green grub with a black head, and not so plump in body. It folds the leaves together in the same way, and generally acts in the same obnoxious manner; but it is more active, and has the power of running backwards as quickly as forwards, so that it will often escape and fall to the ground, where it lies quite still and is not easily found.

We shall now begin to find those larvæ of moths which are more generally called caterpillars. Most of these belong to the group of loopers, or geometers, i.e. earth measures, so called because the middle of the body, where there are no legs, is constantly being raised in a loop as the creature progresses. 
Many of the geometers do not fasten the leaves together, trusting to other means for concealment, but the commonest of all, at least in my garden, does do this. There are a great many species, but the habits and general appearance are much alike. They fasten the leaves together and hide between them and feed on the leaves, but always work towards the top of the shoot, and will attack the bud as soon as it is formed. It will be noticed that the caterpillar, if hatched as usual on the point of the growing shoot, keeps hold by a silken thread of each leaf as it unfolds, and is able at any time to leave its hiding place for a new one in a leaf spray higher up, and thus gradually to mount towards the bud.

By this means it also sometimes escapes; the distortion of the leaf spray it has just left is very conspicuous, but its new abode is most cleverly concealed, looking quite natural except that two leaves happen to touch back to back. A novice on unrolling the curled leaves would often come to the conclusion that the insect had escaped or been taken by a bird, but the experienced eye will always look upwards to the next leaf spray, and the experienced finger will always go there first, and not waste time on the decoy beneath. These caterpillars are often very abundant from the end of April to the beginning of June, and as they grow very fast they camnot be looked for too frequently.

Other geometer larvæ do not hide themselves or spin the leaves together, but trust to their colours and attitudes for concealment. A dark brown one (Phygalia) simulates the appearance of a dead stick, and another, of a lighter brown with a yellow 
stripe, imitates a dead leaf stalk. Their attitudes are stiff and motionless, and it is astonishing how easily the searching eye passes them over though they are comparatively large caterpillars. When one is found the appearance should be carefully noted that the eye may be trained to detect another and not be again deceived, for though not so common as the leaf-rollers one of these pests will soon destroy a bud.

The larvæ of a good many other moths occasionally feed on Rose plants, and in certain districts some may become locally special pests. The caterpillar of the gold-tailed moth (Aurifua), sometimes called the palmer worm, I have found occasionally devouring Rose leaves. This is a beautiful and highly coloured caterpillar, with bright tufts of hair; it feeds on the leaves of many sorts of trees, but I have most commonly found it on the havthorn.

The saw-flies (Tenthredinida) are so called from the shape and nature of their ovipositors, the instruments with which the females pierce the leaves or bark for the insertion of their eggs. There are several genera and species which feed on Rose plants, but I have found it impossible, with these as with the moths, to name them all. I was told by the late Rev. J. H. Hocking, who most kindly assisted me in the identification of insects, that there would be no room for Roses in my book if I were to attempt it. In my grounds there are two special saw-flies (Selandria), very distinct in habit, and perhaps including more than two species, which are particularly troublesome.

The presence of the first may be known by the singular appearance of the lower and older leaves 
of the plant, which seem to be semi-transparent in patches as if the colouring matter had been eaten away but the leaf not actually pierced. In such a case the upper and under sides of the leaves should be carefully examined, and good eyes will soon detect the culprits. These are small slug-like larvæ, tapering in width towards the tail, and exactly the colour of the leaves so that they are very readily overlooked. They are easily destroyed when found, as they make no attempt to escape, but as they do not appear till Midsummer, when eyes are naturally more occupied with the blooms, they often escape notice. As far as I have seen they always work gradually up from the lowest leaves, and I have never known them do any harm to the buds.

The other saw-fly is also late in its visitations, and fortunately not very common, as it is, I think, without exception the most destructive insect among Roses that I know. The female deposits her egg in the top of the strongest shoot she can find that has not yet formed a bud, and thereby absolutely prevents it from doing so, without any remedy that I can see. The grub when hatched bores straight down into the pith of the shoot for an inch or two; the leaves do not flag till the harm has taken place, and only a tiny black spot in the top of the shoot, which seems to have stopped growing, reveals the mischief that has been done. Cut off about an inch of the top of the stem and you will find it hollow; at the bottom of the excavation a fat maggot of a transparent white colour may be seen : and pray do not omit to execute summary justice, for it will be readily understood that this is a most 
dangerous insect whose presence cannot be detected till the shoot is ruined. Preventive measures consist in having all the shoots in bud fairly earlyin this point and in many others the early man has an advantage over his competitors. I only find this grub on the latest and strongest shoots, and fancy that when once the bud is formed it is safe from this pest's attacks. I have been told, however, by other Rosarians that with them it has attacked budbearing shoots; with me, it is quite common on the wild shoots of the standard stocks for budding that year-I sometimes find almost every shoot "stopped" by it-but decidedly uncommon on the Rose shoots close at hand.

Another boring grub, probably the larva of a beetle, does only incidental damage, as it confines its operations to old wood where a large shoot has been cut off at the pruning, exposing the pith. It is most injurious to standard stocks as it hollows out the pith at the top of the main stem sometimes right down to, or even below, the shoot wherein the bud is inserted, thereby leading to the settlement of water and consequent decay. It is best, to prevent this, to smear the cut-off ends of the standard stocks when planted with paint or some similar substance which will protect the pith. If, at the first pruning of the maiden standard, it is required to cut off the top part of the stock down to the newly formed Rose-head, this smearing should be renewed, as any freshly exposed pith is liable to attack.

Perhaps the best known of all insect pests of the Rose is the aphis or green fly (Aphis rosce). These creatures are formidable by their astonishing powers 
of increase, and it is only in multitudes that they do any harm. In their anxiety to obey the command to increase and multiply, the presence of males is postponed as a useless luxury till the season is nearly over. In the meantime each individual, as soon as full grown, which will be in favourable circumstances when about a week old, begins to produce young ones ready to commence juice-sucking at once, at the rate of dozens or so a day for weeks. In this manner it is said as many as seventeen generations may be produced before the males appear, and it is calculated that the descendants of a single aphis in one season might thus be reckoned by millions.

Strength, vigour, and cleanliness in the plants seem to be the best preventive measures. It may appear strange that vigour and health should lieep off an insect foe, which we should fancy would be naturally congregated where there was the greatest abundance of sap for food, but though they are to be found on healthy plants, it will, I think, be generally allowed that the weaker ones are the most attacked.

Destructive and remedial measures are many and various. Almost every insecticide known is advertised as destroying them; and no wonder, for they are delicate creatures with no power of escape, and are easily killed. The golden rule for all pestsattack the first symptons with immediate vigouris especially applicable in this case. A constant look out, and crushing every one as soon as seen, never leaving it till to-morrow, is the remedy for aphides.

Of all instruments and apparatus for the destroy- 
ing of pests there is nothing like the industrious finger and thumb, used in the earlier stages. When a zealous amateur discovers a few aphides and sends off at once to get and boil his quassia chips, according to the approved recipe, for elaborate operations on the morrow, while finger and thumb might have destroyed them all in a short time, I am always reminded of the story of the man who was vending some nostrum for the destruction of certain nameless parasites. When the "directions for use" of his specific were disclosed, it appeared that each creature had to be caught and a little of the powder inserted into its mouth, death following infallibly. The obvious objection to this invention was that when once the finger and thumb held the victim no more aid was required.

The aphis brush, deftly used, may take the place of actual fingers where the pest has attained some dimensions: and when, through neglect, or such a sudden and wholesale attack as sometimes occurs, wholesale means must be applied, a syringe and the quassia and soft soap mixture will probably prove the best resort.

The late Mr. B. R. Cant's directions for the use of this remedy are: "Talie 4 oz. of quassia chips and boil them ten minutes in a gallon of soft water; then strain it, and while cooling dissolve in it $4 \mathrm{oz}$. of soft soap: to this may be added another gallon or two of water." The plants should be syringed with this in the morning or evening, not in the sumshine, or badly infested shoots may be dipped in it. Pure water should follow the next day to cleanse the leaves and shoots. There are many insecticides advertised, which ought all to be good enough to 
destroy aphides at least: for they are easily killed, and are only formidable by their astonishing powers of increase. For pot plants under glass smoking with tobacco is the usual remedy, but the too much despised finger and thumb should check the pest at its first appearance.

Occasionally there is a visitation of winged swarms late in the season in such abundance as to be formidable from sheer multitude. Such an invasion occurred in Suffolk one autumn some years ago; it was like a miniature plague of locusts, for they literally covered the whole of the plants on which they alighted till it seemed as if there was not room for one more. With me they alighted principally on green peas, but at Colchester a good many Roses were injured and even killed outright. Syringing on a large scale with a powerful garden engine is the remedy in such a case.

It is pretty well known that ants frequent the shoots which are attacked by aphides for the purpose of feeding on the sweet juice which they secrete, called honey-dew. Entomologists tell us that the ants treat the aphides as their milch cows, and even convey them about to fresh shoots; and I once found a singular instance of this. Some poor briar cuttings had been planted in an odd corner of my garden, on the chance of their doing well enough to be worth budding. They did not turn out well enough and in consequence were neglected, but I noticed in the summer a few aphides on the shoots and that there were ants in the ground. The stocks were dug up to be thrown away in mid-winter, and I then found the aphides quite underground feeding on the roots, and attended by ants. It seems a fair 
inference that, on the approach of winter, the ants had carried the aphides underground for safety.

Ants in themselves are a pest, and should be looked on as such. I am doubtful whether they ever attack a Rose-bud unless it has been first pierced or scratched by another insect or some mischance. But they are readily attracted by the exuding sap from the smallest wound, and flock to the place in myriads, disbudding often offering them such a spot in an undesirable position. When once they have thus attacked a bud nothing short of finding and destroying the nest with boiling water will prevent their devouring the whole of it-even finger and thumb fail here because of the immense reserve force behind-and, as the bud is certainly spoiled, and it will take them some time to demolish it, I generally leave it for them to keep them out of other mischief. It is better though to watch all ants on the Rose beds, especially the black variety, to their nests, and destroy them there. I have tried a preparation called Formacicide, advertised as useful for their extermination, without much success.

Frog-hoppers, commonly known as "Cuckoo-spit," are very troublesome in May in some places. The larva, looking something like an aphis, is to be found in the little patch of froth which is generally situated in the axil of a leaf. He must be dislodged and crushed, for it is plain that all that froth is made somehow from stolen sap from the shoot. Be sure you have him, for he will dodge about and hide in the hollow of the leaf-stalk most cleverly, and will be quite satisfied if you wipe away the froth and leave him behind.

Earvigs only do serious harm in certain seasons. 
In 1888 their great numbers, even early in the year, were a serious nuisance in many ways to dwellers in the country, and but for the cold wet weather they would probably have developed into an actual plague. Somebody who came to see me was incredulous as to the number to be found in the Roses, so I picked two large old withering blooms and counted the occupants. I myself was astonished at the result: there were, oddly enough, twenty-nine earwigs in each Rose!

Bean stalks, or hollow lengths of last year's cowparsley stems laid on the ground or among the plants, are good traps for earwigs; they may be blown out the next morning into boiling water, but chickens will soon learn to pick them up very quickly and be the better for them; I always blow the contents of my stallis into my garden pool, and my pet trout take care that none escape.

It is difficult to realise that earwigs can fly, but in ejection from the stalks the wings, which are wonderfully folded, being nine times the size of the wing covers or cases, are sometimes blown out and can then be seen. A white earwig may be found occasionally, having just changed his skin. The female is said to sit upon her eggs; not of course that she helps to hatch them-she only remains with them to protect them from enemies, and will collect and shelter them and the young ones when scattered; I have found her coiled over her eggs in a little hollow part under the ground, once or twice. Unless in very large numbers, these creatures do but little harm to the Roses.

Certain Weevils (Otiorhynchus) are often in small collections a very destructive pest to newly budded 
Roses, especially standards. Anxiously each day in April the amateur watches the dormant buds of some new and precious sort to see if they are starting. At last he sees that something has been biting at the buds, but no trace of any insect is to be found. Day by day the damage increases till at last the buds, even every bit of inserted bark, are eaten clean out of the stock, and still no vestige of the enemy itself is to be seen. This is the work of that most malevolent pest, the weevil. There may be plenty of strong Rose plants close by, but he will touch none of them if there is a dormant inserted bud anywhere where there is a chance of destroying a whole future plant. It is just the same with fruittrees, as far as I have seen: I have never observed any injury to an established tree (possibly because it would not be noticeable), but a bud or graft is sure to be attaclied if there are any weevils of this sort about.

The reason they are not visible is because they only come out at night. Go with a lamp after dark to the infested places and you will soon find them, little brown beetles with long noses. I used to find the employment of a pretty strong pair of tweezers comforting to my feelings after many buds had been destroyed, but they will drop to the ground at a slight alarm and be most difficult to find. A white cloth spread under the Rose tree to catch them when they fall is a safe precaution.

Other weevils (Phyllobius), of the most brilliant green colour, may be found on the Rose shoots in the day time. The injury they inflict is but slight, but they should be destroyed, as they form a nuisance when present in large numbers. 
Thrips, well known as a pest on many plants under glass, are often very destructive in hot seasons on dry soil. These active, tiny, black insects cannot eat much, it is true, but as what they do eat is the petals of the Roses themselves they often just suffice to spoil an otherwise perfect bloom. In many places they seem to be hardly known as an out-door pest ; and I could scarcely get some friends to believe how much all my light-coloured Roses suffered in this way in rusty and disfigured petals till the year 1893, when owing to the drought the nuisance was more widely felt.

I am seriously inclined to think that for Teas, at all events in my garden, thrips are the worst of all pests. From two good rows of standard Teas in fine health and growth I gathered in 1893 but one decent bloom, the petals being terribly discoloured and even distorted in every other case, and each flower swarming with the enemy.

The remedy for thrips as for red spider is moisture; but unfortunately for Tea Roses the remedy is as bad as the disease. It is probably a good plan to syringe the plants, and the buds before they actually begin to open, with some good insecticide. Syringing, even with plain water, will undoubtedly keep off the thrips, and if continued as long as it is safe without injuring the petals from damp, the pest will not in most seasons be found in much strength. Constant damping of the soil under the blooms would probably be useful.

A species of upholsterer bee (Megachile) lines its nest with pieces cut out of the leaves of Rosetrees. These pieces are taken so evenly, neatly, and cleanly away from the sides of the leaf, generally in 
a semicircular form, that the work of this insect is readily distinguished from the depredations of caterpillars. It is not very common or occurring in large numbers, and usually attacks Roses of free and strong growth. Still, it has the habit of continually coming back to the same plant for its supply of upholstery, and may be found a pest in certain places. The bee may be easily caught in a butterfly net, or when laden can be traced to its nest, which can then be destroyed.

"Scale" insects (Aspidiotus) may often be found on the shoots of neglected wall-Roses. Finger and thumb or a solution of soft soap will soon remove them. Red spider (Tetranychus) is not likely to be found on Roses anywhere but under glass, and the remedy for this is a moister atmosphere. There are other insects which occasionally do damage to Roses, especially chance visitations of caterpillars which naturally prey upon other plants, but these cannot fairly be included among the pests of the Rose.

Protective Insects.-There are a few flies and grubs which actually do good by preying upon well-known pests, and thus acting as allies and friends of the Rose grower. It is important that these should be known, for it is well that we should be able to recognise and spare our assistants, though the enemy is in such overwhelming majority that the advice to suspect and destroy all insect life is common and even safest in cases where the friendly forms are unknown.

Ichneumon flies form one of the strange provisions of Nature for keeping in check the undue increase of insects. These flies lay their eggs in the 
egg's of moths and butterflies, or in, or on, the bodies of caterpillars and grubs, and thus destroy them. They are of all sizes, some very small, and of so many species that almost every insect has a parasite of this class specially belonging to it. On shoots where aphides have been some time, some may appear to have become solidified, and changed in colour to a light brown. These are aphides which have been pierced by tiny ichneumon flies, whose eggs have hatched in their interior: a magnifying glass will often show a hole in the body from which the new-born fly has emerged. These brown transmogrified aphides are therefore foes transformed into friends-an effort of Nature to assist the negligent Rosarian in dealing with the aphis host. There is no need to allude further to the ichneumon flies, for only the perfect insects are generally seen, and these are not likely to be destroyed, nor, as far as I know, capable of being increased.

The well-known lady-bird (Coccinclla) in its larva state feeds upon aphides, but I am bound to say that it is not common enough to do much good. You must have a lot of green fly before the prudent ladybird will lay her eggs on the shoot among them, and the careful Rosarian will hope to see nothing of one or the other. Still the shape of the larva, quite unlike that of a Rose-eating grub, and suggesting the perfect insect by its spots, should be noted, that this small family of friends may be saved from the general massacre.

A bee-like looking insect (Syrphus) also subsists in the grub state upon aphides. This creature is very apt to be summarily squashed as an enemy instead of being protected as a friend. It may be 
known by its shape, which is something like that of a leech, being widest at the tail and tapering gradually to almost a point at the head. It is blind, and resting on its hind parts sways about the head and neck groping for aphides and when it finds one holds it up in the air and devours it, leaving the skin behind. I have often seen and pointed out this larva to friends, that it may be recognised by its shape and escape destruction, for in size and colour-green with a light central stripe-it is much like one of the common caterpillars; but I would not advise that too much reliance be placed on the efforts of our blind ally, for aphides can only be kept completely under by sharp eyes and fingers industriously and constantly used.

A very beautiful lace-wing fly (Chrysopa, i.e., golden-eyed) also lays its eggs on a strange bunch of stalks among aphides, and the larvæ when hatched despatch them very quickly.

It will be seen, however, that all these insects naturally require the aphides to be present before the female will lay the eggs which are to produce the larvæ to destroy them. We want to exterminate the aphis, and this is necessarily not the object of the aphis-eaters, for in that case their food and occupation would be gone.

It is said that the Govermment of China pays a handsome salary to the court physician while the emperor is well, stops his pay when he is ill, and chops off his head when he dies. This extremely sensible system might, with the omission of the last clause, be applied with great advantage by farmers and other residents in the country to ratcatchers and other professional destroyers of vermin. Unfortu- 
nately we cannot make use of it in connection with the aphis-eaters, as they must perish if deprived of their usual food. So that, after all, the wholesale destruction of all insect life, though slightly irrational in that it destroys a few friends among innumerable foes, will do more good than harm to the Roses; and I am afraid it is better that a few friends should perish than that any enemies should be allowed to remain.

To take another analogy from vermin of the farm, there is one rat, most difficult to catch of all, for whose tail the farmer will willingly pay an extra price, and that is the last one. Naturally, perhaps, he is often left, and before long the nuisance is as bad as ever. As aphides are, during the summer, practically sexless in the matter of breeding, it is even more important in their case to get the last one on each shoot, and if finger and thumb or any such means are employed for their destruction the search should be thorough, and the same shoot should again be examined the next day.

Fungoid Pests.-Garden roses are subject to an unusual number of parasitical fungi, between thirty and forty having been enumerated. Happily two only are sufficiently prevalent among healthily grown plants to be worthy of description and warning, and these are mildew and orange fungus.

Mildew.-This is a pest indeed. Sometimes it appears in force all of a sudden in several places at once and spreads like a fire: the hoary leprous growth covers the leaves, checks the transpiration or breathing, and lowers more and more, as it increases, the vitality of the plants and the consequent spread of the roots. I gather from $\mathrm{Mr}$. 
Cranston's book on Rose culture, the first edition of which was published in 1855 , that it was not so prevalent at that time as it has since become. The greatly increased culture, and the introduction of varieties of weak constitution with soft spongy leaves, have probably been responsible for this.

It is an error to suppose that stout thick leaves are proof against mildew : if soft and succulent these are often the earliest attacked. It is the hard shiny well-glazed leaves upon which the mildew spores can find no footing; and Teas, whose leaves are rather more of this character, do not generally suffer much from mildew, except under glass, till late in the season.

Few indeed are the collections of Roses which now pass through a season without at least traces of this pest, though close and confined situations always suffer more than those which are open and exposed to free currents of the air. The amount of harm done will greatly depend upon the time when the mildew first makes its appearance. It is a bad look-out to see the first plague spots in June, for if war is to be waged it must be unceasing, as the enemy will constantly reappear when it has once shown itself. When well into July the buds will probably be sufficiently advanced to escape serious damage in themselves.

The life-history of the fungus, called Oidium leucoconium in its summer and Spharotheca pannosa in its winter condition, has been thoroughly investigated, a full and interesting paper on the subject having been published in the Rosarian's Year Book for 1886, by Mr. Worthington G. Smith. 
The spores or seed are set free from their winter resting places by the heat of early summer, and float in the air, some at least commencing to germinate and throw out roots even before they alight. Like other parasitical fungi-spores, a certain condition of the atmosphere and also of the leaves on which they fall is necessary for the actual development of the fungus growth; when these are present the first visible sign is a spot or curl on a young leaf, which is raised or depressed according as the mildew has attacked the upper or under surface.

It should be noticed, as an important thing to remember, that the mildew is always worst on the under side of the leaf, and is often found there alone. For this at once puts aside as useless the merely dredging the affected parts with sulphur, as this cannot touch the worst places; and it is evident that it must be puffed from below as well as from above, and that in all syringing with liquid the under surfaces of the leaves must have even more attention than the upper.

The first thing the mildew spore does when it begins to grow on the Rose-leaf, is to form the mycelium - the tiny white threads which are common to all fungus growth from mildew to the mushroom of the fields. This, when woven closely together in masses, forms the spawn, and then the white efflorescence is seen on the leaf.

The leaf breathes through pores on the under surface; these are choked by the woven mass of mildew spawn which also pierces the membranes and lives upon the juices. The leaf may thus be said to be suffocated and bled to death at the same time. 


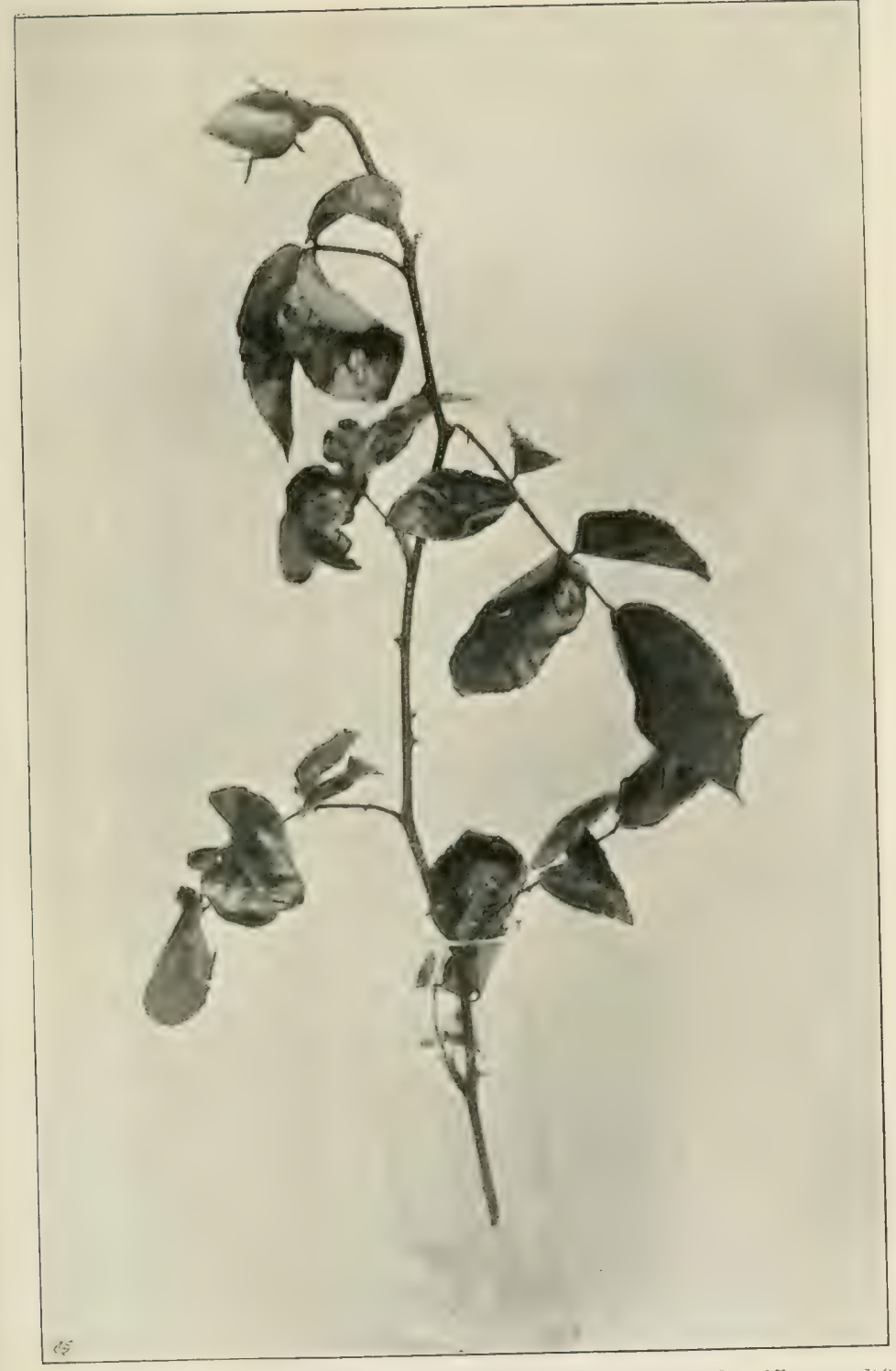

Munfw. The first sign, as seen in the eurl of the Leaf. [Fue preye 180 . 

At such a time-the first appearance-the time for checling a pest-I quite believe that, as in the case of aphides, there is nothing to beat the human finger and thumb. With them take a pinch of sulphur, and gently rub the affected part on both sides of the leaf. Sulphur is death to all fungoid life, but is rendered more efficacious if the mycelium is thus broken and wounded: just as there would be much difference between poison merely sprinkled on the human shin or rubbed into an open wound.

When the pest is advanced and whole plants covered with readily disturbed fresh spores have to be dealt with, one of the now advertised remedies, applied by spraying-pump or syringe, so adjusted as to reach the under as well as the upper sides of the foliage, must be employed. For the plant, so to speak, of the mildew very soon springs from the spawn, and fresh spores are ready in a wonderfully short time to be borne by the wind to other leaves.

On touching a shoot infected with mildew on the roof of a greenhouse or anywhere where there is plenty of light underneath, quite a little shower of dust or mildew seed may be seen to fall. Nothing need be feared from those that fall to the ground: they are very short-lived, and cannot stand much of heat or cold, dryness or moisture. Their strength is in their appalling numbers, and their chances of falling on another Rose leaf depend entirely upon currents of air.

With the first touch of cold weather in Autumn, mildew, as we know it in its summer form, disappear's and is seen no more that season, only dark unhealthy-looking marks on the shoots showing where the pest had spread from the leaves to the 
stems. In such places, and especially on the leaves which are now fallen, the mildew seeds have retired to rest for the winter, and no frost or cold, drought or moisture, can harm them.

These winter places of retreat are tiny black spots, only visible on the dying leaves by the aid of a magnifying glass, though a higher power of the microscope reveals them as round black receptacles or boxes, each containing eight spores. In these minute black spots on the leaves Rose mildew passes its winter sleep, unhurt by all that may befall, save fire or being buried deeply in the ground. The sun of the following summer will burst the walls of the cases, and set free the spores once more.

Collecting and destroying by fire the fallen leaves is thus plainly the only mode of prevention, which in most cases will probably be found impracticable, but even a partial carrying out of this plan should have some effect. It is impossible to say how far the spores may be carried by a strong wind, but probably many miles. An actual stamping out of the pest is therefore, I fear, beyond our reach.

Preventive measures consist first in the choice of an open situation: in a confined place the seeds floating in the wind are more apt to drop, or to be carried round and round till they do attach themselves to the leaves: where there is free passage for the air, the same wind that brings them will take most of them farther on, and only a few will find resting places.

Against harmful seeds brought by the wind, there are therefore two preventive measures : either absolute exclusion from any wind or even air, or entire 
exposure to all wind. After a snow-drift, the least snow will be found in the most exposed places: the most where the wind is checked or just on one side of its full force. A stream in flood brings down much light matter, and deposits it anywhere that it can reach, except just in the strongest current.

Draughts should be avoided: places where the wind comes round a corner or even through an open door are often the first to be attacked. And another point is just what we should recommend to a human body exposed to disease-germs: keep up the constitution and general health and hardiness as much as possible. Avoid drought by hoeing rather than watering if practicable: see to the food supply, and avoid unhealthy conditions.

Certain Roses are peculiarly susceptible to mildew, Her Majesty, for instance. It is a good plan to grow these among the Teas, or, better still, by themselves, where they will not, in the early part of the season, do so much harm by infection.

For remedial measures, keep the sharpest look-out when mid-June arrives, or even before, for the first spots. Search them out, and attack them all above and below with finger and thumb, powder distributor, or syringe. Sulphur alone is good enough, especially if accompanied by gentle abrasion of the mycelium, if it reaches every part, the under as well as the upper side of the leaves, for it is, I believe, the destroying agent, whatever mixture or specific is used.

For Roses under glass preventive measures will consist of great care in the ventilation. One year, by way of experiment, I never opened the ventilators at all for my Maréchal Niel, and it bloomed 
extremely well. Better no air at all than a cold draught when the sun is hot, I am sure. Sulphur upon the hot-water pipes is the well-known remedy, and for pot Roses I should use finger and thumb with sulphur or sulphur solution.

Orange Fungus or Red Rust.-This fungus-pest is not so well known or so harmful as mildew; but it is more difficult to combat, either by preventive or remedial measures, for its growth is inside the leaves and stems of the Rose, and it is only when the spores are ready for dissemination, and scatter with a touch, that it bursts the membranes of the Rose plant and appears outside.

The life-history of this fungus, known as Coleosporium pingue and several other names according to its different stages, is much the same as that of Rose-mildew. Orange fungus has, too, the resting stage of winter in small but visible black spots on the fallen leaves, the woven mass of mycelium of spring in the leaves or leaf-stalks attacked, and the summer spores which proceed from it.

It can be recognised at once ly its colour, which in the spring is a purple spot with a concave yellow centre on the upper part of the leaf and a convex bright orange spot underneath, sometimes red at midsummer, changing to simple black spots on the leaves, which fall quite early in August. In my own garden I see very little of the yellow or orange stages, but plenty of the last one.

A considerable point in favour of this pest is that it very rarely makes its presence disagreeably and harmfully felt till the first bloom, the "season " of exhibitors is over. August is the month of its power, and at that time whole rows of Roses of 
certain sorts may be sometimes seen standing leafless except for just a tuft of the youngest foliage at the top. All the other leaves, covered with the black spots, have withered and fallen, as if it was winter.

The Victor Verdier race are the most liable to suffer in this way, and in fact are generally badly off for leaves by the end of August, but a great many other H.P.s are often victims, especially the very dark ones, and all that are budded on manetti. Teas are entirely exempt from it, and it is rare under glass.

Partly from the fact that the first and principal bloom is not affected by it, and that it does not seem to do much harm to the next year's growth, and partly because there appears to be no remedy short of cutting off the attacked shoots and burning them, this pest is very little heeded by nurserymen or even by amateurs, and I confess I take no notice of it and have never found it to do my summer blooms any practical injury.

It is plain, however, that the loss of the leaves, in what is but little past the middle of summer, must be a considerable check to the plants, and as the growth of the fungus is within the membranes of the Rose plant there seems to be actually no remedy short of cutting off the orange-spotted leaves and shoots in early summer and buming them; but I think gentle rubbing with finger and thumb with a pinch of sulphur is likely to do good in the early stages.

On light soils, especially those rich in humus or vegetable matter, like an old garden, the attacks are less frequent. They are worst in a dry hot Angust on heavy lands which have not had much 
farmyard manure. It would be almost impossible to stamp out the fungus, as it is much more frequent than mildew on the wild briar. The Dog-Rose in fact seems to be its natural host, though it is sometimes found on other plants. Manetti stocks themselves are rarely troubled with it, though it often comes first on the Roses budded on it, but seedling briars often suffer much and are seriously crippled by its attacks.

I can suggest no other remedies than finger and thumb or cutting off and burning in the early stages, and diligent hoeing, with watering if necessary, in early August. Exhibitors, whose season is over by mid-July, are rather apt to neglect the hoeing and general culture when the important operation of budding is in full swing. As no real remedy is known for the red rust, and little if any practical damage is done by it to the blooms, it is not to be wondered at that it is often unheeded as a minor and necessary evil.

It seems best to speak here of Suckers, which are a pest at all times, especially in the growing season, when we are on the look-out for enemies. They are most common from standards, especially tall ones which are insecurely staked these latter, when pressed by the winds, naturally throw out suckers to support themselves-a shoot goes out from the underground stem for a foot or so, then grows up and in due course sends a little root down, which forms an anchor for the original stem-two or three more on the opposite sides, and the plant is held firm and cannot be rocked by the wind.

The wild stock will, bowever, often form suckers 
on well-staked standards and on dwarfs, particularly if the Rose be weakly, and underground buds on the stock were not originally extirpated. A keen look-out should be given to all plants on manetti, as only an eye well accustomed to the appearance of the growth of this stock will distinguish it from the Rose, and many a gardener has hopefully pruned great bushes of manetti for years, wondering at the absence of bloom, and ignorant that the Rose itself bas been starved and killed outright.

The usual way of removing suckers ("succouring" your plant which is being robbed) is by the aid of a spud, cutting them off as close to the main underground stem as possible. This course must be pursued with any that had started the year before or that do not prove amenable to other treatment. But there is some risk in doing this of cutting or injuring useful roots, and even a small bit of sucker left will often start afresh; so, to make a really good job of it, it is advisable where possible to make a way carefully with the spud down to the place where the sucker starts from the underground stem, and there cut it off with a sharp knife, being mindful of the sides, which are sure to start again, unless shaved level and smooth.

The best plan, as with all pests, is to take the suckers in time as soon as ever they are seen, and then, not to cut them, but to pull them out. This can be done with practice in most cases, and when done it is thoroughly effectual: the sucker comes clean away right out of the socket, and grows no more. It requires humouring, and testing, and 
CHAP.

trying first this way, then that, now up and now down.

When the great red shoot pushes up through the soil, plump and gross and brittle like a head of asparagus, lift it and handle it gently - " treat him as though you loved him," as Isaac Walton said of the worm to be threaded on the hook-try to find out the angle at which it grows from the stem, and then, grasping it as low down as possible, pull so that the strain comes on the very socket, and it will generally yield. If it breaks, the spud and knife must complete the operation.

In the anxious month of May, among the multitude of pests nothing is worse than a sharp frost, which is very harmful, and does more injury by distortion of the just-formed buds than is ever imagined at the time. Happily, such a visitation as that of May 21st, 1894, coming as it did after an unusually early and forward spring, is not common, at all events in the Midland and Home Counties, and it is to be hoped that it will be long before we have such another.

Preventive means are possible, at all events in small collections. A little weather knowledge, with a careful study of the thermometer, will generally give warning of the approaching calamity before sunset, and if the danger is great all hands should be roused and encouraged to noble efforts, even though the work must be continued by lamp-light well into the night.

The first thing to remember is that the greatest danger is to those buds that are just formed, hardly visible; forwarder buds that have got hard will stand 
some frost without injury, and shoots where the bud is not yet formed, even though apparently crippled at the time, will often eventually grow through it and completely recover.

Protecting material must evidently be very light, as there will be little time to spare for driving stakes into the ground to support it above the highest shoots. Anything in the shape of light muslin or similar material should be hunted out and spread as gently as possible over the plants; bent shoots can easily be straightened again, but of course care must be taken that they are not cracked or broken. The frost is not likely to be dangerous at that time of the year if there is wind, as that will probably bring cloud, the best and safest of all coverings; so even old newspapers or any large sheets of thin paper may be made useful in such cases.

For remedial measures, when serious May frost has come and caught us unprotected, I would recommend, first and foremost, patience. Touch nothing at first: no one can tell for some little time, till the sun has shone warmly on the plants, how much or how little damage has been done. Then it may be plain perhaps that some shoots, utterly blackened and shrivelled at the tips, are done for; but still I would advise the removal of nothing till such time as fresh growth has commenced.

The soil should be well stirred, and a little nitrate or some other stimulant applied; this will hasten the renewal of growth, and we shall then see which of the shoots that had not formed buds have been actually "stopped." Those that grow straight away again as before from the tip of the shoot are all right. Never mind some leaves having been destroyed; the 
shoots are young and they will "grow out" of the injury, just as a child will from a severe wound or accident. Those that are stopped, and commence growth again from the side buds, are not likely to produce exhibition blooms that year; but it is better to let the top bud grow and pinch out all the others, if most of the shoots on the plant are in the same condition, than to cut them all away or severely back, as that must involve a severe check to the roots and the strength of the plant.

I am sure it is a mistake to cut away the shoots in a hurry before fresh growth has shown how far the injury has extended. It is better to put up with browned and maimed foliage for a while than to risk destroying a shoot that may yet recover. It is always sad to suffer from not having "let well alone." A friend of mine had a fine Wellingtonia, of which he was justly proud, growing near his house. One year, to his disgust, he found that it had developed two leaders; he naturally wished to cut one of them away, but the tree was very tall, and too pliable and slender at the top to bear the weight of a ladder. He was (and is) a capital shot with rifle or gun; and having an air-gun that threw a bullet accurately, he determined to try to cut off the offending shoot with it. He rested his weapon on the sill of an upper window, took a very careful aim, and with the first shot succeeded in doing what he wanted-the false leader was cut off. Much pleased, he now noticed there was another shoot that had somewhat of an upward tendency, and would be better removed-he fired at that, with perhaps less care than before, and by a cruel mischance actually cut off the sole remaining leader! 
To find out for certain what buds have been injured by the frost will take more time and patience. By no means remove them in a hurry; some will soon be seen to become a paler green with white unhealthy-looking blotches on them. One or two of the worst of these might be cut open, and if the rudimentary petals are brown, the bud is rotten and would soon drop off of its own accord. Others may be tested by pinching, when the points of some will be found soft and hollow; these are of no use. Gradually thin and disbud them: take off no side buds till you have settled whether the crown bud is worth leaving or which of the others is the best; or, remove only the worst at each time of inspection till there are only two between which to choose. The lower side buds of Teas, if the parts above them are removed, will often make a good bit of growth, and practically become the main stem. Above all, remember, after a severe May frost, that the power of recuperation in the main shoots of a Rose, while they are yet soft, young and growing, is very great indeed; but nevertheless it must be confessed that no embryo bud which is in existence during a frost that injures the leaves is likely to come to any good. 


\section{CHAPTER X}

\section{ROSES UNDER GLASS}

THIs is a large subject, capable of being treated at considerable length, for if there is so much to be said upon the growing of Roses out of doors under natural conditions, even more care, skill, and experience are required for their cultivation under artificial circumstances, and at unnatural seasons. There would, however, I think, be no need for such a treatise in this book, even if I were capable of compiling it. Professional Rosarians and skilled gardeners have nothing to learn from me in this matter. I write for the genuine amateur Rose grower and Rose lover who takes a warm personal interest in his favourite flowers. If he be wealthy enough to grow and force them on a large scale he will no doubt employ a man who has learned the art under more able guidance than mine; but for others I hope to give some general principles and outlines of routine which should help those who wish to make " a bit of glass" useful in the cultivation of the Rose.

The glass-house for Roses, whether it be merely a "pit" or "lean-to," or a more ambitious structure, should run lengthways north and south, so as to 
catch the sun in the morning and afternoon, and not suffer from excess of heat in the middle of the day. I do not propose to enter into any details of structure; but in a cool house, especially if the Roses are planted in the soil and not grown in pots, it is advantageous that the whole of the roof should be removable during the summer, when canvas may be substituted for the glass for a short time if necessary till the plants are hardened to exposure; and in all cases the ventilation should be principally at the top, and means should be provided in tanks and troughs on the hot-water pipes for the evaporation of moisture within the house. For early forcing a pit is best, because the plants can be placed nearer the glass and the light, and the pots may be so arranged that they can be lowered to keep them the proper distance from the glass as they grow higher. Something in the nature of an outside blind, which can be pulled up under a ridge on the roof, is a very desirable adjunct to a house where Roses are grown after the sun has attained its summer strength.

The simplest form of Rose culture under glass will consist of standards or dwarfs, planted in beds in a cool house where the roof, and indeed as much as possible of the structure, can be entirely removed by the middle of June. The plants will then be subject to natural conditions and treated in the usual manner till about the middle of October, when the roof may be entirely replaced, but plenty of air may still be given on fine days. Many late buds thus sheltered from the damp which would have destroyed them in the open may be preserved in this way, and some of the thin and free-flowering Teas may continue to produce a valuable bloom or two up to 
nearly Christmas. The formation of these late buds may be promoted by removing all flower buds in the summer, till the end of August.

In a cool house like this nothing but protection is aimed at, but that is quite sufficient to make the plants bloom much earlier than they would in the open air. They should not be pruned before January, if there are no means of lieeping the frost out in severe weather, and in the meanwhile the soil should be cultivated and cared for in the usual manner. As soon as the plants commence growing, however, they will require a good deal of attention, and some at least of the many troubles of growing Roses under glass will be experienced.

Grvery outdoor pest has also to be contended agrainst under glass, and mildew, red spider, aphides, and thrips are even more troublesome than in the open. One of the greatest difficulties is the maintaining just the right amount of moisture in the air. If there be too much, mildew will probably show itself, and may soon make terrible havoc, the tender leaves being much less able to resist it than the hard foliage of outdoor Roses, at midsummer. Incautious ventilation, to $\mathrm{dr}^{2} \mathrm{y}$ the air, will probably increase the evil, unless the weather outside be very mild. If, on the other hand, there be a lack of due moisture, red spider and thrips are sure to appear, and may do as much damage as the mildew. To hold the scales evenly in this matter of moisture is one of the most important points of successful culture under glass, and it seems difficult to frame any special rules on the subject save those that are founded on experience, with a knowledge of the dangers on either hand. The uninitiated would 
probably err in keeping the plants in pots too dry. Syringing them three times a day seems a strong measure and likely to lead to the danger of mildew, but it is practised by some of the best growers during April and May. We are apt to forget, perhaps, that out of doors, in the spring months at least, the air, earth, and foliage are almost always very damp at night from dew, which much refreshes the foliage.

Insect pests of all kinds, and especially aphides, will come whether the house be damp or dry. Prevention is better than cure, and sharp eyes constantly looking for the first aphis, assisted by ready fingers to catch and destroy it at once, form the best protection. I remember, on going through a large range of glass-houses where different flowers, not Koses, were grown, hearing a boy who was cvidently employed there addressed as "Mealy." On inquiring whether that was really his name or only a sobriquet, I was informed that it was his sole business to go over all the houses from end to end and look for "mealy bug." There had been a great visitation of this pest, which is very difficult to exterminate, and constantly reappears; but the boy's eye became by training and sole use so sharp at its detection, that the houses were quite clear of it before long, and "Mealy" got a change of occupation, and I hope of name.

A determination that no aphis shall be seen is a saving of trouble in the end, but there are now safe and effectual insecticides which may be used in spraying and syringing without the disagreeable and dangerous fumigation with tobacco. But in such cases it should be remembered that one or two of 
the enemy are sure to have escaped: a close examination the next day is necessary, and often a second application may be desirable.

When the blooms are just ready to open we may take a hint from Nature, and, remembering that Roses in the open, especially H.P.s, are far better when a dull cooler day follows after some hot weather, endeavour to shade the plants from the full sun, and keep them, if possible, a little cooler. If a light blind be used, or the glass roof be syringed on the outside with a mixture of whiting and milk, or some similar clouding material, the flowers will be brighter, more lasting, and altogether of better quality.

Ventilation is a most important matter in all forms of Rose cultivation under glass : the foliage is very tender, and a cold draught is almost sure to bring on mildew. It is far better to give no air at all than to open the ventilators to an icy wind. Still, Roses must have air, and there will be few days when it cannot be admitted on the lee side for an hour or even less. Where the plants are grown in beds in a cool house, air should be given as often as possible, and in increased quantities as the season progresses: the final removing of the roof or top lights, after the plants have bloomed once, should be arrived at by gradual and easy stages, so that as little check as possible may be felt when all covering is taken away.

As an early second crop of flowers may be expected, and a third from some of the freest sorts, especially of Teas, it is necessary that the feeding and cultivation of the soil should not be forgotten, or the plants neglected because the outdoor Roses claim so much attention. Some of the weaker shoots may be 
thinned ont after the first blooming, but there should be no pruning except in the winter or early spring, for one of the most prominent objects in view is to have strong dormant buds on well-ripened shoots, to prune back to in the winter and to rely upon for the production of good vigorous growth for the next season.

If the plants grown in the cool house be in pots, they should either be planted out in the open ground about the second week in June, or plunged in coal ashes and mulched with good decomposed manure in an open airy place sheltered from strong winds, where the shoots, slightly thinned, may ripen and mature. In either case, they should be re-potted about October, the crocks being removed, and also as much of the surface soil as possible without disturbing the bulk of the roots. The compost generally used is two-thirds of fibrous but strong loam with one-third of thoroughly decomposed, old, cow manure. For the Teas, a little sharp grit and leaf mould may be added.

Roses, if well taken care of, get used to a pot life whether forced or more naturally treated. They will get accustomed to an early spring growth, and will rest and ripen in the autumn as if it was really their winter. They should however be kept rather dry at that time to help the ripening and check undesirable growth. After re-potting, they will of course require watering and attention, that the roots may spread in the fresh material provided. By November the pots may be taken into the cool house, for pruning in January, and to be ready for a warmer house to be forced.

In forcing Roses, it should be remembered, as 
Mr. William Paul so well explains in The Rose Garden, that we change all the seasons for the plants under our care. We make winter spring, spring summer, and summer autumn, and we must make autumn like winter, in that it shall be a season of rest. In making artificial seasons we must see that they come gradually as they do in Nature, and when we commence to start the plants about the New Year, we must remember that spring nights are cold, and spring days are not very warm, so that a temperature of from $45^{\circ}$ to $50^{\circ}$, or $55^{\circ}$ from sunheat, by day, and $38^{\circ}$ to $40^{\circ}$ or a very little more by night, will be quite high enough for a beginning.

A commencement should be made with plants purchased in pots and specially prepared for forcing, for without the education of an autumnal rest they will not break and grow strongly in midwinter. Several firms make a speciality of this branch of the business. The plants used generally to be grown on their own root, but H.P.s on the manetti and Teas on the briar is now the usual practice. If the pots have holes at the bottom of the sides it will facilitate giving liquid manure when necessary by plunging, but the embedding them in the house pretty deeply in cocoa fibre or some similar material is not now generally recommended.

The plants should be pruned rather closely to well-ripened outlooking buds, and the first year, while they are young, only a few shoots well apart from each other should be allowed to grow. It is most important that there should not be too much heat at first, and that it should very gradually rise with the increase of light. Even when the buds are well formed and soon about to open, the artificial 
temperature should not exceed $75^{\circ}$ by day and $50^{\circ}$ at night. A further slight rise from sun heat will do no harm, nor a small decrease when the weather outside is very dull and cold.

Next to temperature, the most important part is moisture. The aim should be to lieep the plants and atmosphere sufficiently damp by syringing and wetting of exposed surfaces in bright weather to avoid red spider and thrips, and yet not so damp as to bring on mildew; two syringings a day may be taken as a general rule, three in dry hot sunshine as the season advances, and in very dull damp weather only one. Some fresh air is most desirable; if the weather be at all mild, the top ventilators may be opened a little, but not on the windward side and only for a short time-mind they are not forgotten ; and do not open the house at all to let in a wind which is really cold, or in frost or fog. Watch for all insects, especially aphis-try how soon you can get the first one, and perhaps it will also be the last.

Clear liquid manure may occasionally be used for the feeding; as the plants increase in vigour, do not make the food stronger, but give it gradually a little oftener, with always pure rain-water, which should never be below the temperature of the house, between each dose. Very strong ammoniacal liquid manure is kept by some growers in troughs on the hot-water pipes, and it is generally believed that the plants benefit through their leaves from the gases thus diffused in the air.

For a succession, the simplest plan is to bring in fresh plants during the first few weeks, if there is only one house. As the Tea Roses, and those that are sensitive to wet, begin to show the petals, some 
care should be taken to avoid syringing the blooms, but the house must by no means be allowed to become dry; the paths and walls should be damped three times a day in sunny weather at 8 A.M., noon, and 5.30 P.M. ; and there should be at least an hour or two every day, at the time the buds show colour, when air can be given. If there is also a cool house, those plants, especially the H.P.s, which are nearly opening their blooms, will show better and more lasting flowers if they can be removed to it, or at all events shaded from bright sun. A slight fall of temperature and a little less light are always beneficial for the actual blooming, but of course the decrease of heat should not be great.

There is considerable danger in over-watering forced Roses in pots when the growth is young and the flower buds are forming, for "damping off" is even a worse misfortune than mildew. Tapping the pots with a knob-stick or something similar, to judge by the sound whether it be wet or dry, is a well-known device, similar to that of the wheel-testers on railways. A clear sharp sound indicates dryness and soundness, and a duller one damp or fracture.

After blooming, summer-flowering Roses, if any such have been forced, may be removed at once to a cool pit or some other shelter and hardened off; the others may be shifted to a cool house, and will give another useful crop of flowers in April and May. If there be no other house, and warmth is still desired to be kept up in the forcing house, some means must be resorted to for gradually hardening the plants off till they can be finally removed out of doors. Then, instead of all trouble being over with the pot plants for the year, comes as important a time as any, for 
next year's growth and flowers will depend very much upon the strengthening, maturing, and ripening without breaking, of the dormant buds at the base of the shoots which have flowered.

The pots should be plunged out of doors in cocoa fibre or some similar material with a bottom of coal ashes, and a top dressing in each pot of good decomposed manure, in a sheltered position, but where they will get some sun: and here they should be kept thoroughly clean and be by no means neglected, but encouraged as much as possible gradually to get into a condition of rest, not growing much, but ripening and hardening the wood. They must be frequently examined for aphides, and should have only sufficient water to keep them in health, not so much as to encourage them to grow. If they have already bloomed twice, or in any case if it does not excite the dormant buds lower down, flower buds should be picked off.

About the end of September or the beginning of October they should be re-potted: they must be turned out of the old pots, the crocks or charcoal drainage removed, and also as much of the surface soil as can be got away without disturbing the main ball of roots. Thoroughly clean pots should be provided, a size larger than before if necessary, and the loam in the new compost should be as fresh as possible, that from an old pasture being the best. The new drainage, whether crocks or charcoal, and everything else, should be fresh, clean and sweet the plants potted very firmly, and then plunged afresh in a similar position out of doors. They will require a little more water after the potting, but if the operation has been delayed till the season men- 
tioned, though many fresh roots will form in the new soil, no growth will be made except at the tips of the shoots, where it will do no harm. The pots may be removed to some cool shelter where there is danger of frost or snow, and about Christmas the earliest plants may be pruned and brought into the forcing house for another season.

To have Roses in bloom in November and December the plants in pots should be so managed and arranged as to form a crop of flower-buds out of doors in October. Thin-petalled, readily opening sorts should be chosen, especially the free-flowering thin Teas, such as Safrano; but some of the freest, semi-double H.P.s will also answer the purpose. These should be lightly pruned about August, and supplied with more water: when the buds have formed in October the plants should be left outside as long as possible, and when brought into the house ought to be liept quite cool, giving plenty of air whenever it is mild enough. Keep the house rather dry, and the buds will open at any time by the application of a little gentle heat, or even without it.

Few, if any, growers nowadays care for the trouble that must be incurred to produce the wonderful specimen pot plants which used to be exhibited in May by some of the professional growers. These were generally summer Roses, Charles Larvson, H.C., being a favourite variety for the purpose, as this group has the habit of bringing the majority of its flowers to perfection at the same time. Such a pot plant, eight feet high, seven feet through, and with between 300 and 400 expanded full-sized blooms upon it at the same time, was a 
grand sight; but an immense amount of labour, care, and time was expended to bring about such an astonishing result. There is no real dificulty in the matter, as the summer Roses grow freely after the bloom is over, and patience and care for several years in disbudding and tying out the required shoots at the proper distances from each other is all that is required. I have been told it would often take a man three days to tie out and wire one of these big plants. The lower shoots were given sufficient lateral direction by long ties fastened to wire surrounding the pot; and these were pruned first to give them a start over the central upright shoots, which would otherwise get more than their share of the sap. A pyramid or cone was the usual shape aimed at, but sorts of short stiff growth were sometimes trained in globular form.

For the pruning and training of Marechal Niel and other similar climbing Roses under glass, see Chap. VI (p. 108). In this case, if the roots run in the outside border, little or no syringing will be required, and as a consequence there will be less necessity for fresh air in cold weather. 


\section{CHAPTER XI}

\section{EXHIBITING}

THE instructions hitherto given have been meant to show how to grow Roses in the best possible manner, so as to produce the finest blooms. There are probably few who will go thus thoroughly into the matter without desiring sooner or later to put their care and labour to the test by showing, in friendly rivalry, against their brother Rosarians. The true Rose lover may perhaps enjoy and appreciate all the winter and spring work simply from his personal devotion to the Queen of Flowers. But if he visits Rose shows he will soon be anxious, I think, to get an important judgment upon his own blooms, and see what rank his much-cared-for plants can take in the world of Roses.

We may perhaps hear a man say, "Oh! I don't exhibit, but I can assure you I cut some very good Roses from plants under such and such a treatment (perhaps from plants on their own roots, from cuttings). In such a case, without throwing the smallest doubt upon his veracity or bona fides, we are apt to wonder what he considers "very good" Roses, and unless his blooms have been seen by a 
competent and impartial judge, or better still, actually tested at a show, the assertion loses weight, as his standard of excellence may be a low one.

It is odd to notice how generally those Rose lovers who do not exhibit are set against Rose shows, and have hardly a good word to say for them. According to these critics the least lovely of Roses are most shown and encouraged, the manner of exhibition is faulty, the grace and beauty of the flowers are lost and the public taste is generally led astray. Even the accusation of ignorance is sometimes laid at the doors of men who have made the Rose the study of their lives, though such a charge naturally defeats itself.

It is not unlikely that some good has been done to the Rose and to Rose-showing by such critics. Any cause is purified and strengthened by a little healthy opposition: there may be a grain of truth here and there in the sweeping charges made, and there is no doubt that a mania for exhibition does sometimes tend to the destruction of good useful types, and to the setting up of unnatural and undesirable ideals.

It is, perhaps, owing to a reaction against show Roses of approved form that there has been of late a good deal of interest taken in what are called "garden" Roses. These were originally old varieties, superseded as florist's flowers, but still cherished by some from sentiment and love of the old-fashioned, or memories of childhood.

An immense number of new Roses are put forth every year, and those few only survive which stand the test and prove superior in comparison with existing varieties. A very small proportion indeed of those thus failing in the struggle for existence are 
retained as garden Roses, only those which in colour, habit, growth, or freedom of bloom are superior or very different from those already known. Yet most of the modern failures are probably much better than the old-fashioned garden Roses which still have their worshippers, thus proving that sentiment and affection rather than merit cause them to be still recognised.

This is very likely as it should be : it is well to see those old Roses of forty years ago, if only to realise and be thankful for what we have gained: the grand H.P.s and Teas of the present day have certainly no cause to be jealous of the old favourites, or to dread comparison with them; and the most inveterate exhibitor will rejoice that the Roses which so charmed our fathers are still loved and admired by some.

It will be found that more or less serious objections may be urged against all exhibitions, where a "fancy" or fashion decrees arbitrary points in the things exhibited apart from their useful qualities. Thus it has been said of dog shows that breeds notorious for their service for sporting or other purposes are not judged or awarded prizes for their useful qualities, but for fashionable points of colour and shape. And it is also alleged that certain varieties of poultry have deteriorated because they have been judged by their feathers and other useless points to the detriment of their capabilities of furnishing plenty of good eggs and chickens.

On the other hand, fewer complaints are made against shows of fat or dairy cattle, because there is no "fancy" here, and the animals are usually judged according to their marliet value for use. And if it 
be said that there is a "fancy" in Roses, and that the very term "show-Rose" proves it, we must see what are the desirable and useful properties in Roses, and whether the system of exhibitions favours or hinders them.

Beauty and fragrance are the charms of the Rose. It may be said beauty is a matter of taste, but, as tastes differ, for the purposes of competition ideals must be agreed upon and rules laid down. In this matter I think the show system of the National Rose Society has laid down fairly correct canons of beauty. Unhappily, fragrance cannot be accounted for in competition at Rose shows. It is plain that among such a number it could not be tested, and that rules for estimating the amount and quality of fragrance in each bloom could not be satisfactorily framed. Individual taste will also differ much in the appreciation of it, the scent of Narćchal Niel, for instance, so highly estecmed by some, being not a pleasant one to my senses.

In fact, the judging of fragrance would have to be a matter for experts, properly trained, as tea-taster's are, for the part. Such persons, who have made the matter a special study, tell us that there is no scent of tea among what we call Tea Roses, but that some of them, like Maréchal Nicl and Madame Bravy have a fruity scent resembling the raspberry, that Safrano has the odour of pinlis, the Macartney Rose of apricots, and the Dog-Rose of mignonette. They even say that some Roses have a disgusting scent, the flowers of certain varieties of the Sweet Briar (of all Roses!) developing a mixed odour of coriander and a certain horrid parasite which shall be nameless! I gather these and a few other items as to 
Rose scent from a pamphlet called Rhodologia, by Mr. J. Ch. Sawer, F.L.S., of Brighton, which will be found useful to those interested in the scent of Roses, especially from a commercial point of view.

So it is a charge against shows that scentless Roses are encouraged, and fragrance, a chief part of the dowry of the Rose is ignored. But there are really not many scentless Roses, and I think fragrance is sometimes over-estimated. Would Baroness Rothschild have attained no fame without Exhibitions? or is it fragrance which lifts the Rose so high above the mignonette and the violet?

Another common complaint against exhibitions is that prizes are given for mere size, and not for beauty. This is not correct: size has its influence, all other things being equal, as it rightly should, a Rose which is good in all points and large being naturally better than one which is equally good but smaller. "But," it may be said, "we hear of soand-so getting the first prize because his blooms were 'heavier.' Are Roses judged by weight like dead geese?" The answer to this is that "heavier" means greater thickness and solidity of petal; and it will not take long for a young Rosarian's eye to become sufficiently educated to prefer the thick fleshy petalled and consequently lasting Rose to one that is formed of more flimsy material.

Another complaint will probably be that showRoses are all so formal and regular, and that négtigée forms, often so truly artistic, are not appreciated. The answer to this will be, that Rose shows are held to test cultivation, as to who can grow the best Roses, rather than decorative powers, as to who can 
show them the best. A large advantage is held, as it is, by those who are gifted in the power of display, especially in Tea Roses, but if all the merit were in the showing there would be small encouragement for the cultivator in his yearly round of work.

And also that as the judging must be accurate and by strict rule, so only those formal styles of beauty which can be judged by rule can be held admissible. It is very unsatisfactory to enter into any competition where you do not know precisely by what rules you will be judged.

Thus the charge against Rose shows are that they encourage size and formal beauty, and care nothing for fragrance or artistic elegance. Even if these accusations were unanswerable, which I do not think they are, it must be considered whether exhibitions have not done very much for raising the popularity of the Rose, for the increase of varieties not only of show sorts but of every description, and for making England the true home and centre of the national flower?

The large and rapid growth of the trade since Rose shows were established would be sufficient answer to these questions. Where ten Roses were at that time raised by nurserymen and grown by amateurs, a thousand would now be a more likely figure: and whereas such a thing as making a living out of raising Roses alone had not then been heard of in England, and the number of Rose nurserymen of note might be counted on the fingers, there are now and have been for several years three large and flourishing establishments for the growing of Roses in one English town, two of which devote themselves solely to this object. 
It cannot be doubted that the popularity of the Rose, and its greatly increased cultivation, have been much fostered by Rose shows and by the National Rose Society which encourages them. With a possible exception in the matter of fragrance, I do not think that exhibitions have fostered any undesirable qualities in the flowers: it is true that some modern show varieties are weak and difficult to grow, but they are often so lovely that it would have been a great loss if they had not been known: and even the few scentless forms would, I believe, have found a footing on their merits.

A young exhibitor should begin by making sure that he knows a good Rose when he sees it-that he is well acquainted with the types and ideals which authority, as represented by the National Rose Society, requires. And the first thing to be learnt is that "form," the shape of the Rose, is the most important point of all.

In Latin, "forma," shape, is "beauty," and "formosus, " shapely, is " beautiful." Form comes before colour as drawing before painting. A tumbledown cottage or a lopsided spray may be picturesque, but it is only formal beauty that is amenable to the strict rules necessary in competition. The "tumbledown" style of beauty may be admired in the garden, but cannot be admitted to judgment at Rose shows. A Rosarian soon becomes accustomed to look upon form as the primal beauty of the Rose, and to regard colour, though necessary, as a secondary consideration.

Unfortunately, no proper terms have yet been devised and used for the different types of form in Iioses, for it cannot be denied that the expressions 
used in the N.R.S. Catalogue are unsatisfactory. Five types were originally set out:-imbricated, globular, globular high centre, cupped, and flat.

"Imbricated" is a term with which no fault need be found, if no plainer English word that all gardeners would understand could be hit on. It implies that the petals are regularly and thoroughly reflexed (bent back) upon each other, with a "pip" in the centre, like the flowers of a Camellia. A. K. Williams, H.P., and especially Mrs. Paul, B., are good examples of this shape. It is the shape of a "Rosette," but not many " little Roses" are of this form, though Boule de Neige, H.N., and the small flowers of Ethel Brownlow, T., are capital Rosettes. There are several gradations in this form, some being half-imbricated, and some with the outer petals only regularly and completely reflexed. Madame Cusin, T., is a form which would be imbricated, but that the petals, instead of lying close, stand apart from each other.

"Globular" is a term which may perhaps be fairly applied to Madame Bravy, T., which at its best is like an incurved chrysanthemum, and even to such varieties as Violette Bowyer or Eclair, H.P.s. The latter is of the cabbage form, no longer esteemed. Baroness Rothschild and its race should also approach this form. But the N.R.S. Catalogue gives it, for instance, to Maurice Bernardin, which is just the common shape of an ordinary crimson H.P. It is plain that in this and many other cases the term is quite a misnomer, the flower being roughly the shape of a hemisphere or half a globe, semiglobular.

"Globular" or (as I think it should be) semi- 
globular high centred, pointed or reflexed, are rather cumbrous expressions, but they may be understood, and I am not prepared to offer amendments.

"Cupped" is another unfortunate term, for, contrary, I believe, to all botanical and scientific nomenclature, it is used in the N.R.S. Catalogue to signify, not that the flower is hollow within, but that it is outwardly of the shape of a chalice-an inverted cone. It is the more misleading because a hollow centre is considered a very serious fault, and " cupped high centre " must be a considerable puzzle to the uninitiated.

"Flat" is a plain term with which no fault can be found, Souvenir de la Malmaison, B., and Her Majesty, H.P., when expanded too far, being typical examples of this shape. It is rightly considered a very faulty shape for exhibition, as every one will admit that the plate-like form is inferior.

There should also be a name for the type of Rose whose petals are folded on either side at the extremities so as to form points, as in Mrs. W. J. Grant and many others: the outline is not so smooth as in those Roses whose petals retain their rounded extremities, but it is perhaps even more effective.

Variations of the above standard forms may be found in Madame de Watteville, which might be called the "winged" or "butterfly" rose, an addition to the pointed or high-centred shape being found in the long outer petals which project as wings: and in Innocente Pirola, where the petals radiate away from the centre point in the perfect form of the whorl of a shell. But a regular shape, 
with full somewhat high centre, circular outline whether smooth as the edge of a Pansy or a ring of points as in many other flowers, and perfect arrangement of petals, is necessary to every form of a good Rose.

The yearly round of care for Rose plants intended for exhibition purposes will begin with a strict attention to the rules of planting, winter protection, and manuring. Pruning for exhibition has already been noticed ( $p .106$ ), and it must be really severe to ensure strong growth. In the subsequent thimning of the buds and shoots he who would win cups and first prizes must " harden his heart," and see that he does not leave too many, however strong and healthy they look. But in this matter of pruning and thinning, careful regard must be had to the "manners and customs" of the variety: for, to take two instances, while Horace Vernet must have all the sap the plant can give it, La France (as good a show Rose at its best as any of them) must be almost starved in that respect or the blooms will not come to perfection. Before rubbing off the others the selected young shoots should be carefully examined to see that they have not been injured by frost or grub, as the hopes of the plant will now depend on them.

Even among dwarf cutbacks, stakes should be supplied to support all Roses with flexible stems such as Earl of Dufferin and Marie Baumann among H.P.s and most of the Teas. A sufficient number of bamboos or other stakes of various heights should be stored in handy corners ready for this purpose.

As a general rule, all buds but the centre or crown bud should be removed as soon as possible, and 
when the wood buds push, further down the stem, these also should be rubbed out, if dealing with a Rose that requires "liberal treatment," but not with one that is apt to come coarse or requires semi-starvation. To take the two examples lately mentioned, Horace Vernet requires that all such wood buds should be stopped, but La France and Maman Cochet will be much better if they are left to grow. The phrase "liberal treatment," which I have borrowed from the excellent catalogue of B. R. Cant and Sons, means that the flower can assimilate, and be the better for, all the sap that can be given it: it implies therefore the best of soil and manure, close pruning, rigorous thinning of shoots, laterals, and buds, and that the best blooms may be expected on maiden plants. Horace Vernet, Dr. Sewell and Xavier Olibo, for instance, are examples of varieties requiring "liberal treatment": while La France, Her Majesty, and Marie Rady are examples of Roses which will be spoiled by such high culture.

A quill toothpick or knife-point is sometimes used for the removal of the tiny flower buds as soon as they can be distinguished, but finger and thumb will soon get expert at the work and do it mechanically.

Be careful about delegating this operation to inexperienced hands. I remember a trade exhibitor telling me that he once thought he would employ some women at it. "I want you," said he to them, suiting the action to the word by taking the cluster at the end of a shoot and rapidly removing all but the centre bud, "to take off all these buds like this." They set to work with a will, and when he came back some time afterwards to see how they were 
getting on, not a single bud of any description remained on the rows which they had devastated.

The rule has its exceptions: there are certain Roses which are apt to come coarse, or too full, so as to be too long in opening if they are over-freely supplied with sap. The treatment in these cases must be modified, the small buds being gradually destroyed, or one or more left on till the end. With some varieties, known as bad openers, the crown bud should not be "taken" (to use a phrase of chrysanthemum culture) but removed, and a side shoot with a bud selected in its place. Her MIajesty, Robert Scott, and Ernest Metz are the better for this treatment: and, as a general rule, where any bloom comes "balled," i.e. the petals covering the centre point and coming down the other side so that the flower cannot open, is a sign that the growth is too strong. In such a case, less "liberal treatment," i.e., less pruning, less thinning, perhaps less manure, or even the pinching off the crown bud, is called for. Only experience, a good knowledge of the habit of the variety, and a regard to the strength and number of shoots on each plant and the character of the weather can guide the grower in this most needful regulation of sap supply. If the season be hot and dry more buds may be taken away, as the Roses will open easier and the natural supply of sap will be less and more quiclily assimilated.

The same caution must be exercised with maiden plants: some of the weakly growers will give the best blooms if only a single stem with one bud on it be left. But many would come coarse or deformed under such treatment: and in these cases if there be only one maiden shoot, one or two, according to the weather, 
of the lower wood buds should be allowed to grow out, and they may form perhaps almost as good blooms as the older one. Thus Ethel Brownlow, T., by no means a very strong grower, when grown as a Standard Maiden should always have the crown bud removed : it will come to no good, and very likely will have a prominent green centre.

The chosen bud should be carefully examined before it is entrusted alone with the sole responsibility of the shoot. Any insect perforation however small, or any unusual appearance or sign of deformity, should cause the dethronement of the crown bud at once, and the election of the most perfect of its two or three companions in its place. Even with the utmost vigilance many a fine bud will be tended and cared for and only found to be malformed at the very last when it should be in perfection and ready for show.

Where there is still a choice of buds later on when the first signs of colour are visible, signs of malformation may often be detected in an uneven appearance of the green calyx enclosing the petals. If this is irregularly disposed so that more colour shows on one side of the bud than the other there is a strong probability of there being a deformed arrangement of the petals, leading to the bloom being " divided " or "quartered," a very serious detriment to the shape of many of the finest blooms. There is no remedy : another bud, if possible, should be chosen in its place. An exception must be made in the case of Madame de Watteville, whose buds are curiously wrinkled to enclose the great wing petals.

The tip of the bud should be quite sharp and green : if at all blunted so that the colour shows, there has 
been injury and can be no perfect bloom. Such buds, if left, will often in June look as if they had been clean cut in two horizontally with a knife, and though they will harden and may swell a little, they will not open at all. This injury is due to frost, or perhaps a very cold night without actual frost, when the bud is just formed and the extreme tip, at that time most tender, exposed to the air.

Before the buds begin to open, measures must be taken to shelter the delicate blooms from rain and sometimes from sun. Almost all the Teas and certain of the H.P.s are liable to a good deal of injury from rain and sometimes even from heavy dews. Of the many kinds of protectors which have been tried, from old umbrellas to Willesden waterproof paper shades, there are probably none better now than the protectors of white calico brought out by Mr. R. E. West, of Reigate. They seem a little small, but the square stick and square socket form an excellent contrivance to prevent horizontal movement by the wind, and the simple spring to hold the cone higher or lower is a decided improvement. In placing the protector over a bud great pains should be taken to see that both are firm and not likely to be moved by the wind. Severe gusts often accompany thunderstorms, the protectors offer a good deal of resisting surface, and the bud, if chafed while it be wet, is sure to be spoiled.

The protectors should be raised or removed when the rain is over, particularly if the bud is close to the ground, as they check the evaporation from the wet soil and keep the bud in a damp state. It often does good rather than harm to bend down the shoot of a Tea Rose bud to get it under the protector, in 
very forcing weather, or if the Rose be of a variety that is apt to open too soon. Such a proceeding: slightly checks the sap, and the bud is likely to grow a little more before opening.

Pendulous Teas on dwarfs are apt to be splashed with mud in heavy showers, and this forms an additional recommendation for standards for such varieties; no protection short of a universal mulch is much good, but when all Roses are wet, simply dipping a splashed Tea face downwards a time or two in a pail of clear water has often made it look at least as well as its fellows.

The effect of unshaded sun upon the colours of Roses seems peculiar:-undoubtedly it gradually absorbs or weakens the yellow tint, which may not only be preserved but also increased by close shading or covering: and it appears also generally, at first, to weaken the pink in Tea Roses; but a very hot sum will sometimes bring a second red flush on some, such as Marie van Houtte and Princess of Wales, and I have seen such a flush come on old blooms of Maréchal Nicl on a scuth wall in a very hot time.

On the other hand, all red H.P.s certainly come much brighter in colour on a dull cool day after a hot time, and there seems to be little effect in shading to prevent the "burning" or browning of the petals of the dark varieties. Generally, for Teas, remember that very close shading increases the yellow and destroys the pink or red tints: so that all those varieties which have both these tints will lose the pink and come of deeper yellow only, and pale yellow Teas, like Madame Hoste, are much deepened in colour. 
Papering the buds, that is, wrapping them while yet undeveloped in cones of white paper, has sometimes a very good effect with the pointed forms of white or yellow Teas, making the bud grow longer and preserving the richness of colour. It only answers in quite dry weather; if rain comes, the paper must all be removed at once or the Roses will commence to rot.

Boxes of the approved shape and size, with tubes and wire supports, can now be readily purchased, saving much trouble with the village carpenter. Strength must not be sacrificed to lightness, as heavy men will not scruple to stand on them in railway or horse vans. The corners should be bound with iron, and there should be some readily distinguishable mark on the lid of each, a white bar or star or something of that sort, so that each man can comnt his own boxes in transit, or find his own lids easily at the end of the show.

They should all be made exactly alike, so that lids and trays are interchangeable. Spare trays picreed for trebles shown in triangles should be provided, and a large deep box for spare blooms is very useful but unwieldy. The National Rose Society has now rightly established regulation sizes for the usual classes, for setting the Roses closer together somewhat conceals their want of size.

The providing a sufficient quantity of good moss for placing on the trays between the tubes is sometimes a difficulty when there are many boxes to be prepared. The ordinary moss of hedge-row banks is generally used, but it is sometimes difficult to find in a gravelly district. The north side of a clayey railway embankment is gencrally a good place. It 
should be taken up cautiously so that it may be placed root downwards, and not half of it upside down, in the boxes, and will require the weeds and grass to be picked from it.

A much more effective moss is that which grows on old thatch or even roof-tiles, but it is apt to lose colour, unless kept damp. If it can be found on an old north roof, it is much easier to prepare, and has a far more velvety appearance than the first kind mentioned, which sometimes looks little better than badly made hay.

The trays when trimmed with moss should be watered occasionally and kept in the shade. But a good overhauling is desirable before a night journey. In one very dry season my mossed boxes had been kept in the shade and duly watered, with the result that two huge slugs each as big as my thumb came attracted by the damp, and concealed themselves either in the moss or underneath the trays. It was either in the night journey or during the very early hours of rest at the Crystal Palace that one of these brutes crawled out and ate away just the top of my very best H.P., a large specimen of Her Majesty.

Boxes and all are ready - to-morrow is the day of the show-when shall we cut the blooms? The distance and the convenience of trains will almost answer the question, for a start at three or four o'clock in the afternoon is by no means unusual for those who live at a distance from main lines, and want to show on the other side of the country.

It used to be always laid down that the morning of the show is the time to cut, and that those who are near enough at hand to do this are at an advantage. Modern instances, and especially, I 
think, the superior staying power of modern Roses, have considerably modified this view. If the show is within driving distance one would naturally cut in the morning; but very small advantage, if any, must be expected over those who have come from a greater distance and had to cut over-night.

I used often to get up to cut very early in the morning, an hour or more before the mowers made their appearance in the neighbouring hayfield, but have long ago come to the conclusion that unless one can cut after six o'clock in the morning it is even better to do it the evening before.

I soon noticed that :about six o'clock a change came over the Roses, every one taking, so to speak, his day's step forward, and that many fine lasting blooms altered and aged as much in half-an-hour about that time, whether cut or not, as they would in the whole of the long summer day to follow. So, if it is possible to cut after that hour and yet be in time, we may be glad to do so, and can choose blooms a stage in advance of those we should have cut over-night. But I believe it to be just as well, and perhaps better as getting them in safety before a chance shower, to cut at from four to seven o'clock the evening before, rather than at four or five o'clock in the morning.

Begin in good time : it is better to start at two or three o'clock in the afternoon, with the boxes in deep shade, than to be hurried at the last. There are several H.P.s too, Horace Vernet and Le Havre for instance, which shut up their petals towards night, and though they will open all right next day it is difficult to choose the best specimens when they are closed. 
The old idea was that the water in the tubes should be as cold as possible. This is now, I think, rightly held to be a mistake, and some hold that the mysterious collapse which sometimes takes place early in the exhibition tent, when a fresh young bloom, generally a dark H.P., suddenly begins " to grow smaller," arises from this cause. I would advise that the water be taken from a clear pond on which the sun has been shining.

Roses should always be cut with strong sharp scissors; if at any time a stranger is allowed to cut blooms from your plants, forbid the use of a knife, or damage by the breaking of a shoot is sure to be done.

Perhaps it is best to commence with the Teas, as these are most lasting, and require longer time for selection. A large number of them hang their heads down, and a great many must be lifted and examined, while among the H.P.s few are so pendulous as Maric Baumann and Earl of Dufferin. Be sure that the examination and selection are thorough : I have gone off once or twice at least without a good Tea Rose, overlooked because it was hidden under some protection.

Cut the stems long enough : they must be set up high when they are shown, and it is very annoying to find that a good bloom must be set lower than the others to keep it in the water. It is a shock for a precious little plant of Comtesse de Nadaillac to cut away so much wood, but this is the hour of the Rose's trial and would-be triumph, and now if ever it must be prepared to make a sacrifice.

Some expert exhibitors do little arranging, choosing or setting up at the time of cutting, but, putting 
a sufficient quantity of their best blooms into the tubes, leave all that for the place of exhibition. A beginner, however, had better wire and set up his best Roses at once as he cuts them, taling others for spares and arranging them all afresh at the show.

Wiring the blooms, like all mechanical operations, should be learnt by watching an old hand; it is a very different business, with the improved supports now available, from what it used to be when we had to tie the stems in trwo or three places to a small stick or simple straight wire.

A beginner should label each bloom as he brings it in, and it will always save time even with those who know the Roses well. The printed labels look nice -at first-and are convenient if you can always leep them arranged so as to find at once the one you want. But they very soon get dirty, especially if not removed before the home journeys, and many find the writing each name in pencil on blank labels as required the shortest and most handy in the end. But please write plainly.

In cutting the day before a show, the state of the weather must be considered. If a very long journey and a hot night are in store, allowance must be made for rather more than one day's age in the Rose; but for a short journey and a cool night, some of the fullest Roses and those with the thicliest petals may be cut almost as it is hoped to show them. Nothing but experience can aid the judgment in this case. If there is plenty of choice talie another bloom of the same variety not so far advanced; and three times out of four the younger bloom will be found the best when the time comes.

Most Roses are at their best when about three- 
quarters open, but some will stand the full exposure of their charms, and thin-petalled sorts should be shown when not more than half open. It is now the universal practice to tie up the centres of all pointed blooms to prevent their opening too soon, and sometimes it may be advisable to do this on the plant a day or even two before the show. Soft cotton or wool-not too thin-should be used, and the outer row of petals being left free, the point or spike of the bloom should be firmly tied round sufficiently low to prevent slipping. The form of knot should be the first half of an ordinary knot, only with two turns instead of one: an inch or two of ends should be left, and then the advantages are, that though the knot will not slip it can always be tightened by pulling the ends, and is very readily removed.

Teas are much more lasting when cut than H.P.s, especially if they be really good blooms of first-class sorts. On one occasion I showed as a specimen of Comtesse de Nadaillac at three separate shows; on the first occasion it won the distinction as best Tea, on the second the medal as best Rose, and the stand in which it was exhibited won first prize at the third show. On another occasion I showed twelve Teas unsuccessfully at one show: the same blooms with the exception of two or three were shown two days later at another place where the competition was quite as severe, and won first prize. Much rain had fallen in the two days and freshly cut Teas were spoiled.

In the hot season of 1893 , I cut a bloom of Marie van Houtte on the Monday and showed it well in my winning stand at the Crystal Palace, on the 
Saturday. It was liept for three days in a dark and nearly air-tight cellar, and for two days more in another cellar with a little light. A few drops of spirit of camphor were added to the water in which it stood, but I am doubtful if this has much good effect. I think the equable temperature of a dry cellar has a good effect in preserving the blooms, but they will probably lose colour.

If rain is feared, and efficient protection is not to be had, the Teas should be cut in good time, even though the buds are hardly opened enough. It may be noticed that Maréchal Niel improves in colour after being cut, and a really fine bloom may often be better the second or even the third day, if it be dry when gathered, and can be shown on a cool day.

If the boxes remain at home during the night it is best, especially if the Roses are not dry, to give some air by propping up the lids a little way, so as to exclude chance trespassers in the way of cats and the lilie. Still this admits of the entry of slugs or carwigs, and as we should think little of keeping the boxes entirely close through a night's journey, it is not necessary. The lids should be securely fastened when they are shut down for travelling, care having been taken that the lioses are sufficiently low in the tubes to prevent the roofs of the lids touching them; but only those perfect persons, who never even in a hurry leave their keys at home, should use locks.

Railway porters are now becoming used to the sight of Rose-bores, and recognise that "something belongs to" the careful handling of them, to use a Suffolk expression. But personal supervision at all times when they are moved is still very desirable, 
and the legend "Flowers in water this side up, with care," is not much heeded if there is no one prominently visible from whom a tip may be expected.

On one occasion Mr. Burrell of Cambridge and I were travelling together by night to the Northern Provincial Show of the National Rose Society. At a certain station we had to change, and after keeping guard over our pile of boxes for a while, we thought, as all seemed quiet, we might leave them for a little. We were not absent more than five minutes, but on our return all the boxes had absolutely disappeared. It was not till just as our train was starting that we were assured, and satisfied ourselves by the dim light of a lamp, that our boxes were all in the van. We thought it was all right, but my pet twenty-four, on which I had spent a great deal of trouble, travelled the whole of the rest of its journey actually upside down. My companion, who had arranged to take care of the boxes on our arrival, during the small portion of the night that remained, discovered the mishap soon after I had left him: and with a kindness I shall not readily forget, did his best to restore order, and comfort, and cleanliness to the poor Roses, with such success that they gained a third prize.

At another of the N.R.S. Northern shows I was going to show "six new Roses." A six box is, or at least mine was, nearly square, but that does not seem a legitimate reason why a porter should have rolled that poor box out of the van just as if it were a cheese. Though my remonstrance was meant to be severe, the man hoped I should "remember him," and I have done so.

Truly much depends upon the setting up and final arrangement of the Roses at the place of exhibition, 
and, in Teas especially, a man who shows his Roses well will often beat a worse performer even though the latter have better raw material. An old friend and rival (one of the editors of this edition), the Rev. F. Page-Roberts, who by his splendid showing had often beaten me when I felt my blooms were naturally the finer, once most good-naturedly set up my Teas as well as his own at the Crystal Palace, though we were showing in the same class. Poetic justice was for once triumphant, for we came out "equal first."

Though perhaps a pity, it is inevitable that the art of display should have this advantage; it would never do for the judges to pull the blooms about and see what they are capable of. So the beginner must learn how to show his Roses to the best effect in the first place by watching others; and he will find that, next to experience, plenty of patience with a good allowance of time is the principal requisite.

The first thing will be to "set up " the blooms in their tubes higher than they were, level, even, and straight, each Rose so turned as to present its best side to the front. The ties should be removed from all except those which open too freely, and an endeavour should be made to tie them again one row of petals nearer to the centre, the second row being encouraged to open out. If any defect should be thus exposed in the centre, it will depend upon the greatness and nature of the flaw and what spare blooms you may have, whether the bloom is to be rejected or whether it can be tied up again as it was before, so that the defect can be hidden. A younger though smaller bloom is generally the safest. An old hand by keeping the points of his Roses tied up 
till the last minute will sometimes present for judgment fine-shaped perfect blooms which two or three hours later have opened and lost their form and beauty. It may be a matter of regret that this can be done, but some risk is run, and ingenuity and boldness, provided that all is fair, should have their chance of reward.

Some blooms will be found hardly more than buds, and these will require a little assistance to make them open further. "The National Rose Society was quite right in framing rules against " dressing" when this took the form of forcibly bending down the outer petals by creasing them. This gives quite a different appearance and shape to the Rose. Yet a little assistance, by removing short malformed or discoloured outer petals, and by gently pressing back at the base the next row, is a legitimate accessory of the art of exhibiting.

The handle of a budding linife was the instrument formerly used for opening a bloom, and I have seen a pencil do wonders in experienced hands; still a cainel's-hair pencil of fair size is the best thing to use, for it is soft and does no injury to the petals and may be utilised for the removal of specks of dirt, aphides, or thrips. Work patiently away at the outer row of petals only, without creasing them down: it is no use meddling much with the inner rows, except by a sharp puff or two from the lips, which will sometimes improve matters somewhat.

Some sorts camnot be opened at a show-Reynolds Hole, for instance; however much the petals be pressed back, nothing short of creasing or mechanical obstruction will prevent them from closing up again. 
I remember a case where a fine-looking bloom of this variety was being examined by the judges as the most likely candiclate for the silver medal for best H.P. The owner of the Rose at the door of the tent was anxiously watching the movements of the arbiters, and was horrified to see one of them pull the bloom downwards through his lightly enclosing hand. Click! the petals, released from the laborious mechanical opening, sprang back to their places, and Rose and owner were "shut up" simultaneously!

Other Roses, of the "thin" type, like Thomas Mills, are pretty sure to open well enough, and due regard will have to be paid to this at the time of cutting, as such sorts should be talien to the show in an earlier stage of their development than the very stout and lasting ones like Reynolds Hole or Horace Vernet. Great attention should also be paid to the weather and the place: a hot tent forces on Roses wonderfully, but it used to be generally fairly cool in the Crystal Palace.

It seems hardly necessary to say that the setting up and arrangement at the show should be in a cool and shady place, but even this rule may have an exception. On one occasion I cut my blooms for a celebrated Southern show in a very undeveloped condition, expecting that my assistant who was to go with them, as I was unable to do so, would have a hot time for his night's journey. The weather unexpectedly changed, the night proving very cool, and when he arrived at the place of exhibition he found to his dismay that my Roses were not nearly open enough, and that they made no show at all by the side of the developed blooms against which he 
had to contend. Being a plucky man of resource, he resolved on an unusual experiment; he uncovered the boxes, and set them to stand for a considerable time in the full glare of the sun. Whether the others took him for a lunatic or an ignorant novice I do not know; but I do know that he brought me back the first prize.

In several of the handbooks of instruction on how to show Roses the exhibitor is warned to be careful how he arranges them as to colour for general effect. Of course this is worth doing, if it means arranging all the best blooms thus, but under no circumstances should a light or dark bloom be introduced for the sake of colour if it is not worthy in itself. I am bound to say that it is very rarely that judges pay any heed to the arrangement: they look at the merits of the blooms themselves, and a preponderance of dark over light flowers or vice versî would have usually no effect with them. Successful arrangement is only taken into consideration where rival stands are very nearly equal in the merits of the individual blooms.

There will seldom be any need to look over the stand at the last to see if there are any duplicates, i.e. two of the same sort, if care has been exercised in this respect from the beginning, and no Rose is introduced without being sure about it. But a bloom may sometimes be accidentally changed without altering the label, so these should be run over to see that they are right. The National Rose Society authorities are lenient in this matter, provided there be no duplicates, but country judges are sometimes more strict.

There is room for a good deal of legitimate 


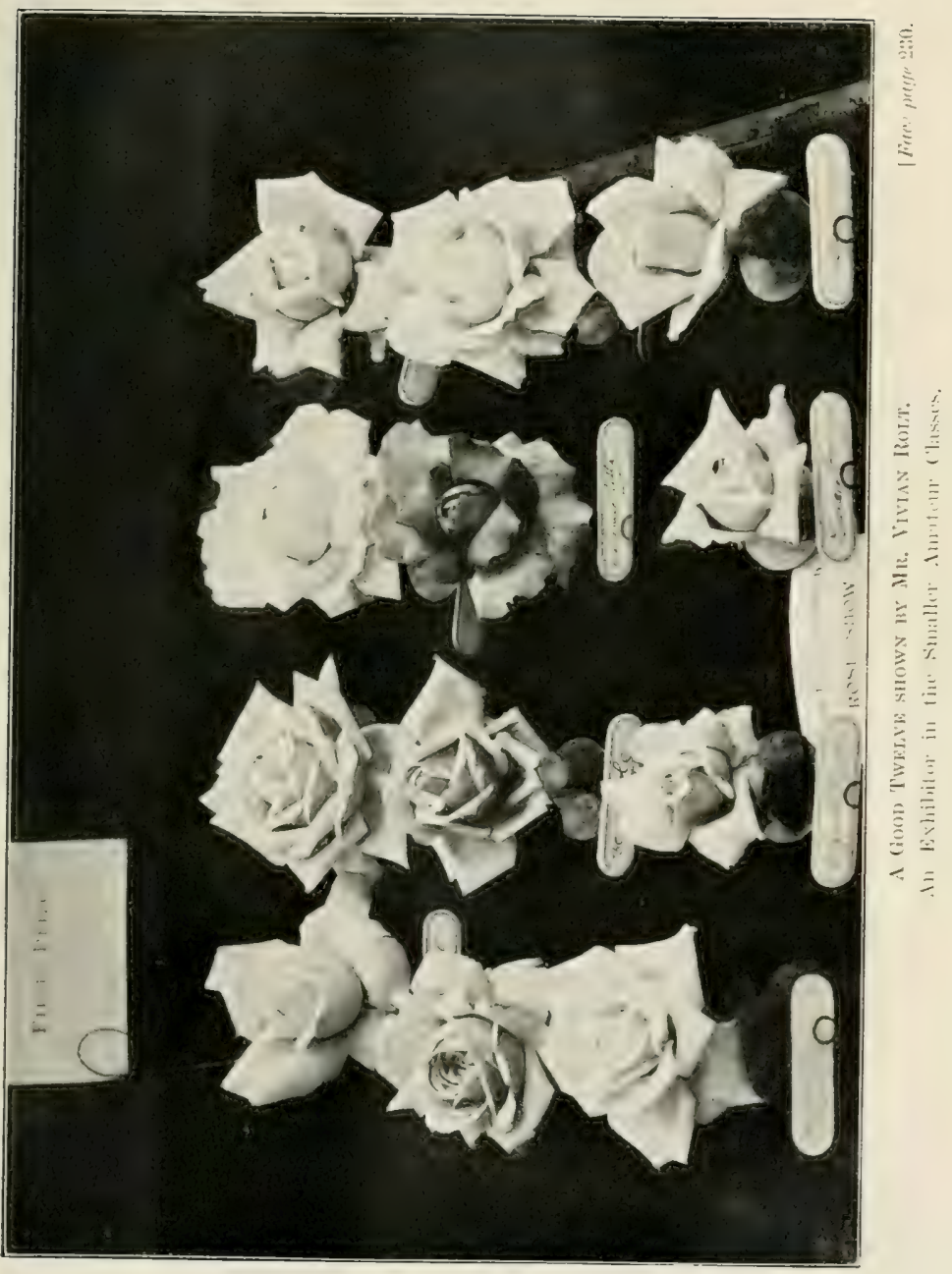



manœuvring and generalship in the last hour or so before the judges enter. If a man, who has entered in several classes and is only moderately strong, divides his best specimens among his several stands, he will probably get no first prize and run considerable risk of being ont of it altogether. $\mathrm{He}$ should concentrate his strength on one or at most two classes, take a critical survey of his rivals' blooms, and show pluck or discretion as the case may be in selecting the best class in which to put all his finest flowers.

On one occasion, late in the season, when it was not likely that there would be more than one or two serious rivals, I sent my assistant (being unable to go myself) to a large show, with stands of thirty-six and twenty-four. He found one rival only of any note, but he was Mr. X., and to beat lim just then required the best amateur Roses in the lingdom. My man returned with two seconds, saying triumphantly, "I ran Mr. X. close; for he came and looked at me five times." I could not help replying, "If you had followed his tactics and gone and looked at him, you might very likely have got first for the twenty-four." By dividing his forces my man was beaten in both classes: the expert had come and looked so often to satisfy himself there was no concentration of strength requiring a similar move on his part.

No personal fancies, or likes and dislikes of certain Roses, should be entertained by the man who wishes to be successful. Some have an antipathy to the appearance of the striped Pride of Reigate: and I have heard, " $\mathrm{Oh}$, I don't like that Rose," of such a variety as Sonvenir d'un Ami. It 
is all very well for such as can afford it, but few can : and it is to be remembered that the judges will not let their own personal predilections have any weight in deciding on the merits of each Rose.

JUDGING.-Nothing is more surprising to exhibitors of dogs, poultry, \&ce., than to hear that at all National Rose Shows the judges are appointed from those who are actually exhibiting at that very show. Of course no one judges in the class in which his own stands are, and as a matter of fact probably no exhibitor would have it otherwise than it is. Many judges are required at a large show, and even with much subdivision they have often as much or more than they can do to get through their task in the hour: and besides this, cyes thoroughly accustomed to the appearance of lioses as shown are required to recognise the different varicties, and note subtle distinctions of merit. A year or: two's absence from Roses and Rose shows would probably seriously impair a man's efficiency as a judge.

Judging is performed by the rules of the National Rose Society according to the form, size, and brightness of each bloom, which should be at the time " in its most perfect phase of possible beauty." A general survey of the class should first be taken, for it may be that the case is clear and beyond a doubt. Where the stands are of large numbersthirty-six and upwards-there should be another survey a little way off to judge better by comparison, and to give at all events an idea of which stands are "out of it," and which seem to be more nearly equal.

Those stands about which there is any doubt 


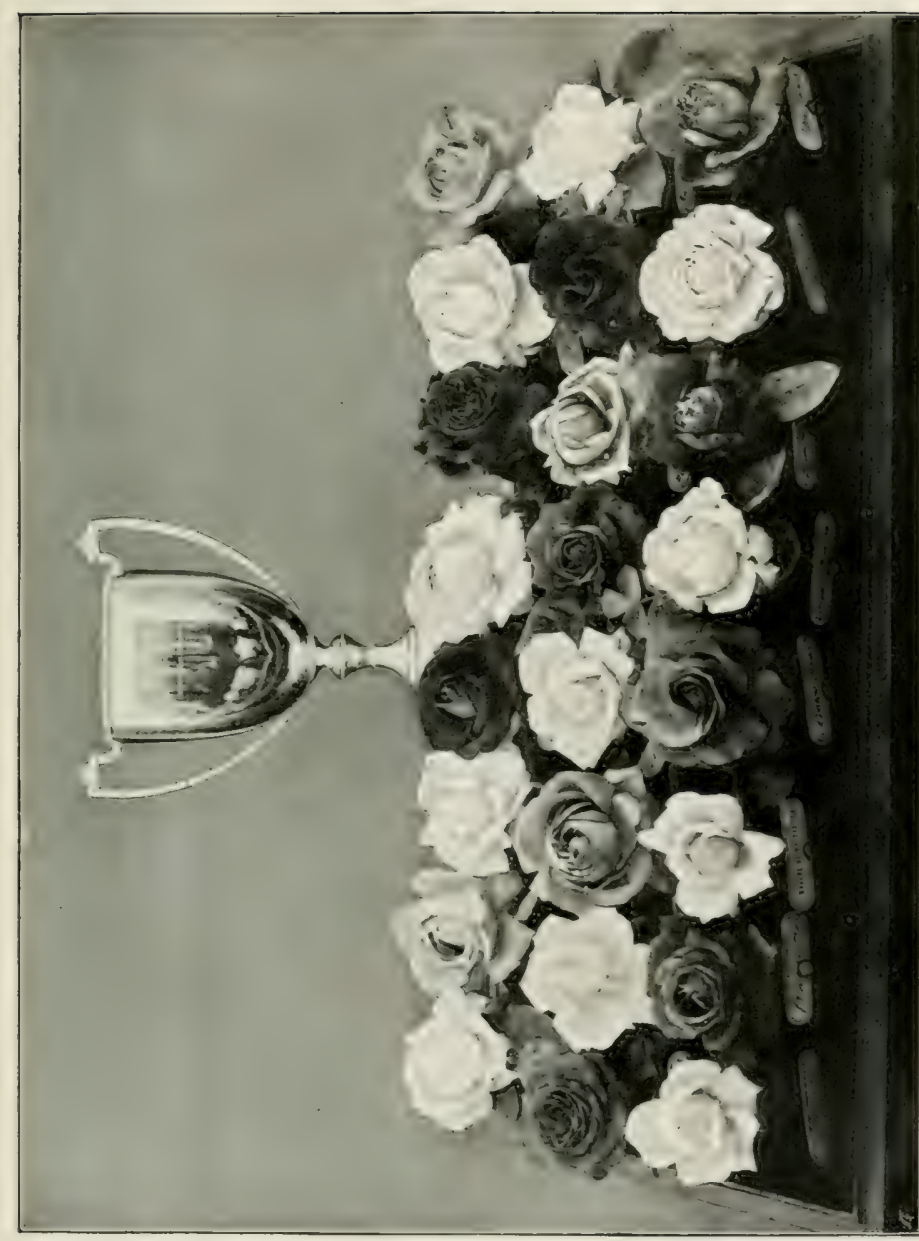

हैं

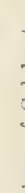

$=\quad$

$5=$

궁

-

$=$

63

$\sum_{-2}$

$+\frac{1}{3}$

$=$

!

할

츨

$=$

$\sim$

อ 

should now be "pointed," i.e. judged by points. Minus one, nought, one, two, three, or in rare cases four points should be awarded to each bloom, according to merit, one of the judges suggesting the number of points to each, the others assenting or dissenting and one noting the number of points totalled.

The first thing to be done is to choose and agree upon a certain Rose worth three points to serve as a standard. This is important: being useful not only for reference in cases of disagreement, but also in the large classes of forty-eight or seventy-two to prevent the standard becoming insensibly depreciated. Pointing generally begins with the back row and from left to right: boxes are often set up in the same order, and the exhibitor would naturally put his worst blooms in last, which would therefore be at the right hand of the lower row. At any rate, considerably smaller and woaker blooms will generally be found in the front row, and the judges must take care that their standard remains unaltered; the fall in the scale is often very gradual, but a frequent reference to the chosen standard, which one of the judges should carry in its tube, will prevent any lowering or raising of the ideal.

In cases of equality, or when in a large class only a point or two of difference is found between two stands, it is well to "point" them over again, beginning at the other end of each. If still there is little difference, taking the boxes down and holding them with their long sides touching, in closer juxtaposition, will sometimes throw additional light on the matter. Comparing each bloom with 
the corresponding Rose in the other stand and adding or subtracting points accordingly is a method I have used when judging alone in a "near thing"; looking at the Roses from the level of the trays so as to get a comparison of the depth of the blooms may sometimes be of service in the task of arriving at a decision: and if the verdict should still be doubtful, arrangement, neatness, foliage, and even moss may help to turn the scale. In such extreme cases, however, it is better to judge them as equal where the prizes are money and can be divided; if a cup be in question, of course one must be declared the winner.

I went once some little distance to a show solely as judge, there being no class suited to me. The prize was a cup for forty-eight, and there was no second or other prize whatever. I was the only judge, and the exhibitors were two noted rival nurserymen of the very first calibre. I was shut up quite alone in the tent, and proceeded to my task with cheerfulness, not knowing what was in store for me. I "pointed" each bloom with great pains, and took care not to add up the total of the first stand till I had done the other, lest I should be insensibly influenced. To my horror they came out exactly equal. I went through them again from the other end, and this time I did get about one and a half points' difference, but still felt that the second judgment was not quite so trustworthy, as I might be unconsciously anxious to find a difference. I compared them in every way I knew, but still could make hardly more than a point between them, if so much. No difference was to 
be found in arrangement. I knew who the exhibitors were, as I had seen them, but I did not the least know which stand belonged to each. Their style was the same, as they had been brought up in the same school, and they were well known as at that time of very nearly equal strength. Yet one must have the cup and the other get no prize at all. In my perplexity I mounted on the central table in the tent, and took a careful bird's-eye view, holding on by the pole. This confirmed me in my previous idea that there was the slight shade of difference that I had noticed at my second attempt: I gave my judgment accordingly, and was most sincerely pleased when I found the loser was quite satisfied. I have since, on two or three occasions, found the bird's-eye view useful compared with the view of the depth of the blooms from the level of the trays.

Another very equal case was in a class for seventytwo at a Northern show. I had the proper number of two coadjutors this time, one being a very experienced and able Rosarian, and the other a local man who was generally discreetly silent. We pointed through both the best stands without any disagreement except in the case of one bloom, where I was for three points and my experienced friend for one only. The third judge opened his mouth for the first and only time, and gave his voice against me. That decided the principal prize of the show, for we found only one point of difference between the two stands of seventy-two each, and if my view of that one bloom had been acted on, the other seventy-two would have won by one point.

The silent judge played his part and did what was 
required of him. He did not act, I hope, or give his judgment from the same motive that influenced one at a village cottagers' show. There were three judges for the fruit and vegetables, \&c.-Mr. A, the head gardener from the big house; and Messrs. B and C, gardeners in humbler establishments. Mr. A, by right of his position, took the matter in hand and distributed the awards, the others humbly assenting in silence. Presently $\mathrm{C}$, perhaps thinking it was better, if only as a matter of form, to assert himself a little, suggested a small point of disagreement. The matter was promptly referred to $B$, and he decided the question by saying, "Oh, I always goes with Mr. A"! It was all right, for Mr. A was a good judge, but it was plain that, unless for ornament, $\mathrm{B}$ and $\mathrm{C}$ might as well have been at home. 


\section{CHAPTER XII}

\section{MANNERS AND CUSTOMS}

ON looking over a good collection of Roses a keen observer, even if he be unlearned in their culture, cannot fail to be struck with the difference observable in what is called the "habit" of each sort, for there is almost endless variety in wood, leaves, thoms, strength, and manner of growth, apart from the blooms themselves. He would also probably notice a good many of what he would call "red" Tioses, very much alike to his untrained eyes in general appearance, and he might wonder how they could be all distinguished apart. But as a good shepherd can tell every member of a large flock of sheep by a diligent study of their faces, and an English apple, or even apple-tree without its leaves, can be correctly named by some clever pomologists, so a fairly representative bloom of any liose can be distinguished by a thoroughly expert Rosarian.

Descriptions of the different varieties are to be found in the catalogues issued by nurserymen, and many of these are now fairly full and accurate. The colour, naturally enough, occupies the principal part of the descriptions: but the different shades, 
especially of Teas, are very difficult to express to ordinary readers in language that they will clearly understand, for some are extremely variable in their tints, and others come much fuller in colour when grown strongly.

It is not every one who is, without studying the matter, well conversant with the different tints expressed in the terms frequently used. Among these may be found-ivory, cream, lemon, chrome, straw, canary, sulphur, nankeen, saffron, apricot, fawn, buff, salmon, copper, bronze, blush, flesh, peach, rose, cerise, coral, cherry, currant, madder, vermilion, scarlet, lake, carmine, lilac, plum, violet, magenta, claret, maroon, and amaranth. It requires not only a good eye for colour, but also a certain amount of training, for an ordinary man to distinguish accurately between these shades; perhaps the description "a soft shade of écru, passing to a lovely golden yellow " might leave him not much wiser than he was before. I confess that some of them beat me, and that even the first two on the list, ivory and cream, as seen in Roses, would present very slight distinctions to my eyes.

A good many of the Tea Roses, especially the light yellows, come practically, if not pure, white, when exposed to strong and continued sun; and as these are generally credited as to colour with the first descriptions of the raisers as seen under glass, there is sometimes a little disappointment with the tints as seen out of doors. Thus Devoniensis, Edith Gifford, and Innocente Pirola used to be described without any mention of the word "white," which must seem very strange to those who know the Roses.

Such good old colour-words as white, yellow, pink, 
red, scarlet, and crimson are my strongholds, and in the following catalogue I shall mostly use the descriptions of colour to be found in the trade-lists, the best of which are carefully compiled from a long and widespread knowledge of the various sorts, and a study and comparison of the different shades. My endeavour will be to supplement these descriptions with other matters that the purchaser and chooser would like to know as an addition to and commentary upon published catalogues.

For instance, the novice student of these seductive pamphlets will only require a little knowledge of human nature to enable him to take a fair discount off the description given by the raiser himself of any one sort: and he will find it advantageous to be acquainted with some slight vagaries in catalogueEnglish which custom has sanctioned. In this language "medium-sized" means "small," and "pretty" generally implies the same. In growth, "moderate" means "wealily," "free " describes a plant which is rather weakly but branching, and "vigorous" stands for ordinary growth. "A good pot Rose" might very likely mean that it would not stand any bad weather out of doors, a " nearly full" one mean shows an eye, and we should probably be doing no injustice in supposing that a Rose which is "good when caught right" is bad as a rule.

It has become a matter pretty generally known how unwise it is for a begimner to select his sorts from those blooms which take his fancy at an exhibition: and there are drawbacks to the cultivation of a good many of the show varieties, which we cannot expect to find noted in catalogues for sale. These demerits and bad habits of certain Roses I want to point out as well as their good qualities, as they are of the 
utmost importance to those who wish to choose their sorts, and have only trade catalogues and the flowers to be seen at shows to go by. For, among Roses, there are a great many "little ways" belonging to the different tribes, families, and individual varieties, and many an otherwise excellent sort has a nasty habit of doing this, that or the other which just prevents its being as good as it might be.

A variety may be faulty as a plant, having an unhealthy constitution, weakness of growth, deficiency of foliage, a special tendency to mildew or orange fungus, or a lack of freedom of bloom, or of good qualities in the autumn. And if the plant is all that can be desired, there may be serious demerits in the flowers as a rule, however good an occasional specimen may be. Among such faults may be-a liability to be stained, gummed, or rotted by rain, or to "burn," that is, turn brown, in hot weather, or to come badly shaped, malformed, quartered, or divided, or to have some deficiency in stoutness and smoothness of petal, fulness of centre, accuracy of form, or brightness of colour.

The Teas have a special fault in that some of them will not bring blooms to full perfection when grown as dwarf plants, and they are also peculiarly liable to be injured by rain; but, on the other hand, they are somewhat less injured by mildew and completely free from orange fungus. Besides these general faults, many Roses have private habits, either good or bad (generally bad !) of their own. It is most desirable that these should be known, but it should be added that situation, climate, soil, and culture have wuch effect upon the manners and customs, sometimes to a very striling extent. 


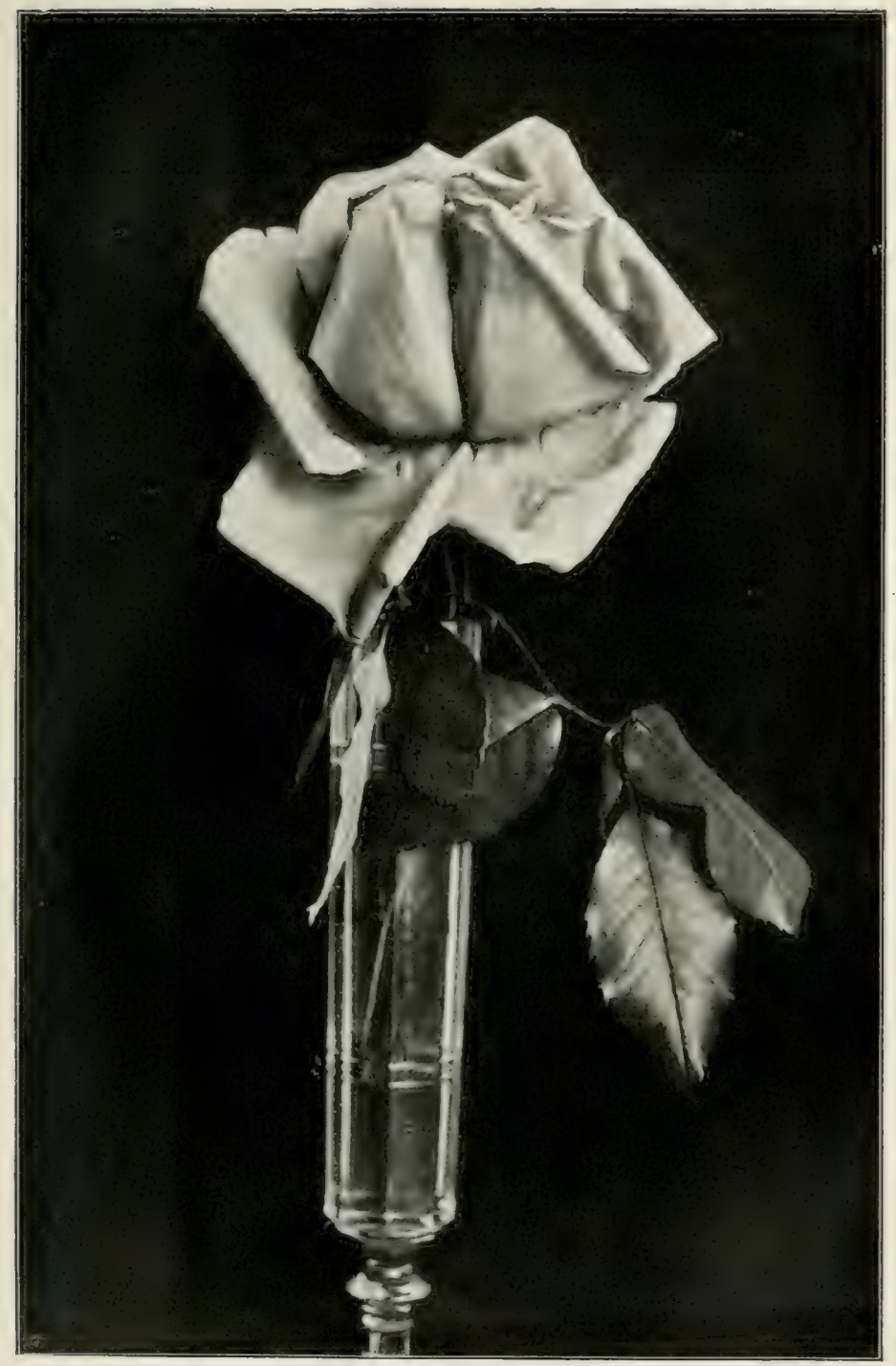

Rime Fallts. A "DINIned" Rose.

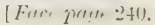



It is quite common to hear one amateur say of a certain variety that it is uscless with him-that it will not grow, or the blooms come to no good-while another answers that he finds it all he could wish in growth and flower. After a fair trial, it is far better to give up a Rose that does not answer: there are plenty of different sorts and many new ones each year, and I should strongly advise a vigorous weeding out every autumn of all those which have been thoroughly tried and found wanting.

Usually it takes two or three year's' trial at least of a new variety to find out its own particular manners; so, that, unfortunately, I cannot give a reliable account of the newer hoses, of which Rosarians of standing who are exhibitors will most wish to hear. Not only that, but all lists and catalogues get out of date before very long, the least valuable varieties being superseded as others, more perfect in their especial line, come into commerce.

In revising the following list, I have made a few additions and a good many omissions: and, however fleeting and ephemeral lists and selections may be, a great many are here mentioned which are not likely to go out of date for some time, and whose manners and customs are now thoroughly established. I have also, in deference to general opinion, placed those which are held to be Hybrid Teas in a separate division from the Hybrid Perpetuals.

\section{HYBRID PERPETUALS}

Abel Carriere (Verdier, 1875).-Eliminated by the editors of this edition.

Alfred Colomb (Lacharme, 1865).--Of fine growth 
and foliage in good soil but not on poor or light land. Seldom attacked by mildew and can stand some rain. The blooms generally cone good, but occasionally divided, of fine typical shape, what the N.R.S. Catalogue calls "globular, high centre," which I think should be rather "semi-globular, high centre" : very good in petal, centre, size, lasting qualities, fragrance, and colour. This is a first-class late show Rose, good as a standard, fragrant, free in bloom, and fine as an autumnal, with clean, smooth-skinned, handsome wood, striking well as a cutting. The flowers are often extremely like those of Marie Baumamn, though the wood and habits of the plants are very different. In my opinion, if either of these two well-known Roses was now brought out as a novelty, having been hitherto unknown, it would be considered synonymous with the other. Marshall P. Wilder is held to be too much alike and therefore considered a synonym, but a very capable amateur considers it an improved strain.

Alfred K. Williams (Schwartz, 1877).-Makes long shoots as a maiden, or at times on good soil as a cutback, but the constitution is weak. Thorny, with good foliage, and will stand some rain. This is a Rose of great reputation, because the blooms nearly always come perfect, forming first-class examples of the popular "imbricated" shape, i.e. something after the form of a camellia. Not a good bloom to last, or of the largest size, but prominent as a show Rose from its shape and bright colour. It is not a very free bloomer but comes again pretty fairly in the autumn. The shoots, though not very stout, run up to some height, and though the plant requires 


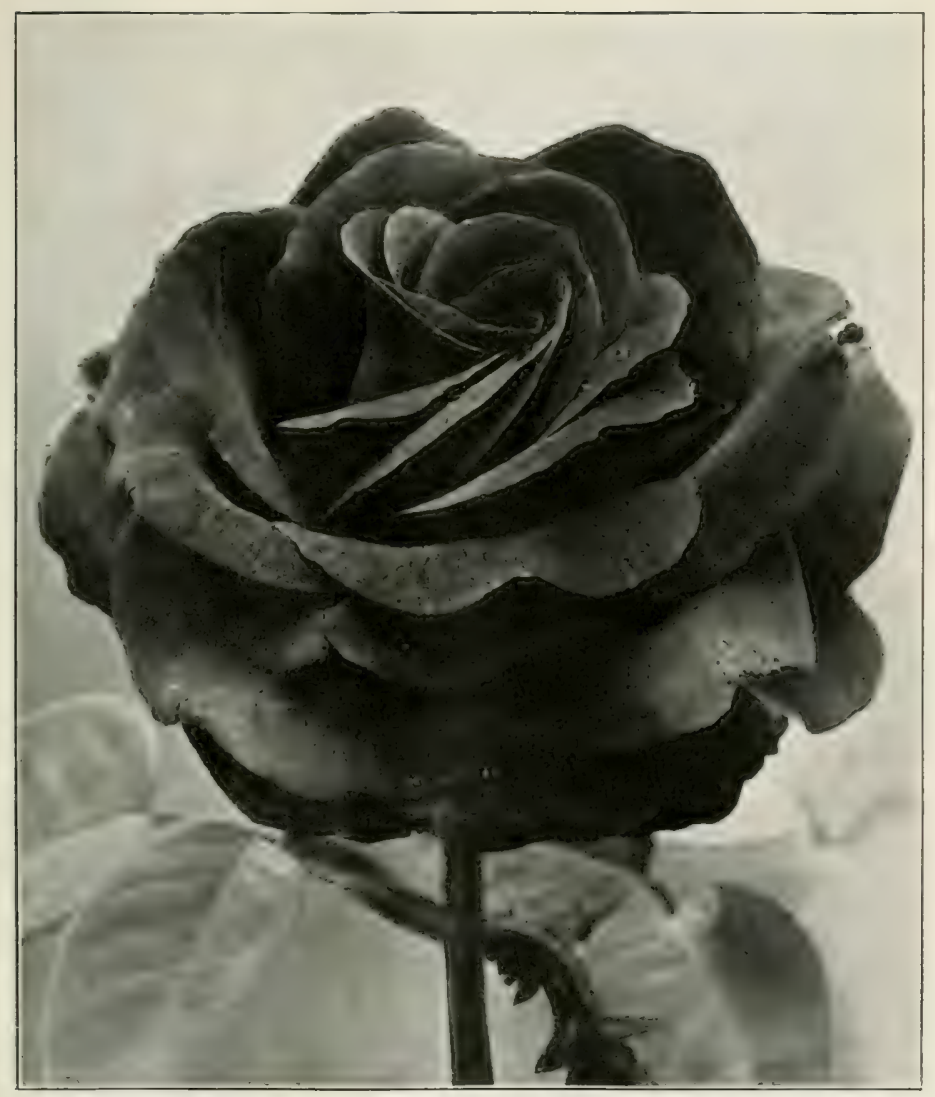

A. K. Wimliam:

[Face pary: 240.

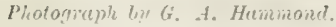



"liberal treatment," they should not be pruned back too closely. The variety is not hardy or long-lived, and should be budded every year, preferably on the briar, as, though some do well as cutbacks, maidens are more to be depended on: some find it answers best as a standard. Not to be recommended for those who cannot give it good soil, and high culture. Grand Mogul is said to be a seedling from this beautiful Rose.

Baroness Rothschild (Pernet, 1867).-Eliminated by the editors of this edition.

Beauty of Waltham (TV. Paul \& Son, 1862).-Fair in growth and foliage, and not much liable to injury from fungoid pests or rain. The blooms come true and well, being seldom divided or malformed. The shape varies according to situation and cultivation. The N.R.S. Catalogue calls it " imbricated," and the raiser "cupped": my specimens do not come in either of these forms, but the petals are very closely curved inwards in the centre in a manner that proclaims the variety at once. Nevertheless it should be noted that on better soil than mine it does come regularly of semi-imbricated form, and is then a fine flower. Like some other's somewhat of this shape, and those of the pointed form, this Rose has the good custom of closing in and guarding its centre more tightly in hot weather when it is most needed than at other times. Not first-class, but a free bloomer, rather late, good in lasting qualities and as an autumnal, but not very large, very fragrant. It has produced a seedling, Lady Arthur Hill (Dickson, 1889), of a novel shade of colour, but not large enough.

Ben Cant (B. R. Cant \& Sons, 1902).-Raised by 
the sons of the late well-known professional Rosegrower at Colchester, and named after him, this Rose, a seedling from Victor Hugo, has been grandly shown by them, and gained the N.I.S. Gold Medal in 1901. It is of fine, clean, strong growth with grand foliage, and seems to be a splendid crimson Rose for exhibition when grown on good H.P. soil, but many amateurs have not been successful with it. As I have always associated the name with the very finest of Roses, it has been a great disappointment to me, but I still hope we shall do better with it, when it has become more established. This Rose should only be included in the largest collections as only occasionally will it give a show bloom.

Boule de Neige (Lacharme, 1867)._Eliminated by the editors of this edition.

Camille Bernardin (Gautreau, 1865).-Eliminated by the editors of this edition.

Captain Hayward (Bennett, 1893).-This was a seedling Rose that Mr. Bennett, the raiser of Her Majesty and Mrs. John Laing, \&c., left behind him unflowered when he died. At its very best, grown as strongly as possible, in a cool season, it is with its pointed form and beautiful long smooth petals of scarlet-crimson as magnificent an example of the bright red H.P.s as we have at present. It is of extra vigorous growth with very fine foliage, but the petals are rather thin and few in number, and it opens very quickly. It requires the most "liberal treatment" (a phrase which implies good soil, plenty of manure), close pruning, vigorous thinning, and that it is best as a maiden-in short, as much sap as possible put into the bud from the beginning), and early tying of the bloom for exhibition : but it is im- 
possible to show it in very hot weather. It has even been recommonded that it be planted in a shady spot. Large in size, not much liable to fungoid pests or to come malformed, and a grand Rose for pot-work and forcing.

Charles Lefêbvre (Lacharme, 1861).--Synonyms, Marguerite Brassac and Paul Jamain. Of strong growth, with stout stiff smooth wood and fine foliage, requiring strong soil. The secondary shoots are much stronger than the early ones, and on cutbacks the latest blooms of the first crops are generally the best, the first buds being most liable to injury from cold nights in May. More liable to orange fungus than to mildew, and can stand rain pretty well. The flowers generally come good, fine in petal, centre, and size, lovely in colour, very fragrant and beautifully smooth and round in appearance. The shape is open and semi-imbricated, which is very effective, but not a good form to last. Free in bloom and a good autumnal, this was for many years the G.O.M. of the dark crimson Roses.

Clio (W. Panl \& Son, 1894).--Eliminated by the editors of this edition.

Commandant Félix Faure (Boutigny, 1902).-A hardy vigorous grower with very large foliage and free flowering-but the flowers, excellent otherwise, are on the small side for exhibition purposes-still their wonderful colour (dark crimson, shot vermilion) makes the plant worth noting, more particularly as the colour is more lasting than the majority of Roses of this shade. Useful as a front row flower-but must be severely disbudded.

Comte de Raimbaud (Roland, 1867).-A reliable full-sized rose of good form and colour, with good 
form and colour, with good average growth and foliage and clean handsome wood, not particularly subject to fungoid pests or to injury from rain. An odd thing about it is that it does not seem to have been much noticed, or at all events appreciated, till it was fifteen or twenty years old.

Comtesse de Ludre (E. Verdier, 1880).-Eliminated by the editors of this edition.

Countess of Oxford (Guillot, 1869).-Eliminated by the editors of this edition.

Countess of Rosebery (Postans, 1879).-Eliminated by the editors of this edition.

Crown Prince (W. Paul \& Son, 1880).-Eliminated by the editors of this edition.

Dr. Andry (E. Verdier, 1864).-Of capital growth and foliage, hardy and of strong constitution on all forms of stock, early in flowering, not much subject to mildew or orange fungus, and standing rain fairly. The blooms generally come with a pretty good point, but are apt to be divided, and sometimes irregular in the circular outline. Fair in size, good in petal and centre, and very bright at first in colour, but as often happens this does not last so well as the shape. It is very free flowering, a row of it making a grand show for a few days, but is not very good in autumn. A useful and thoroughly reliable Rose, which will do fairly well in poor soil.

Dr. Sewell (Turner, 1879).--Eliminated by the editors of this edition.

Duc d'Orleans (E. Verdier, 1889).-Eliminated by the editors of this edition.

Duchess of Bedford (Postans, 1879).-Of rather weakly growth and best as a maiden. A lovely and striking flower, beautiful in its semi-imbricated form, 
and bright with glorious colour, a mixture of scarlet and crimson. Not strong in constitution, free flowering, or good as an autumnal, and often fails to come good, either in colour or shape. An exhibitor's Rose, and never very large, it seems to like a cool season, and is therefore best in the North and Midlands.

Duchesse de Morny (E. Verdier, 1863).—Of fair growth and foliage in strong rich soil, the wood and leaves being very distinct and characteristic. Decidedly liable to mildew, and camnot stand much rain. The blooms come well shaped, with very smooth stout petals, beautifully full, of distinct and lovely colour, large size, and fair lasting qualities. This Rose is one of the very smoothest and most regular in semi-globular imbricated shape that we have; a free bloomer, but not so good in antumn, and rather dainty as to soil and treatment. The buds should be well thinned, for this is one of the true aristocracy, where no fear of coarseness need be entertained, and the variety is a great favourite with me. The shoots often come wholly or partly fasciated,-i.e. two or more joined together-a bad habit, and such growth at pruning time should be clean cut out. Ellen Drew (A. Dickson \& Sons, 1896) is a pale sport of this Rose.

Duke of Edinburgh (Paul \& Son, 1868)._-Of strong good growth and foliage, with characteristic wood; the secondary shoots are very long and rather spindly and pliable, so that the blooms are sometimes pendant. Not very liable to mildew, or much injured by rain, but in some places a victim to orange fungus. It generally comes true to its shape, which is good so long as it holds its point; but the petals are not 
very stout or the centre very full, and it is not a good laster. Of full size and most brilliant colour, vermilion, crimson. In strong specimens the crimson predominates when the bud shape is passed, but the self vermilion, which is generally found only on the weaker blooms, is perhaps the most effective. Not lasting in colour or shape, but of large size, a fair autumnal, good on all stocks. This was for years the brightest of all red Roses, but has been surpassed in this respect by later introductions. Of good constitution, but apt to rum to wood instead of to bloom, especially in autumm, and on the manetti; it should therefore be lightly pruned, the shoots being left of some length.

Duke of Teck (Paul \& Son, 1880).-Very like the last named in most particulars. Others of the same class and apparently of the same family, all coming from Cheshunt, are Reynolds Hole and Sultan of Zanzibar, but these last two are very delicate in constitution, while the Dukes of Edinburgh and Teck are strong and hearty. Duke of Teck is not so dark in crimson and not so brilliant in vermilion as the earlier type, but, like it, should be left long in pruning. Best on old plants.

Duke of Wellington (Granger, 1864).-Syn. Rosiériste Jacobs. This is marked in the N.R.S. and some other catalogues as moderate, i.e. wealily in growth, but it is quite fair in vigour and foliage with me, and does well as a standard in many places. Of strong constitution, my oldest dwarf plants on briar cutting being still my best and stoutest. Not very liable to mildew or much injured by rain, a free bloomer and quite a good autumnal. 


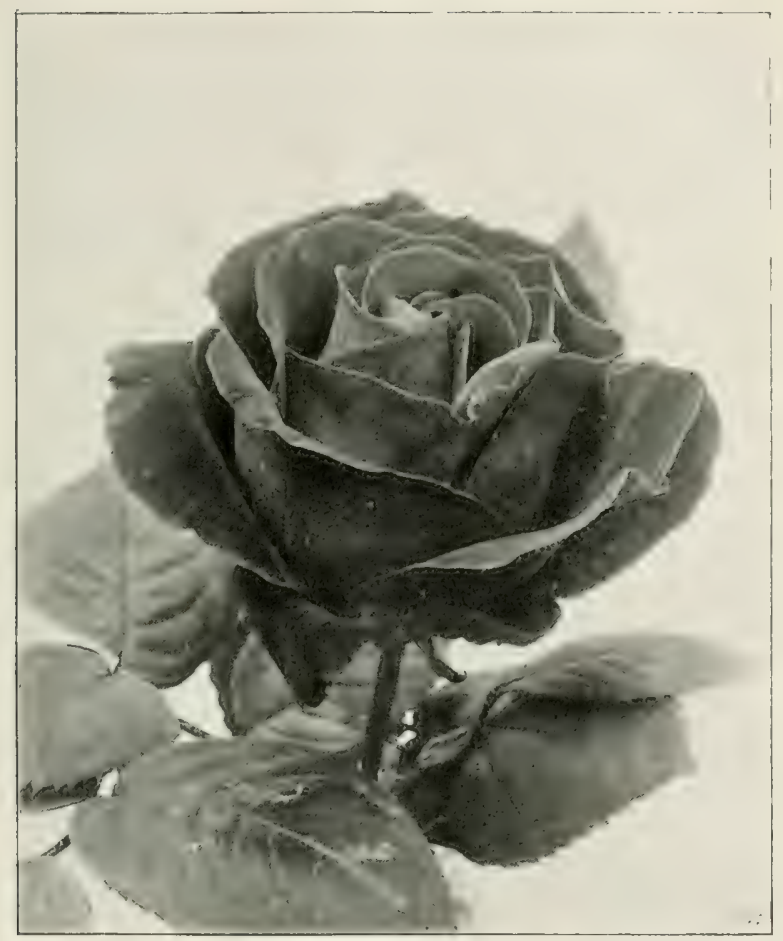

U) UKE OF WLLIN WTON, H.I'.

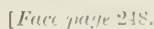



The blooms come well in what I call the pointed form and are capital in petal and fulness, grand in dark crimson colour and lasting qualities, and of fair average size. Will not do in hungry soil, or where not well treated, but high feeding and close pruning will generally produce splendid blooms. Older than the Duke of Edinburgh, and, in spite of general repute, much the better show Rose of the two with me. This is one of those varieties which close their petals in the evening, thus seriously disconcerting at times exhibitors who have to choose their blooms at late hours.

Dupuy Jamain (Jamain, 1868).-Of very strong, stiff, stout growth and foliage, good on all stocks, with vigorous, clean, smooth shoots, such as a Rose should have. Not liable to mildew, but little injured by rain and does not need close pruning. I ought to say that all H.P.s, except perhaps Paul Neyron, Uhich Brumner, and some others inclined to coarseness, are sometimes attacked by mildew, and are the better if rain does not fall on the open flowers, so "not liable" must be generally taken as not especially liable. The round fat smooth shoots of Dupuy Jamain produce round fat smooth blooms, which generally come well-shaped, but the petals are not so stout as they look, and the centre is weak in hot weather. For exhibition it should be cut young and the point tied up for travelling, as it opens only too well. Of large size, but a bad one to last; very free in bloom, and perhaps the best autummal of its colour. If I wanted a red Rose at the end of October I should come here first, and if any H.P. will bloom at Christmas this will. A 
good and reliable cool season Rose, of strong bardy constitution, which will grow almost anywhere, and well repay good treatment.

Earl of Dufferin (A. Dickson \& Sons, 1887).-Of long but pliable growth, which, in the case of dwarfs, must be staked, or the heavy bloom will bend the shoot right down to the ground. The foliage is rather weak, and the buds even when they begin to open do not look promising or attractive. Nevertheless under favourable circumstances they slowly grow into large highly-coloured blooms of semi-globular shape, sweet-scented, lasting, and sometimes very fine. It is quite a late Rose, not very free-flowering, nor of much use as an autumnal. Its principal fault is roughness of outline, which makes it look ragged, and I have never had a decent bloom of it. A Rose for exhibitors, but not for garden culture in this country.

Etienne Levet (Levet, 1871).-Of robust and smooth but very uncertain growth; long, strong, and stout in rich soil where it has a good hold, but otherwise quite short and stumpy. The foliage is very fine, and the blooms come early and well, with large very smooth shell-like petals; there is, or should be, a good point, but the general shape is flat, the centre weak, and the form not lasting. Must be cut young for exhibition and tied up at once, for it is of no use in hot weather. Not much injured by mildew or rain, but not good as a free bloomer or autumnal, and of no use in hot climates. It is of large size, and its grand petals and smooth, even outline make it an effective show Rose in a cool season; but, though it does well on the manetti, for general cultivation or on weak soils it is not one 
of the best. Duke of Fife (Cocker, 1892) is a deep crimson sport from this variety, and a much worse grower. Noteworthy, as a sport generally comes of a lighter colour than the type.

Eugènie Verdier (J. B. Guillot, 1869).-Syn. Marie Finger (Raimbaud, 1873).--Eliminated by the editors of this edition.

Exposition de Brie (Granger, 1865), see Maurice Bernardin.

Ferdinand de Lesseps (Verdier, 1869), see Maurice Bernardin.

Fisher Holmes (Verdier, 1865).-Of good growth and foliage. Particularly liable to milder, but not much hurt by a little rain. The blooms come well, of the good pointed shape of the Duke of Wellington, and the shape is lasting, though the brightness soon fades. Below the average size in ordinary soil, but free blooming and a capital autumnal. This is a most useful sort, which accommodates itself well to circumstances - shuts up its petals at night, tightens its point in hot weather, and forms a beautiful button-hole in autumn or when not thinned for show purposes.

François Michelon (Levet, 1871)._Of peculiar and very characteristic growth, with green, slender yet fairly stiff stems, and thin, poor foliage. This is the Rose above all others whose performance is better than its promise. It seems incredible that such a little bud on its spindly stem should open into what is one of the largest and finest show Roses we have : but it does. The petals look thin and the growth seems so weak that an exhibitor who did not know the Rose would be slow to believe it would stand or hold its shape in a hot tent: but it does this too. 
Little affected by mildew, but soon injured by heavy rain, the blooms come fairly well, but the centre though almost always well covered has seldom a defined point and is sometimes irregular. The outline is often rough and the colour is not lasting. It cannot be called a free bloomer, and is one of the worst autumnals in our list of H.P.s, a large proportion of the plants having no second crop. In propagating this Rose and others which are shy bloomers and bad autumnals, care should be taken to bud from a flowering stem, for the young plant will probably not bloom the first year if the bud has come from a non-flowering autumnal shoot; and a " punaway maiden" is a source of disappointment, even among Roses. Requires the briar stock, a cool season, and generous treatment. This Rose is apparently the progenitor of Mrs. John Laing, still one of the most reliable of Hybrid Perpetuals.

Frau Kurl Druschli (P. Lambert, 1900).-This liose, which came from the Continent with no great blowing of trumpets, has proved itself to be the best H.P. sent out for many a year, and is universally ackinowledged to be the finest white Rose in cultivation. It is of extra strong healthy growth with very fine foliage, an abundant bloomer, and a good autumnal. The long buds are pink on the outside but open into pure snow-white flowers of the largest size and of quite first-class form. They will not hold their shape very long in hot weather, but last generally long enough for exhibition purposes; so that the variety has already become one of the most popular of all Show Roses, and has also proved itself invaluable for garden decoration. It is not proof against mildew, and like all white Roses is soon 


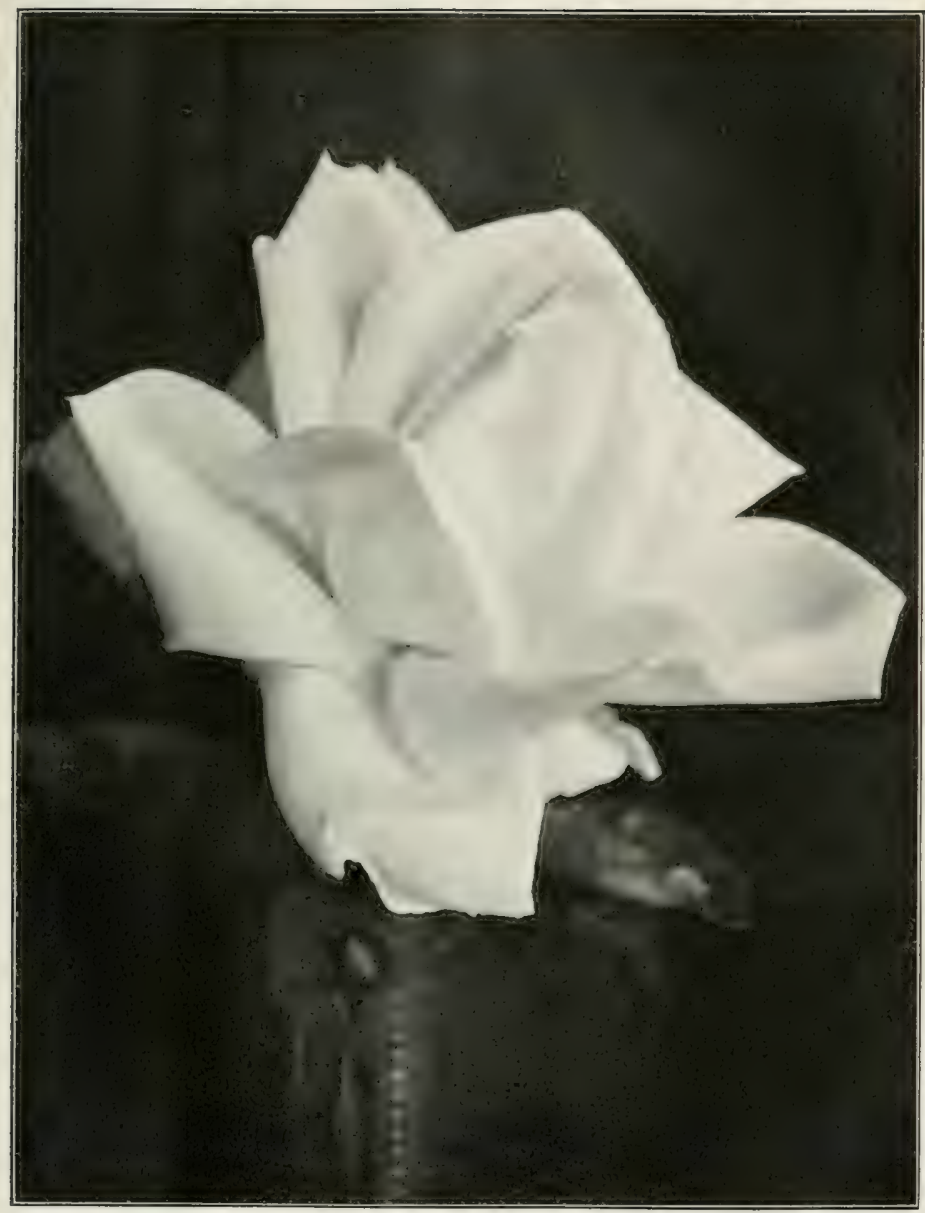

Frat Karl Drtschiki.

[Eace pane 252.

Photomerph tor G. A. Huminond. 

injured by rain, but must be highly recommended for even the smallest collection.

I can remember when Madame Noman was the best white H.P.: then came Madame Lacharme, larger and better: Merveille de Lyon quite superseded these two, and was in its turn threatened by Margaret Diclison. All these should now be given up, as they are manifestly inferior for all purposes to Frau Karl Druschki.

Général Jacqueminot (Rousselet, 1853).-Good but rather slender growth, and fine but thin foliage; liable to mildew, but not much injured by rain: very free-flowering, fragrant, and a good autumual, but decidedly thin. It must be grown very strong and cut young to be fit for exhibition, but it is still often well shown, principally by nurserymen and large amateurs, and is best as a standard maiden. As bright as Duke of Ldinburgh when grown to perfection, but not lasting or of the largest size: still "le brav' Général " knows its wealness, "pulls itself together" in hot weather, and tightens its point as hard as it can. Few Roses have had such a lasting reputation: for this grand old veteran is the great-grandfather of almost all our red H.P.s, and is still grown very largely on all stocks for market and florists' purposes, "Generals" being almost as well and affectionately known in the trade as "Niels." It has held a prominent place for many years, not only for pot-work and forcing but also for garden and "massing" purposes.

Gloire de Margottin (Margottin, 1887).-Eliminated by the editors of this edition.

Grand Mogul (W. Paul \& Son, 1887), sce Jean Soupert. 
Gustave Piganeau (Pernet \& Ducher, 1889).--Very short in growth, which is nearly the only fault of this very fine Rose. The foliage is good, and the plump fat buds above it open into very large, brilliant, grandly shaped blooms, with broad stout petals and beautiful centre. Very little liable to mildew, and not much injured by rain. It was a great disappointment when this splendid Rose proved to be a poor grower. Moreover, the plant is not lasting in vigour, but often gets weaker, and it is best as a maiden, either on briar or manetti. It is very free-flowering, which seems to be a cause of its weakness of growth; it will not make wood, but is constantly forming buds. I must say, however, that of late years fairly long secondary shoots have not been uncommon: and as these have naturally been selected for budding, the general habit of growth is, I think, decidedly improved. A good autumnal, capital for forcing and a large, lasting reliable exhibition Rose.

Heinrich Schultheis (Bennett, 1882).-Eliminated by the editors of this edition.

Helen Keller (A. Dickson \& Sons, 1895).-At its best this is a very beautiful Show Rose. In a favourable season it would often be among the three or four most noteworthy H.P.s in the large stands of the leading nurserymen. Not of very strong growth, "moderately vigorous" representing it fairly. The blooms are of the ordinary "semi-globular" shape, very regular and seldom malformed, of a very bright shade of pink catalogued as "rosy cerise," fragrant, full-sized, with stout petals and good lasting qualities. The buds form early, with frequently fatal results in low-lying districts subject 


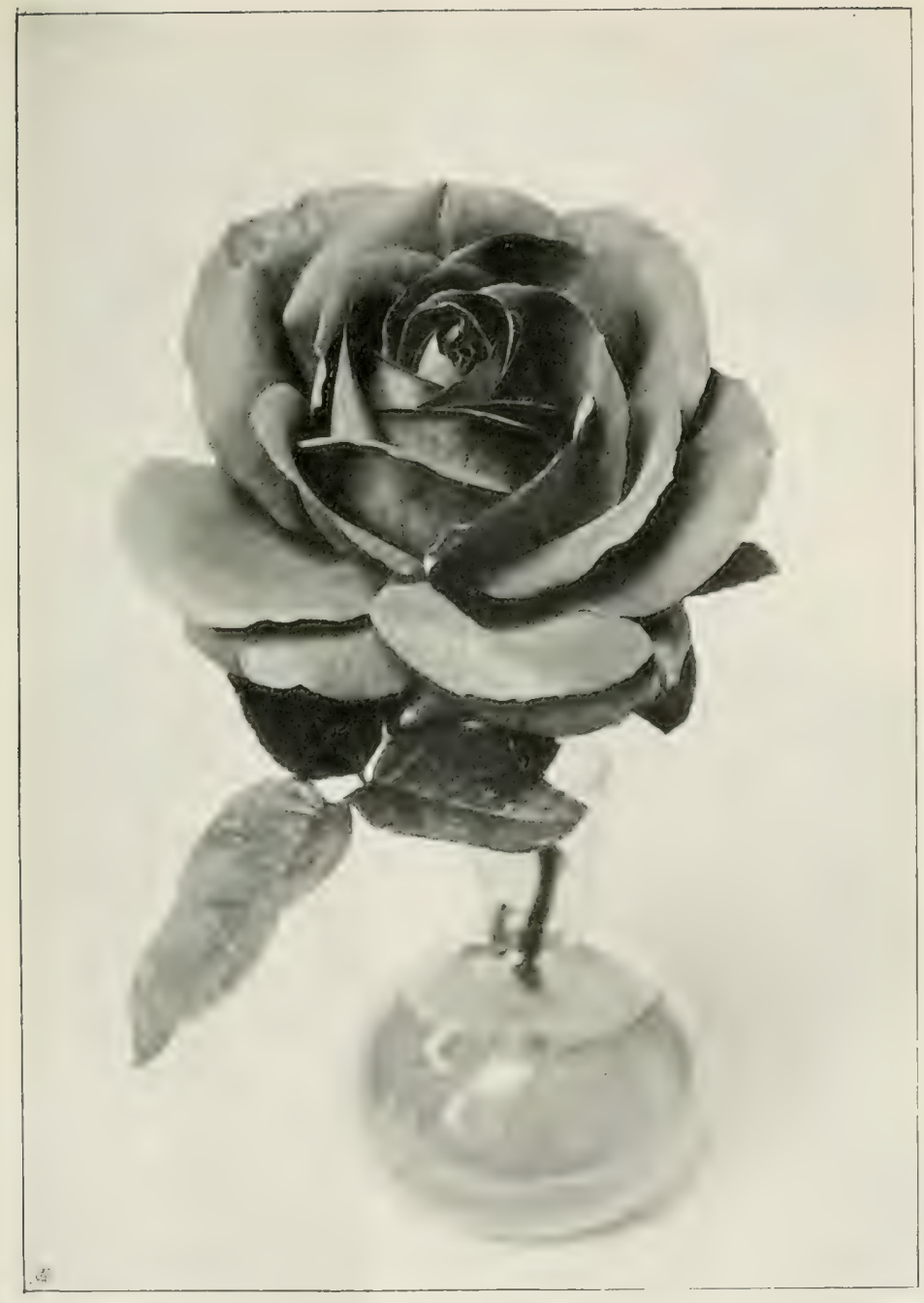

Gustaym Pranfidu, II.P. 

to very cold Nay nights : it is only in exceptionally good seasons that any but the longer later shoots yield good blooms with me: but the variety is well worth growing if only a few fine specimens can be secured.

Her Majesty (Bennett, 1885).-Manners and customs are notoriously strict and exacting in royal circles, and in this remarliable Rose we certainly have some striking peculiarities. Of long, strong and yet robust growth if well fed, but by no means free: it makes extraordinary growth under favourable conditions, but a poor show if not treated regally and favoured with fine weather. Prune high or low you will get but few shoots to a plant, and if the single growth of a maiden shoot be stopped, instead of breaking in several places like the vulgar herd, Her Majesty generally shoots only from the top bud left, and continues one stem upwards as before. We may place the plants close together, for the stems of each are few in number and upright and stiff. It has fine foliage and large stems with tremendous thorns, the whole being extremely and notoriously subject to mildew, so that it is best planted by itself or among the Teas, where the infection will be less dangerous in the summer season. It is a very slow starter in growth if pruned hard, and as it is advisable to get the blooms as early as possible before the plant is crippled with the inevitable mildew, this Rose alone of all may, with possible advantage, be pruned in the Autumn, as it will still not start growth early enough to be injured by frost. Better still perhaps is it to leave it so long in pruning as to get a plump and well developed bud for the coming shoot: indeed it should not be pruned too 
hard, or have too " liberal treatment." I would not advise the application of liquid manure after the buds are formed. If grown well, a large proportion of the blooms come good, and they can stand a little rain. They have fine stout petals, and are wonderfully full in the centre, so much so that the Rose has quite two shapes, and the best one was not known for the first year or two: for it has in the first stage a grand regular semi-globular shape, and when expanded and overblown it is yet so perfectly full, even when as flat as a pancake, as to show no eye, and to be still presentable and wonderful, though not so beautiful as a Rose. The colour is best and purest in the first of these stages: in the second it is more mixed. When presented for the Gold Medal, which was granted by acclamation, it was shown by Mr. Bemnett in great quantity, several large boxes of it being staged. Every bloom was fully expanded, and its true beauty remained unknown. It was then sold to America and we had to wait a year for it. When it was at last obtainable, there was a large demand for the half-guinea plants, with the result, I believe, that there was hardly a bloom seen in the country that year, the plants having no doubt been budded from non-flowering shoots. The following year the true form was seen, and it is not now quite so shy a bloomer as it was. In size and lasting qualities it is quite at the top of the tree: as a free bloomer and autumnal, absolutely at the bottom. A secondary or true autumnal bloom is rare: it does bloom as a maiden, otherwise its title to the term Perpetual might yet be in abeyance. It is decidedly a hot-season Rose with us. A remarkable point about this Rose is its 



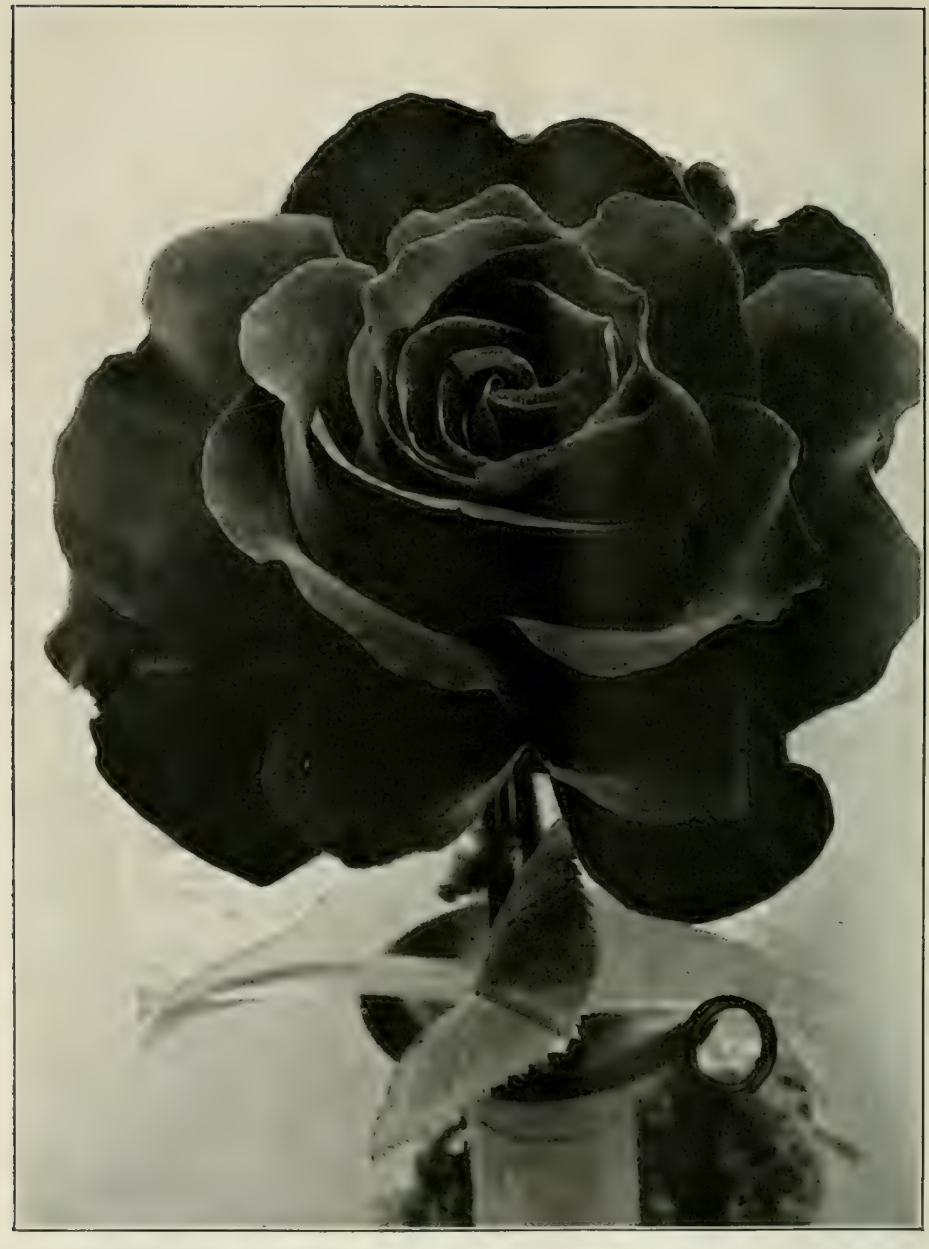

Horace Vernet.

[Fece \}rege 257.

Pleotograple by G. A. Hammonel. 
reputed parentage; for it is said, though it is generally supposed there must have been some mistake or accident, to be a seedling from the old Tea Canary, a yellow flimsy thing according to modern notions, and Mabel Morrison, a white sport from Baroness Rothschild, which is particularly open and deficient in the centre. If this is so, it should strictly be called a Hybrid Tea. Mr. Bennett was one of the first to practise hydridising in this country, and sent out his new issues as Pedigree Roses: but one would think that on beholding the illustrious progeny of this apparently ill-assorted pair he must have been inclined to consider chance quite as likely to be successful as the careful choosing of seed-parents.

Horace Vernet (Guillot, 1886). - A typical show Rose: grand in the extreme in every way on the exhibition table, equalled by few, and surpassed by none; but to be avoided by those who grow Roses for ordinary garden purposes. The plant is of a weak constitution; and often cannot be kept in health and strength beyond a year or two. Indeed it is in some places useless as a cutback; no other Rose is more worthy of the annual system of culture - budding anew on fresh strong stocks every year and cutting away the old plants to get the strongest buds-and for none is it more necessary. When thus treated, the growth and foliage are good enough, one would think, to keep the stock roots in health; but the plant is almost sure to dwindle if preserved, lasting best, I am told, on the seedling briar. Not very liable to mildew or to be injured by rain. The blooms are large and generally come good; and good they are, with the stoutest of petals which shut 
up at night, capital centre, perfect shape (pointed passing to imbricated), good dark colour, and lasting qualities of the first order. Not a free bloomer or a good autumnal : these are "lions," to be made much of, and we must not expect many of them. Cut away the plant, as soon as it has bloomed, with a ruthless hand, to get the best and biggest buds for propagating. Waste none on weak stocks or on manetti, and bud a good many, not delaying too long, for some may fail and require rebudding; and, whether you keep the old plants or not, you will not often cut from them so long as you have young plants to go to. I think, howerer, that this Rose, like Gustave Pisaneau, has improved in growth and habit of late years; and probably from the same cause, viz., the constant propagation from the longest and strongest maiden shoots. In the British Isles hundreds of gardeners and Rosarians, who would otherwise never have heard of the great French artist, have had his name "familiar in their mouths as household words" by the help of this most noble Rose, his namesake.

Hugh Dickson (Hugh Dickson, 1904).-This is a great addition to this class-although there are not wanting those who say it would more fittingly be placed among the Hybrid Teas. Of a good crimson shaded scarlet, it has become one of the most popular of Roses and should be in every garden. It is a very vigorous grower, free from mildew, has no conspicuous fault, is in the front rank of exhibition Roses, and at the same time one of the indispensable garden Roses.

Awarded the Gold Medal of the N.R.S. and a 
Nickerson Cup as the best all-round crimson or: scarlet rose. Very fragrant.

Hugh Watson (Alex. Dickson and Sons, Ltd., 1904).-Also a crimson but with a good deal of carmine in its flowers. This is a good exhibition variety-fairly vigorous in growth-the bloom of medium rather than of large size but excellent in shape. Should be more grown.

Jean Soupert (Lacharme, 1875)._Eliminated by the editors of this edition.

Jeannie Dickison (A. Dickson and Sons, 1890).Eliminated by the editors of this edition.

John Hopper (Ward, 1862).-Eliminated by the editors of this edition.

John Stuart Mill (Tumer, 1875).-Eliminated by the editors of this edition.

Jules Margottin (Margottin, 1853). - Eliminated by the editors of this edition.

Le Havre (Eude, 1871).-O Of fair average growth, with good foliage: not especially liable to mildew, but rain will impair its quality. A beautiful show Rose, one of the best examples of the imbricated form, but the blooms will not come of good shape or colour in bad weather. Almost like A. K. TVilliams at its best, but not often large. Like Fisher Holmes and some others, this Rose shuts up at night, the petals crinkling inwards: besi as a maiden, not free in bloom or a good autumnal, but with a high reputation for its lasting qualitics on the plant as well as when cut.

Louis Van Houtte (Lacharme, 1869).--Of weak growth and small foliage; not much injured by mildew, but suffers from orange fungus and rain and 
"burns" in hot weather. The blooms will only come fine if strong shoots are produced and this is a difficult task with purchased plants, as the constitution is weak and does not bear removal well. It is best to bud it annually; but plants which have not been moved will sometimes do well as cutbacks for a few seasons. It requires high culture on briar and is not free-flowering or good as an autumnal, but it is a fine, well-built bloom when you get it good, with stout petals, high centre, fine globular outline, full size and dark, sometimes rather dull, colour. The flowers being heavy and the wood weak, flowering shoots of dwarfs should be staked when the bud is formed. The lasting powers of the blooms are particularly good, and it is worthy of notice, as an example of the odd manners and customs of Roses, that some of the weakest growers have the most lasting flowers, and vice versa. For instance, Marquis de Mortemart and Madame Ducher, two H.P.s that have dropped out of cultivation from their extreme poorness of growth, were especially noted for the lasting character of their blooms, while such strong growers as Heinrich Schultheis and Thomas Mills show the opposite side of the picture. Louis Van Houtte will not do with me : a respectable bloom even on strong shoots is a rarity : but many others grow it well and esteem it highly. For anything but exhibition purposes, however, it should be avoided.

Madame Charles Crapelet (Fontaine, 1859).Eliminated by the editors of this edition.

Madame Eugène Verdier (Verdier, 1878).-Grows well as a maiden, but the first growths of cutbacks are sometimes very short; still the blooms come just as well, and the foliage is fine. The constitution 
is delicate in some localities and the plants often gradually die; it should not be cut back too hard, as severe pruning seems to produce canker. It is not very liable to mildew, but a slight shower will stain the colour, and much rain will cause the petals to "gum," i.e. stick together, and rot. The blooms are likely to be coarse and are not often of refined shape or appearance; but they are very large with wonderfully fine petals and well-filled centres. Fairly free in bloom and a pretty good autumnal: the shape is globular, but delicacy and regularity of outline are often wanting, and really it is sometimes almost like a prize cabbage, for it is quite one of the largest Roses. It should be noticed that there is a Tea Rose of the "Dijon" race, of exactly the same name, besides Eugènie Verdier, H.P., whose synonym is Marie Finger, and Souvenir de Madame Eugène Verdier, a Hybrid Tea.

Madame Gabriel Luizet (Liabaud, 1877).-A Rose of distinct habit, with strong vigorous growth, which only flowers in summer. The foliage is very fine and sweet-scented, but liable to mildew: it is, however, maintained through the autumn more completely than that of any other H.P. The blooms are occasionally divided, but generally good. On cutbacks they come early and all at once, also after the fashion of summer Roses, and as they are easily injured by wet, two or three hours of rain at a critical time will destroy three-quarters of the crop. A once popular Rose and general favourite, for exhibition of bedding and massing purposes. It is not particularly good in lasting qualities, but of fair size, very smooth, with good petals and a capital pointed centre, and is noted for its delightful 
fragrance, and for its colour, which is the most attractive shade of pink among H.P.s. A very free bloomer in the season, but a shocking autumnal, hardly averaging more than one or two poor things as secondary blooms to each large plant. Hardy and of strong constitution, good on all stocks, making a great deal of thorny growth in the autumn, and forming quite a big bush or fine standard in good soil. It should be left long in pruning and only the outer shoots retained.

Madame Isaac Pereire (Margottin, 1880).Eliminated by the editors of this edition.

Madame Victor Verdier (Verdier, 1863).-A strong grower with fine foliage beautifully coloured in the early spring. Not especially liable to injury from mildew or rain. A well-known crimson Rose, forming large cluster's of buds which should be carefully thinned. The later blooms on the longest and strongest shoots are the best, and occasionally these are very fine, full, lasting, and bright. Fairly free-flowering and good as an autumnal, but though it is a hardy good grower with strong constitution, high cultivation is necessary for the production of really good blooms. Ella Gordon (W. Paul \& Son, 1884) is said to be a brighter form of it, but it has not been satisfactory with me.

Magna Charta (W. Paul \& Son, 1876).-Eliminated by the editors of this edition.

Marchioness of Downshire (A. Dickson \& Sons, 1894). - Eliminated by the editors of this edition.

Marchioness of Dufferin (A. Dickson \& Sons, 1891). - Eliminated by the editors of this edition.

Marchioness of Londonderry (A. Dickson \& Sons, 1893).-Eliminated by the editors of this edition. 
Margaret Dickson (A. Dickson \& Sons, 1891).Eliminated by the editor's of this edition.

Marie Baumann (Baumamn, 1863).-Syn. Madame Alphonse Lavallée. A Rose of great reputation. The growth as a cutback cannot be called more than fair, and the foliage is not large. The wood is weak and pliable, and the flowering shoots of dwarfs must be staked, as the stem is not stiff enough to support a heavy bloom. This habit much detracts from the appearance of the flowers while on the plant, as they crenerally fall over with their faces to the ground. Fragrant, not much injured by rain, but decidedly liable to mildew. It is especially noted as one of the most reliable of Roses, for the blooms nearly always come good and well shaped, semi-globular, without high centre. Free blooming and a good autumnal, fair in petal, good in centre, of large size and fair lasting qualities, and particularly excellent in smothness and regularity. More often good than Alfred Colomb, which is sometimes very like it in shape and colour, though the habits of the plants are widely different. Does fairly as a standard, but not so well on the manetti, must be highly cultivated, and requires rich soil, not perhaps quite of the strongest constitution.

Marie Finger (Raimbaud, 1873), see Eugènie Vernier. Eliminated by the editors of this edition.

Marie Rady (Fontaine, 1865).-Syn. Comtesse de Choiseul. Capital strong growth and foliage, not very liable to mildew, but the flowers are utterly destroyed by any rain, even when quite in the bud state. Requires dry hot weather, and then frequently brilliant and superb; a striking contrast to the ugly brown rotting balls which are seen in a showery 
time. The blooms are large and particularly heavy, and any poet who speaks of being "pelted with Roses" as an æsthetical luxury may, I think, be convinced of error if he will allow me access to my Marie Radys in a damp season. A free bloomer, but does not shine as an autumnal. The buds are very hard and do not open readily, but a fair proportion come well if the weather be right, with stout petals, very full centre, semi-globular shape, sometimes rather rough, brilliant red colour, and capital lasting qualities. It does not do well as a maiden, as is common with those Roses which are extra full, and will often prove a failure if too closely pruned or "liberally treated." Still it is a good healthy, hardy, late sort, likely to be in demand after a dry season, and to be neglected after a wet one.

Marie Verdier (Verdier, 1877).--Eliminated by the editors of this edition.

Marquise de Castellane (Pernet, 1869).-Eliminated by the editors of this edition.

Maurice Bernardin (Granger, 1861).-Eliminated by the editors of this edition.

Merveille de Lyon (Pernet, 1882)._Eliminated by the editors of this edition.

M. H. Walsh (Alex. Dickson \& Sons, Ltd., 1905). - This Rose is apt to be rather too late in flowering to come in as a useful exhibition variety, but in a very early season it would be wanted. Velvety crimson in colour, it is a first-rate autumnal, fairly vigorous grower, and fragrant, needs shading as it is apt to burn.

Mrs. Cocker (Cocker \& Sons, 1899).-A seedling, I believe, from Mad. Gabriel Luizet, this Rose is like it in wood, foliage, and habit, often not blooming as 



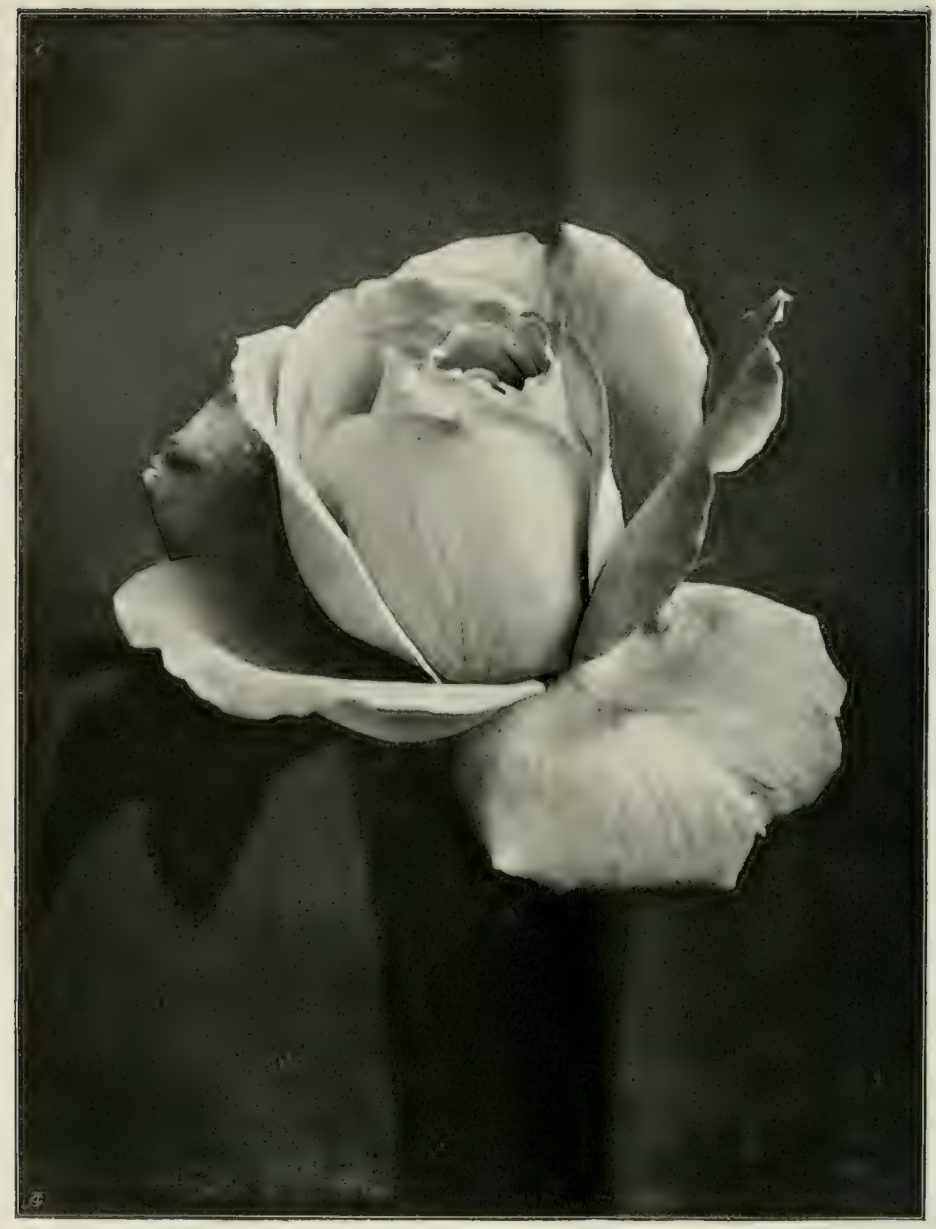

MRS, JOHN IJATNG, H.l'.

[Fice prege 265 
a maiden, and of not much use in autumn. The blooms are a lovely shade of pink, large, and very full, but not pointed, with fine petals and good lasting qualities. It is a fine exhibition Rose, but not recommended for general cultivation.

Mrs. John Laing (Bennett, 1887).-One of the best half-dozen; apparently, from a similarity in the wood, a seedling from François Michelon, but stouter and stiffer in stem, with much better foliage. Coming so soon after Her Majesty, this Rose, though not so showy at first sight, was a still greater triumph for Mr. Bennett and English-raised Roses, and was even more worthy of the Gold Medal. In the matter of " coming good," there are few Hybrid Perpetuals to beat it, for it rarely suffers from any malformation even in the autumn. Not liable to mildew or injured by rain, and retaining its foliage well in the autumn. First rate in petal, fulness, semi-globular pointed shape, lasting qualities, size, and freedom of bloom in summer and autumn, the only thing that can be said against it is that the pink colour is not very decided or bright. Hardy, doing fairly well in lightish soil, and excellent as a standard or a dwarf, it is everybody's Rose, with perhaps fewer imperfections than any other. Mrs. F. IV. Sanford (Curtis, Sanford \& Co., 1898) is a light blush sport of this variety, similar in other respects.

Mrs. Paul (Paul \& Son, 1891).-Eliminated by the editors of this edition.

Mrs. R. G.Sharman-Crauford (A. Dickson \& Sons, 1894).-This Rose was a very valuable introduction, it is of fair growth and not much liable to mildew, very free-flowering and a capital autumul : in fact, it is almost a continuous bloomer. The flower's are 
a lovely shade of pink, and quite large enough; they seldom come malformed, though the shape is not of the highest class. It has a high reputation as being easy to grow, and not exacting in its requirements. A capital Rose for young exhibitors, and it may confidently be recommended as one of the best for all purposes.

Paul Neyron (Levet, 1869).-Eliminated by the editors of this edition.

Pride of Waltham (W. Paul \& Son, 1881).-A sport from Countess of Oxford, with all the manners and customs of the well-known Victor Verdier family. This is one of the few that have survived modern competition, being as good a grower as any of them, with large blooms opening well to good shape, with stout petals and fine colour. Countess of Oxford has sported, in more than one place to my knowledge, to the same shade of pink.

Prince Arthur (B. R. Cant, 1875).--Of good vigorous growth, but the rood is not quite stiff enough to support the blooms, and the shoots of drvarfs should be staked; liable to mildew and orange fungus, but not much injured by rain. The blooms come generally well, in a characteristic form, and though the petals are thin and the flowers look fragile, they last well. I gathered from the late $\mathrm{Mr}$. $B$. R. Cant that the origin of this fine Rose is rather obscure, but the general appearance points to Général Jacqueminot as an ancestor. It is, however, much darker in colour, larger, and does better with me in every way. It is very free blooming and fairly good in autumn, but requires good treatment to be seen in perfection, though it is hardy and healthy in most soils. 


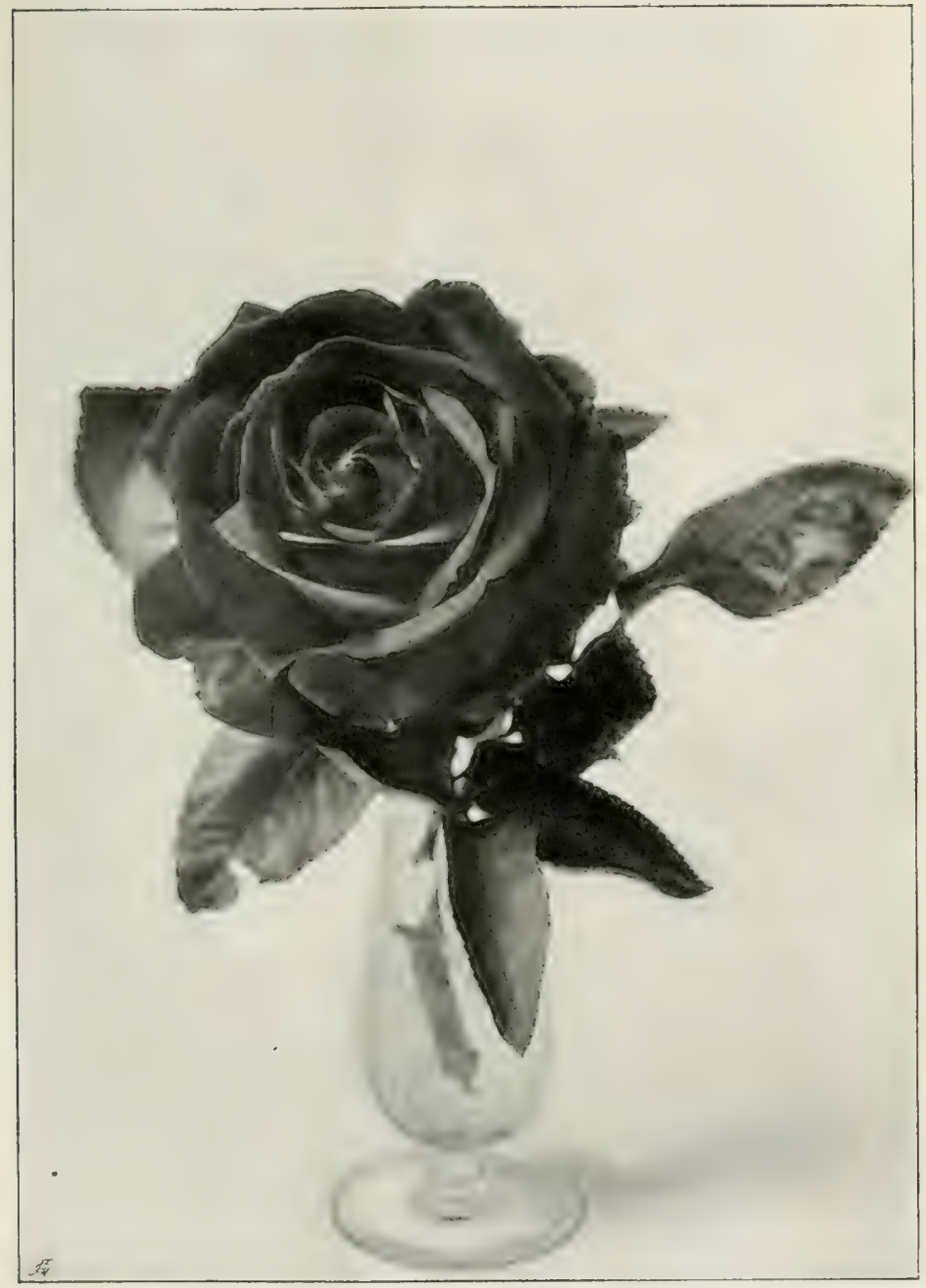

Prince Arthur, H l'. 

Prince Camille de Rohan (E. Verdier, 1861).Eliminated by the editors of this edition.

Purity (Cooling \& Sons, 1895)._Eliminated by the editors of this edition.

Rev. Alan Cheales (Paul \& Son, 1896).-A very good grower which does not require close pruning. It flower's freely and is a "good doer." The blooms are of a nice fresh colour- " pure lake with reverse of petals silvery white"-but not very lasting. The shape is rather loose, and the raiser calls it a "peony-like Rose," but I do not think it is quite so bad as that, and I have seen it with a good point, and shown well.

Reynolds Hole (Paul \& Sons, 1872).-Eliminated by the editors of this edition.

Senateur Vaisse (Guillot, 1859).-Eliminated by the editors of this edition.

Sir Gurnet Wolseley (Cranston, 1875).-Eliminated by the editors of this edition.

Sir Rowland Hill (Mack, 18s').-Eliminated by the editors of this edition.

Souvenir de la Malmaison (Beluze, 184:).Eliminated by the editors of this edition.

Star of IValtham (IV. Paul \& Son, 187.5).Eliminated by the editors of this edition.

Suzanne Marie Rodocanachi (Leveque, 1883).Of Victor Verdier race, and requiring therefore no description here of manners and customs. A noble Rose, the best of this family. The colour is not only bright, glowing, and most attractive, but also lasting, a most desirable attribute for a show Rose; it also retains its shape when cut better than any other Rose of the globular form that I know. The growth is good, it does well as a standard, 
is free-flowering and a good autumnal, and the blooms are very large and well formed, but nearly scentless. A rose held in high estimation by exhibitors, and worthy of a name more suitable to British tongues and pencils. Rosslyn (A. Dickson \& Sons, 1900) is a lighter coloured sport of this variety, and Marie Corelli (Prince, 1901), perhaps the better of the two, is another.

Thomas Mills (E. Verdier, 187.3)._-Eliminated by the editors of this edition.

Tom Wood (A. Dickson \& Sons, 1896).-A fairly useful Rose, of vigorous hardy growth, with good foliage, not much liable to mildew. The blooms are well-shaped and seldom deformed, of average size and with stout petals, but the colour is rather a dull shade of red. It is a good autumnal, and the plants have a good constitution, growing and doing well where others fail.

Ulrich Brumner (Levet, 1881). - A seedling from Paul Neyron, of very stout stiff growth and foliage untouched by mildew. The blooms come well, of extra large size, with stout petals generally tightly incurved in the centre, fine regular smooth shape as a rule, and capital lasting qualities, not much injured by rain, though the colour soon fades. A great Rose in many ways, one of the best, of the red H.P.s: free blooming and capital in the autumn, hardy and of strong constitution and does well almost anywhere and on all stocks. When asked to recommend three good hardy standards for cottage gardens, I suggested La France, Mrs. John Laing, and Ulrich Brunner, as likely to give satisfaction.

Ulster (A. Dickson \& Sons, 1899).-This is just one of the Roses for which this chapter is needed. 


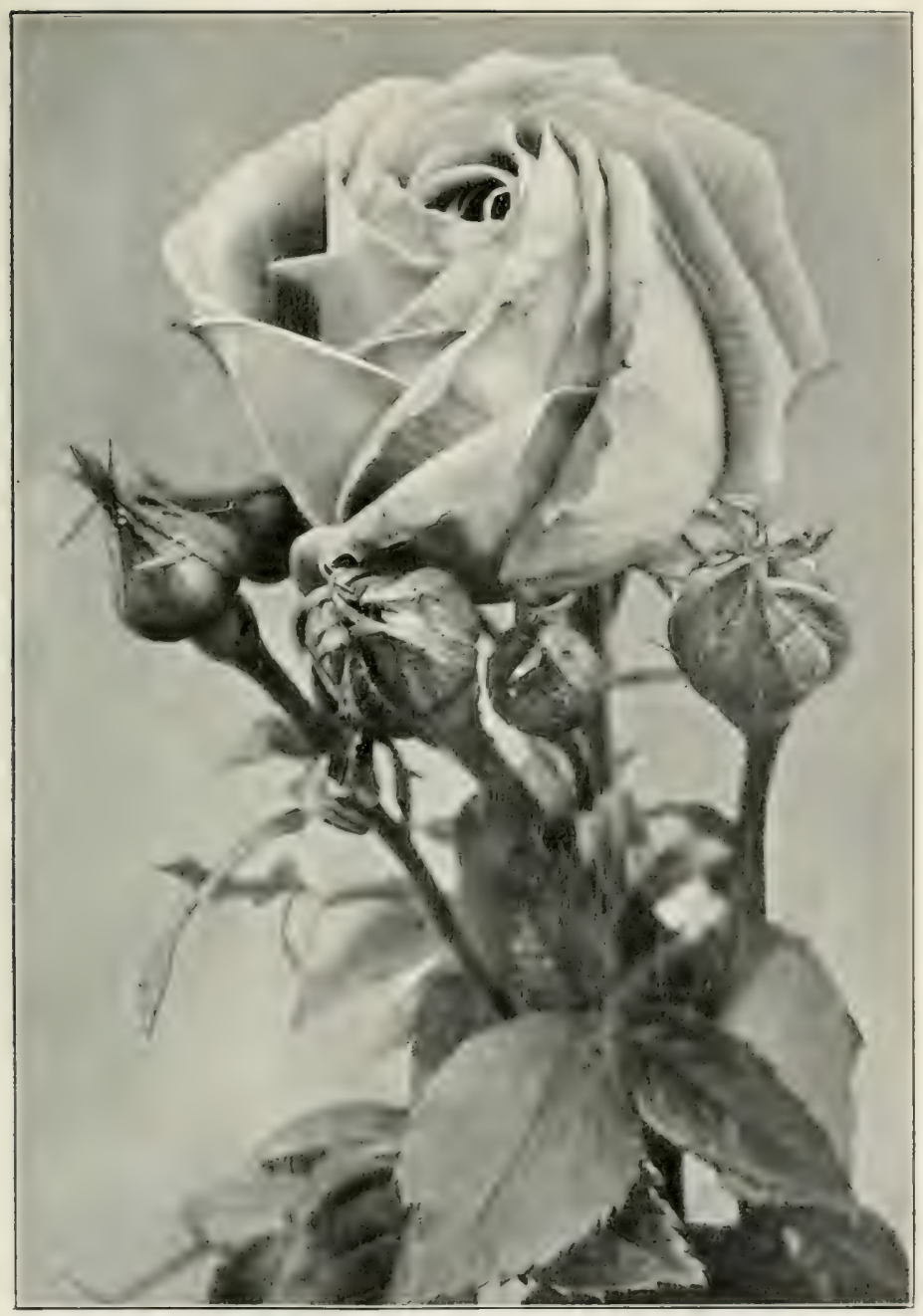

ULRICH BrTSAF,

lin paten whic

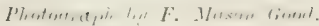



The flower, as seen in a show stand, is magnificent, very large, and very finely and regularly formed, with beautiful bright colour and good fragrance. But its growth though "robust" is very short and it is plainly a rose for exhibitors only, and for those only of them who can give it the most " liberal treatment." Nevertheless, I think this variety also has improved in habit, and I find it will often make a fair " head" as a half-standard.

Victor Hugo (Schwartz, 1884).-Of good growth in rich soil, with very distinct foliage and habit, liable to mildew, and requiring high cultivation and "liberal treatment." When "well done by," the blooms are very handsome, of fine shape, fair petal and centre, glorious colour, and good size. This is a very taking sort from the glow of its crimson : the constitution seems pretty good on strong soil, and it is fairly free blooming in summer and in autumn, but the petals are rather thin, and the blooms not very lasting. A really fine bloom of this Rose, seen at its best, will attract great attention. Fragrant.

Victor Verdier (Lacharme, 1859).-Eliminated by the editors of this edition.

Waltham Standard (IV. Paul \& Son, 1897).Eliminated by the editors of this edition.

Xavier Olibo (Lacharme, 1864).-Evidently a seedling from Général Jacqueminot, as the wood is very similar. A weak grower with poor constitution, not liking manetti, and rather liable to mildew, answering best if budded annually on the briar either standard or cutting, but occasionally doing fairly as a cut-back if not moved. This Rose used always to be described as "velvety black, shaded with amaranth," a taking description, 
especially to those who had hazy ideas of what colour "amaranth" is. The word means "fadeless" or "everlasting," and seems to have been applied to the cockscomb family of flowers because of their lasting qualities. In describing a new Rose of purplish crimson, the French raisers therefore called it "amaranthe," i.e. "cockscomb colour," a fair description of the shade of Xavier Olibo. The blooms come divided sometimes, but it is often a fine Rose, with centre sometimes incurved and sometimes with a fine point: a good lasting bloom, of full size. It will not answer on poor soil, must be "liberally treated," and from its weak growth is necessarily not good as a free bloomer or autumnal, or suitable for general cultivation.

\section{Hybrid Teas}

I have already (p. 26) endeavoured to show that, in making a separate class of the Roses that are crossed with the 'Teas, difficulty is sure to arise sooner or later in classifying varieties, which have a predominance of the Tea strain, but yet some slight strain from a distant cross with some other race. But, in deference to the general opinion, I have placed here those varieties which are generally reckoned as Hybrid Teas. As it is, there are a few that are not very casily distinguishable from the Hybrid Perpetuals. Some of the very finest of all Roses, such as La France and Mrs. W. J. Grant, are to be found among them, and all colours, though as yet yellow is only present in a few instances. Its fast increasing popularity is shown 
by the fact that the large majority of new Roses belong to this division; nor is this to be wondered at when we consider that we have here the hardiness against frost of the H.P.s combined with the true perpetual character of the Teas, with a gain if anything in size and beauty of shape. As a rule, the Hybrid Teas should be pruned fairly closely. They withstand a hot, dry climate or summer much better than the H.P.s, and are not so exacting in the matter of soil requirements.

Alice Grahame (A. Dickson \& Sons, 1903).-Eliminated by the editors of this edition.

Alice Lindsell (A. Dickson \& Sons, 1902).-It is of fair growth and habit, and the blooms are unique in shape, being truly globular with yet a decided point in the centre. Unfortunately the colour is not very distinct, but the young flowers have colour in them, which fades, however, in the older flowers to nearly white.-Gold Medal, N.R.S.

Antoine Rivoire (Pernet-Ducher, 1895).--This is no longer considered an exhibition varicty. Eliminated by the editors of this edition.

Apotheler G. Hofer (N. Welter, 1900).-Eliminated by the editors of this edition.

Augustine Guinoissecu (Guinoisseau, 1889).-A whitish sport from La France, of similar manners and customs, except that the flowers are very inferior in size, colour, and shape. No good for exhibition.

Avoce (A. Dickson \& Sons, Lta., 1907).-A beautiful shaped flower, of medium size, only useful for the late shows, as it is produced on the ends of long shoots which take time to grow. Colour crimson scarlet. Awarded Gold Medal N.R.S. Not very free flowering. Fragrant. 
Bardou Job (Nabonnand, 1887). - Eliminated by the editors of this edition.

Bessie Brown (A. Dickson \& Sons, 1899).-This is a Rose that, for exhibition, is quite one of the best, if not the actual best and most reliable of all Roses. The growth and foliage are strong, stout, and stiff; the blooms come exceedingly well, being rarely divided, and if there is any malformation it is usually of a slight nature. They are very large, slightly perfumed, of perfect pointed semi-globular shape, and the fine petals open just as they should do, neither too stiffly nor too easily. The colour is a good true creamy white unstained; but it does not display the beauty of the flowers well upon the plant, for the stalk, though stout, is pliable, and the heavy blooms hang their heads. With some Roses, such as Maréchal Niel, this is a very awkward habit; the stalk, bent by the heavy bud, stiffens in that position, and is very apt to crack if an attempt is made to straighten it. With Bessie Brown the stalk remains pliable, and may be straightened and wired without fear. But, for general purposes, those who may admire this fine Rose at a show should know that it will not hold up its head on a plant or in a vase without being wired. I have not found it affected by mildew; and though rain will harm it as it will all white Roses, its pendent position protects the centre. It is not good in autumn, and is purely an exhibitor's Rose, though one of the easiest to grow.

Betty (A. Dickson \& Sons, Ltd., 1905).-In a cool season this Rose is indispensable, but from the small number of its petals it is quite useless to 


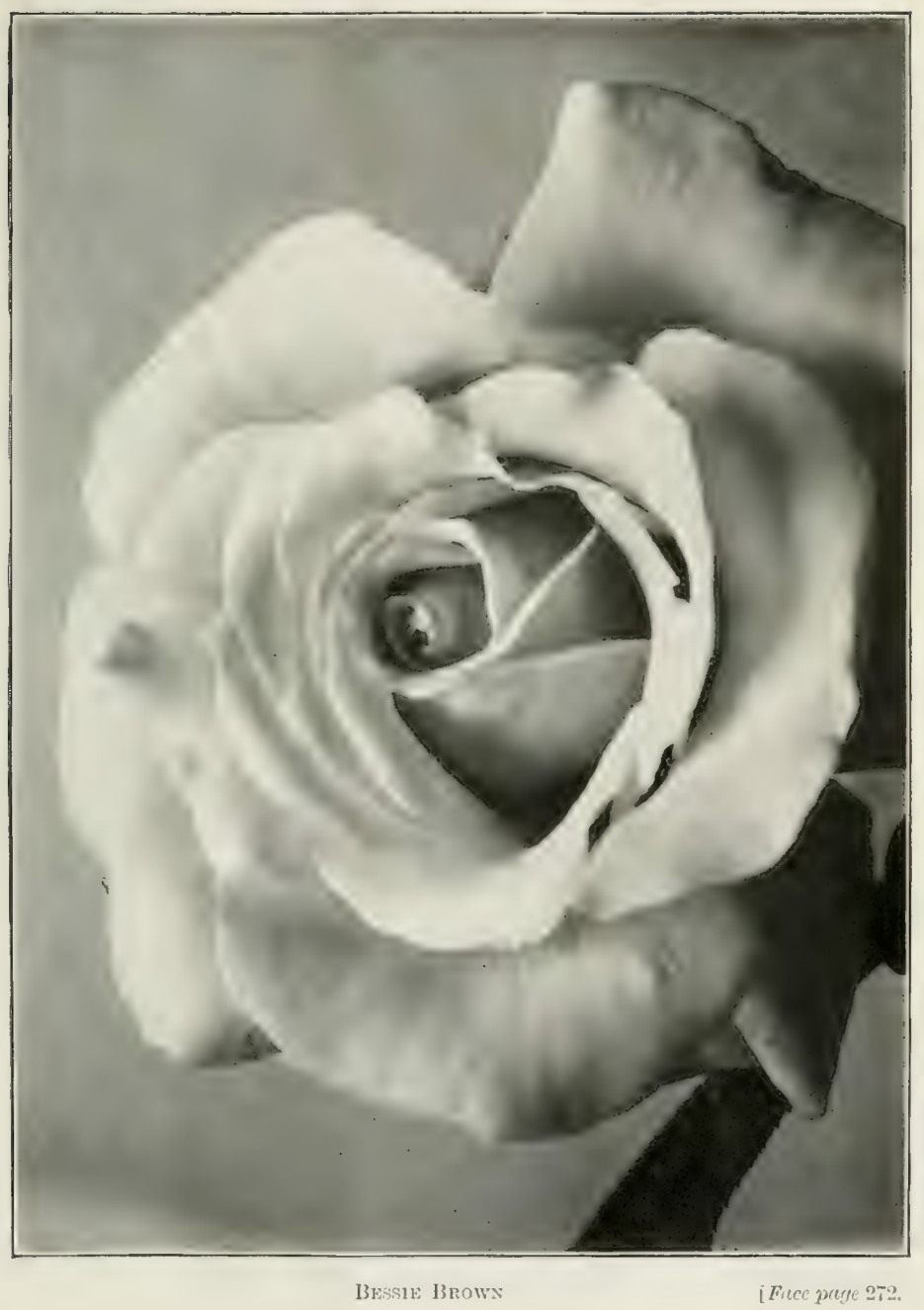



attempt to show it in a hot one. The petals are very large, few Roses have longer petals, but tied, and cut young, it is a beautiful flower useful for its colour, a coppery-yellow, tinted rose. Awarded Gold Medal N.R.S.

Captain Christy (Lacharme, 1873).--Eliminated by the editors of this edition.

Caroline Testout (Pernet-Ducher, 1890).-An cxcellent Rose, justly popular everywhere. It is of fair foliage and thomy growth, and flowers are large and seldom malformed, though the shape is not of the most refined type. The colour is a good decided self-pink, and lasts well. A very free bloomer, quite hardy, and not dainty in its requirements; it is one of the most reliable of all Roses and should be in every collection, however small ; is equally good for exhibition or general garden purposes, and it is one of the parents of very many of our new Hybrid Teas. Admiral Dewey is a light-coloured sport of this Rose from America.

Charles J. Grahame (A. Dickson \& Sons, Ltd., 1905).-A cool summer Rose only, but at its best there are few Roses brighter in colour. The flower's are excellent in shape, fragrant, but the number of petals is small. A good grower apt to make one tall shoot, that must not be stopped as it will only shoot away again from the first eye.

Countess of Caledon (A. Dickson \& Sons, 1897).Of good growth and foliage, rather of the H.P. character, and a fine Rose, hardly as much appreciated, I think, as it deserves. The stems are stiff and the flowers show themselves well; they are sweetscented, of good semiglobular shape, and a fine rich 
pink colour. The variety is a good example of the H.P. side of this class; but its thorough reliability for autumnal blooms shows the Tea cross.

Countess of Derby (A. Dickson \& Sons, Ltd., 1905).-Distinctly a cool season Riose, and perhaps one of those Roses that are best described as garden Roses first and exhibition Roses afterwards-meaning by that, that only occasionally will one get a flower large enough for exhibition. A good grower, very free flowering, so it must be rigorously thinned out, shoots and buds too, if exhibition flowers are desired. A good shape with a fine wing petal; not so subject to mildew as some of the "Irish" Roses.

Countess of Gosford (S. McGredy \& Son, 1906).A Rose that improves every year; inclined at first to be very thin, it now produces flowers of substance. Few Roses are of more refined shape. A good grower that will stand hard pruning. It is an early Iose, and should be cut young as it opens quickly.

Danmark (Zeiner-Lassen \& Dithmer, 1890), and

Duchess of Albany (Wm. Paul \& Son, 1888), sce La France.

Duchess of Portland (A. Dickson \& Son, 1901).fair growth and habit, with very fine well shaped flowers, the petals being smooth, stout and well arranged. The colour is weak, being very pale yellow, occasionally something like Kaiserin Augusta Victoria : and if not strongly grown, it is practically white.

Dean Hole (A. Dickson and Sons, Ltd., 1904).Messrs. Alexander Dickson and Sons of Newtownards, Ireland, have griven the Rose world many fine exhibition lioses, they are indeed facile princeps 
in thąt connection, and this Rose must rank as one of their finest productions. It was a happy thought that suggested naming such a good Rose after such a good Rosarian, and it was a singular coincidence that the last letter the Dean wrote on Roses had as its subject matter this Rose that had been named after him. He saw a flower of it, but never saw the plants growing. Those best qualified to judge awarded it the Gold Medal of the National Rose Society; but its honours do not stop there. It has received the Niclierson Cup for the best Hybrid Tea introduced between 1900 and 1907, and many a silver medal for the best bloom has since fallen to its share. In Mr. Mawley's well-known "Analysis of Exhibition Roses" (see N.R.S. Anmual, 1909) it stands second on the list of IIybrid Perpetuals and Hybrid Teas, beaten only by Bessie Brown; it was actually first on the year's record taken by itself. It is needless, therefore, with this record in front of us to sing its praises. It is difficult to name its faults. It occasionally comes split; it is impatient of too much wet; it is subject, but not badly, to mildew-that is the worst that can be said for it. It is a good grower alike on maidens and cutbacks, at its best, perhaps, on standards, and very free flowering. It is clear, therefore, that it is one of the absolutely indispensable Roses to all exhibitor's.

Dr. O'Donel Broune (Alex. Dickson and Sons, Ltd., 1908).--It is early days to say very much of this variety, but what little has been seen of it has been satisfactory. In general habit and appearance it more nearly approaches the Hybrid Perpetual class than the Hybrid Tea class. It produces a large flower of good shape that opens well with a 
nice smooth petal, and should prove very useful to the exhibitor. Colour carmine rose, very strongly perfumed. A good grower.

Earl of Warwick (Wm. Paul \& Son, 1904).-This Rose has taken some time to become generally known, but it is now recognised as a sterling variety, and was frequently exhibited in 1909, gaining the two silver medals as the best bloom in the Hybrid Tea classes in both the Amateur and Trade Section at the National Rose Society's Autumn Show in that year. The colour is not easily described, being variable, but is generally of a soft salmon flesh pink, with a deeper centre. The flowers are of good shape, and are freely produced-at its best on standardsshowing a certain amount of Tea blood in its veins. A fair grower, not particularly subject to mildew; perhaps at its best in autumn. Altogether one of the best exhibition Roses this well-known firm have produced.

Edith d'Ombrain (A. Dickson \& Sons, 1902).-Eliminated by the editors of this edition.

Florence Pemberton (A. Dickson \& Sons, 1903).This is a good all round Rose, an excellent grower and one that in an ordinary season may be relied on to produce large flowers of good quality. Its petals are slightly tissuey in texture and are somewhat impatient of wet-but it is one of those Roses that have improved very much since introduced and is quite first rate in every way.

Frau Lilla Rautenstrauch (P. Lambert, 1903).Eliminated by the editors of this edition.

George C. Waud (Alex Dickson \& Sons, Ltd., 1908). -A promising new Rose, remarkable for its colour described by the raisers as glowing orange vermilion 
-it is a good grower, is sweetly scented and has been well exhibited, received the N.R.S. Gold Medal.

Germaine Caillot (Pernet, 1887).-Eliminated by the editors of this edition.

Gladys Harkness (A Dickson \& Sons, 1900).--Inclining to the H.P. side of the class, this variety is sturdy and hardy in growth and foliage, and the pink blooms, though not of the most refined shape, are large, with fine petals, sweet-scented, and good in the autumn.

Gloire Lyonnaise (Guillot, 1884)._Eliminated by the editors of this edition.

Grace Darling (Bennett, 1884)._-Eliminated by the editors of this edition.

Grace Molyneux (A. Dickson \& Sons, Ltd., 1908). -A vigorous growing Hybrid Tea of good habit and constitution, the flowers are produced freely on long stalks-are sweetly scented and of refined shapewith high culture and severe disbudding will produce exhibition flowers. It has been awarded the N.R.S. Card of Commendation and the R.H.S. award of merit-but it is as a bedding and garden Rose that it can be most strongly recommended.

Gruss an Teplitz (Geschwind, 1897).-Eliminated by the editors of this edition,

Gustav Grïnervald (P. Lambert, 1903).-This is a good early variety that properly grown will give good exhibition flowers. It must be disbudded freely, and only one flower allowed to come on each shootthe flowers are large and full of petals, cup shaped with high centre-and of a bright carmine pink in colour -it is a good grower-not subject to mildew and while useful to the exhibitor is really a bedding rose of excellence. 
Gustave Regis (Pernet-Ducher, 1890).-Eliminated by the editors of this edition.

Helene Guillot (P. Guillot, 1901).-The flowers are of unusually good shape, something of the form of Catherine Mermet, and of varied colour. Not a particularly good grower, and impatient of wet, but at its best a useful exhibition Rose.

J. B. Clark (Hugh Dickson, 1905).-Few Roses of recent introduction have been the subject of more controversy amongst Rosarians than the Rose under notice. The sensational Silver Medal bloom at the N.R.S. 1905 National Show, led the majority of exhibitors to expect great things and when their plants did not at once produce the like they condemned the Rose. Then the unusual character for an exhibition variety of its growth was not in its favour, and those who only grew their Roses in the orthodox rows found that J. B. Clark wanted rather more elbow room than they cared to give it. Be that as it may, J.B. has lived down most of its bad repute, and now has many friends. It has admittedly peculiarities all its own, and should probably now take the place formerly held by Annie Wood and be described as having "Manners" none, and "Customs" beastly-it is best grown as a pillar Rose and the long autumnal growths should be retained almost full length allowing a few laterals only on each. This method seems to produce less split blooms-and J.B.'s besetting sin is "split blooms." Shaded, its colour is superb-" it is probably the largest crimson or scarlet flower in cultivation. Mr. Mawley's analysis, before referred to, shows its 1908 record as tieing with Caroline Testout for the honour of sixth place amongst the 
H.P.s and H.T.s. After that its detractors must surely take a back seat.

John Cuff (Alexander Dickson \& Sons, Ltd., 1908). -One season 1909 and such a season! is not a fair test of the qualities of any Rose-let alone a new variety-but such as it was, John Cuff came out of it very much better than the majority of his compeers. The flowers are of exceptional size and are early in point of season-the colour is a pleasing shade of bright carmine, the outside petals are of good substance and enclose a well-shaped flower. It is a good vigorous grower and is well worthy of a trial-one cannot speak more definitely of a Rose of such recent introduction but it is distinctly promising.

Taiserin Augusta Victoria (Lambert \& Reiter, 1891). -Of fair growth and foliage, but requiring "liberal treatment" if it is to be seen at its best. The blooms, which are full-sized and of good semi-globular shape, with fine petals, come very well if grown strongly. In such cases there is a distinct tinge of green or "lemon" in the centre of the cream-coloured young flower, which is very pleasing, but this will not be seen in blooms on weak stems, which will be simply white. A fine show Rose, thoroughly reliable and lasting, and not often malformed. Not, however, a variety of strong constitution which will do anywhere: it is rather a difficult one to propagate, the inserted buds, though alive, being often slow at starting in the spring. It stands hot weather well. A climbing sport (A. Dickson \& Sons, 1897) has been issued, which is quite reliable: and another, Perle von Godesberg (Schneider, 1902), claiming to show more yellow in the flowers, has done well with me, 
and though the advance in colour is slight it is a better grower than the type.

Killarney (A. Dickson \& Sons, 1898).--Sent out, I believe, by Messrs. Dickson as a garden Rose, this variety has proved itself to be, except in very hot weather, a show Rose of great merit. It is a good grower, flowering freely in summer and autumn. The blooms are very large, of quite first-class pointed shape, and the colour a lovely shade of pale pink. The petals are long and stout, but there are not enough of them, the centre being badly filled. As long as it holds its half-open shape, which with ordinary precautions it will do very fairly under general conditions, it is as fine a show Rose as one would wish to see, the great petals standing up stiffly around the centre point; but when the point goes the Rose is gone too, though as the colour is lasting it is still a decorative flower. For show purposes it should be liberally treated and grown as a Standard. Subject to mildew.

Königin Carola (Turke, 1904).--This Rose has been rather a long time obtaining recognition. It is a seedling, with Caroline Testout as one of its parents, and it much resembles that fine Rose in colour and habit of growth, but is a distinctly better shape, having a well-developed point. Its great fault is that sooner or later the blooms reveal a split. Still it is worth growing in a large collection, but it is not recommended to the small amateur.

Lady Alice Stanley (S. McGredy \& Son, 1909).A very promising new exhibition variety. The growth is vigorous and the flowers large and of good shape and distinct colour. 


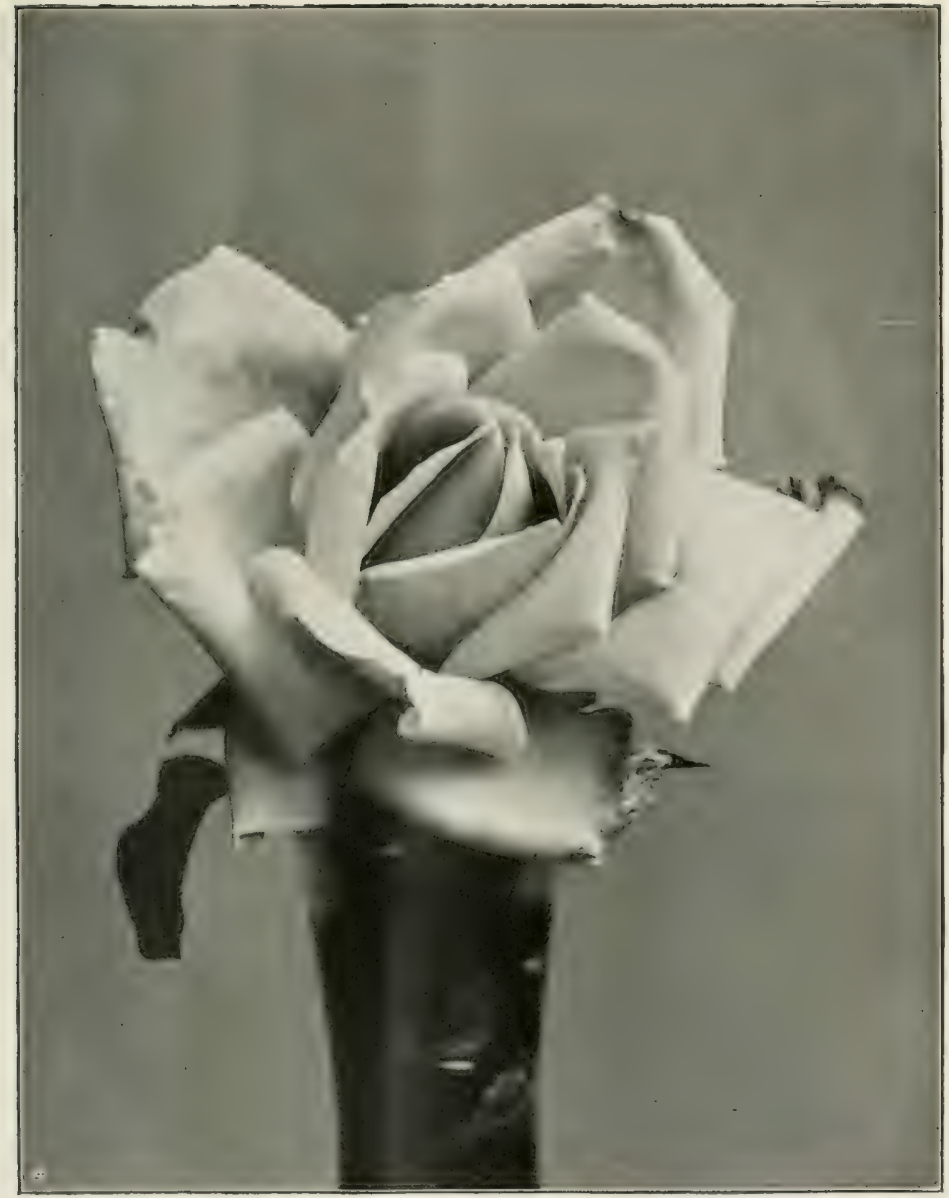

KILL.INNF. H.T.

[Face preate 280. 




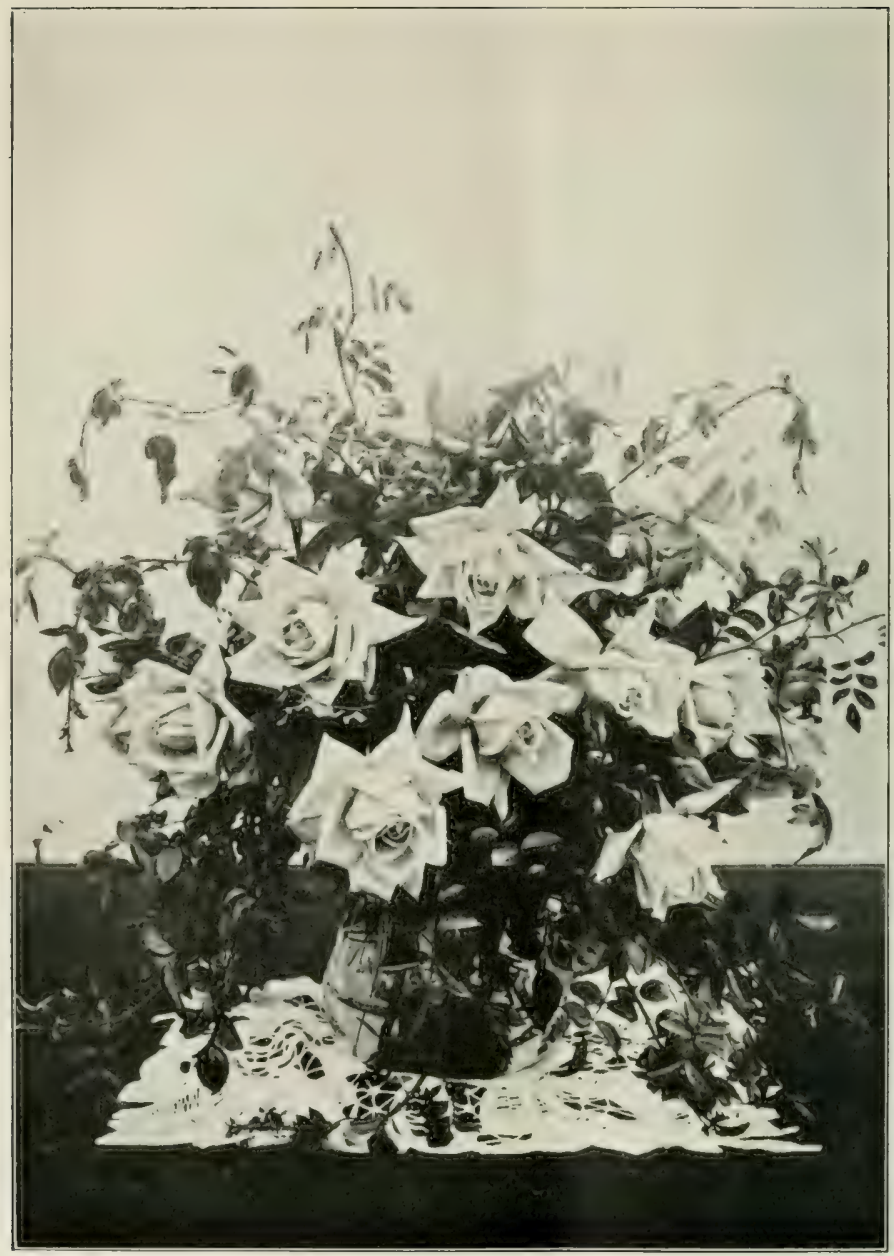

A Bowl of LADr AsmTOWN

[Fece prege 281. Exhibited by Mrs. H. E. Molyneux. 
Lady Mary Fitzwilliam (Bennett, 1882).-Eliminated by the editors of this edition.

Lady Ashtown (A. Dickson \& Sons, Ltd., 1904).This is one of the most satisfactory Roses that have been introduced of recent years. It was unfortunate in missing the award of the N.R.S. Gold Medal, as few Roses have deserved it better. It has steadily increased in popular favour and is now to be found in every exhibitor's collection. It is easy to grow, generally comes of excellent shape, will stand high culture without getting coarse, and has few if any faults. It is subject to mildew, moderately vigorous, and very free flowering, and a good autumnal. It is high up in Mr. Nawley's analysis, and would be placed by most Rosarians in the best dozen H.P.s or H.T.s.

Lady Helen Vincent (A. Dickson \& Sons, 1907).One cannot say very much about this Rose, particularly as last season was such an unfavourable one. It is a good grower, and in a fine season its large buds, which are produced at the end of each shoot, should give good flowers. It was well exhibited by the raisers, and has been awarded the Gold Medal of the N.R.S.

Lady Moyra Beauclerc (A. Dickson \& Sons, 1901).-A very fine variety, which for some reason never gained the Gold Medal, though it certainly deserved it. It is of long vigorous growth, showing a good deal of the Tea habit, but the shoots are slender and pliable and the heavy flowers will need support. They are very large, well shaped and beautifully tinted, but the freshness of the colour does not last in hot weather. Very free-blooming, and fair as an autumnal. This is a reliable Rose for exhibition, but variable in colour. Some ex- 
hibitor's, notably Mr. E. B. Lindsell, think very highly of it.

Lady Ursula (A. Dickson \& Sons, 1908).-A Rose of promise but of too recent introduction to be more than mentioned. It is a strong grower, very free flowering with blooms of good shape and high centre. By many thought to be the best of Messrs. A. Dickson's 1908 set.

La France (Guillot, 1867).--Mons. Guillot must have been inspired when he gave the name dearest to Frenchmen to the best Rose "La France" has produced. If everything be taken into consideration that can be said for or against a Rose, I am of opinion that this popular variety might be called the Queen of Roses. The growth and foliage are good and very characteristic, and but little liable to mildew. It should be very lightly pruned, especially if on strong soil, and the buds should not be thinned too much, or the flowers will come "bull-headed" or "balled," the petals covering the centre too far so that it cannot open. I have seen plants of this variety in beds with other H.P. Roses, and subjected to the same "liberal treatment," utterly failing to produce a single decent flower: and the same plants, when moved to poorer soil, unpruned and comparatively neglected, giving splendid show blooms in the season and a fine succession all through the autumn. They are very large and unique and characteristic in shape and colour: they should be and often are of a particularly silvery brilliance, but though not more injured than many others by rain, it is difficult in some sorts of weather to leep them "clean." It is not a good laster in very hot weather, but in this matter also there are many worse. The scent is most 


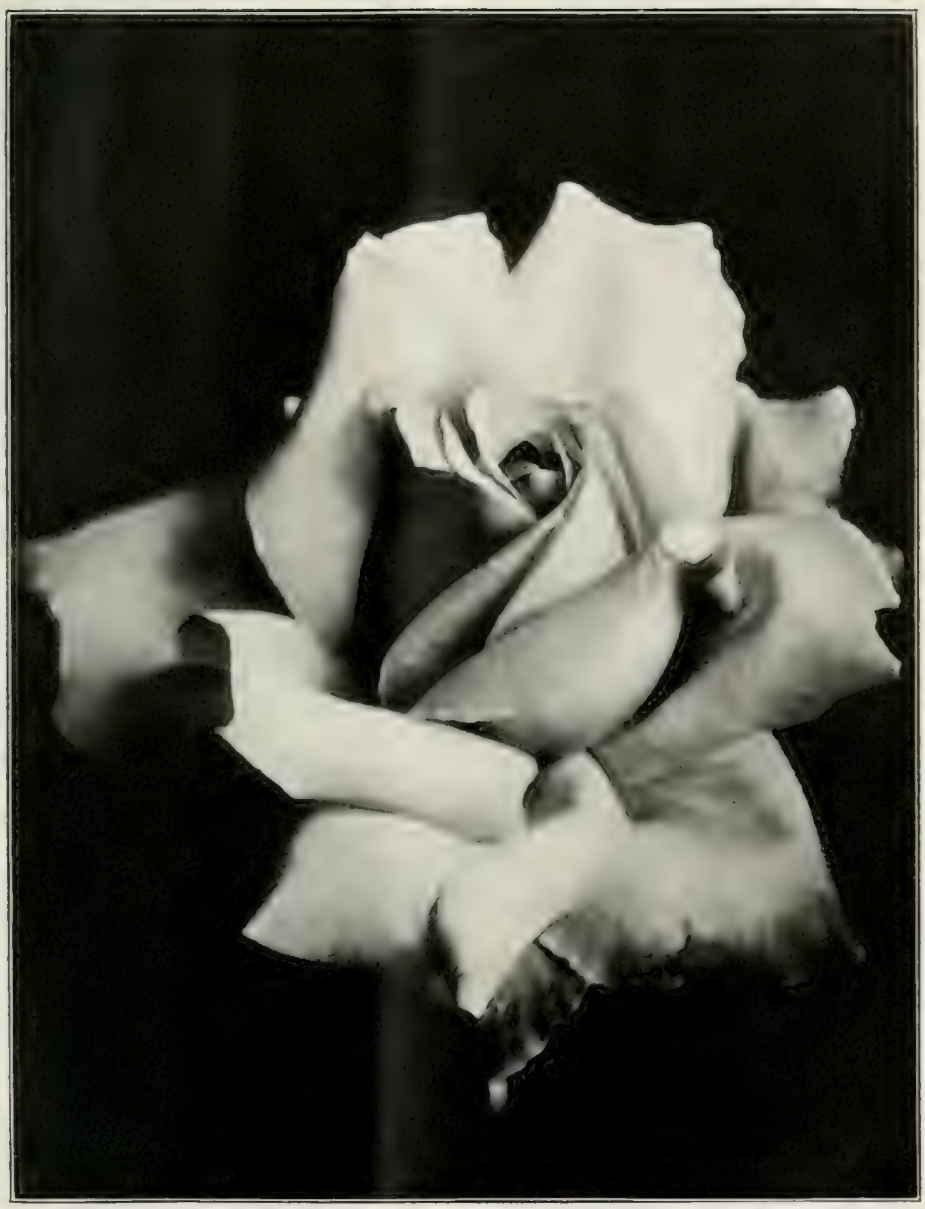

LADY MOYRa BEaUCLERC.

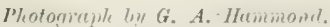

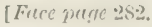






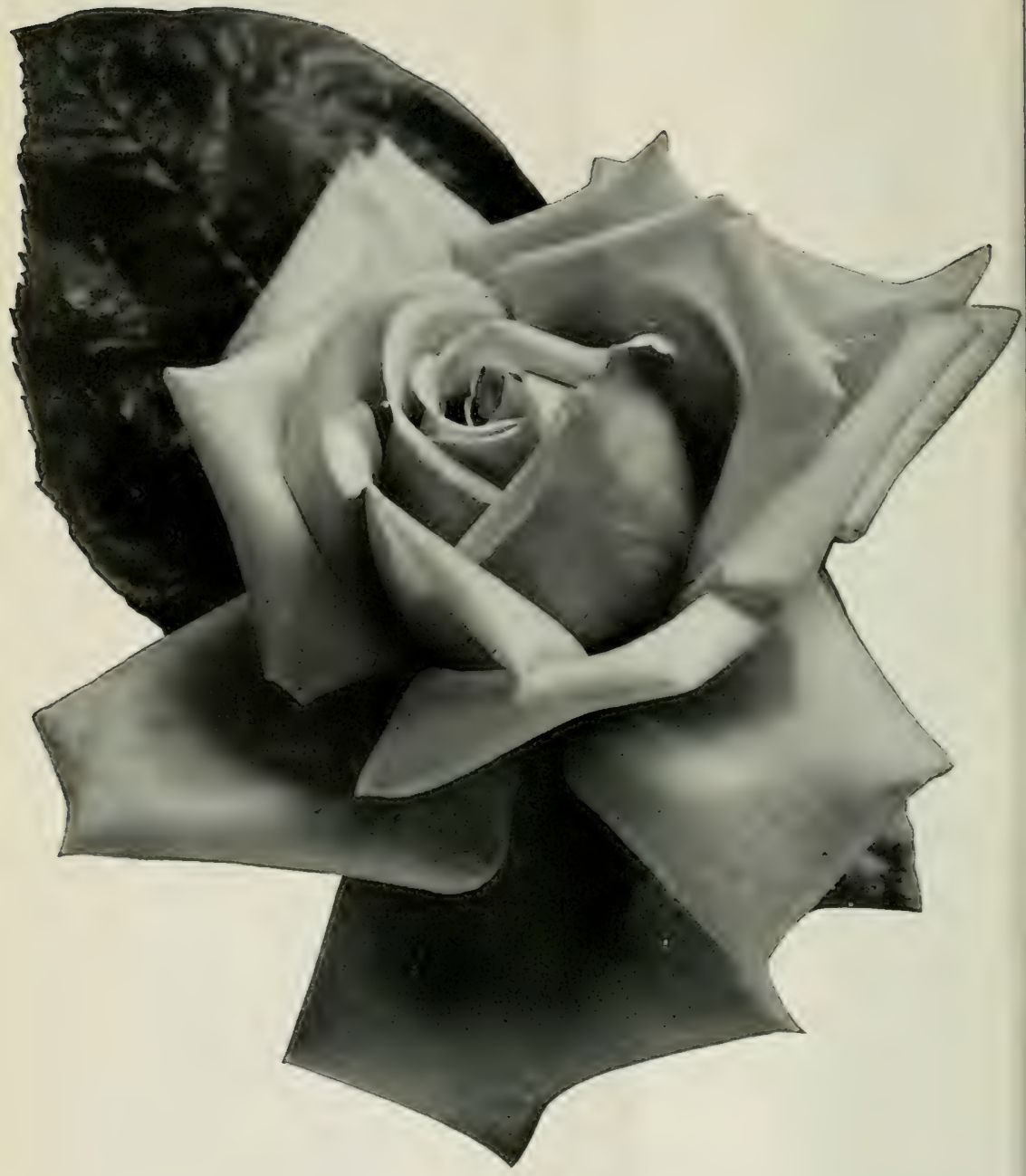

LA FPANCE,

[Fuec pege 2s3,

Photorrente bir B. R. Crent a Son. 
distinct and exquisite-the most pleasing, to my sense, of any liose. It is emphatically everybody's Rose, on all soils and stocks, standard or bush. None of the seedlings or sports of this famous Rose have been so good as the original-a climbing sport (Henderson, 1894) is good for a wall-Duchess of Albany (W. Paul \& Son, 1888) is a little darker in colour-Augustine Guinoisseau has been mentioned, and Danmark (TV. Paul \& Son, 1900) is not so good in growth and very apt to ball.

Liberty (A. Diclison \& Sons, 1900).-This is a variety which, in America at least, has "supplied a want." It has there, I believe, taken the undisputed first place as the crimson Rose for forcing, since the flowers show themselves well on stiff upright stems, are gloriously coloured with brilliant crimson, very well shaped, and last well when cut. It is not often large enough for exhibition and is not very strong in growth, but it seems likely to supersede Général Jacqueminot and kindred varieties as a red Rose for forcing. Richmond is similar in colour and more reliable out of doors, its flowers, especially the early ones, being of larger size.

Lohengrin (Schmidt, 1903).-Purely an exhibitor's Rose of very fine shape, but fleeting colour, a medium grower, the flowers nearly always come good, but it is not recommended to the small grower.

Lyon Rose (Pernet-Ducher, 1907).-A continental Rose that came over with a great reputation and which has been quite borne out by what has been seen over here these last two seasons, it may indeed be styled the sensational Rose of 1909 , and so great was the demand for it that the majority of trade 
growers were sold out quite early in the season. The colour, its most striking feature, is very variable, from shrimp pink to salmon without any shading of that yellow which is such a conspicuous feature in the typical flower, and makes it such a striking object in the centre of an exhibition box. It is a vigorous grower, that requires hard pruning and is an early flowering variety, of fair shape, not too good a centre, but cut young will last. It is one of the numerous offspring produced from the original cross with Rosa lutea of which Soleil d'Or was the first hybrid and all of which are now called by the raiser Rosa pernetiana, but for sake of convenience the N.R.S. has placed them amongst the Hybrid Teas.

Madame Maurice de Luze (Pernet Ducher, 1907). -A promising variety that one can hardly say more about. It is a fine large flower with large petals, a vigorous grower. The trade showed some excellent flowers last season cut from maidens but nothing can be said yet of its manners and customs.

Madame Mélanie Soupert (Pernet-Ducher, 1905). -A very beautiful garden Rose that with high culture and much disbudding will yield good exhibition blooms, especially in a cool season. Its colour will make us want to exhibit it as often as possible as we are badly off for yellows. The petals are large but few in number, cut young it will keep its shape in the same way that Killamey does, but too much heat and it collapses. Some very fine flowers have been exhibited this past season, notably the one that obtained the Silver Medal for the best Hybrid Tea at the National show in the Royal Botanical Gardens. It has been largely used by bybridists, but it is too soon to write about the 


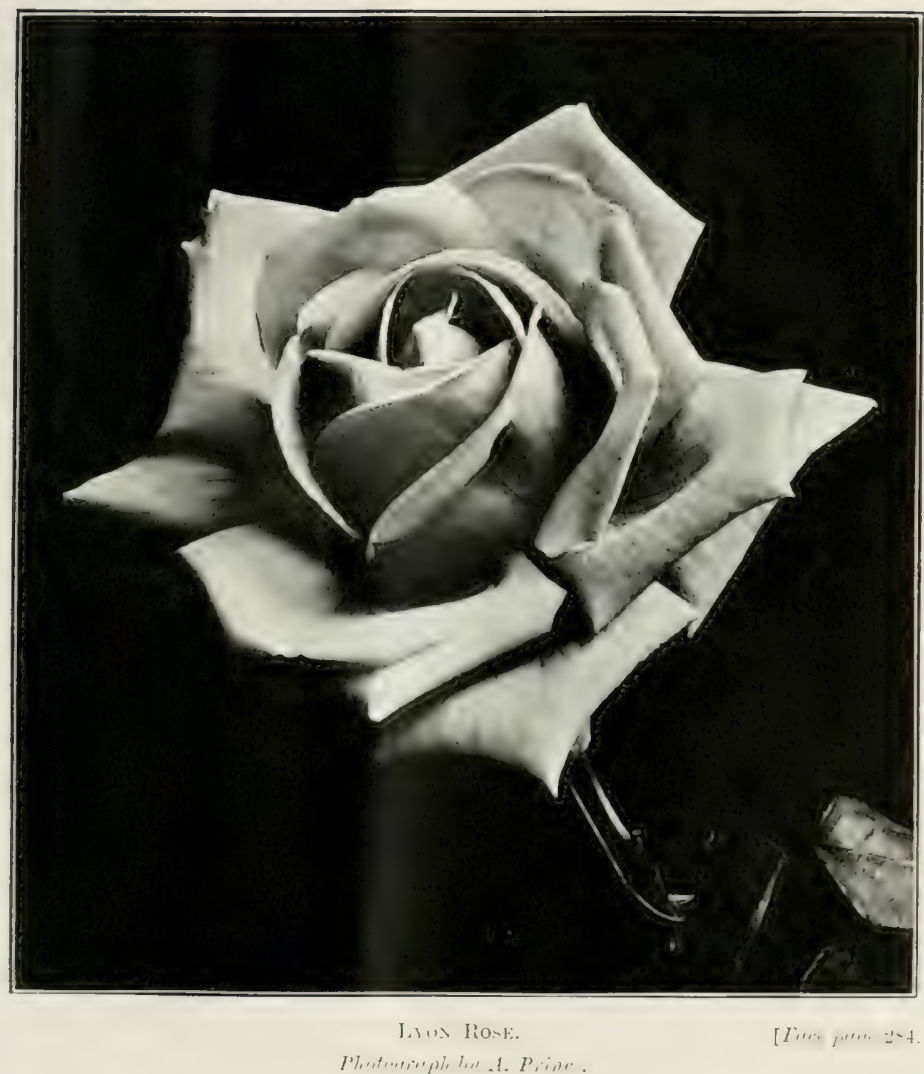






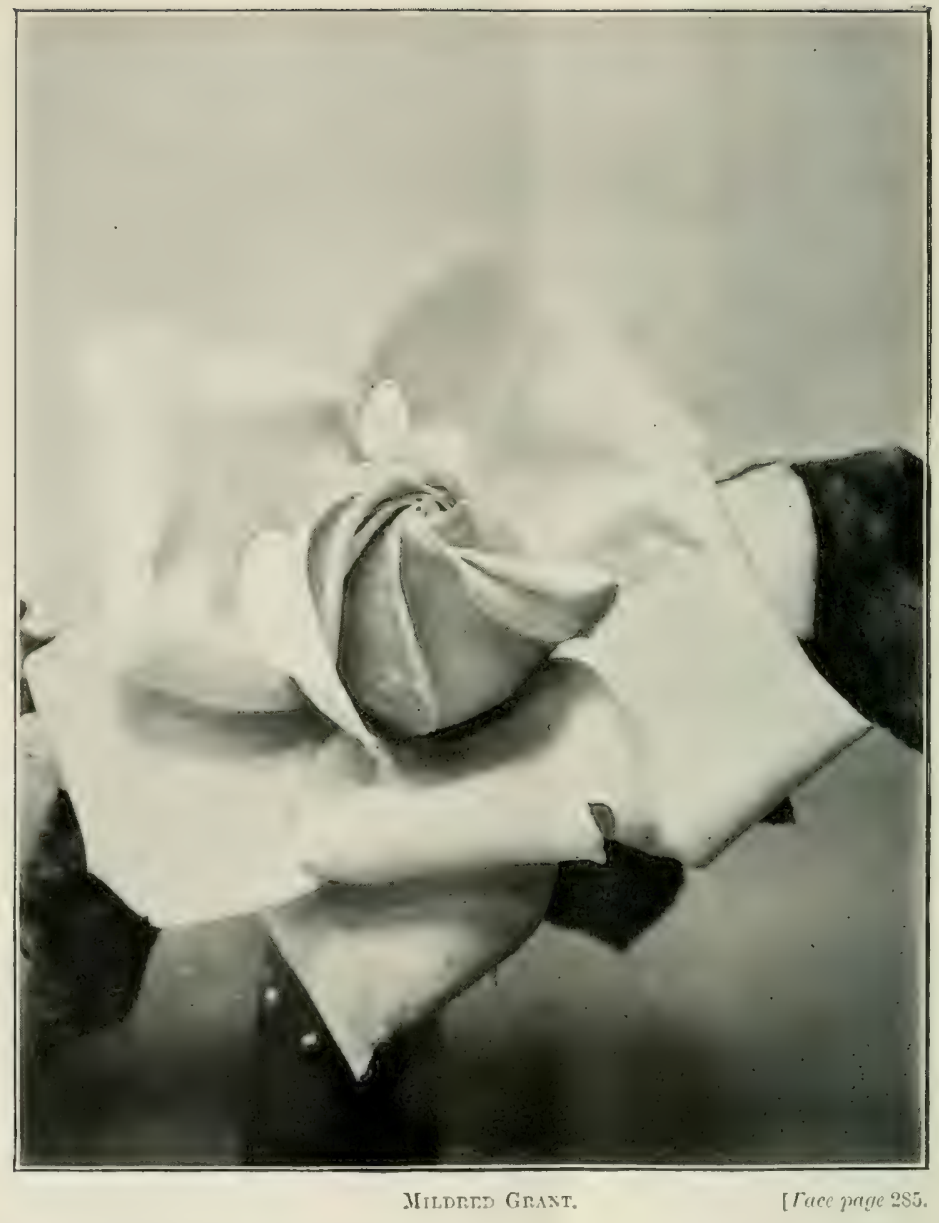


results though we hear of great things. So far Lyon Rose is the first of what will be a new race mostly of good yellows.

Madame Ravary (Pernet-Ducher, 1891).-Eliminated by the editors of this edition.

Mamie (A. Dickson \& Sons, 1901).-Of strong healthy growth with good foliage. The buds are large and open slowly into very full flowers having fine petals and globular shape with high centre. A fine Rose for exhibition, and most reliable, as it is the best variety to "stand"-i.e. keep its shape and colour-in a cut state I know, outside the pure Tea class. It is the only Rose, other than pure Tea, of which I have successfully shown the same bloom at two exhibitions.

Marquise Litta (Pernet \& Ducher, 1893).-This very soon became a well-known and popular variety. It is of stout, stiff, thorny growth, with foliage and general appearance of a H.P. character; and the flowers are very distinct, there being something characteristic in the arrangement of the inner petals which is often very regular and pleasing. They are large, very bright and fairly lasting. Free-flowering, and a good autumnal even in hot climates, it is a Rose to be recommended for its fine colour and shape.

Mildred Grant (A. Dickson \& Sons, 1901).-This is, no doubt, at its best one of the finest of all Show Roses, no well-shaped bloom of the true pointed refined form equalling it in size or in length and stoutness of petal. The habit is robust, the wood short and stout, and the leaf petioles very long. Each shoot produces a flower, and strong plants will bloom well again in the autumn. These great 
flowers take some time to develop, and it is probably best not to hurry them with liquid manure, as they are apt to come divided, and a full-sized bloom is not often perfect right through to the inside of the centre point. In perfection the faint pink tint on the cream-white veined petals is lovely, but very often the flowers are nearly white. It has improved in constitution of recent years, and though at one time could only be grown successfully as a maiden now many exhibitors find it equally good on cutbacks.

Mrs. E. J. Holland (S. McGredy \& Son, 1909).As seen growing at Portadown, this is an exceedingly promising Rose of vigorous habits and good constitution, with flowers of good shape with that most desirable point in the centre. Colour deep salmon rose shaded lighter towards the edges. Said to be mildew proof. A Gold Medal Rose of the National Rose Society.

Mrs. David McKee (A. Dickson \& Sons, Ltd., 1904).-A Rose that has improved since it was introduced. It will give good shaped flowers in fair quantity and is to be preferred to the Duchess of Portland, a Rose of similar colour and better shape but of poor constitution. Its colour, pale creamyyellow, makes it useful to the exhibitor and it was awarded the Gold Medal of the N.R.S.

Mrs. John Bateman (A. Dickson \& Sons, Ltd., 1905). - A Rose that is gradually finding favour with the exhibitor by reason of its perfect shape. The colour does not appeal to many; it is not a vigorous grower and last season did not suit it, but it is a good Rose that might be more grown if only for its lasting qualities when cut.

Mrs. Stewart Clark (Hugh Dickson, 1907).-A 



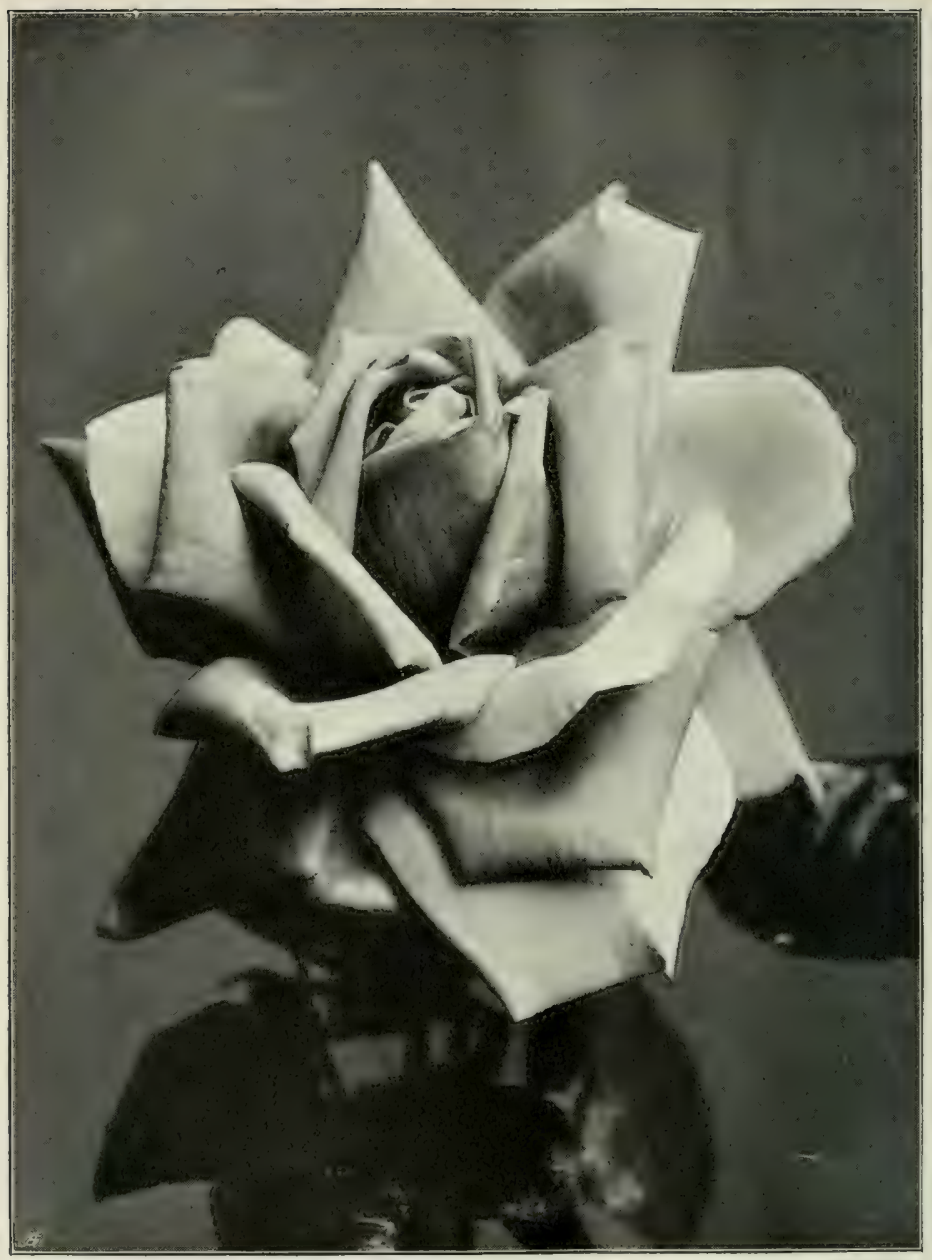

MRs, W. J. GrANT, H.T.

[Fitere parte 257. 
very promising variety of large size and fine shape. Its colour is a little against it, approaching the magenta shade that is objectionable to some. A very vigorous grower, almost too much so, it is deliciously fragrant and was awarded the N.R.S. Gold Medal.

Mrs. Theoctore Roosevelt (Hill, 1903).-This is undoubtedly one of the best exhibition hoses we have received from America. It has no bad manners and its customs are excellent. Its flowers almost always come clean and of good shape, and imbricated rather than pointed. Lasts well when cut, and in fact hasn't a bad feature. It has gaincd many Silver Medals for best blooms, and as it is easy to srow is strongly recommended to the small exhibitor. Makes a fair standard but does better, if anything, on dwarfs.

Mrs. Alfred Tate (McGredy \& Son, 1909)._This is a very beautiful colour but little is known of its manners and customs, it has not too many petals, but like Killarney and Betty, roses of similav: character, it will no doubt be useful to the exhibitor. It is of good habit and growth and is sweetly scented.

Mrs. W.J. Grant (A. Dickson \& Sons, 1895).-This truly splendid Rose gained the Gold Medal at the National Rose Society's Metropolitan Exhibition in 1892. It was then sold to America, like Her Majesty ten years earlier; and, as in that case also, we did not get jt back for two or three years. The purchasers changed the name to Belle Siebrecht, but in England we naturally restored the original name under which it had been shown and received the Medal. The plant is unfortunately not strong in growth, and is 
best as a maiden: it is said to be a cross between La France and Lady Mary Fitzwilliam. It is exceedingly free-flowering till quite late in the autumn, and the blooms at their best are very large, of a bright deep pink colour, and very fragrant. The flowers generally come good if the plant can be grown strongly enough, for it requires "liberal treatment": and a good specimen is indeed something for a Rosarian to feast his eyes upon. The weak growth is an unfortunate drawback, but a climbing sport has been issued (W. Paul \& Son, 1899), which I can thoroughly recommend. I hoped, in trying it, that some plants at least would not "run" (i.e. make really long flowerless shoots), but would yet be of increased vigour. As far as one can judge, this is actually the case, a large majority of budded plants not making real climbing shoots, but showing decidedly stronger growth in wood and flower. I would therefore strongly advise a trial of this climbing form, on standards and dwarfs in the open, even for purposes of exhibition : and if a plant does " run " it can be removed to a pillar, paling, wall, or pergola, or even staked out in the open, the stout, flowerless shoots being left in a horizontal position nearly at their full length, for such growths will the next season produce a profusion of magnificent flowers.

(Monsieur) Joseph Hill (Pernet-Ducher, 1904).Another garden Rose that will give us an exhibition flower occasionally, especially at the end of the one long strong shoot that it is the custom of this variety so frequently to make. The flower requires careful shading to secure the orange-yellow tint in its petals which are of good size but rather more twisted than usual. It is moderately vigorous in growth, has 
very fine foliage of a deep bronze colour, leathery in texture, and is altogether a desirable variety. Not recommended for standards as it "takes" very badly.

Oberhofgartner Terks (WVelter, 1901).-Purely an exhibitor's Rose, of very fine shape with a point like a needle. It is not a pleasing colour, the pink flush often turning magenta, and it is very impatient of wet and "balls" badly, but in a dry season is a very useful Rose. It must be pruned hard.

Papa Gontier (Nabonnand, 1883).-Eliminated by the editors of this edition.

Papa Lambert (P. Lambert, 1899).-Eliminated by the editors of this edition.

Princesse Marie Mertchersliy (S'chwartz, 1903).-A vigorous growing rose of excellent habit and all round good qualities, and of refined shape and delicate colour-in a cool season will be a useful exhibition variety-but it has not too many petals, and dislikes being tied.

Queen of Spain (Bide, 1907).-This Rose has not come up to expectations but possibly the season last year was against it. The difficulty is to get the flower's to keep a point, they develop and grow into big flower's, but the point is missing when you want it and a nasty hole that one can put one's thumb in, takes its place. Still it can be grown, as it was exhibited by the raisers in fine form when it won the N.R.S Gold Medal. It is robust rather than vigorous and may improve in time.

Robert Scott (R. Scott \& Sons, 1901)._Eliminated by the editors of this edition.

Viscountess Folkestone (Bennett, 1886)._Eliminated by the editors of this edition. 
W. E. Lippiatt (Alex. Dickson \& Sons, Ltd, 1907).-This is probably the best dark H.T. in cultivation-the colour is deep crimson shaded maroon. Rather late flowering, but particularly good in autumn. It is a good grower, free from mildew, fragrant, and the flowers are of good size and shape.

William Shean (A. Dickson \& Sons, 1906).-The giant amongst Hybrid Teas-this variety has leapt to the top of the tree. Its only fault is that the colour is not very clear and is apt to come streaky. It is a good grower, good alike on maidens or cut-backs and makes a fine standard, and is quite indispensable to the exhibitor. Awarded Gold Medal N.R.S.

White Lady (W. Paul \& Son, 1890).-A creamy white sport from Lady Mary Fitzwilliam, and as a Show Rose superior to that dwarf mother of fine Roses. It is not much longer in growth, but seems a little stronger in constitution, and is best as a standard. The petals are very long and fine, and the shape and centre are good. A good white Show Rose, best as a maiden, early.

\section{Teas AND Noisettes.}

The Teas, that is, Roses of the true Tea-scented China group, with which may be classed two or three Hybrid Noisettes not of climbing habit, are especially liable to the following bad manners: impatience of rain, susceptibility to frost. But these are more than counterbalanced by their good qualities, viz., being generally freer in the summer from mildew 
than the H.P.s and entirely exempt from orange fungus, nearly all free bloomers and the best of autumnals, lasting better than H.P.s and thriving better than they do on light soil. All the Teas and Noisettes require dryness and warmth in the soil as well as the air : thorough drainage is a first essential, and strong heavy land, such as is most loved by the majority of H.P.s, is not so much appreciated as that which is at the same time highly enriched and thoroughly porous.

Anna Olivier (Ducher, 1872).-A good grower with bright foliage, but the secondary shoots from the base are much stouter and longer than the spring growth. It does better as a dwarf than perhaps any other of this class : quite as well, many think, as on a standard. All the Teas are liable to be spoiled by rain, the petals sticking together and then decaying. Those which are fullest and stoutest in petal are the worst in this respect, and this Rose, being inclined to be thin and not so full as some, does not suffer perhaps so much. The blooms usually come well, it being the case with Teas, as with H.P.s, that the largest and strongest blooms are the most likely to come divided or otherwise malformed. The plant should not be pruned too closely, for this is one of the varieties which resent this treatment, and are apt to die back if it be continued. A lovely Rose of the charming pointed shape and capable of reaching a full size : it requires to be grown very strong to be fit for exhibition, but is then very effective. The colour varies very much, a terra-cotta tint, generally present at the base of the petals, sometimes attaining to a more lively shade and covering nearly the whole bloom, as in Lady Roberts (p. 298). Not 
in general a Rose of lasting qualities for a Tea, and slowly being ousted out of the Exhibitor's garden.

Boadicea (W. Paul \& Son, 1901).-A fine Tea Rose for exhibition. The plant is of fair growth and habit, and the wood is stiff, showing the flowers up well. With "liberal treatment" the blooms will come very large and of fine pointed shape, with capital stiff petals. The colour is good, and altogether this is a useful addition to the ranks of exhibition Tea Roses.

Bridesmaid (F. L. Moor, 1893).-An American sport of Catherine Mermet, with much higher and better coloux-a clear pink. This makes it a decided improvement on the original, whose one fault is weakness of colour. In all other respects it is identical, save that it seems to me that the outer petals do not reflex and open so readily as in the type.

Caroline Fïster (Pernet, 1872)._Eliminated by the editors of this edition.

Catherine Mermet (Guillot, 1869).--Of rather moderate growth, with rather poor foliage, a little liable to mildew, and easily injured by rain. The blooms, as a rule, come well, and the amateur who can get some really strong shoots and keep the buds dry will generally be richly rewarded, for this was long held to be one of the finest of Tea Roses when grown to perfection. It must be strongly fed, and all the power reserved for two or three blooms; then in petal, fullness, size, lasting qualities, and lovely shape it is truly a glorious flower, but the colour is more fleeting than the shape. The variety should always be grown as a standard, as it rarely does really well in the British Isles as a dwarf. It is very odd why certain of the Teas, if budded 


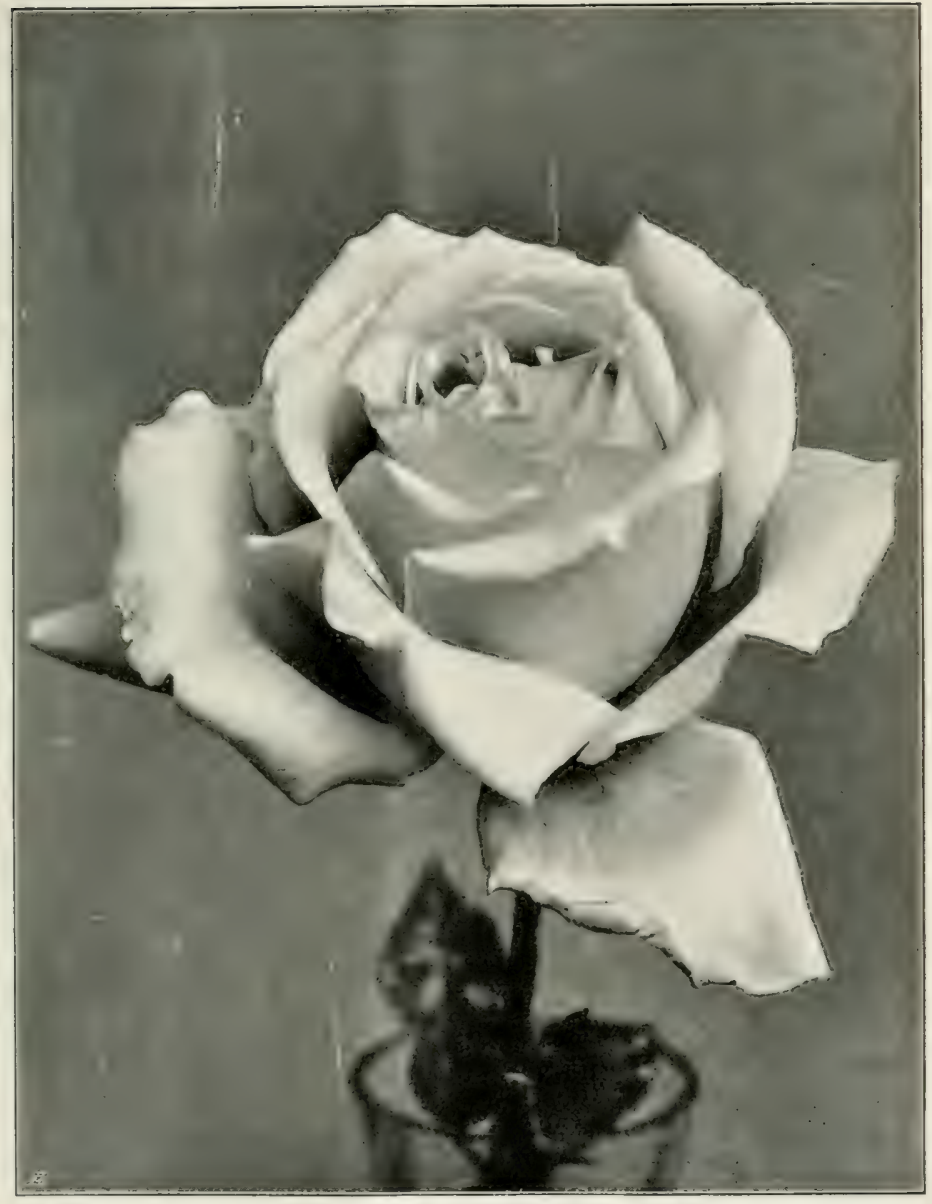

Catherise Mrryet, 'T.

[ Fuce purey 2012?. 




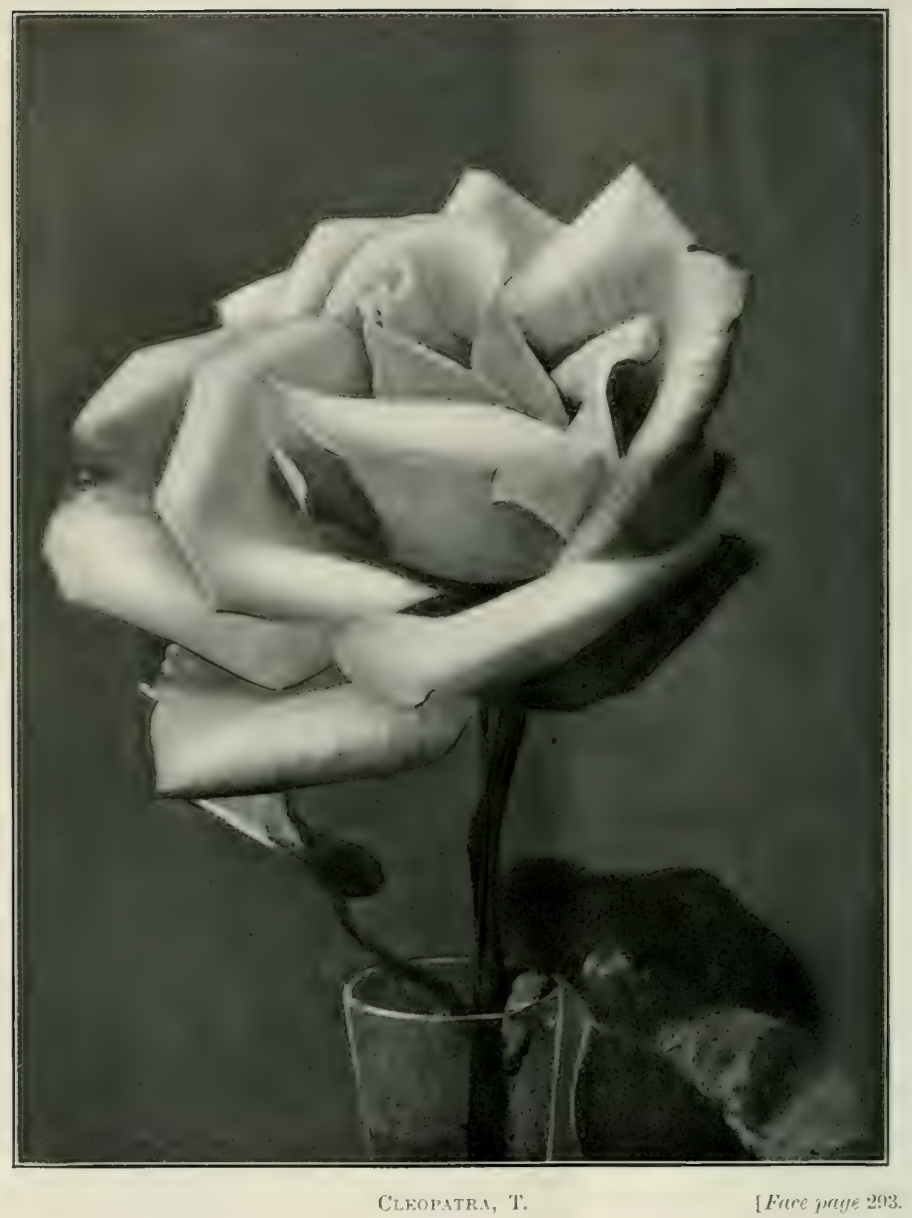


on the briar close to or under the ground, do not flower so well as when budded on the same stock a little higher-even eighteen inches will make a great difference-but so it certainly is; and as even short standards are much more difficult to protect effectually in severe frost, this little piece of bad manners is especially annoying to growers in low districts. It cannot be called hardy or of strong constitution, particularly free in bloom, a good autumnal. Its colour is a rery weak point, for the light pink shade of the bud very quickly fades, sometimes degenerating, when the form of the bloom is still at its best, into a dull and dirty sort of cream colour. In this matter it has been quite surpassed by three of the sports of the variety which have been issued, Bridesmaid, The Bride, and Muriel Grahame. For show purposes each of these is superior to the type in colour. Catherine Nermet, much grown under glass for market, going out of cultivation for other purposes.

Cleopatra (Bennett, 1889).-A poor grower, one of the worst in this section. The wood is fairly stiff, but often thin as well as short, and it is one of the most difficult to propagate, as the buds are small and scarce, and to get two or three often involves sacrificing nearly the whole of the plant. This is one of the type of Tea Roses, of which Princess Beatrice is another example, wbich grows fairly well and fast in the spring, but makes no secondary growth, much less bloom, worth mentioning. The flower buds are particularly long and pointed, and if fair growth can be obtained they open into grand blooms, retaining the fine point 
in the centre, with splendid long broad smooth petals most symmetrically arranged. A truly magnificent Rose, but really only suitable for exhibitors, for it is difficult to grow to perfection; much best as a standard, but tender and requiring full protection; indeed hardly worth growing except where the situation and soil are very suitable, for though the buds are lovely, it is not free-blooming enough to be cultivated for their sake, and it will only retain its point when expanded where it can be grown pretty strongly. Nevertheless, I have noticed that standards of this variety seem to bear moving very well; and will often yield as good flowers the first year after transplanting as subsequently. The maiden blooms do not come good.

Comtesse de Nadaillac (Guillot, 1871).-Of dwarf, thorny, and, unless thoroughly well treated, weakly growth and foliage; not liable to mildew, but spoiled by rain, though more tolerant of it than some. This is a Rose which, despite its small growth and generally feeble appearance, is commonly considered second to none as a show Rose, and it is seldom that a good stand is shown without it. The habit of this variety is peculiar, though that of Princess of Wales is somewhat similar. With almost all other Roses the finest and strongest shoots give the finest blooms, but with this sort it is very difficult to tell which will do so. A bud at the end of a very small shoot may grow and swell for weeks before opening, and will then probably show a bloom that not only for beauty, but also for size, will utterly eclipse anything that can be produced from even such strong rampant growers as Gloire de Dijon or Climbing Devoniensis. If the bud remains hard 


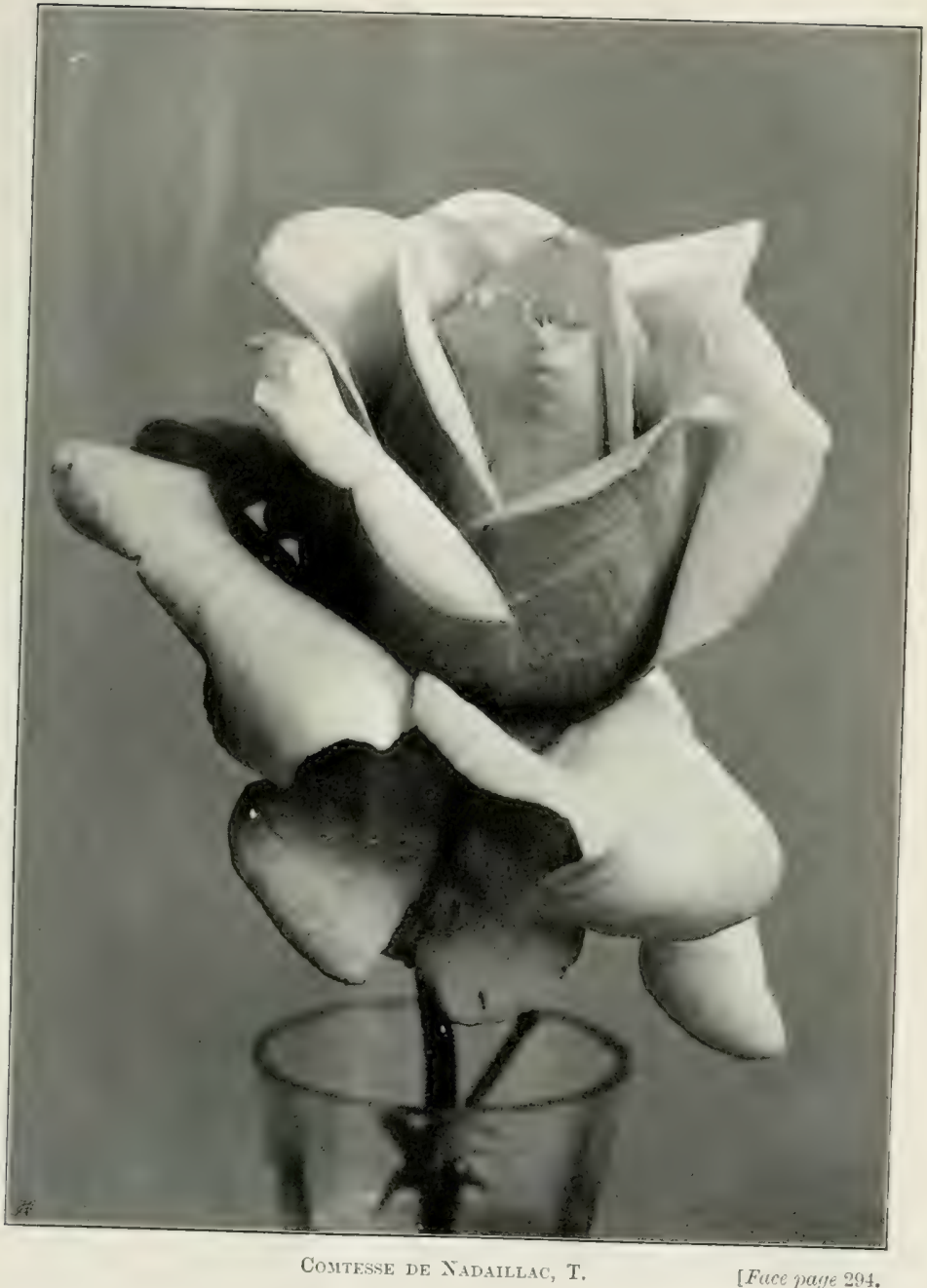



and well-shaped-a perfect smooth cone-and swells slowly even in forcing weather, while the stem thickens and stiffens in proportion, it is a good sign. On the other hand, a thick, strong, tall, fleshy shoot may open its bud almost at once and produce a comparatively poor bloom. It does decidedly best in every way as a short standard, but will also yield fairly fine flowers as a dwarf. (In speaking of standards, here and elsewhere, I would strongly advise the always asking for "half-standards." I know of no advantage, but of much disadvantage, in standard stems being more than two feet high.) The blooms sometimes come divided, but when good they are first-rate indeed in petal, fullness, and shape, and wonderful in size and lasting qualities. The colour is lovely, having many shades, and like many other Teas, is variable. Mr. Prince call show it as a yellow Rose, but this is generally when it is too much expanded and the point is gone, pink being much more predominant than yellow in my specimens. The plants are of pretty good constitution, by which I mean that they will live and not deteriorate for years if well cultivated, and they will stand close pruning, but are tender and must be well protected from frosts. Though they are so dwarf they should not be put too close together, for the habit of growth is singularly lateral, and the principal shoots of old plants will often be horizontal. It is a free flowering sort for one of such dwarf habit, but is not of much use in the late autumn, unless the weather be very fine and dry. Its freedom of bloom is a nuisance to the propagator, as it is often difficult to find a sufficiency of buds which have not started. 
Comtesse de Panisse (Nabonnand, 1877).-Eliminated by the editors of this edition.

Devoniensis (Foster, 1838).--Eliminated by the editors of this edition.

Empress Alexandra of Russia (W. Paul and Son, 1897).-Eliminated by the editors of this edition.

Emest Metz (Guillot, 1888).-Of good growth, stout and stiff, with fine foliage best as a standard. The blooms do not come well, a large proportion of the finest being often divided and opening badly, and they must be sheltered from rain; but it is a very fine large Rose when there is no malformation, with strong stout petals, good centre, and fair lasting qualities. The stiff growth and large leaves show the flowers off well, and the plant is fairly hardy, but not very free in flowering. It should be left rather long in pruning, and not too severely thinned, as the strongest shoots seldom give perfect flowers. This is again rather an awkward Rose to deal with. If "liberally treated" and grown strongly, the buds are apt to get too much sap, and to become flat, cracked, and distorted in anything but very hot weather. It is well in such a case to pinch off the crown bud and take one of the side ones, which will probably be quite large enough. Unfortunately, even the strong buds very often come singly, and there is no side bud to take. And if the plant is not liberally treated it may hardly bloom at all. A fine Rose indeed, when at last caught right, but it should only be grown by exhibitors.

Ethel Brownlow (A. Dickson \& Son, 1887).Eliminated by the editors of this edition. 

Francisca Krüger (Nabonnand, 1879).-Eliminated by the editors of this edition.

Francois Dubreuil (Dubreuil, 1895).-This is a dark crimson Tea, in many respects like Souvenir de Thérèse Levet. Opinions seem to be divided as to which is the better of the two. This has come rather more uniformly of good shape with me, and of rather clearer and lighter colour, but, except to an expert, there is very little difference between them.

Georges Schwartz (V. Schwartz, 1899).-Eliminated by the editors of this edition.

Golden Gate (Dingee and Conard, 1892).-Of only fair growth, with habit and foliage somewhat similar to Niphetos. A Rose for exhibitors, capable of producing very large, finely shaped, creamy white blooms, but not vigorous or free flowering enough for general purposes. The name, of course, is taken from the harbour of Sian Francisco, but English gardeners are naturally apt to expect it to be yellow; whereas it is certainly not golden, any more than it is like a gate. Deliciously fragrant.

Harry Kirk (Alex. Dickson and Sons, 1907).-In growth this rose more nearly approaches the Hybrid Teas than a pure tea, its chief feature is its colour, a good deep yellow-sulphur almost in the centre of the flower, fading to white at the edges of the petals. The flowers so far have not come so large as one would like-it is free rather than vigorous in growth - has not been exhibited very much up to the present, and one can say very little of its manners and customs. It will require shading and high culture. 
Homère (Robert, 1859).-Eliminated by the editors of this edition.

Hon. Edith Gifford (Guillot, 1882).-Of good stout, stiff, but not long growth, with fine foliage, liable to mildew in the autumn, and requiring protection from rain. A good Tea Rose in the old days, a large proportion of the blooms coming good, of fine shape, petal, centre, and size, on straight stiff upright stems. It is thoroughly reliable, one of the earliest, very free-blooming, a good autumnal, and does excellently as a dwarf. A "good doer," giving little trouble and ample returns; but it looks very small nowadays among modern Show Roses.

Innocente Pirola (Ducher, 1878).-Only fair in growth and foliage; requires rich soil and in many places does not do well as a dwarf; rather liable to mildew, but for a white Tea Rose little injured by rain. The blooms come well, and the typical shape is unique, one of the most perfect we have, something like the whorl of a shell. Fairly free in bloom, lasting, and quite full-sized. A first-class Rose, fine in petal and centre, it should be a great favourite with those purists (with whom I have much sympathy) who insist upon regularity and perfection of shape as the one thing desirable above all others.

Jean Ducher (Ducher, 1874).-Eliminated by the editors of this edition.

Josephine Malton, see Madame Bravy.

La Boule d'Or (Margottin, 1860). - Eliminated by the editors of this edition.

Lady Roberts (F. Cant \& Co., 1902).-A highlycoloured sport or form of Anna Olivier, which has 
gained the Gold Medal. Anna Olivier itself is very variable in colour, sometimes on the same plant being entirely pale yellow and sometimes entirely of different shades of pink and buff and terra-cotta, with many intermediate stages. Lady Roberts at its best is very beautiful and of superior colouring to any of the variously shaded Anna Oliviers we have been accustomed to. It is well to bud only from the shoots which have produced the best coloured flowers, to prevent reversion to type. In manners and customs it seems identical with the parent variety, possibly a better grower if anything.

Ma Capucine (Levet, 1878).-Eliminated by the editors of this edition.

Madame Bravy (Guillot, 1848)._Eliminated by the editors of this edition.

Madame Charles (Damaizin, 1864).-Eliminated by the editors of this edition.

Madame Chédane Guinoisseau (Lèvêque, 1880).Eliminated by the editors of this edition.

Madame Constant Soupert (Soupert et Notting, 1905).-This is quite first-rate and one of the best exhibition Teas of recent introduction. It suffered rather badly from overproduction, but has now got over the ill-effects and proves itself to be a vigorous grower for a Tea. It requires heat to open properly so last season did not suit it, but given a fair season it will probably be found to be the most reliable yellow Tea in cultivation. It should be pruned hard and does almost as well on dwarfs as Standards.

Madame Cusin (Guillot, 1881).-Of "robust," but often poor growth, with distinct wood and foliage. It is rather liable to mildew, tender to frost and 
CHAP.

requires hot dry weather. Much better as a standard, from which a fine maiden bloom may sometimes be cut, but it is difficult to grow well, and requires very good treatment. The blooms almost always come well, though they are often undersized; and the shape is unique and very good, with a fine point in the centre, and the petals arranged in imbricated form, but standing well apart from one another. This is the true form, but large flowers sometimes do not show it. No dressing for exhibition is required for this Rose, which naturally shows itself to the best possible effect. Very free-flowering: it must be well thinned for the production of exhibition blooms, but even the small flowers are lovely and of good lasting quality. A fine colour sometimes, but this is not often very lasting. Mrs. Pierpoint Morgan is an American sport of this variety, of a deeper colour, but it has not been found satisfactory: and MIrs. Oliver Ames (May, 1902) is a paler sport of very little service.

Madame de Watteville (Guillot, 1883).-A notable and most distinct Rose, in habit and flower. The growth as a dwarf is frequently poor, and it is decidedly best as a standard. It is somewhat capricious, and some good growers have but little success with it; indeed, for the first few years of its existence it was, I think, only shown in its full beauty by one Rosarian, but several of the leading exhibitors are able to grow wonderful blooms of it now. They come well, even though the buds be crinkled and apparently badly shaped, and it is quite a type of the "long-winged" Roses, the great petals standing out well, and giving it a most 
effective appearance. It is, in fact, perhaps more distinct in shape than any Rose. Liable to mildew, and very tender in hard frost; a free bloomer of most charming buds, but these must be thinned with an unsparing hand to see the Rose in perfection. It is sometimes of large size if grown as it should be, able to hold its own with H.P.s in a mixed class, and excellent if caught right. Fair in a dry autumn, but having serious demerits in its uncertainty of growth and want of hardiness. This and the foregoing variety, Madame Cusin, of weak constitutions, tender in winter and apt soon to deteriorate as plants, are among the fow Teas which are best as maidens.

Madame Falcot (Guillot, 1858).-Eliminated by the editors of this edition.

Madame Hoste (Guillot, 1887).-Of good growth and fine foliage, doing pretty well as a dwarf, but better as a standard. The flowers are rather thin, and though they stand a long time in the advanced bud stage, when once open they soon go, showing a weak centre. They are, however, very large and of very fine shape, and produced in great abundance, often very fine in the autumn. In fairly cool and dry weather this is a very effective Rose for exhibition and all other purposes, as the stems are stiff and straight and the buds long and clean. It is a pity it is not deeper in colour and a little stouter in petal, but even as it is we nust consider it one of the best. I remember the late Mr. B. R. Cant, in the year that it came out, showing me a tiny bud on a grafted plant, with a prophecy, which has been amply fulfilled, of its future value and popularity. 
Madame Jules Gravereaux (Soupert et Notting, 1901).-An exhibition Tea of the highest rank, in fact it was more frequently exhibited than any other Tea at the National of 1909, and threatened to depose White Maman Cochet from the place of honour in Mr. Mawley's Analysis. Not a true Tea in the ordinary acceptation of the term as it is a climber of the Gloire de Dijon family-it yet produces flowers that rival in size any other Rose in this section-it was awarded the Nickerson Cup for the best Tea introduced since 1900. It is easily grown, very free flowering and must be severely disbudded. Its only fault is that it is a little impatient of wet, but what Tea isn't? It makes a very fine pillar and is best grown in this form or on a fence or wall.

Madame Lambard (Lacharme, 1877).-Eliminated by the editors of this edition.

Madame Vermorel (A. Mari, 1902).-A good " hot season" Rose useful to the exhibitor, but very impatient of wet, so much so that hardly a flower of it was seen the whole of last season. Fairly good grower that produces its flowers on stems of some length. Not recommended to the small exhibitor.

Maman Cochet (Cochet, 1893).-This is still one of the finest Tea Roses for exhibition purposes, and it speedily aitained a great celebrity and popularity. The growth is very strong for a Rose that cannot be called a climber, but it has a tendency to put all its strength into one shoot rather than to form a wellbalanced head. The foliage is good, but has a liability in the autumn to attacks of what is called " silver-leaf" on other plants. This does not do much damage, however. The blooms are very large, stout, 


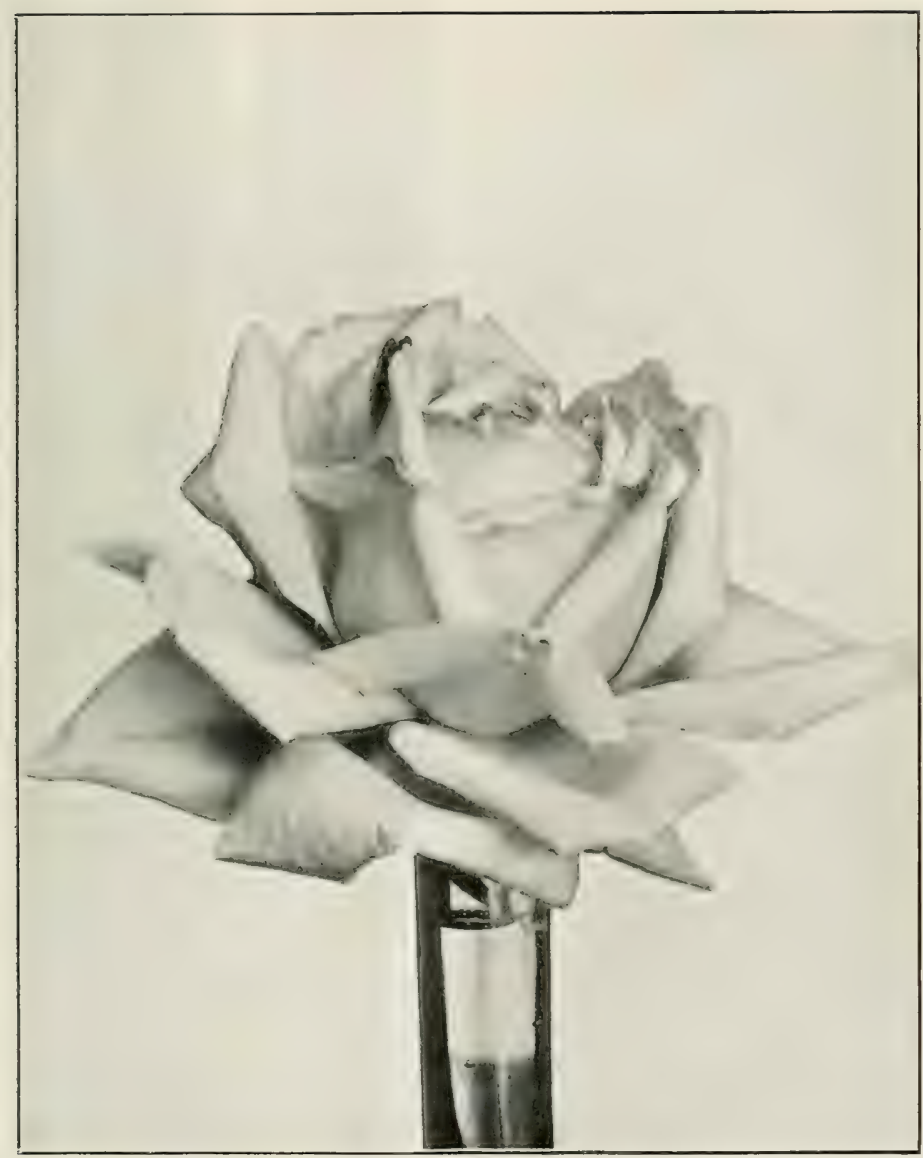

Madaje Jules Gravereaux.

Photograinh by G. A. Hemmond. 




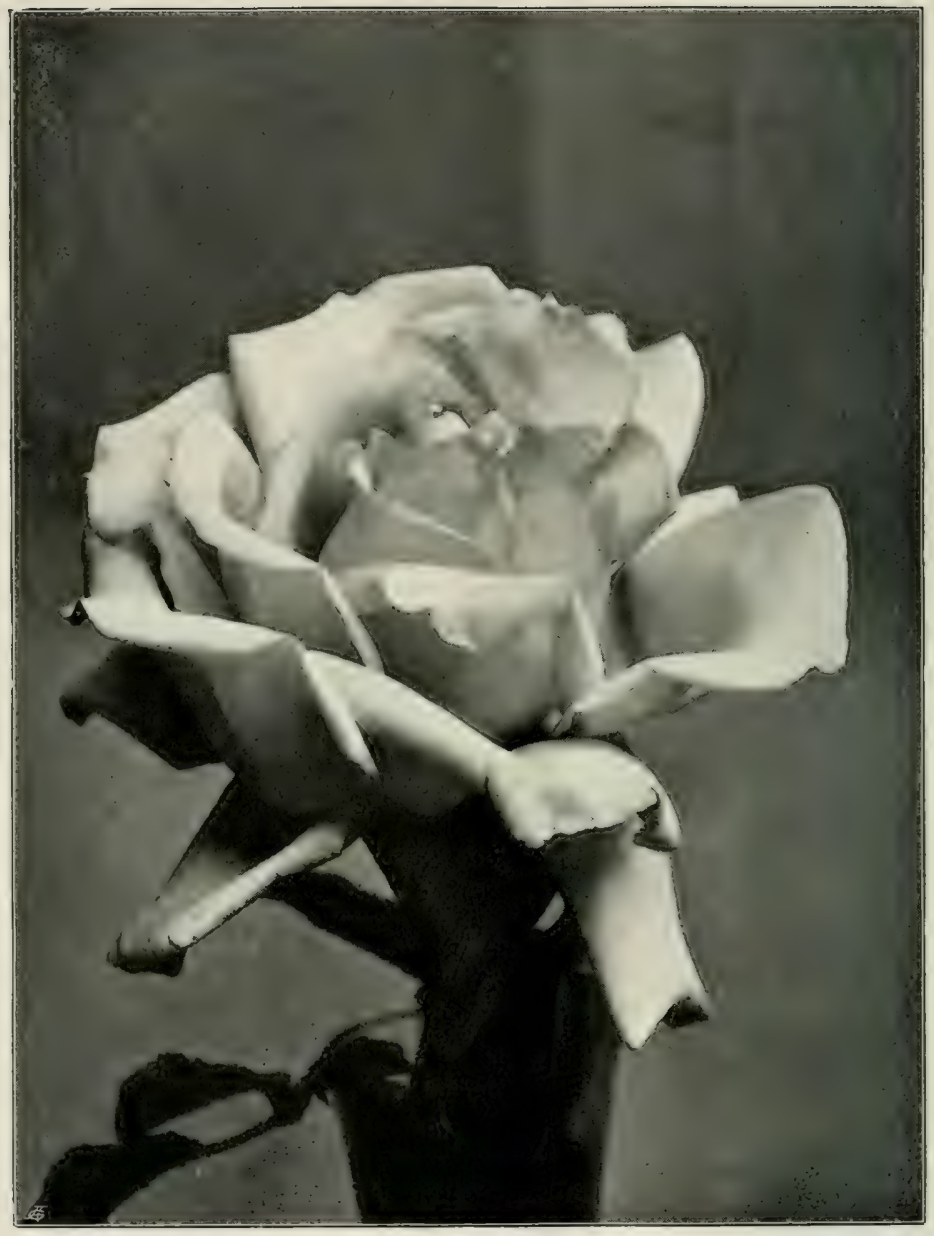

MaMAN Cochet, T. 
and lasting: they are also very well shaped, but have often some little disarrangement in the petals, which just prevents perfection. The colour of the flowers is rather mixed: in fine hot weather sometimes beautiful, but often undecided and weak. Occasionally, also, the blooms are rather coarse and rough. Still, a very fine Rose and easy to grow and get good : lasting and thoroughly dependable and very popular for exhibition; it succeeds very well as a dwarf, and does not require close pruning: with too "liberal treatment" the blooms are almost sure to come divided: when laterals issue from the wood of the shoot bearing the chosen bud great caution should be used in suppressing them, for they are the safety valves of the sap supply, and it is only on weakly plants or in very hot weather that they should be stopped. Said to be a seedling from Catherine Mermet, but if so the other parent would seem to have had a much more vigorous constitution.

A lemon-white sport of this Rose was issued in 1897, which is quite the finest and best white Tea Rose of the pure pointed shape which we have at present. Identical with the type in all manners and customs, it has done for Maman Cochet what the Bride did for Catherine Mermetcorrected the weakness of colour while retaining the beauty of shape and all other good qualities. It is now probably the most popular of all the Exhibition Teas: and thus the most highly appreciated Roses in the three classes-Frau Karl Druschki, H.P., Mildred Grant, H.T., and White Maman Cochet, T. -are all white. But a tinge of lemon just prevents this Rose from being pure white. 
Marie van Houtte (Ducher, 1871). - Eliminated by the editors of this edition.

Medea (W. Paul \& Son, 1891).-O Of stout stiff growth, but susceptible to frost, not very freeblooming, a fine Rose for exhibition, but not well suited for general cultivation. The blooms are particularly full, with the rounded centres which require a hot season or situation for their full development. They are sometimes very large, and in perfect blooms the outer petals reflex well, making a very fine shape. A very excellent Show Rose, which would be better still if the colour were a little deeper.

Mrs. B. R. Cant (B. R. Cant \& Sons, 1901).Eliminated by the editors of this edition.

Mrs. Campbell Hall (Dr. J. Campbell Hall). This very fine Tea is not yet in commerce, but it has been awarded the Gold Medal of the National Rose Society. As seen growing in Monaghan it is a Rose of excellent constitution; habit similar to Maman Cochet; very free flowering, and the flowers are of exquisite shape and colour. It will become indispensable to the exhibitor, and the trade and the amateur alike await its advent with impatience.

Mrs. Edward Mawley (A. Dickson \& Sons, 1899). -A Rose of the first rank, singularly free from bad manners. Taken all round, it is, I think, the best of the three very fine Show Roses (Ulster H.P. and Bessie Brown H.T. being the other two) which Messrs. Dickson issued together in 1899. Said to be a seedling from Mrs. W. J. Grant, it hardly shows a strong family likeness to that fine Rose, nor is it a better grower. Here, then, is one of those cases, which might easily have been foreseen, where it 


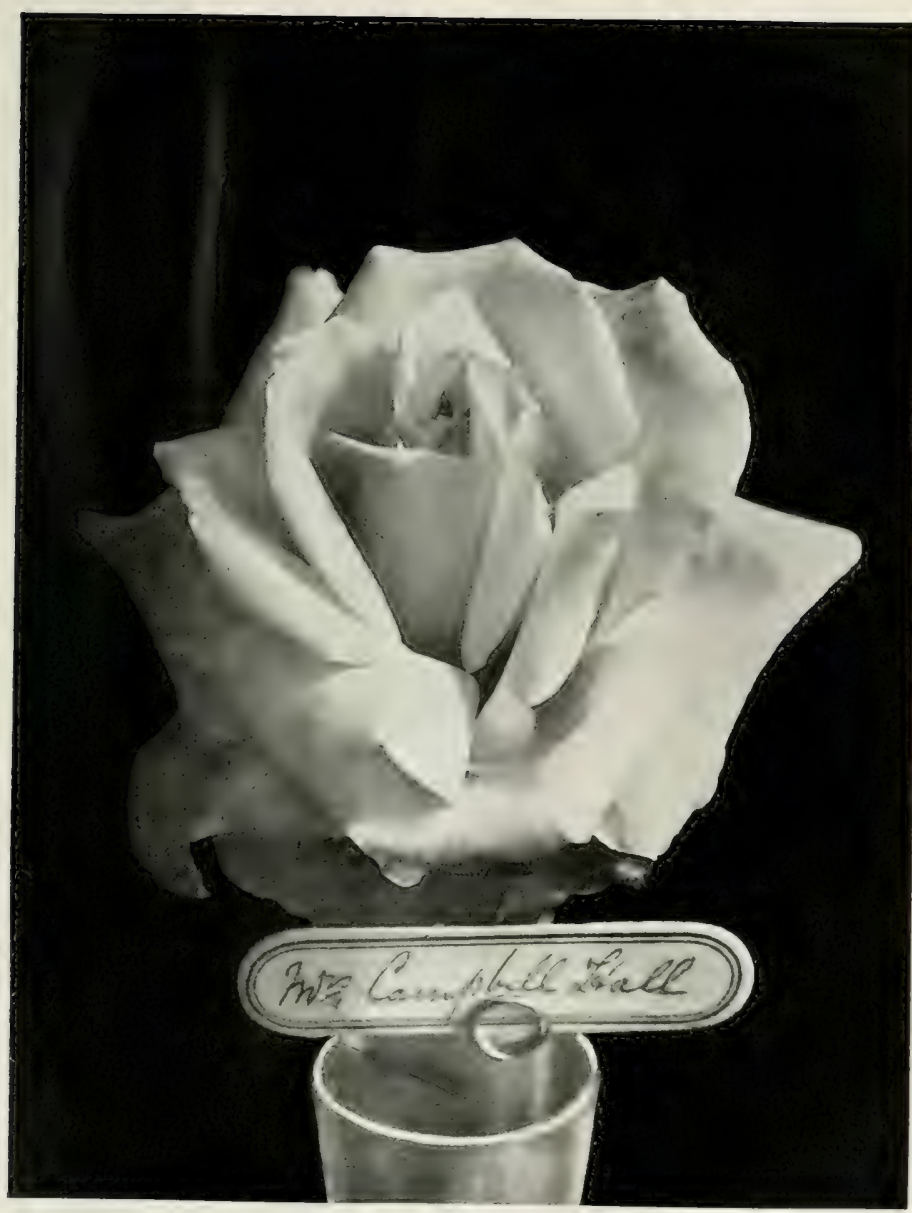

Mrs. Campeeli Hall.

Photograph by Dr. Campbell Hall.

[Face pare 304. 




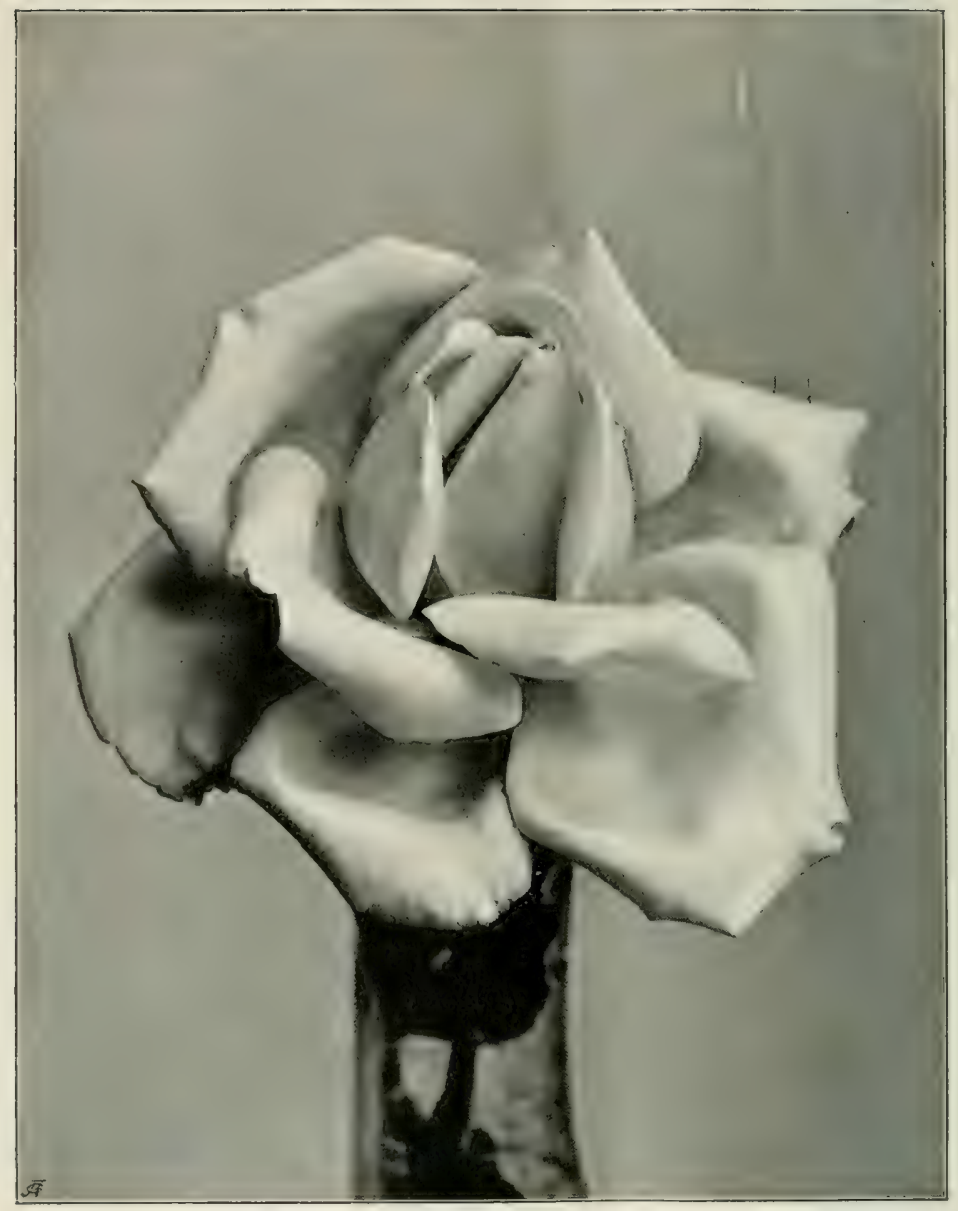

Mrs. E, MAWLET, T.

[Fuce page 305. 
seems almost impossible to decide whether the Rose is a Hybrid or pure Tea (p. 26, \&c.). At any rate, it is an extremely good Rose, free in growth, very freeblooming, and producing extra large finely shaped flowers even quite late in Octoher. The shape of the blooms is quite first-class, colour very good, and size magnificent. It does not show at its best in a very hot season, but even then it will come again very fine in the autumn. Best as a standard, and producing its finest blooms as a maiden, with grand wing-petals and very sweetly scented. I have detected no bad habit, save some loss of colour and stiffness of outer petals in very hot weather, in this truly fine variety. Its constitution is not, perhaps, so good as it might be, and it undoubtedly does best as a maiden.

Mrs. Hubert Taylor (Alex. Dickson \& Sons, 1909). -A beautiful Tea, with a flower reminiscent of Madame Cusin, but nearly white in colour; has been shown well, and awarded the Gold Medal of the N.R.S.

Mrs. Myles Kennedy (Alex. Dickson \& Sons, 1906). -A promising exhibition variety, with flowers of great size. Colour silvery white, with a delicate picotee edging to the petal. It is purely an exhibitor's Rose, and requires high culture. A fairly vigorous grower for this class, and was awarded the Gold Medal of the N.R.S.

Molly Sharman-Crauford (A. Dickson \& Sons, 1908).-A beautiful Rose, as exhibited by the raisers, but 1909 was all against it. The flowers are large, with a good centre, and are of a pleasing shade of white, with a slight suggestion of eau de nil. Nothing can yet be said of its manners and customs. 
Muriel Grahame (A. Dickson \& Sons, 1898).-A pale cream sport of Catherine Mermet, which at first seemed hardly sufficiently distinct from The Bride. It is thoroughly distinct, not only in colour, but in shape, when grown strongly, preferably as a maiden standard, but weak flowers of it and The Bride would still look much alike. Not a hardy grower, it resembles Catherine Mermet in manners and customs, and differs from The Bride, when both are at their best, in being more pointed and less globular in shape, and of a cream white colour instead of the pure white with lemon tinge of the other. A very fine exhibition Rose, but not of sufficiently strong constitution or free-flowering habit for general cultivation.

Niphetos (Bougère, 1844).-This rose is a good instance of what is termed "free" growth, i.e. neither long nor stout, but branching and generally growing somewhere. The foliage is good and not much liable to mildew, but the blooms will not stand rain. This old Rose has attained a very great reputation for its free-flowering qualities and its purity of colour. I do not know how many thousand feet run of glasshouses have been maintained for the purpose of growing the Rose which Mons. Bougère, the raiser, appropriately named Niphetos ("snowy"), but I apprehend the figures would very much have astonished him could he have known them when he issued it, and he would perhaps have wished to attach his own name to it instead of to the much less valuable production (Bougère, known in Australia and elsewhere as Lord 'Tarquin) of twelve years before. White flowers are always in special demand, not only 


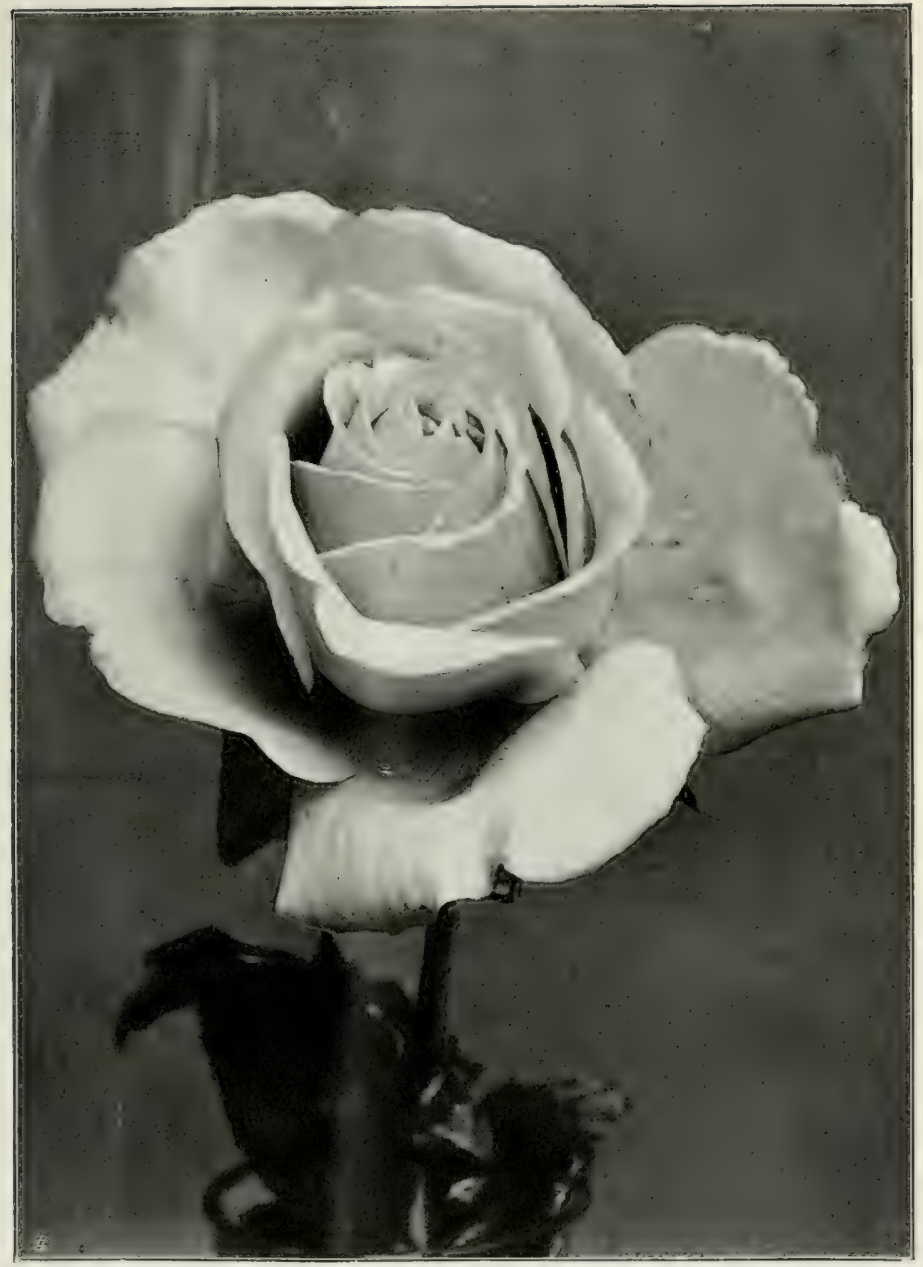

Murtei. Grahame, T.

Face prege 300. 

because they are lovely in themselves, do not lose their colour, and go well with everything, but also because they are considered the most appropriate on the three great occasions of birth, marriage, and death. It so happens that Niphetos, the purest of all white Roses, has a long bud especially suitable for bouquets and wreaths, and is also free-flowering and bears forcing well. It is no wonder therefore that it is, and has been, cultivated for market purposes to an astonishing extent. It opens very easily and freely, and for this reason will probably continue to hold its own for winter forcing against the newer white Ioses which are better for exhibition. For this latter purpose it is no longer of use against their increased competition, for, though capable of attaining a very large size, with fine long outer petals, it is almost always malformed or divided in the inmer centre if not throughout, the shape is very fleeting, and when the outside petals do come down they fall completely, giving the idea of a total collapse. It is free-blooming throughout the season, but the autumnal buds do not come large and require fine weather. It does not do as a dwarf, for the blooms come smaller, and, the wood being neither stiff nor upright, the petals get much injured by wind and rain unless the flowers are well held up above the ground. A good Rose, if fully fed, for a low wall.

Perle des Jardins (Levet, 1874).--Of good stout stiff growth, with reddish wood and fine foliage, doing well as a dwarf, but a Rose of shocking bad manners. We want much a well-shaped Tea of a good decided yellow to take the place of Maréchal Niel when it is off bloom; and Perle des Jardins is always promising to do this, and very, very seldom 
doing it. It comes divided, or quartered, or malformed in some way almost to a certainty during the summer, but manages to stave off execution of just judgment by the aid of better-shaped and far more valuable blooms in the autumn. At that season it will often prove the only available sort which is really yellow, and even one bloom of this colour will make a wonderful improvement in a bouquet of autumn Roses. The plant is tender and the newly formed buds are spoiled in shape by our cold nights in May. This theory not only accounts for this variety producing better-shaped blooms in the autumn, but probably also supplies the reason for all malformed Roses of midsummer. A climbing sport of this Rose (Henderson, 1891) seems if anything more tender, but is good under glass or in a tropical climate; and another called White Perle, has not met with much favour. Two other sports, Sumrise and Sunset, equally tender, are mentioned in their proper places.

Princess Beatrice (Benmett, 1887).-Eliminated by the editors of this edition.

Princess of Walcs (Bennett, 1882).-Eliminated by the editors of this edition.

Rubcns (Robert, 1859).-A good grower, producing strong clean shoots with very fine foliage, and quite capable as a short standard of covering the wall of a one-storeyed building. It is not liable to mildew, and the blooms, which are slightly pendent, can stand a little rain. They can be generally relied on to come of good shape, but the petals are thin and the form fleeting. The fine half-open buds are well supported by grand foliage, but the flowers are difticult to exhibit well, as they look weak and un- 
substantial when shown with other Teas. It is pretty hardy, best as a standard and in cool weather: capital, early and late, against a dwarf wall: very free blooming and a good autumnal, thriving well on lightish soil.

Safrano (Beauregard, 1839).-Eliminated by the editors of this edition.

Souvenir de Catherine Guillot (Guillot, 1896).Eliminated by the editors of this edition.

Souvenir d'Elise Vardon (Narest, 1851).-Not of free growth or of good constitution, but there ought to be at least one pretty strong shoot on each plant: not liable to mildew, but easily injured by rain. The blooms come generally well, though sometimes divided, and when fine on a strong shoot and taken at the right stage it used to stand easily at the head of all Tea Show Roses. For some strange reason or other this is not now the case, and a fine perfect bloom is not now often seen. The late Mr. B. R. Cant used at one time almost every year to take the medal at the Crystal Palace with a flower which simply had no rival for size, purity, and faultless shape: and I have taken several medals with it myself, but not for the last six or seven year's. This may be owing to some deterioration in the variety, but also we have not had seasons suitable for it. It requires cool, weather in which it can srow slowly, a burst of heat bringing it out too soon. Being a weak grower, one would expect from the analogy of Teas of a like character that it would do best as a Standard, but it is not so in my experience, all my best blooms having come from established dwarf plants. In freedom of bloom it is not good, for the blooms come singly, and the weak shoots 
will often not flower at all. The growth is shy and the constitution delicate. It is a Rose for exhibitors and enthusiasts, and not for garden purposes or general cultivation.

Souvenir de Pierre Notting (Soupert et Notting, 1901).-As this variety is said to be a cross between two such Roses as Maréchal Niel and Maman Cochet, it naturally aroused "great expectations" which perhaps have not been entirely realised. Still it has proved a very useful exhibition Tea, and is worthy of being considered in the first six. It is an excellent grower, very free flowering, its only fault being a weak outside petal. Makes a fine Standard.

Souvenir de Thírèse Levet (Levet, 1882).-Eliminated by the editors of this edition.

Souvenir d'un Ami (Defougère, 1846).-A grand old Tea Rose, of strong, healthy, vigorous growth with extra fine foliage. This is one of the hardiest of the show Teas, doing well on light soil, and fairly as a dwarf, but much better as a standard: a free bloomer and a capital autumnal, and the blooms generally come well, of fine shape, substance, and petal, the largest size and good lasting qualities. The principal fault is that the flower soon loses colour and is apt to look dirty, but it is still a general favourite for all purposes.

Souvenir de S. A. Prince (Prince, 1889), syn.: The Queen.-This is a pure white sport from the last-named, and very valuable as giving us a really white Rose of good pointed form, though the bluntness or roundness of the point prevents the shape being so refined as White Maman Cochet. In habit and general manners it is just like the type, and we have here another instance, of which we have 


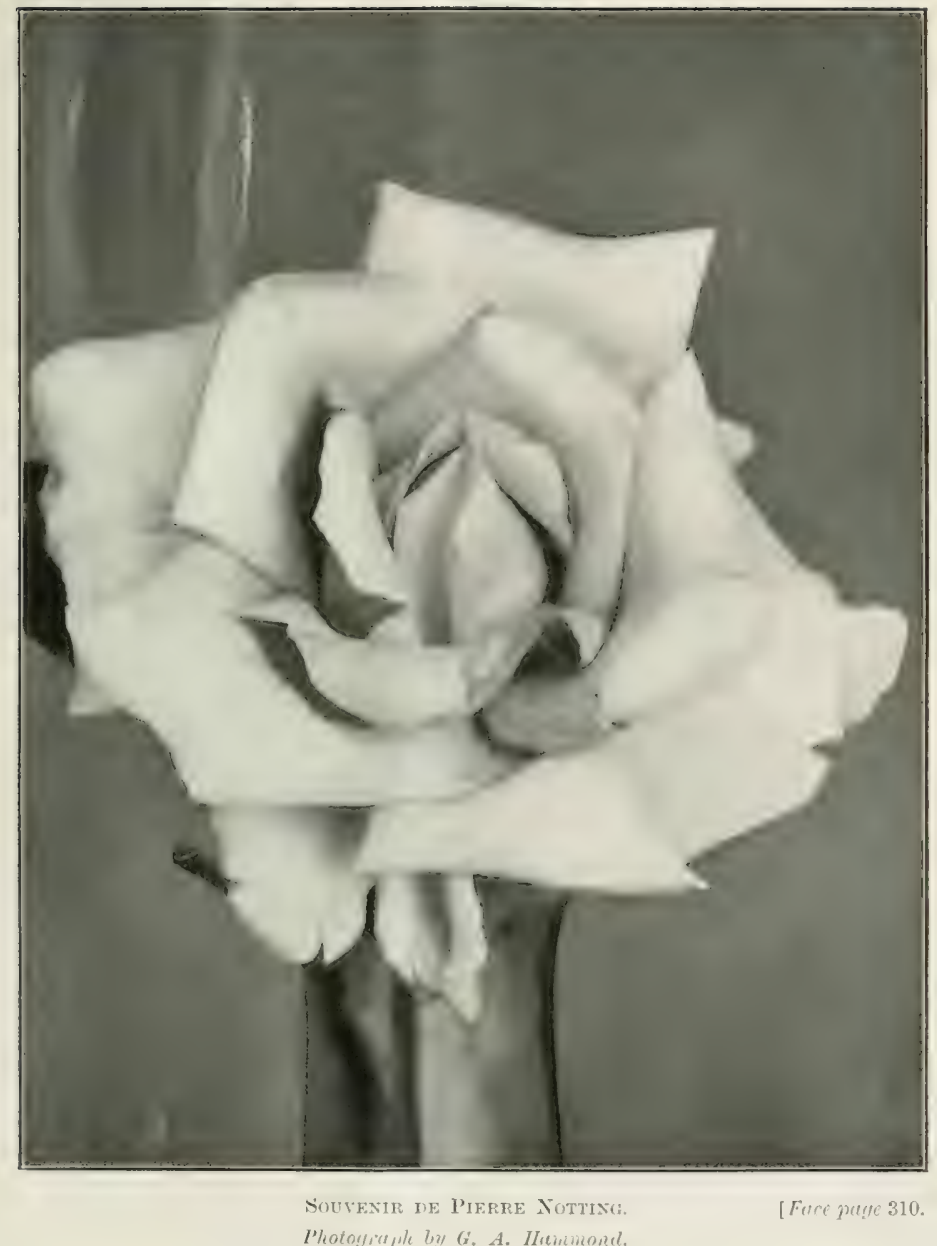



noticed two already in Catherine Memet and Maman Cochet, of a Rose being much surpassed in popularity by its white sport, for the obvious reason that the latter maintains its colour so much better after being cut.

Sunvise (Piper, 1899).-This is a sport of smaller size from Sunset, next mentioned, a button-hole Rose of most varied and beautiful colours when grown under glass. It appears to be even more tender than the variety from which it sported, and a worse grower, and it is quite useless out of doors.

Sunset (Henderson, 1883).-Eliminated by the editors of this edition.

Sylph (TV. Paul \& Son, 1895).-Eliminated by the editors of this edition.

The Bride (May, 188.5).-A pure white sport from Catherine Mermet, of great value. It speedily took a high rank, and gained a great reputation quite equal to that of the type, and was at once acknowledged as being one of the best half-dozen. Newer varieties have now to a certain extent displaced it from this high position. In manner's and customs it is similar to C. Mermet, but, like its sister sports, Bridesmaid and Muriel Grahame, differs from it a little in form as well as colour. The true form of The Bride is perhaps the most charming disposition and arrangement of the petals round a centre point to be found among Roses. From Muriel Grahame it differs, when both are at their best, not only in this matter of form, but also in being of a purer white with occasionally in a young bloom a greenishlemon tinge at the base of the petals. There are very few, if any, white Roses which are more lovely than a perfect flower of The Bride. 
White Maman Cochet (Cook, 1897).—see Maman Cochet.

W. R. Smith (Henderson, 1908).-This is an exceedingly promising new Tea of excellent growth and habit. The flowers are creamy white, the outside petals of the younger flowers being tinged a delicate pink. Of good shape and size, its only fault being that it develops a split. Sent out only last year by Messrs. Hugh Dickson, of Belfast, it has already created a reputation, and has undoubtedly come to stay.

\section{Climbing Roses}

I will next endeavour'to deal with Climbing Roses of all classes, for as they cannot be grown with others in beds, but require to be trained to something, it will perhaps be more convenient to have them by themselves. Walls are best suited for the more tender varieties, such as the Banksias, Climbing Devoniensis, Fortune's Yellow, and others, which require heat and protection. Pillars are best for those which are not too strong in growth, hardy, and do not get naked at the base, but flower well from top to bottom when growing upright, such as Crimson Rambler, Carmine Pillar, and the climbing sports of H.P.s. For arches the Wichuraianas, Ayrshires, the Dijon, and other strong growing and hardy Teas are the most suitable: these flower best on the shoots that are more horizontal, as at the top of the arch; and it should be noted, as a rule, that the same Rose will not flower well on the horizontal and on the perpendicular shoots, so that a Pillar Rose 


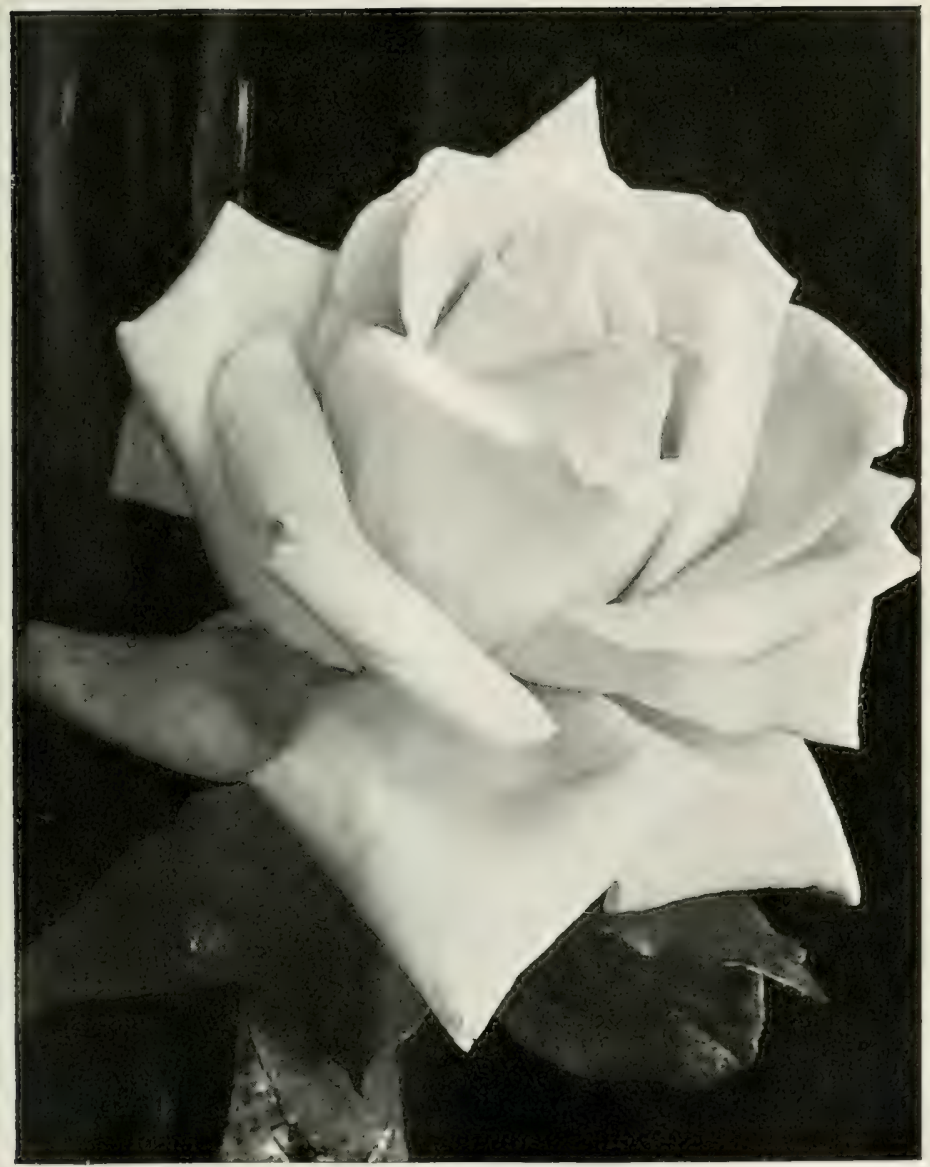

Wutte Mamax Cocheto

[ Ture jugre šl:. 




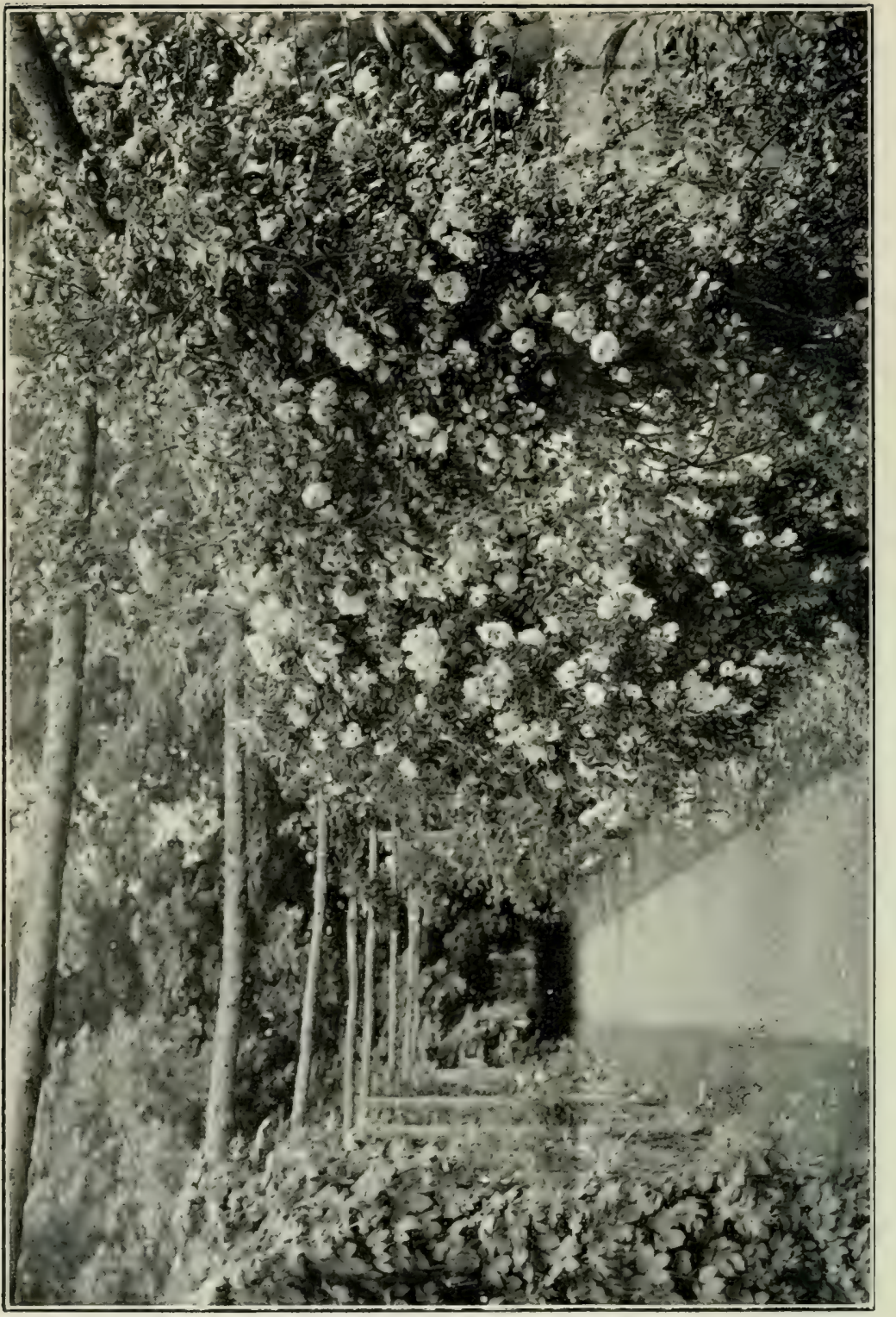


should be used for the uprights and an Arch Rose for the horizontal top of the arch. There are a good many comparatively new Climbing Roses, but most of the best will be found in the following list:-

Alberic Barbier (Barbier, 1902), an early flowering hybrid Wichuraiana, buds creamy yellow changing to white, a good grower as are nearly all the Wichuraianas.

Aimie Vibert (Vibert, 1828).-An old Rose, one of the very few true Noisettes, showing the characteristics of the race by its hardiness and clusters of small flowers. Almost evergreen, with full, rosette-like clusters of small white flowers. The climbing form should be chosen, as the original strain was less vigorous. Not such a strong climber or so effective as a white cluster Rose as some of the Ayrshires and Evergreens, but good for pillars.

Alister Stella Gray (Paul \& Sons, 1894).-Raised by the well-known amateur, Mr. A. Hill Gray, of Bath. A Noisette, free-blooming and perpetual, with small flowers of a pale yellow, borne in clusters. Suitable for pillars and arches.

Ards Pillar (A. Dickson \& Sons, 1902).-Hybrid T'ea is a later introduction by the same prolific firm of raisers, with good, full crimson flowers, a fine pillar rose.

Ards Rover (A. Dickson \& Sons, 1898).-A Hybrid Perpetual, with handsome foliage, and good-sized flowers with stiff petals; worth growing for its colour of dark shaded crimson, a rare tint among Climbing Roses. Suitable for walls, pillars, and arches. This variety was awarded a Nickerson Cup for the best crimson climber.

Ayrshires.-This class, with the Boursaults and 
Evergreens, are the quickest and longest growers of all Roses, blooming in clusters in the summer only. There is nothing to equal them for quickly and thickly covering a space, either for walls, pillars, arches, pergolas, or even as hedges by themselves. Trained a little at first to grow among the branches of a half-dead tree, they should then be left to themselves, and the highest shoots will hang down when no longer supported, and will be a mass of bloom for a short time in the following summer. They will cover an ordinary-sized summer-house, forming in time a deep, thick mat all over the roof. Budded on Standard stocks 8 or 9 feet high they make the most perfect weeping Roses, at last quite hiding the stems, and becoming huge bushes. They differ but little, except in colour, which can be learnt from the Catalogues. Among the best known are :-Ayrshire, Dundee Rambler and Splendens; Bennett's seedling or Thoresbyana: Evergreen, Félicité et Perpétue and Madame D'Arblay.

Banksias.-Tender Roses, which require a warm wall, and must not be pruned or even tipped, only the dead and unwanted wood being cut out. They will not flower much till well established, and have quite small blooms in large clusters. There are only two varieties, in general cultivation, the White (Kew, 1807), very sweetly and characteristically scented, and the Yellow (R. H. S., 1824), with smaller, scentless flowers, but more of them.

Blush Rambler (B. R. Cant \& Sons, 1903).-This beautiful Rose is quite the best of the descendants of Crimson Rambler. Very strong in growth, producing large clusters of beautiful apple blossomlike flowers - single, but lasting well on the plant. One of the best for pillar, pergola or hedge. It has 


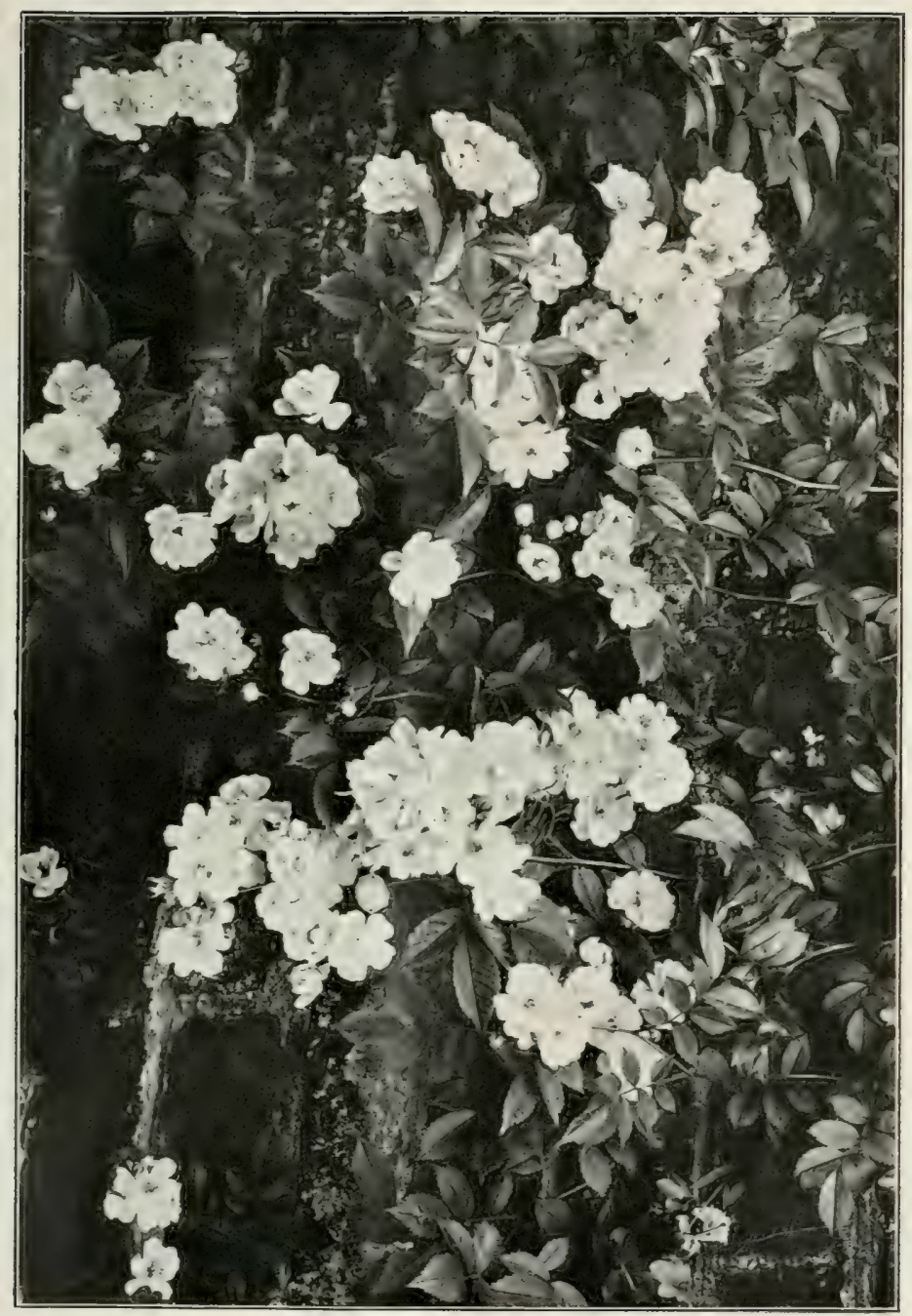

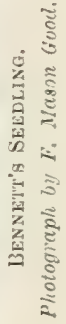



no faults, and was deservedly awarded the Gold Medal of the National Rose Society.

Billard et Barré (Pernet-Ducher, 1899).-Probably the best semi-hardy yellow climber suitable for pillar or wall. Very fine in the half open bud stage.

Bouquet d'Or (Ducher, 1872).--Another of the Gloire de Dijon family, and one of the best, being quite distinct in colour, as hardy as the type and superior to it in form, nearly good enough to show ; a fine yellow with coppery centre. This Rose was sent out, probably by accident, as a Noisette : it has rather more of a branching habit than others of the same family, suitable for walls, arches or pillar.

Carmine Pillar (Paul \& Son, 189.5).-For a single Rose which is not an antumnal, this is perhaps one of the best. It is very bright in colour and freeflowering, remaining in bloom a sood while, makes a fine pillar and does well on an arch.

Cheshunt Hybrid (Panl \& Son, 1873).-Eliminated by the editors of this edition.

Claire Jacquier (Bernaix, 1888).- Rather susceptible to frost but a very vigorous grower, the flowers are produced in clusters and when established the rose is very free flowering-colour yellow.

Climbing Caroline Testout (Chauvry, 1902).-A very reliable climbing sport of this well-known Rose with all the good qualities of its parent, suitable for arches and walls.

Climbing K. A. Victoria (A. Dickson \& Sons, Ltd., 1897).-A useful Rose for walls or pillars not so vigorous as the last named but quite reliable.

Climbing Devoniensis (Pavitt, 1858).-Eliminated by the editors of this edition. 
Climbing Mrs. W. J. Grant (The E. G. Hill Co., Ltd., 1899).-A vigorous growing free flowering sport of this well-known Rose suitable for arches but at its best on a wall, where it is unusually early and produces quantities of flower's of good size and quality. The three climbing sports above mentioned can all be relied on as excellent climbing Roses for wall, or arch.

Climbing Niphetos (Keynes \& Co., 1889).-This is a valuable climbing sport of the well-known Tea Rose, though there is sometimes a little difficulty in getting it to commence "rumning." It will not answer well except under glass, and requires to be liberally treated, it is most useful with its large constant supply of fine pure white flowers, not recommended for out of door culture.

Cloth of Gold (Coquereau, 1843).--Eliminated by the editors of this edition.

Crépuscule.-A noisette worth growing for its colour only; it is a deep copper yellow with pink shating-fainly free flowering and the young buds make a relightful buttonhole. Semi-climbing only and best grown as a pillar or on a screen. Does well on a wall.

Crimson Rambler (Turner, 1893).-A strong growing form of Polyantha, introduced from Japan. "Rambler" does not seem to be a very good name for it, for though it is of strong long growth, very different from that of the dwarf Polyanthas, it has not a true rambling habit, fresh strong shoots constantly trying to rise from the base of the plant instead of high up on the shoots, as would be the case with a true rambler like Polyantha Simplex, for instance. The wood and foliage, covered with 



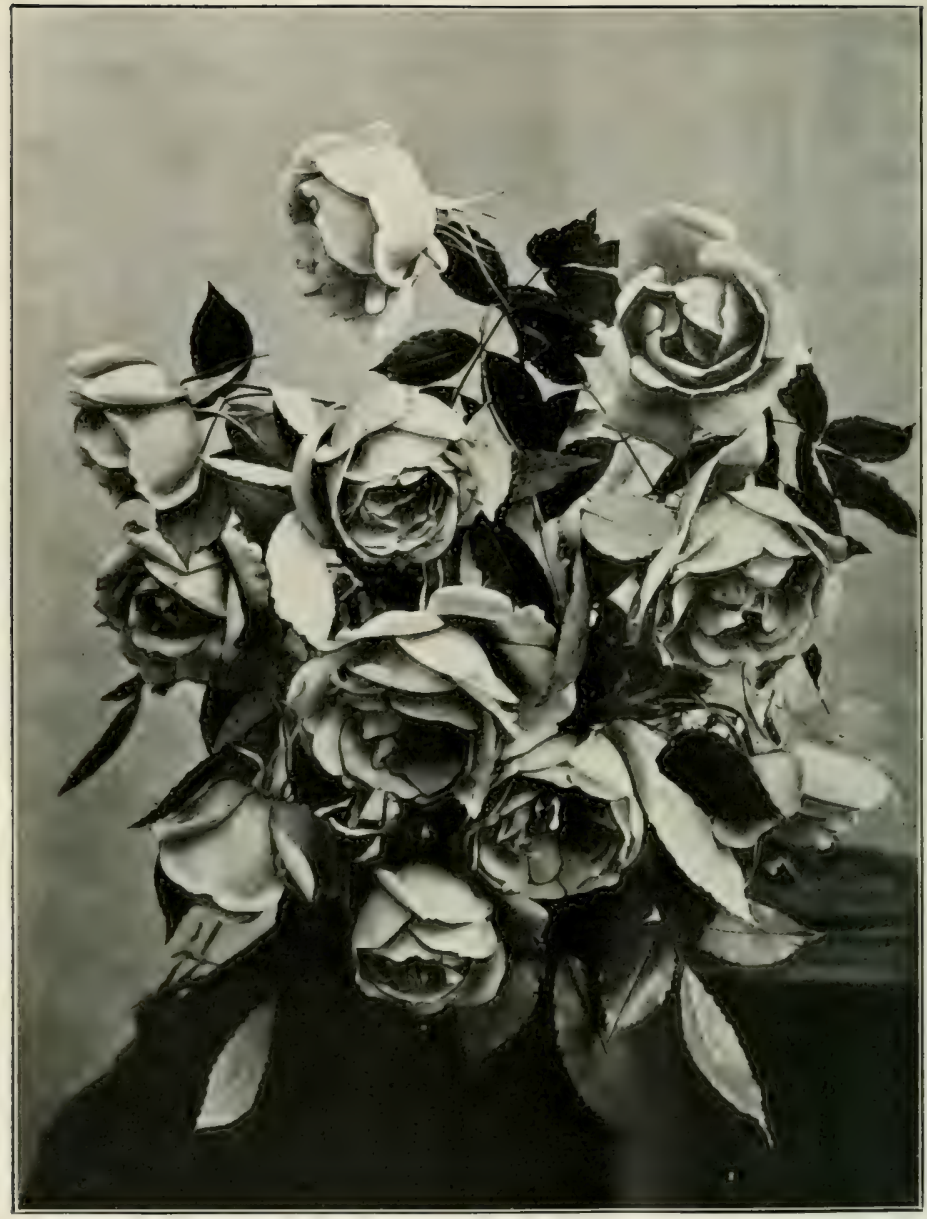

Foptratis Yelinw.

[Fire, parf 317

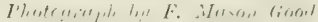


short hairs, are very distinct, and the trusses of small crimson flowers which come, in perfection, in the shape of a bunch of grapes, produced quite a sensation from their unique character when the Rose was first exhibited. It is not an autumnal, but lasts in bloom a long time. It does not do well against a wall, fairly as a bush with the shoots supported by bamboos, and decidedly well as a pillar Rose, though autumnals are certainly best for that purpose. With the same reservation it will be found to answer well as a hedge, but is subject to mildew. Psyche (Paul of Son, 1899) is a seedling of this variety, with paler flowers and similar habits. Queen Alexandra and Blush Rambler, mentioned on p. 24, are later descendants. The flower-trusses last well, either on the plant or in water, and the plants themselves are thoroughly hardy, even in America.

Débutante (M. H. Walsh, 1905).-Pretty soft shade of pink belonging to the late flowering section of the Wichuraianas. Makes a good weeping standard.

Evangeline (M. H. Walsh, 1907).-Sent out as a Wichuraiana but apparently more allied to the Polyanthas, a single flower of a bright apple blossom colour, very strongly scented-very strong grower-late flowering.

Flower of Fairfield (Schultheis,1908). - A perpetual flowering sport of Crimson Rambler that should be an acquisition as perpetual flowering Ramblers are scarce.

Fortune's Yellow (Fortune, 1845). - A strong growing Noisette, which requires a warm wall and a dry situation. The flowers are only semi-double 
and of loose and irregular form, but they are very beautiful, of a lovely colour-yellow flaked with carmine and the fine loose petals are of charming texture and "complexion." It is very early, quite one of the first Roses to be gathered out of doors, and will almost always be in bloom in May on a warm wall, but is tender and will not do everywhere.

François Crousse (Guillot, 1900).-One of the best crimson pillar roses, rather late flowering, hardy and perpetual.

Francis Foucard (Barbier, 1901).-An early flowering Wichuraiana, pale lcmon yellow flowers, medium size, slightly more perpetual than most of this class. Makes a good weeping standard.

Gardenia (Manda, 1899).-The best all-round yellow-flowered Wichuraiana. Exquisite in the bud, useful for all purposes except as a weeping standard as the growths are to stiff. Early flowering.

Gloire de Dijon (Jacotot, 1853).-Perhaps the best known of all Roses. It is always classified as a pure Tea, but there can be no doubt it is a hybrid, having a cross in it of some other race, for the plant is absolutely hardy in this country, of very vigorous climbing growth, and the foliage is that of a Hybrid Tea. Like the Noisettes, Roses of this race must not have the strong young shoots pruned back, or wood instead of flowers will be produced; but, when this is understood, no Rose, save the common pink China, blooms so profusely and constantly, early and late, as the one under notice. Dean Hole says, "Were I condemned to have but one Rose for the rest of my life, I should ask, before leaving the dock, to be presented with a strong 
plant of Gloire de Dijon." For my part, I would choose La France, for there is very little beauty of colour or form to a florist's eye in the well-known "Glory Die-John," except perhaps quite in the bud, and even these are comparatively fat and squat, and wanting in the elegance of the long, clean, pointed buds of the aristocrats of Roses. A plant of Gloire de Dijon may be a hundred times the size of one of Comtesse de Nadaillac, and may have more than a hundred times the number of blooms; but take the finest Gloire de Dijon that ever was seen and set it in a stand by a fair representative flower of the other, and the great inferiority in every respect, even in size, would at once be manifest. The foliage is very fine, but it is not so evergreen as Maréchal Niel and some other of the Noisettes, nor does it clothe the bases of the branches so well as Reve d'Or. It is not liable to mildew, cares little for rain, and its bushels of blooms come unusually uniform in colour and generally of the same weak open shape. It is thoroughly hardy in this country, and will grow and flourish almost anywhere and anyhow, tolerably well even on a north wall ; but in America it has not proved so hardy against really severe winters as some of the pure Teas, such as Francisca Krüger and Edith Gifford, and it is not so popular in any country as it is here. A Rose of such notoriety, which forms seed vessels freely, has naturally been a prolific parent of varieties of similar habit, forming a race, almost a class in themselves. They differ only in colour, in shades of yellow, salmon, and white. Among the best are Belle Lyonnaise, Bouquet d'Or, Duchesse d'Auerstadt, Emilie Dupuy, Henriette de Beauveau, Kaiserin 
CHAP.

Friedrich, Madame Berard, Madame Chauvry, Madame Eugène Verdier, Madame Jules Gravereaux etc.

Gruss an Zabern (Lambert, 1904).-A very freeflowering semi-climbing pillar Rose, blooms in large trusses of sweet scented pure white flowers, summer flowering only.

Hiawatha (M. H. Walsh, 1905).-A single flowered Crimson Rambler of rather better colour with a white eye, a good grower and likely to prove a very popular variety. Makes a good weeping standard as its growths are long and pendulous. Late flowering.

Jersey Beauty (Manda, 1899).-One of the first and still one of the best of the single Wichuraianas, its pale yellow flowers with their cluster of yellow stamens are unique. Useful for all purposes and one of the most rampant. Early flowering and nearly evergreen.

Johanna Sebus (Müller, 1899).--One of the best of pillar Roses, exceptionally good in the autumn, deliciously perfumed, should be more grown.

Joseph Lamy (Barbier, 1906).-Flowers large size white flushed pink, mid-season, Wichuraiana.

Lady Waterlow (Nabomand, 1902).-A Hybrid of exquisite colour, salmon pink with petals edged with bright carmine, long pointed buds opening into a large flower. A fine dwarf pillar Rose of good constitution.

Lady Gay (Walsh, 1905).- Similar to Dorothy Perkins but a slightly larger flower. Late flowering, Wichuraiana.

Lady Godiva (Paul \& Son, 1908).-A very beautiful sport from Dorothy Perkins, very promising. Late flowering, Wichuraiana. 



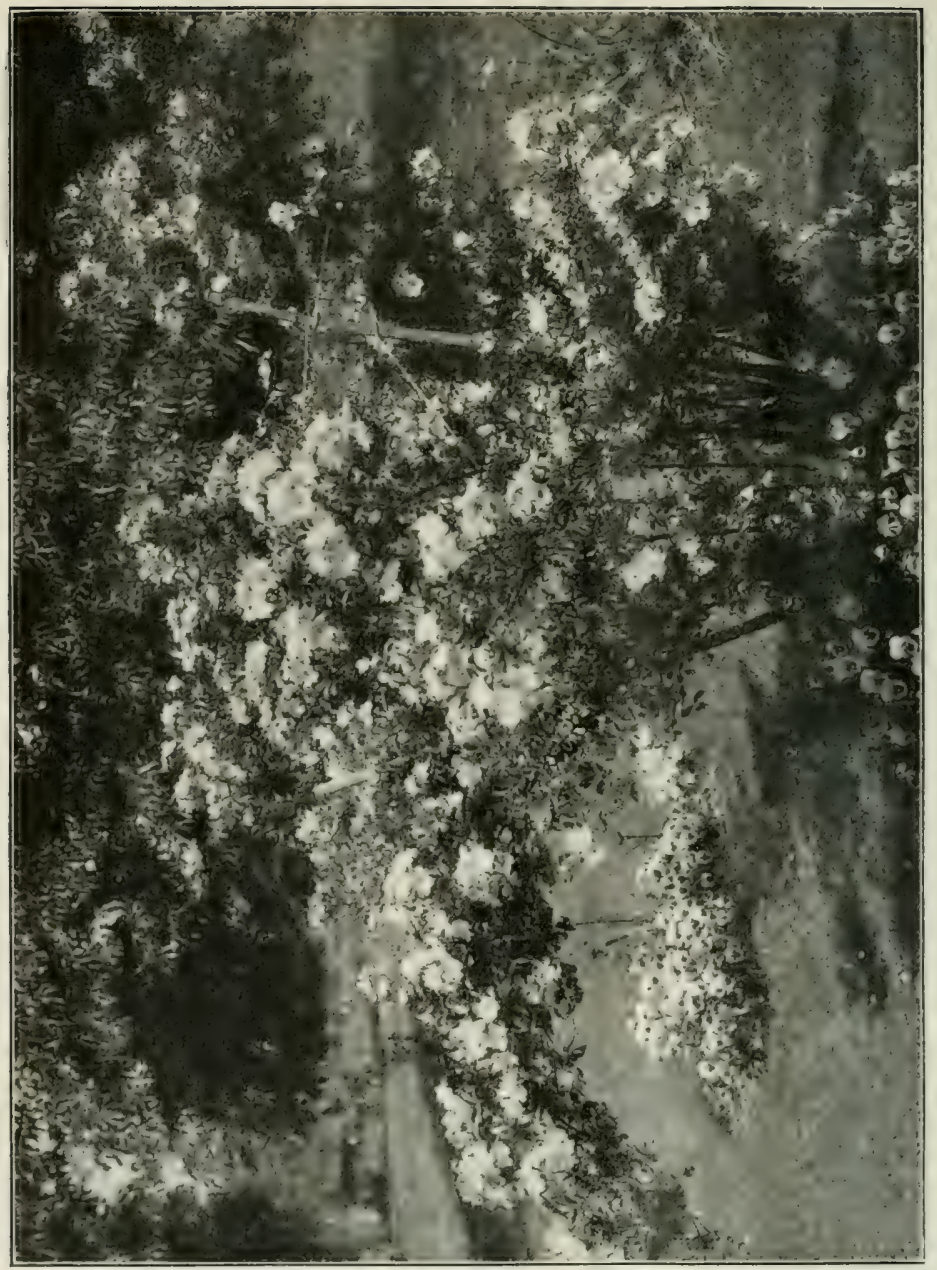


Lamarque (Naréchal, 1830).-A Noisette which was highly prized fifty years ago, when varieties were few. Of strong climbing growth on a south wall, with bright small shiny foliage, not thoroughly evergreen. It produces with great freedom in the season large open flat blooms not fit for show, but the second crop on a wall is scant. Very sweet scented, the fragrance being distinct and said to be like Violets. Not hardy against severe frost, but tolerably safe on a south wall. Said to be the parent of Cloth of Gold and grandmother of Maréchal Niel.

Leontine Gervais (Barbier, 1906).-Salmon rose tinted yellow, a pretty variety, early to mid-season flowering, a promising new Wichuraiana.

Leuchtstern (Schmidt, 1899).-A good pillar or bush Rose, free flowering, colour-bright rose, with a prominent white eye, single flowers in clusters.

Lina Schmidt-Michel (Lambert, 1905). - Soft bright pink semi-double flowers, makes a fine dwarf pillar.

Madame Alfred Carrière (Schwartz, 1879).-A Noisette of very fine growth. The flowers are large and showy, sweet-scented, and practically white. It is very free-blooming and perpetual, and may be depended on to cover a large space and make a good show. The best white climber for all purposes.

Madame Bérard (Levet, 1870).—Of Gloire de Dijon race, one of the best in shape and colour, very pretty at times, but not as hardy as the type.

Marćchal Niel (Pradel, 1861).- This is without doubt the finest yellow Rose in existence, no real rival to it having ever been issued. It is a Noisette, said to be a seedling from Cloth of Gold, and 
strongly Tea-scented. To a large extent it stands by itself, being thoroughly distinct in growth, habit, and flower, its reputed seed-parent being the most like it of existing Roses. It is of very strong climbing growth, with magnificent foliage evergreen under glass, but very liable to mildew. The blooms, which lose colour when exposed to the sun, come generally good if not exposed to cold nights in the early bud stage, and are fine in petal, centre, shape, colour, fragrance, and size: of fair lasting qualities if kept dry and fairly cool, but apt to go before the day is out in a hot exhibition tent. It is a very free bloomer if treated properly, and flowers fairly well throughout the autumn on standards where these can be grown and flowered in the open air. Like most, if not all, other yellow Roses, instead of losing colour after being cut and kept in the shade, the colour deepens, but loses in brightness. Like all Noisettes, the best blooms come on the long secondary shoots of the previous year, which should be as well ripened as possible, and left nearly of full length. Though often grown on its own roots in pots-for it strikes readily as a cutting-it does much better if budded on the briar, preferably as a standard. It is decidedly tender, being much liable in the open to be injured or killed outright by severe frosts; but on a wall, particularly if there be anything in the nature of a coping above, it will stand ordinary winters in most localities. In such a case, do not forget to give it plenty of water or weak liquid manure in all dry times in the summer: things growing on walls require much more water than plants in the open, and often get none at all : a large shallow basin-shaped depression should be 


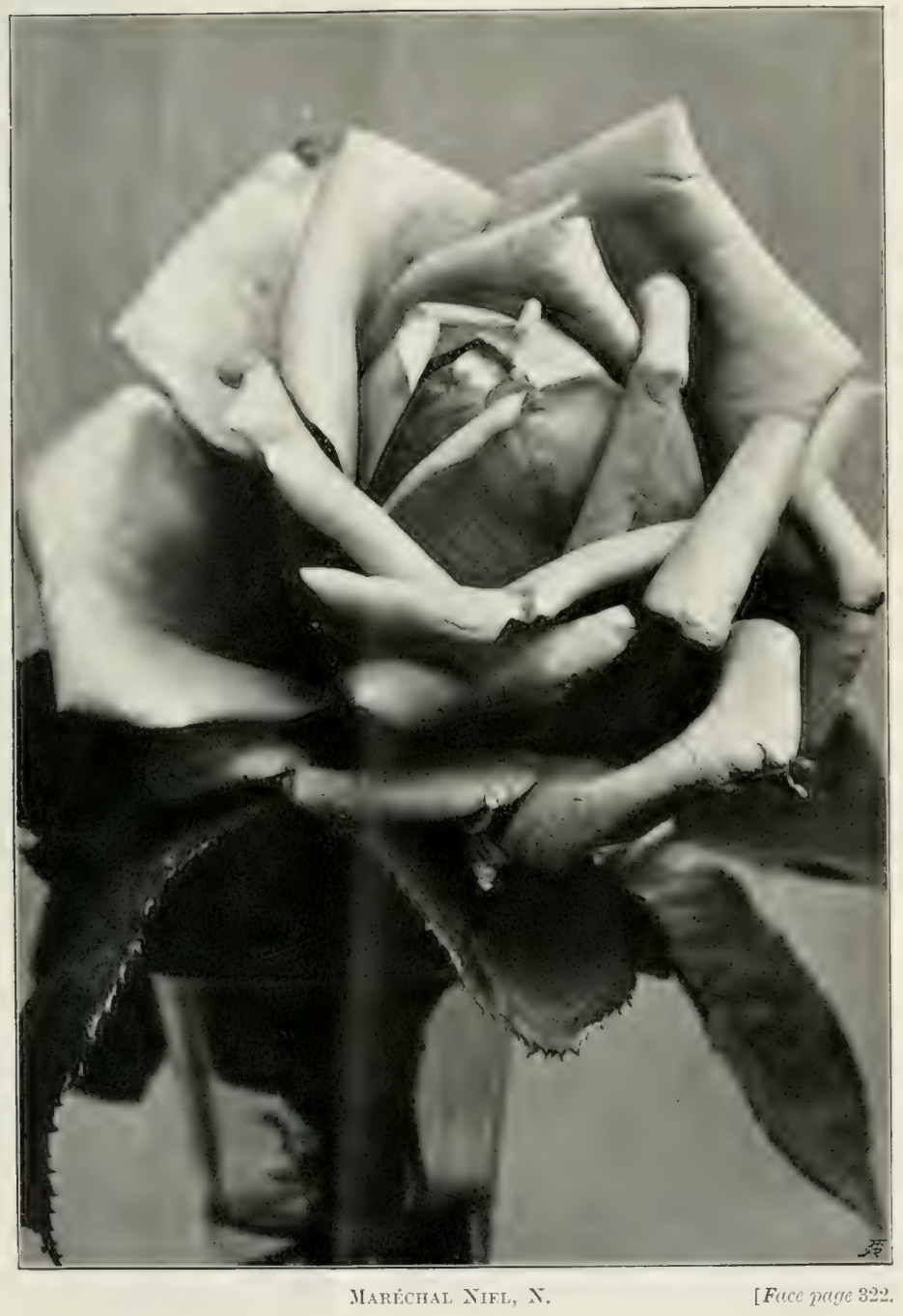



formed and maintained round the base of the plant that liquid may be put down by the pailful and sink in, instead of running away.

Like other Noisettes it is an early bloomer. And, on walls or other places where it is likely to stand the winter, the first crop of flowers (and in such hot, dry positions there is seldom much of a second one) are over considerably before the time of shows. For exhibition purposes, therefore, the problem is how to preserve standards in the open from frost in winter, and from breaking too soon in the spring, for they must not be hard pruned. I have for some years been successful in this, and have had plenty of these glorious yellow blooms to shine like lamps in my show-stands among the reds and pinks and whites. A row of half-standards is planted, some two or three yards from plant to plant, leaning in the row at a sharp angle, so that the head of the plant is not much more than a foot from the ground. For winter protection the stem by the head is bent and pegged down to the ground as far as it will go without straining the roots, and the long shoots are similarly laid down. Any long dry rubbish is now laid thickly over the whole row (nothing green or damp that will ferment and rot should be allowed), forming a long mound, and finally the whole is covered thickly, deeply-the thicker the better-with earth, and smoothed and made as air and water-tight as possible with a spade. In short, they are "clamped" just like mangolds in a field. It will be well to remove the very sappiest and greenest of the shoots before doing all this, as they would not be of much use if preserved, and will probably rot when buried. This treatment 
CHAP.

should preserve them from frost till the middle of February; and then, instead of removing the protection, mend it and restore it by covering any cracks with more earth till April, for the very opposite reason, to keep them from the heat and influence of the early spring sun. I do this, not only to delay the flowering that the blooms may be available for exhibition, but also because the very first buds to break are those of the flower-bearing shoots which will be injured by cold nights, and perhaps actually destroyed by late frosts. If the latter calamity should occur, the plants may be flowerless throughout the season, for autumnal blooms will only come, as a rule, from the shoots which have already flowered. When the protection is removed, at such a date in April as may suit the locality and the danger of frost, the plants may be slightly raised again, the heads being tied to bamboos and the long shoots cut back only where they have died, being kept in a fairly horizontal position.

Naréchal Niel is easily forced and much grown for the market, the best method of pruning and training under glass to get a fine crop of these splendid blooms in early spring having been described on p. 108. Pruned under this system, the power of growth of a well-fed Rose of this variety under glass is astonishing. A gentlemanMr. Bagshawe Dixon-purchased a house in this parish and with it a small greenhouse which had a somewhat neglected short standard of Maréchal Niel in one corner. He very much enlarged the glasshouse, and by my advice cut the Rose completely back, and then fed it highly, when it grew very, strongly. In April, 1903, he cut it back again 
completely to one horizontal arm, according to my instructions, and then fed it twice a week with liquid manure. The growth was so great that at Christmas in the same year he had not only 213 feet of strong new wood trained under the glass, but had also actually cut away of new wood (much of these being secondary laterals), as too much for his room, no less than 291 feet. The plant had thus made 168 yards of new growth in 9 months! The trained shoots, after judicious thinning of the buds, produced 416 fine blooms between Christmas and April; there ought to have been more, but several of the shoots had, owing to the exigencies of the space, to be trained for a short distance perpendicularly, and they only broke into flowering shoots when laid horizontally.

All was cut away again in April, 1904, to the old horizontal arm, and 11 shoots from it, most of them as thick for a considerable distance as one of my fingers were allowed to grow. These shoots I took the pains to measure and they were aggregated over 227 feet, and were still growing fast.

In this mode of culture under glass mildew is the principal trouble, and the ventilators should be kept entirely shut when the wind is cold. The variety has another piece of bad manners which is most troublesome under glass, because there is more growth there, viz., a liability to canker, especially at the point of union between stock and scion. As this probably arises from the inability of the briar stem to swell sufficiently for the growth of the Rose, a useful preventive measure is to make one or two longitudinal cuts through the bark, passing through the point of union and extending some little way 
above and below it. This will not cure established canker, but may help in a great measure to prevent and modify it. There is no cure in a really bad case: good strong young plants are cheap and soon come into bearing, but when putting in a new plant where a large Rose has stood, remember to take out a good deal of the old soil and to replace it with rich fresh stuff in which Roses have not been grown. A white sport of Maréchal Niel has been issued; but it seems to me to differ little from that undesirable pale yellow which is the natural colour of the original when exposed to strong hot sun. On a very hot wall the sun will sometimes cause weak blooms to show a tinge of red on the outer petals. Within the last few years two Roses have been issued which are said to be crosses with this variety -Grand Duke Ernest Ludwig, red, a cross with Général Jacqueminot-and Souvenir de Pierre Notting, said to be a cross with Maman Cochet, which gained the Gold Medal (see p. 310). In America Maréchal Niel will not do well out of doors much north of Washington, but it is most highly appreciated in all tropical countries.

Minnehaha (Walsh, 1905).-One of the best pink Wichuraianas. Medium sized flowers borne on an exceptionally large truss. Makes a handsome weeping standard, and is useful for all purposes. Late flowering.

Mrs. F. W. Flight (Cutbush, 1907).-A polyantha of very strong growth, producing its flowers in large loose panicles suitable for arches and pergolas.

Noëlla Nabonnand (Nabonnand, 1900).-A Hybrid Tea suitable for tall pillars or walls. The flowers are sweet scented and of good shape and size, but the 



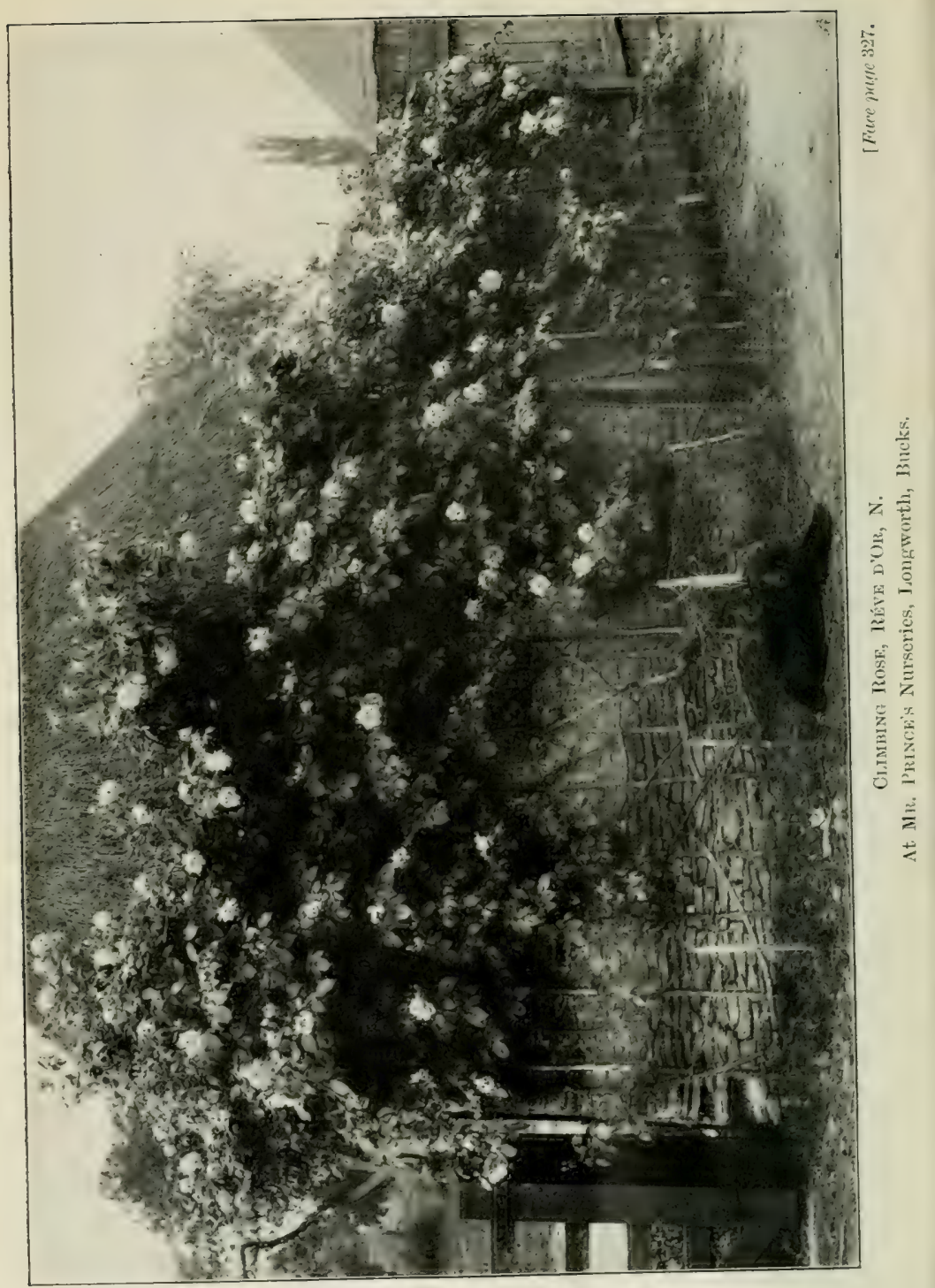


colour is rather against it, the crimson having a bluish tinge.

Paul Transon (Barbier, 1902).- Shows more traces of the Tea than most of the Wichuraianas. Salmon pink, a good creeper, sweet scented, and mid season flowering.

Psyche (Paul \& Son, 1899).--A seedling from Crimson Rambler, but not such a rampant grower. Colour, pale flesh; flowers produced in trusses, suitable for arches.

René André (Barbier, 1900). - Saffron-yellow tinged red. An early flowering TVichuraiana.

Reine Marie Henriette (Levet, 1878).-A Hybrid Tea, which, though now an old Rose, is still useful. It is very vigorous, with good foliage, and the blooms are large, red, and bright, full and good. I have occasionally seen extra good specimens well exhibited. It is sonetimes called the red Gloire de Dijon, which, as there is no resemblance between the two in any particular, I take to mean that the one should be as well-known as the other. It is thoroughly hardy, is one of the very best and most constant of autummals. Useful for pillars and arches and perhaps at its best on walls, still fairly popular, and would perhaps be more so if people would remember that climbing Roses require food and water even more than those in beds.

Reine Olga de Wurtemburg (Nabonnand 1881).An excellent Hybrid Tea of fine vivid colouring, and good shaped flowers which are freely produced, one of the best of the crimson climbers useful for all purposes.

Rêve d'Or (Ducher, 1869).--A very strong climbing Noisette, with stout and rapid growth and early 
evergreen foliage. This valuable Rose has one most desirable piece of good manners as a climber ; other Noisettes and Roses of the Gloire de Dijon race are apt, when grown as climbers, to become weak and bare of foliage towards the bottom so that all the blooms are out of reach and the plants look unsightly from the naked condition of the lower branches. This is not the case with Rêve d'Or, and it adds considerably to its merits as a climber that the lower parts of the plant are fairly covered with blooms and foliage. The blooms come in clusters, well shaped, of much the same colour as Safrano and Sunset, but not good enough in shape, size, or lasting qualities for exhibition. It is wonderful as a free-bloomer, the plant being smothered with flowers from top to bottom during the first crop, and a fair amount of blooms continue into the autumn. Quite hardy in this country, a capital Rose for arches, and all round one of the very best of climbing Roses. Not so large as Reine Marie Henriette or even Gloire de Dijon, but superior to either in its manner of growth on the lower parts of the plant.

Ruby Queen (Conard and Jones, 1899).- -Not so well known as it deserves. Early loose flowers-in small truss. Recommended as a weeping standard.

Tausendschön (Schmidt, 1907).-A charming addition to the dwarf pillar Roses, colour bright satiny pink, the flowers produced in clusters with a pendulous habit that stand well out from the foliage.

Tea Rambler (Paul and Son, 1903).-A beautiful Hybrid tea with strong polyanthaleanings-a rampant grower, very free flowering, its only fault is that it is not perpetual. Colour deep coppery pink in the bud, 



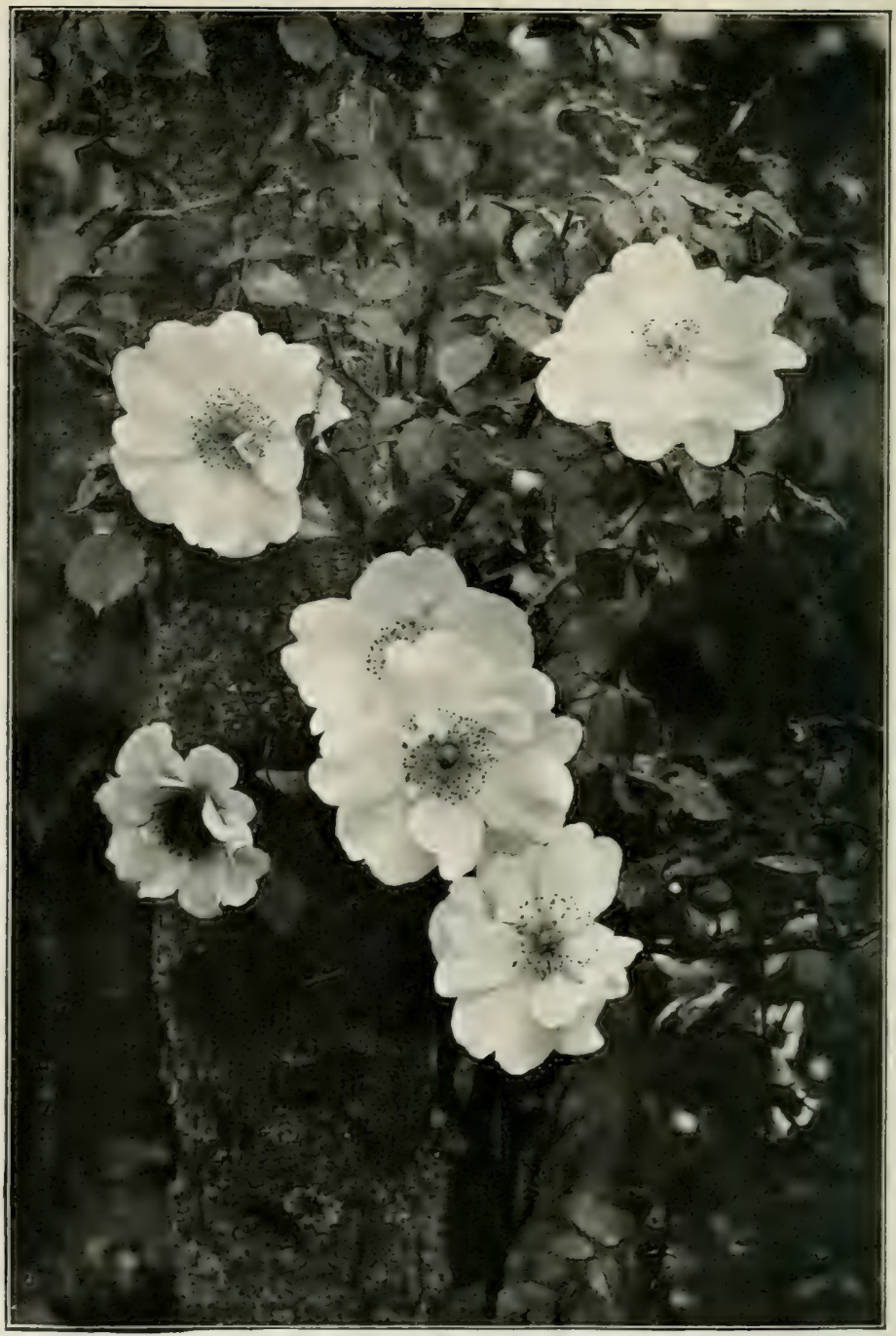

IXx.

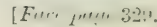

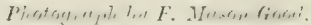


changing to soft pink in the older flowers-suitable for arches and pergolas and makes a fine hedge. One of its parents was the Tea Cleopatra, one of the worst of growers-such is the uncertainty of Rose hybridisation.

Trier (Lambert, 1904).-A perpetual flowering polyantha and a very great acquisition to the pillar Roses-its small but beautifully shaped flowers are fully produced on long panicles-not a vigorous grower for a climber, but a Rose that should be in every garden.

Una (Paul \& Son, 1900).-A Hybrid Tea one of whose parents was Gloire de Dijon-A beantiful, nearly single, pale creamy yellow flower of good size, lasting well on the plant, but summer flowering only. Does best as an isolated bush but can be grown as a dwarf pillar.

White Dorothy (Paul \& Son and Messrs. B. R. Cant \& Sons, 1908). - A pure white sport of Dorothy Perkins that should prove very useful. Except in colour similar to its parent in every respect. Late flowering.

Wichuraiana (the type introduced to Europe about 1873)._-Small glistening white flowers, sweet scented, single with golden stamens, very free flowering. Exceptionally good as a creeper, latest of all to flower.

William Allen Richardson (Ducher, 1878).-A Noisette of good strong growth, but not so vigorous as most of those I have mentioned in this section. This is a Rose that very soon gained a great reputation by its colour, which is a real orange, a shade till then unknown in Roses, and even now only to be found in the centres of some few others. It is quite 
small and only suitable for britton-holes and decorative use, being more valued and generally grown for the former purpose perhaps than any other Rose. It is only of value in the bud, which is well shaped, but has a disappointing habit which must often have caused annoyance. The blooms often come practically white with no trace of orange, except perhaps at the very base of the petals: but about the time that the nurseryman who supplied it has received an indignant letter of complaint the buyer on passing by . the plant sees a bud coming of the true colour. For a while they will all come of deep orange, or orange tipped with white, and then some perhaps come nearly white again. Often the weakest shoots produce the highest coloured flowers, but this does not seem to be a general rule. This lovely and favourite Rose should be grown in quantity, in the open, as a pillar, against walls and trellises, and under glass. It is free-blooming, pretty good as an autumnal, does well as a dwarf, and is popular all over the world, but it should be well treated in good soil, and requires protection in severe winters.

Zéphirine Droutin (Bizot, 1873).-A Rose that was almost lost to cultivation in this country but has recently had its merits recognised. It is quite thornless, the flowers are bright silvery pink in colour with a delicious scent. It makes a good pillar Rose but at its best as a hedge. A Hybrid Perpetual Bourbon. 


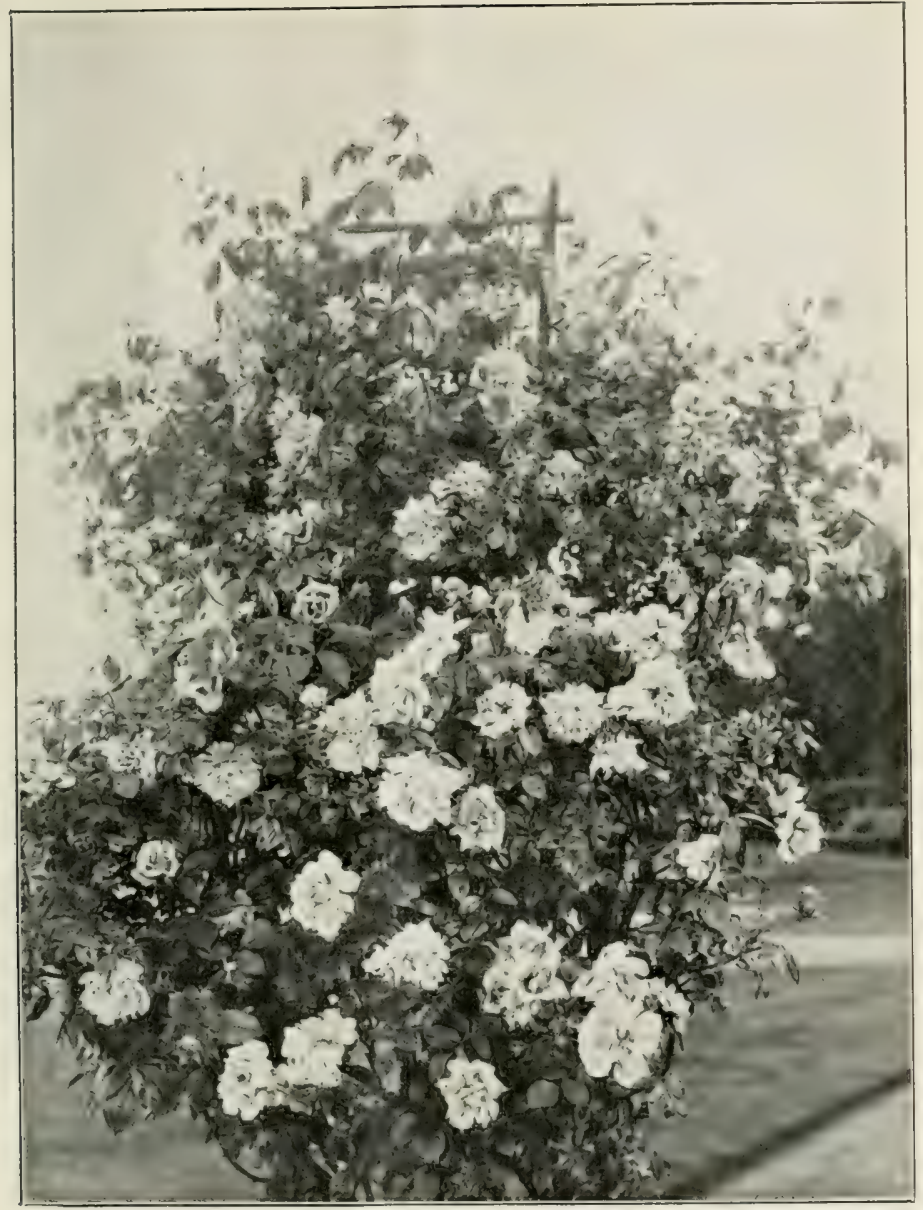

W. A Richardson.

[liwe, fun : :3:11,

Photograple by F. Mluson Gond. 



\section{CHAPTER XIII}

\section{SELECTIONS}

This must always be the most unsatisfactory part of a Rose-book, both to the author and the reader. In the first place, the compiler of a selection feels, or ought to, that he has at least one or two favourites which he places in a higher position than most of his brother Rosarians do, and that there are perbaps as many popular sorts that he does not succeed with. His own situation, soil, or climate has probably more to do with this, in most cases, than actual personal predilections.

Next, a certain number of new Roses, issued within the last three years, have to be dealt with: and, their quality and characters being not yet established, it is difficult to know what to do with them. Great mistakes, either way, may be made in attempting to rank them too soon, but on the other hand it seems impossible to ignore notable issues. I have therefore only included varieties sent out later than 1907 where there seems to be a character already established.

And, also, no one who makes a selection of Roses can shut his eyes to the fact that such a list, 
especially if given in the order of merit, must be of very ephemeral value. New Roses, working their way to the front, not only take the places of established favourites but sometimes entirely supersede them and cause them to drop out altogether. Thus, Madame Lacharme, at one time the best white H.P., was made absolutely useless by the coming of Merveille de Lyon, which in its turn has been quite superseded by Frau Karl Druschki.

Roses suitable for Exhibition.-In these lists it should be noticed that weakness of growth or constitution, or in fact any good or bad manners, are not taken into account. Chapter XII. should be consulted on such matters, for in the following selections the merits of the perfect bloom when once obtained are only taken into consideration.

It has been thought advisable to give two lists of each class, H P., H.T., and Teas; the first list includes the pick of the varieties, the secondary list is supplementary. They have not been placed in order of merit, because it is felt that any such attempt while possible, say, for the first dozen, becomes ridiculous in dealing with larger numbers.

\section{First List of H.P.s. for Exhibition.}

A. K. Williams

Alfred Colomb

Comte de Raimbaud

Captain Hayward

Duke of Wellington

Dupuy Jamain

Frau Karl Druschki

Gustave Piganeau

François Michelon
Helen Keller

Her Majesty

Horace Vernet

Hugh Dickson

M. H. Walsh

Marie Baumann

Mrs. John Laing

Mrs. R. G. Sharman-

Crawford 
Suzanne Marie Rodocan- Ulrich Brunner achi Ulster

Prince Arthur

Second List of H.P.s. for Exhibition.

Beauty of Waltham

Bob Davison

Ben Cant

Commandant Félix Faure

Duke of Edinburgh

Earl of Dufferin

Fisher Holmes

Général Jacqueminot
Hugh Watson

Madame Gabriel Luizet

Marchioness of Downshire

Mrs. Cocker

Rev. Alan Cheales

Tom Wood

Victor Hugo

Hybrid Teas suitable for Exhibition.

First List.

Alice Lindsell

Bessie Brown

Charles J. Grahame

Caroline Testout

Dean Hole

Earl of Warwick

Florence Pemberton

Gladys Harkness

G. C. Waud

J. B. Clark

Killarney

Kaiserin Aug. Victoria

Lady Alice Stanley

Lady Ashtown

Lady Helen Vincent

Lady Moyra Beauclerc

Lady Ursula

La France

Lyon Rose

Madame Maurice de Luze
Madame Melanie Soupert

Mamie

Marquise Litta

Mildred Grant

Mrs. David McKee

Mrs. E. J. Holland

Mrs. John Bateman

Mrs. Stewart Clark

Mrs. Theodore Roosevelt

Mrs. W. J. Grant

Oberhofgartner Terks

Pharisaër

Princess Marie Mertchersky

Queen of Spain

Richmond

W. E. Lippiatt

Wm. Shean 
Second List.

Avoca

Betty

Comtesse Icy Hardegg

Countess of Caledon

Countess of Gosford

Dr. O'Donel Browne

Duchess of Portland

Frau Lilla Rauten-

strauch

George Laing Paul

Grace Molyneux

Gustav Grünerwald
Joseph Hill

Joseph Lowe

John Cuff

Königin Carola

Laurent Carle

Lohengrin

Mrs. G. W. Kershaw

Mrs. Harold Brocklebank

Perle von Godesberg

Yvonne Vacherot

White Lady

Teas suitable for Exhibition.

First List.

Bridesmaid

Catherine Mermet

Comtesse de Nadaillac

Madame Constant Soupert

Madame Jules Gravereaux

Maréchal Niel

Medea

Molly Sharman-Crawford

Mrs. Edward Mawley
Mrs. Hubert Taylor

Mrs. Myles Kennedy

Muriel Grahame

Maman Cochet

Souvenir d'Elise Vardon

Souvenir de Pierre Notting

Souvenir de S. A. Prince

The Bride

White Maman Cochet

W. R. Smith

Second List.

Anna Olivier

Boadicea

Cleopatra

Ernest Metz

Golden Gate

Harry Kirk

Innocente Pirola
Lady Roberts

Madame Cusin

Madame de Watteville

Madame Hoste

Madame Vermorel

Souvenir d'un Ami 



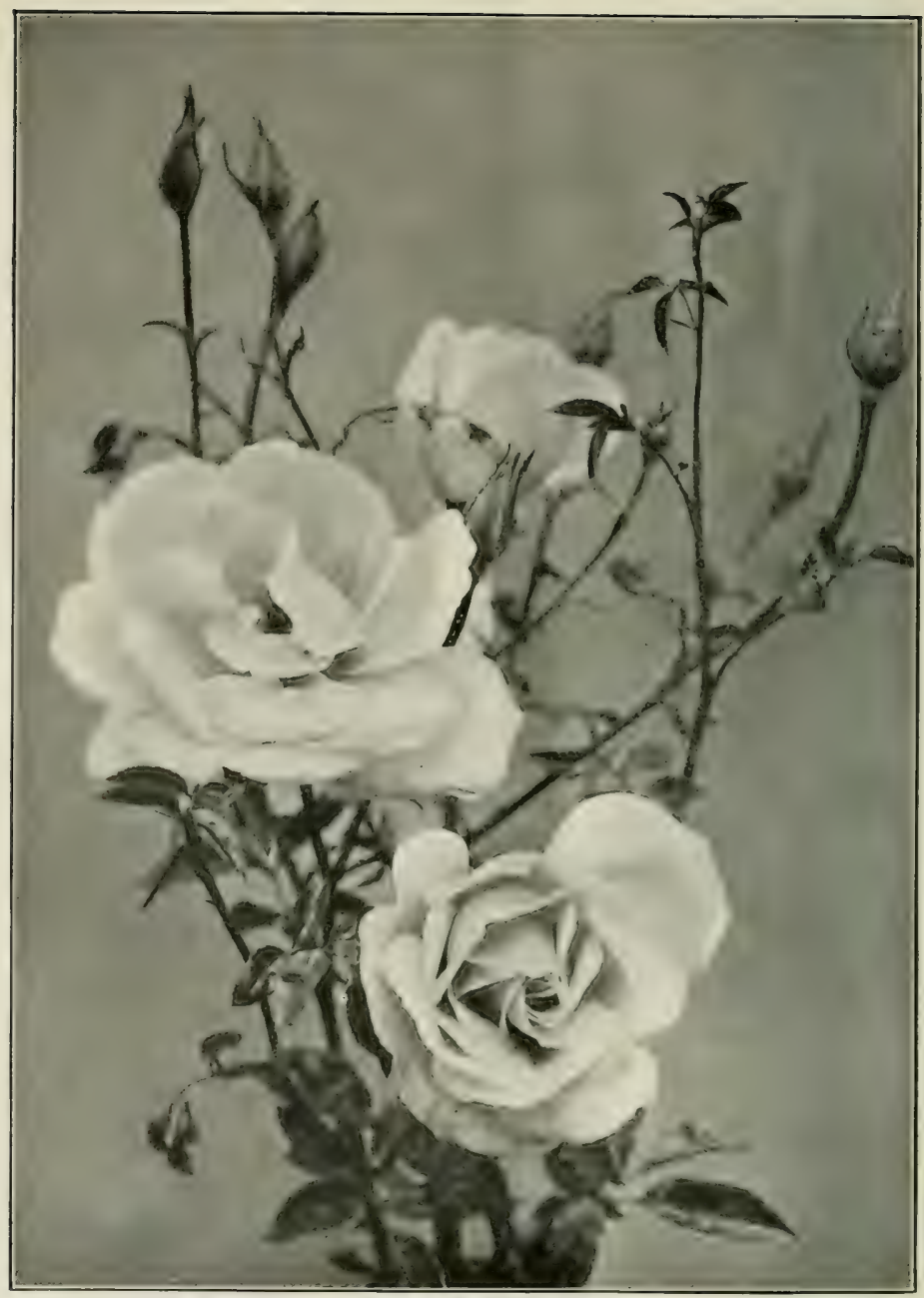

STI.PHURFA,

[Face puege 335. Pleotograpte by Fi. Muson Goort. 


$$
\begin{aligned}
& \text { Roses suitable for Bedding. } \\
& \mathrm{T}=\text { tall } ; \mathrm{M}=\text { medium growth. }
\end{aligned}
$$

Anna Chartron (M)

Antoine Rivoire (T)

Betty (T)

Caroline Testout (T)

Commandant Félix Faure

(T)

Comtesse du Cayla (M)

Corallina ( $\mathrm{T}$ )

Dorothy Page Roberts

(T)

Ecarlate (M)

Edu Meyer (M)

Frau Karl Druschki (T)

G. Nabonnand (M)

Gustav Grünerwald ( $\mathrm{T}$ )

Grand Duc A. de Luxembourg (M)

General McArthur (T)

Harry Kirk (M)

Irish Elegance ( $\mathrm{T}$ )

Lyon Rose (T)

Lady Ashtown (T)

Lady Battersea (M)
La Tosca (T)

Madame Abel Chatenay

(T)

Madame Leon Pain (T)

Madame Pernet-Ducher (M)

Madame Segond-Weber (M)

Madame Jules Grolez (M)

Madame Melanie Soupert (T)

Madame Ravary (M)

Marie van Houtte ('T)

Marquise de Sinety (M)

Mrs. John Laing ( $\mathrm{T}$ )

Papa Gontier (M)

Peace (M)

Sulphurea (M)

Viscountess Folkestone

(M)

Warrior (M)

Roses suitable for Walls.

$\mathrm{T}=$ tender, suitable for South and South-West aspects only.

Banksia alba (T)

Banksia lutea (T)

Bouquet d'Or

Climbing Mrs. IV. J. Grant
Climbing Caroline Testout

Climbing Aimée Vibert

Climbing K. A. Victoria

E. V. Hermanos 
Fortune's Yellow (T)

François Crousse

Félicité et Perpetué

Madame Jules Gravereaux
Maréchal Niel (T)

Rêve d'Or

Sinica Anemone

William Allen Richardson

China Roses suitable for Bedding.

Betty Berkeley

Chin Chin China

Comtesse du Cayla

Cramoisie Supérieure

Ducher
Fabvier

Irene Watts

Laurette Messimy

Madame Eugrene Resal

Maddalena Ścalarandis

Roses suitable for growing as tall weeping Standards.

Dorothy Perkins

Débutante

Evangeline

Félicité et Perpetué

François Foucard

Hiawatha

Jersey Beauty
Joseph Lamy

Leontine Gervaise

Minnehaha

Paul Transon

Rugosa repens alba

Ruby Queen

White Dorothy

Roses suitable for growing as Climbers under Glass.

Climbing Liberty Mrs. W. J. Grant

Maréchal Niphetos
Madame Jules Gravereaux

Madame Abel Chatenay

Fortune's Yellow

Wm. Allen Richardson

Roses suitable for Pot Culture under Glass.

Bridesmaid

Catherine Mermet

Captain Hayward

Dean Hole

Frau Karl Druschki
Joseph Hill

Lady Faire

Lady Roberts

Madame Abel Chatenay

Madame Constant Soupert 


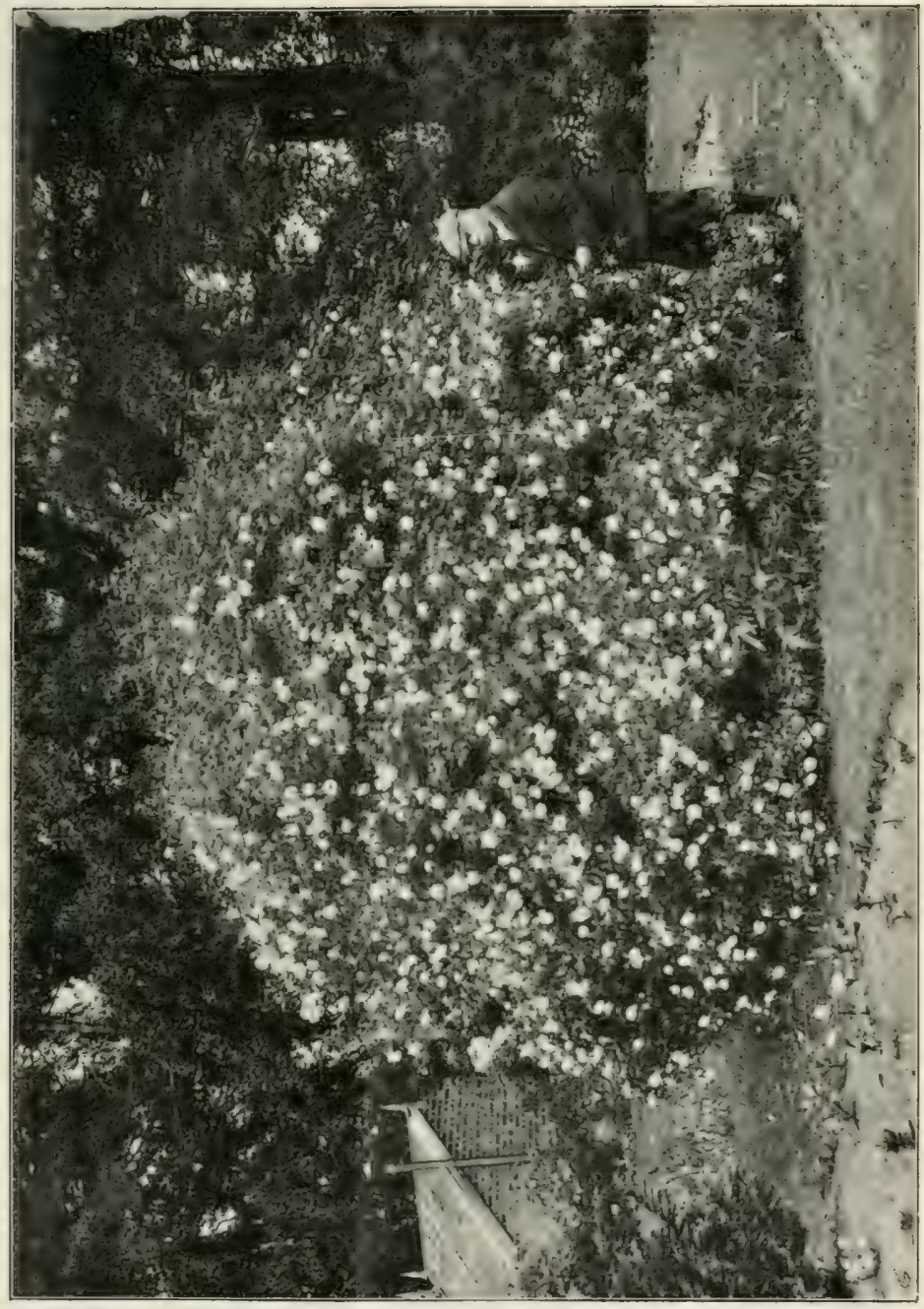



Madame Leon Pain

Maréchal Niel

Mrs. David Jardine

Mrs. John Laing

Mrs. W. J. Grant

Niphetos
Richmond

Souvenir de Pierre Notting

Sunrise

'The Bride

-White Maman Cochet

For the pegging-down system of training, Roses should be free-flowering and strong, yet fairly pliable in growth; but some of the stiffer ones can be bent down, if it be done gradually as they grow.

Roses suitable for Pegging Down.

Frau Karl Druschki

Gruss an Teplitz

Gloire Lyonnaise

Gustave Regis
J. B. Clark

Madame Isaac Periere

Madame Jules Gravereaux

For button-hole Roses, as for exhibition kinds, beauty of form should not be neglected, as it sometimes is, for mere colour, though a combination of both is most desirable. A round fat bud is much less elegant than a long, slender, and pointed one. In this respect the Teas have a decided advantage, but if a bright red or really dark bud is desired, the H.P.s or H.T.s must be called upon.

\section{Roses suitable for Buttonholes.}

Anna Olivier

Anna Chartron

Gustave Regis

Lady Roberts

L'Ideal

Liberty

Madame Antoine Mlari

Madame Chédane Guinoisseau
Madame Jean Dupuy

Madame Falcot

Ma Capucine

Richmond

Rosette de la Legion d'Honneur

Souvenir de Stella Gray

William Allen Richardsun 
For very miniature button-holes the pompons are excellent.

\section{Dwarf Polyanthas or Pompons.}

Cecile Brunner

Eugènie Lamesch

Leonie Lamesch
Petit Constant

Philippine Lambert

Perle d'Or

Roses suitable for Pillars, Pergolas, and Arches.

Alister Stella Gray

Ards Rover

Alberic Barbier

Blush Rambler

Climbing Aimée Vibert

Conrad F. Meyer

Crépuscule

Crimson Rambler

Dorothy Perkins

Flower of Fairfield

Gardenia

Goldfinch

Hiawatha

Hélène

Jersey Beauty
Lady Gay

Lady Godiva

Longworth Rambler

Madame Alfred Carrière

Madame d'Arblay

Marie Lavalley

Mrs. F. W. Flight

Minnehaha

Noëlla Nabonnand

Paul Transon

Paul's Carmine Pillar

Psyche

René André

Tea Rambler

White Dorothy

Roses suitable for Dwarf Pillars.

Billard et Barré

Electra

J. B. Clark

Johanna Sebus

Lady Waterlow

Leuchtstern

Lina Schmidt-Michel

Mrs. O. G. Orpen
Purity

Tausendschön

Thalia (Perpetual)

The Garland

Trier

Franȩois Crousse

Una

Zéphirine Drouhin 


\section{Selection of Single Roses.}

Austrian Copper

Austrian Yellow

Dawn (semi-single)

Gottfried Keller (semisingle)

Irish Elegance

$"$ Beauty
Irish Harmony

Macrantha

Maharajah (semi-single)

Morgenroth

Muriel Jamison

Simplicity

Sinica Anemone

Una (semi-single)

In making a selection of varieties suitable for culture in a suburban or town garden, there is considerable difficulty without linowing the actual circumstances of the situation. It may vary from that of a small country town, or distant and pure suburb of London, in which case if other matters be favourable the best Roses may be grown, to that of a real town garden in a thoroughly smoky atmosphere, where none can be cultivated to periection. I have consulted some good suburban growers, but their lists do not at all arree, the probability being that where good hoses can be cultivated at all, most of the best sorts will answer. It seems, however, to be generally admitted that the Austrian briars are as impatient of impure air as any Roses.

Roses suitable for a suburban garden.

Antoine Rivoire

Betty

Caroline Testout

Blanc double de Coubert

Conrad F. Meyer

Commandant Félix Faure

Dupuy Jamain

Gustav Grünerwald

Frau Karl Druschki
Hugh Dickson

Killarney

Lady Ashtown

La France

Laurette Messimy (China)

Madame Abel Chatenay

Madame Ravary

Madame Isaac Pereire, B

Marquise Litta 
Mrs. John Laing

Mrs. R. G. SharmanCrawford
S. M. Rodocanachi

Ulrich Brunner

Viscountess Folkestone Mrs. Paul

If any of the delicate Teas can be grown, the list should be consulted; the hardier sorts should be tried to start with.

For the sea-side, I do not know of any varieties that are more impatient of violent winds and occasional salt in the air than others. For hardy useful Roses the above list would suffice; but as there is seldom much harmful frost near the sea, Tea Roses may often also be well and successfully cultivated. 


\section{CHAPTER XIV}

\section{CALENDAR OF OPERATIONS}

IN the following list of Rosarian work for each month I have not repeated the details of each operation, but merely noted the times when they are to be performed. This is often important, as delay and loss of opportunity will frequently leave a mark on the work throughout the year. A novice should study some such calendar as this, see how much work he has to get through in a given time, and make his arrangements accordingly. It will be seen that a large collection will supply sufficient work to keep a man "out of mischief" pretty nearly all the year round.

October.-By general consent this is considered the first month of the Rosarian's year. Nurserymen's catalogues for the coming season are now to be had, and they are eagerly scanned by ardent amateurs. Orders should be given as soon as possible, and it is better still to visit the nurseries in the early autumn and choose and order the finest specimens. It is rather hard on those who go by the catalogues, but first come first served is a good old rule of trade, and it is right that those who take 
trouble about a thing should reap some benefit from it. In ordering Standards, do not forget that unless you ask for "Half-Standards" you may get stems 4 or 5 feet high. If new beds are to be made or planting on an extensive scale is to be undertaken, preparations should have commenced even in September, in procuring fresh soil and digging the beds out to the depth of two feet. It should be pushed on at any rate early in October. Pot Roses for growing under glass should now be repotted. Many of the free-blooming Teas, now covered with buds, will open them indoors at a time when they will be much appreciated. But beware of too much heat when the amount of daylight is small. This is the month for taking cuttings out of doors: those of the Roses themselves do better if the leaves have not fallen, and these, if used at all, had better be taken first. Manetti and briar cuttings will do as well without the leaves. All extra long shoots of Roses should now be shortened sufficiently to diminish the wind leverage on the roots; these pieces may be used as cuttings. Towards the end of the month a commencement in planting may be made with those Roses which have simply to be moved from one part of the garden to the other. Such may be planted before their leaves have fallen, much care being taken that their roots are exposed as little as possible; they should be watered and syringed immediately after planting, and will probably do better thus than if moved later. About the middle of the month fresh cuttings may be taken of briar and manetti, and later the rooted cutting and seedling stocks may be planted out, but standard stocks will not be ready yet. 
November.-This is a busy and important month, as it is the time for planting, and the work should be pushed on whenever the soil is fairly dry, for November days are short, and no planting should be done when the ground is sticky. Unpack the purchased Roses carefully, and lay them in the ground when they cannot be planted at once. Be careful in each detail of planting, for much depends upon it. Stocks of all sorts should now be planted also if possible, but there will not be much time yet for getting standards from the hedges. Where seed is saved it should now be gathered. All wild growth is now to be cut away from budded stocks, leaving one or two buds on those laterals of the standards which have been successfully operated on. Roses in pots should be brought into cool shelter before severe weather. In northern districts it may be well to place the winter protection round the 'Teas before the month is out, or they can now be earthed up.

December. - In most English counties it will suffice to apply the winter protection during the first fortnight of this month, but dead leaves should have been collected by the end of the first week in November, and bracken should have been cut and set ready, in sheaves, not in heaps, as soon as it began to change colour. It is perhaps best to commence the protection as soon as the Rose planting is finished, even though the setting out of stocks has to be postponed. They will do nearly as well if planted at any dry time during the winter, but a severe early frost coming before the bedclothes are on the tender Teas may cause much lamentation. Now is the time, on dull damp days, to sally forth with the little stock axe and the Grecian 
saw in quest of standard stocks. If no winter mulch is applied to the Rose beds, the surface should still be kept stirred and loose. Roses for the earliest forcing may be pruned and started at the end of the month, and grafting under glass may be cornmenced about Christmas time.

January. - This is the best month for grafting in heat, though it may be continued in February. In light frosts, strong liquid manure may be put on the Rose beds, when it will sink in rapidly and in quantity. After or during high winds, the Teas may be inspected to see that the protective materials are secure, and standards should be looked to, as they may have broken away from their stakes. Standard stocks may still be got at any time when the weather is open. Even in severe frost work may be found in digging trenches to discover and cut off the invading roots of trees and shrubs. Roses being forced under glass will now be starting and requiring much care, and winter grafting will be in full swing.

February.-If farmyard manure is used in the soil, now is the time to dig or fork it in, but be sure it is thoroughly decomposed, or in my opinion it will do more harm than good. Still, it supplies the vegetable matter of humus, and if the soil in the beds be raw and light-coloured, such an addition is necessary, but the upper portion of the beds should originally have been supplied with humus, in old garden mould or the like. If no digging is practised, the soil should be well loosened by the hoe, as some weeds will probably have grown since October. The artificial manure should then be applied, choosing a still day when it can be 
distributed evenly. If the weather be favourable at the end of the month any arrears of planting may be finished and stocks of all sorts may still be set out; but Roses planted now may require watering in March and April, if the weather be dry, till they have got a hold. Cuttings should be examined, and those that have been lifted by the frost should be set firm again, either by pushing them down or consolidating the soil round them. Roses on sunny walls may be pruned after the middle of the month, and towards the close we may proceed with the summer and hardy garden sorts. Maréchal Niel and other climbing Roses indoors will be starting, and they and all forced Roses should be watched for mildew and insects, and will require much care in the regulation of air and moisture.

March.-This is the month for pruning all outloor Roses except Teas, but the second week will generally be early enough for H.P.s in northern and midland districts. The Teas should not be pruned yet, but the winter protections should be most carefully removed towards the end of the month. Do not be persuaded to take away the shelter earlier, as the weather is by no means safe yet. It is an error to suppose that the winter protection forces them into precocious growth, for it has just the opposite effect. The same blanket that keeps a man warm will also keep a block of ice cold. It is true, however, that such shoots as are made under the protection grow longer than they would outside simply because they are not stopped by frost, but these premature growths would have to come off in any case. Planting may still be done, with care, but watering will probably be required to follow it. The roots of 
all plants moved at this time, whether stocks or Roses, should be kept in water as long as they are out of the ground. All budded stocks should now be staked, and the buds carefully examined, for the grub is sometimes at work before March is out. If it be desired to retard the blooming of Teas, a thick heavy mulch of long wet manure laid on now while the ground is still very cold will keep the roots cool and, to a certain extent have the required effect. Be most careful of the ventilation of Maréchal Niel under glass, and attack mildew and aphides when they first appear. With the increased light, Roses in pots will bear more heat, but remember that all of them, indoors or out, open their finest and best coloured flowers in a slightly decreased temperature.

A pril.- In most seasons, in midland districts, the second week will be soon enough for the pruning of Teas. There will be no difficulty in finding Rose grubs now, if the signs indicating their presence in the shoots and young leaves are known. Maiden shoots and buds should be examined the oftenest, as in these cases the life of a whole plant is at stake. Suckers will begin to be troublesome on all plants, especially on maiden standards. Tie up the maiden shoots as soon as possible; if left too long, even though not blown out, they will grow away from the stake and be troublesome to secure. A regular system of hoeing should now commence on the Rose beds, on which no hard crust must be permitted to form: one of the simpler forms of push-hoes, of which I believe the "Sproughton" to be the best, will generally be found most convenient. If liquid manure is available it may be applied but cautiously, and not among dwarf maidens. The 
pushing buds and shoots of pruned H.P.s may now be well thinned; the sooner it is done the better, as rubbing, or even cutting, out a great fat shoot leaves an ugly wound which bleeds a good deal for a time. See that the shoots left are free from pests. Pinch, "stave," or cut carefully back, to form finer plants, the first pushing buds which were inserted last year in the stocks, as recommended on p. 149. Indoors, cut back Maréchal Niel, climbing Niphetos, and the like, gradually as the blooms are gathered. The first bloom of the forced Roses will now be orer, and liquid manure-not too strong or too coldmay be administered to those intended to flower a second time by immersing the pots.

May.-This is the month for insect pests of all sorts. The only plan is to go over the whole collection as often as possible: I have several times found a large caterpillar or two in the afternoon on a small plant which I had carefully examined in the morning. If a rolled leaf be simply pinched you will probably carefully squeeze the same leaf again half a dozen times; it must therefore either be picked off or unrolled, and the latter plan is best. If several leaf sprays are curled on one shoot the enemy will be found in the topmost one, which probably shows the disfigurement least: he is working upwards towards the bud, and with inherited cunning leaves his past abodes most manifest, and artfully conceals his present one. Be not satisfied with a pinch unless you feel him "go squash." Never go up and down withont a supply of raffia about you; something is sure to want tying: the maiden plants should be looked over for this purpose very frequently. Do not be satisfied with any shoot till 
it is firmly and closely tied to a support. Raffia does not keep well in my pockets somehow: there should be supplies of it ready in places close at hand. Tea shoots should be thinned; harden your heart if you want good blooms: early trusses will require disbudding before the end of the month. Suckers should be pulled out or rubbed off as soon as they appear; in fact, there will now be hardly a plant which will not want a little attention pretty frequently. Liquid manure may be applied, particularly to those plants which are already showing flower buds; and hoeing, especially after rain or liquid applications, must on no account be neglected. A further light dressing of artificial manure may be desirable if there has been much heavy rain since February. Towards the end of the month Teas on sunny walls will be in bloom: let them all be cut as wanted, and not remain to seed on the plants. Indoors the Maréchal Niel will have been cut completely back, by slow gradations as the blooms are gathered to the original horizontal old wood. Potplants which have bloomed should be hardened off by slow degrees that they may be put out in June.

June.-Disbudding will be in progress for a time, of the later sorts. The plague of caterpillars will be waning, but those that remain will be far more dangerous, as they will now be found attacking the buds themselves. The shoots of all flexible varieties should be staked, the ties being made pretty close to the buds. Watering may be necessary if the weather is very dry, but it is probably better to give none at all if a thorough soaking cannot be managed. Hoe the next day after rain, watering, or liquid manure. 
Green fly and mildew must be met and combated at once. Where thrips have been prevalent in former years, or at all events in very dry weather, Teas and light-coloured Roses should be syringed in the evening until the petals begin to show. In dry weather Tea buds may be wrapped in paper where intended for exhibition, and the protectors-waterproof cones attached to stakes-should be got out, overhauled, and placed in readiness. Exhibition boxes, tubes, labels, and wires should also be prepared, and moss procured, picked over, and laid on the trays in a shady place in readiness. Constant watchfulness will be required by an exhibitor, as his best bloom may be spoilt by a caterpillar, a gust of wind, or even a shower of rain, in a few hours. Raffia and stakes for tying, and sulphur for mildew, should always be ready where they can be got at once. The new shoots of Maréchal Niel under glass should be thinned and trained up under the wires. Forward stocks may be budded this month with buds from Roses on walls or grafted plants. Roses in pots should have been so hardened off that they can be planted out if desired by the middle of the month. It is sometimes advisable, to prevent a check, to gently break the pot in the hole made and pick out the pieces rather than turn the plant out. Those plants which are intended for re-potting should now be fit and ready for plunging out of doors in their autumnal quarters. Many Roses will be in bloom by the end of the month, especially the Teas and summer Roses, and the first fruits, often the best and finest, will gladden our eyes.

July.-In many districts this is, in average 
CHAP.

seasons, the month of Roses, H.P.s being a little later than the old-fashioned Roses of the poets. The last week in June and the first fortnight in July are roughly the general bounds of "the season" for the metropolitan latitude. Rose shows will be in full swing, and exhibitors for a time will have enough to do in cutting their blooms and rushing about the country night and day to the various shows. Mildew often gets a chance now of establishing itself, and hoeing and aphides are too frequently neglected. It is harvest time, and the details of culture' are naturally neglected for a while. Still, even before the show-boxes are put away, budding will have commenced with Tea buds on standards stocks, as these stocks often suffer from a stagnation of sap in August, and Tea buds, which cannot always be got in sufficient quantity, will stand the winter better if they be budded early.

While the Roses are still at their best, it is advisable that notes be made of the colours and good or bad qualities of unfamiliar varieties, as even a good memory may hold a somewhat unreliable picture of certain flowers if they be not accurately judged in comparison with others, and the results of observation commited to writing at once. Now is the time to condemm certain sorts for weeding out and to determine to grow more of others. If it be found that some variety does better in a certain situation or on a particular stock, especial notice should be taken of the fact. The foundations of a good deal of work for the rest of the year may depend upon a few days' observation. All flowers should be cut as soon as they are faded, if not before, 
as only the very earliest would be available for seed. Mildew is now likely to be very troublesome and vigorous efforts should be made to keep it under. Hoeing should not be neglected, or watering if the weather is very dry, but no more liquid manure should be used. Pot Roses should not be neglected, and though they will require but little water, they must be watched for aphides and mildew.

August.-This is the month for budding on all stoclis. When buds are plentiful and the sap of the stocks runs freely, the work should be pushed on as fast as possible, for the sooner it is done the better will be the chance for rebudding in three or four weeks' time the stocks that have failed. Layering may be done in this month, and summer cuttings of Roses struck in bottom heat. IVatering and hoeing seem the only remedies for rust, the autumn stage of the orange fungus. 'There is pleny of time for this, and for seeing that aphides do not get a footing anywhere, for the man who does not bud his own Roses; but he who does this in any quantity will generally find his hands full, for the mere settling how many, of what varieties, on which stocks, in what situation, he shall bud will require plenty of consideration and arrangement.

September.-Budding on briars should be finished during the first week, but manettis may still be budded a little later. Roses for forcing should be kept at rest. Maréchal Niel under glass will now probably be growing very fast, and should be liept tied up, and watched for mildew. Wall Roses may require nailing or otherwise fastening up, as they grow rapidly during this month. There will be 
beautiful Roses in abundance out of doors, among which, if the weather be dry, Teas and Hybrid Teas will be pre-eminent; but in spite of this I should strongly advise the hard-worked Rosarian now to take a holiday, for if he does not I do not know when he will get one, unless it be during the snows and frosts of Christmas and January. 


\section{INDEX}

Analysis, of soil and Rose ash Ants

Aphides

April, work for

Arches, Roses for .

Arrangement, of Rose beds of blooms for show

Artificial manures

August, work for .

Austrian Briars

Axe inire Roses.

BAMBoo stakes

Banksian Rose

Bedding Roses

Beds, shape of

Black grub. preparation of : 55

Blooms, shapes of . faults of .

Boring insects

I'TiE

89

171

167

346

338

51

230

sis

:351

20

124

22

150

23

335

5.2

55
169

210

210

Bourbon Rose . . .

Boursault Rose . . . . . . .

Boxes for exhibition . . . 219

Bracken, for protection . . (is

Briar, Austrian . sweet

as a stock

seedling

standard .

cutting
PACS:

Budding . . . . . . 139

Burnt clay . . . . . 44

Button-hole Roses,

selection of $\quad 337$

CALENdar of operations. . 341

Caterpillars . . . . 163

Chalk soil . . . . . 48

China Rose . . . . . . 27, 336

Christmas, Roses at . $\quad 202$

Classification ... 14

Clay soil .... 42

burnt ... 44

Climbing Roses . . . $\quad 312$

Colours of Roses . . . 238

Cuckoo-spit . . . 171

Cultivation . . 66

Cutting for exhibition . . 221

Cuttings of Roses . 155

briar . 130

manetti . . 133

DaMask Rose ..... 18

20 Dijon T'eas, pruning of 108

21 Disburdding of shoots . . 105

115 for exhibition $\quad 106$

133 of buds . . . 112, 213

116 Dog-Rose . . . . . 14, 115

130 Drainage . . . . . 43,56
A A 
Dressing of blooms for show

Dwarf plants, qualifications of good
PAGE

228

58

EARTH, burning of . . . 44

Earwigs as protection • 171

Elevation, advantage of . 38

English Roses

11,13

Evergreen Rose . . 22

Exhibiting . . . 204 boxes for . . 219

Fatry Roses . . . . . . . 28

Faults of Roses . . . . . 240

February, work for . . . 344

Fly, green . . . . 167

Forcing Roses . . . . . . 192

Form in Roses . . . . 210

Frasrance . . . 207

French Rose . . . . . . Is

growers ... . 10

names ... 12

Friends, insect . . . . 175

Frog hoppers . . . . . 171

Frost, injury from in May . 189 remedial measures for 189 protection against . $\quad 68$

Fungus, orange . . . . 184

Garden Roses . . . 31, 335

Glass, culture under . . . 192

Grafting . . . . 152

Gravel soil . . . . . 46

Grecian saw . . . . 123

Green fly . . . . 167

Gross shoots . . . . 104

Hamits of Roses . . . . . 240

Thoe, use of . . . 66, 87

"Sproughton" .. 66

Hybrid Bourbon Roses . . 19

China Roses . . . 19

PAGE

Hybrid Perpetual Roses . 26, 241 selection of 332 Tea Roses . . 26, 270

$\begin{array}{lll}\text { Hybridisation . . . . . } & 158\end{array}$

ICHNEUMON flies . . . . 175

Increased culture of Roses . 210

Insects . . . . . 160

Iron in soil . . . . . . . 92

JANUARY, work for . . . 344

Japanese Roses . . . . 30

Josephine, Empress . . . 10

Judging . . . . . . . 232

July, work for . . . 349

June, work for . . . . . 348

LABels ...... . 67

Larvæ of moths . . . . . 162

Layering . . . . . 156

Lawrenceana Roses . . . 28

Leaves, dead, as protection $\quad 69$

Liquid manure . . . . . 80

Lists of Roses . 331

Loam . . . . . 45

Locality . . . . 36

Macartney Rose . . . 30

Manetti stock . . 115

Manures, natural solid . . 79 liquid .... 80 artificial . . 88

March, work for _ . 345

Marl . . . . . . 48

Marúchal Niel _. . 321

May, work for . . . . . 347

Mildew . . . . 178

Miniature Roses . . 16, 28

Moisture, under glass _. 199 rising in soil . . 64

Monthly Rose . . . . 27

Moss, for exhibition? . . 219

Roses . . . 17

162 
Mulching . . . . . 77

Multiflora Rose

Musk Rose

23,29

29

Nanies, French .

Night-soil

Nitrates

Noisette Rose

Novenber, work for

12

79

94

29

343

OCTOBer, work for

341

Odours of Roses

Old-fashioned Roses

Operations, calendar of

Orange fungus

Otto of Roses

Packixg Rose blooms

Pegged down Roses . selection of

Pergolas, selection of

Pests

Pillars, Rose

Planting

Polyantha Rose

selection of dwarf

Pompon Roses

Potash

Pot Roses

selection of .

Preparation of beds .

Procuring standard stocks

Propagation

Protection against frost

Provence rain

Pruning

for exhibition . roots.

QUEEN of flowers

RaIsers, French

Red rust
111

105

337

338

160

338

50

23,29

338

29

91

19:2

336

55

$1 \cdot 2 \cdot 2$

135

68

217

16

95

106

59

Red spider .

Remedies for

181

late frosts . . 189

orange fungus $\quad 186$

Roots of different stocks 118

Rosarium, pattern or shape of ...... 52

Rose progress $\quad 209$

Rose-water .

SANDY soil . . . . 49

Saw, Grecian _. 123

Saw flies . . 165

Scent of Roses . $\quad 207$

Scissors ... 222

Scotch Rose . . . 21

Sécateurs ... 98

Seed, Roses from . $\quad 157$

Seedlings . . 158

Selections . 331

September, work for . 351

Setting up for exhibition . 227

Shading blooms . . . . 217

Shelter . . . $\quad 36$

Single Roses . . . 31, 339

Site . . . . 36

Soils, different . . . $\quad 41$

Soot.... 88

Specimen pot plants ․ $\quad 202$

Sports, climbing ․ $\quad 315$

"Sproughton" hoe . . $\quad 66$

Stakes for standards . 37,150

Standards . . . . 116

Stocks getting the stocks . 122

Suckers, to eradicate . 186

propagation by . $\quad 156$

Summer Roses . . . . . 16

Sweet briar ..... 21

TALL Standards . . 50, 127, 336

9 Tap roots ... . . 118, 133

Tea Roses . . . 28, 290

10 pruning of . . 107

1 Thinning shoots of 334

1:8t buds . . 112, 213 
PAGE PAr.

Thorns ....... 123 VARIETIES, habits of ... 237

Thrips . . . . . 174 selections of . 332

Top-dressings ..... 77 Ventilation ..... 196

Town gardens . . . . 339

Trailing Roses . . . 22, 24 IVALLS for Roses . . . 335

Training Maréchal Niel . 108 Watering ....... 86

specimen pot plants 202 Weeping Roses . . . . 336

Tying maiden shoots .. 150 Weevils . . . . . . 172

Tying, material for .... 147 Wichuraiana Roses .... 24

Types of Roses . . . . . 210 Wind, danger from . . . 36

THE END

I2 CLAY AND JONS, LTD, BREAD ST. IILL, K, C, AND BUNGAT SUFFULK. 


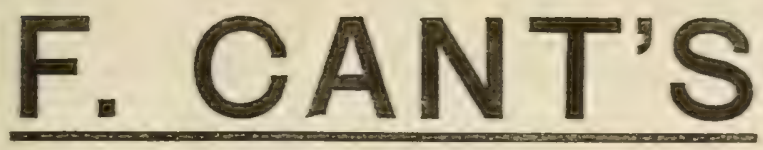

CHAMPION
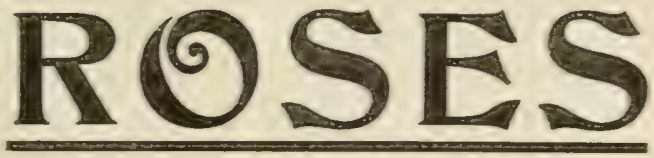

Roses for Exhibition.

New Roses and Old Roses.

Everblooming Roses for Beds and Hedges. Roses for any Soil or Situation.

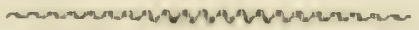

STANDARD ROSES.

BUSH ROSES.

CLIMBING ROSES. PILLAR ROSES.

ROSES FOR GARDEN DECORATION. ROSES FOR PERGOLAS.

Consult our New Illustrated Catalogue, Post Free.
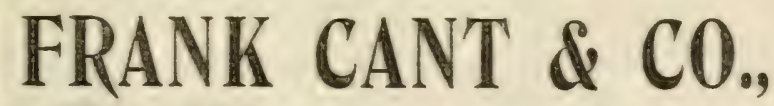

Braiswich Rose Gardens,

\section{COLCHESTER,}

in Picase carefisliy adiress to ensare comrect deliw:.ry.

Winners of the Champion Trophy of the N.R.S. five times. 


\section{BENJN.}
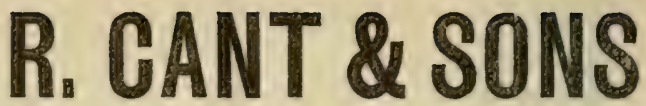

THE OLD ROSE GARDENS,

\section{COLCHESTER.}

Che Finest Roses in the World.

Direct from the Original Firm.

ESTABLISHED 1765.

WINNERS of the

CHAMPION CHALLENGE TROPHY Of THE NATIONAL ROSE SOCIETY ELEVEN TIMES.

Also THE QUEEN'S CUP_-Presented by Her late Majesty, and THE KIMG'S CUP in 1906.

BENJAMIN R. CANT \& SONS' CATALOGUE IS THE BEST PUBLISHED-sent free.

The late Very Rev. S. REYNOLDS HOLE,

Dean of Rochester and late President of the National Rose Society, says:-

"No Roses in the World ean come up to those of BENJAMIN R. CANT."

The Rev. H. HONYWOOD DOMBRAIN, late Hon. Sec. of 'The National Rose Society, writes:"BENJAMIN R. CANT is still the Champion."

ROSES SHIPPED TO ALL PARTS OF THE WORLD. SATISFACTORY DELIVERY GUARANTEED. 


\section{Practical}

\section{Gardening Books}

\section{By Prof. L. H. BAILEY.}

Horticulturist's Rule Book. Thirì

Edition, Revised and Extended. Globe Svo, 3s. net.

The Nursery Book. A Complete Guide to the Multiplication of Plants. Fifth Edition. Crown 8vo, 6s. $6 \mathrm{~d}$. net.

The Forcing Book. Crown Svo, 6s. 6d. net.

The Principles of Fruit = Growing. Crown 8 vo, 6s. 6d. net.

The Principles of Vegetable Gardening. Crown 8vo, 6s. 6d, net.

The Pruning Book. Eighth Edition. Crown 8vo, 6s. 6d. net.

Garden Making: Suggestions for the Utiliza= tion of Home Grounds. Crown 8vo, 6s. 6d. net.

The Amateur's Practical Garden Book. By C. E. Hunn and L. H. Bailey. Globe Sro, 3s. 6d. net.

Children's Gardens. By the Hon. Mrs. Evelyn Cecil. Illustrated. Extra crown 8vo, 6s.

Spraying of Plants. A Succinct Account of the History, Principles, and Practice of the Application of Liquids and Powders to Ylants for destroying Insecis and Fungi. By E. G. Lodeman. Crown 8vo, 5s. net.

Bush Fruits. By F. W. Card. Crown 8vo, 6s. 6d. net.

London: MACMILLAN \& CO., Ltd. 


\section{The National Rose Society.}

\section{The Guide, Counsellor and Friend of the Amateur Rosarian.}

\section{Patroness : HER MAJESTY, QUEEN ALEXANDRA.}

Although the Society has been in existence more than thirty years, the Council feel that there is still a very large number of Amateurs interested in Roses and Rose culture who are unaware how helpful it would be to them if they became members.

Membership. - It is not necessary that a member should he an expert Rosarian. No introduction is required, as there is no ballot for nembership. The number of members is now over $4, \infty 00$, the Society having doubled its membership in the last four years.

The Subscription. - The subscription is only Half-a-Guinea per annutu, and members can with equal advantage join the Society at any period of the year.

The Publications.-Each new member at once receives the following helpful publications. The "Hints on Planting Roses," with a list of the best varieties with which to begin a collection, however small. The "Official Catalogue of Roses," giving descriptions of 500 of the lest Roses of the day, together with select lists of the varieties most suitable for different purposes. The "Handbook on Pruning Roses," which gives directions for pruning I, 000 different varieties. The "Enemies of the Rose," which shows how best to keep these in check. The "Rose Annual," issued each year during the spring. All these publications, except the "Hints on Planting Rose:," are bound in cloth, and several of them beautifully illustrated.

The Metropolitan Exhibition.--This is the Society's prin. cipal Exhibition, and is held each year in London early in July. For that Show - the finest clisplay of Roses in the world-Nembers receive three tickets, and also two tickets for the Autumn Show.

A prospectus containing further particulars than can be siven in this short notice zerll be sent on application to-

$$
\begin{gathered}
\text { EDIVARD MAIVLEY, Hon. Secretar: } \\
\text { Rosebank, Berkhamsted, Herts. }
\end{gathered}
$$




